\title{
Tensional processes and perception of form in three selected compositions by Kaija Saariaho
}

by Brad Jenkins

A 90-point exegesis and portfolio of original compositions submitted to Massey University and Victoria University of Wellington in partial fulfillment of the requirements for the degree Master of Musical Arts (Composition)

New Zealand School of Music 





\begin{abstract}
The primary feature that gives 'spectral music' its stylistic uniqueness within the field of art music is the blurring of the traditionally distinct roles of harmony and timbre, through the use of chords derived from the naturally occurring overtones of instrumental timbre (often referred to as timbre chords). Development of these chords typically occurs very gradually, meaning it is often difficult to perceive the overall form of a spectral work based on the progression through its constituent timbre chords. This approach contrasts with the traditional reliance in both art music and other Western music styles on perceivable pitch-based development as a primary means of providing musical tension and form. Composers of spectral music must rely on the manipulation and development of other musical parameters to provide sufficient interest through 'foreground ornamentation' while its underlying harmonic/timbral macrostructure unfolds beneath.
\end{abstract}

This analysis shows how key musical parameters are manipulated over time to provide tension and resolution (or, in Wallace Berry's terminology, 'progressive and recessive processes ${ }^{1}$ ), giving spectral works a perceivable, dynamic form. Parameters examined include rate of harmonic change, dynamics, spectral/registral spread, rhythmic activity, sound/noise, spectral density and harmonicity/inharmonicity (the latter two providing a spectral analogue to conventional notions of dissonance). Particular focus is placed on the rate of harmonic change in the selected works and changes in the harmonicity/inharmonicity (through spectral distortion) of harmonic material that give spectral music its distinctive harmonic character. The way in which these 'parameter curves' intersect with one another is also examined.

For this study, three works by Finnish composer Kaija Saariaho are analysed. The works cover a range of forces and display varying degrees of overtly 'spectral' influence: Nymphéa (1987) for string quartet and electronics, Du Cristal (1990) for orchestra, and Cendres (1998) for piano, cello and flute. Analysis of the background levels of parametric change reveal how Saariaho manages to maintain microstructural interest in her spectral works while adhering to an underlying macrostructural plan. Findings from this analysis will also be discussed in relation to how they have influenced my own creative output for my MMA portfolio.

\footnotetext{
${ }^{1}$ Berry, Wallace. Structural Functions in Music. Englewood Cliffs, N.J: Prentice-Hall, 1976. 11
} 



\section{ACKNOWLEDGMENTS}

Firstly, I must thank my supervisor Michael Norris for his multifaceted guidance over the course of my Masters studies, which has included proofing my drafts, helping me to shape my stream of words into more coherent prose, technological troubleshooting, providing solid leads on useful related research and giving valuable feedback on my portfolio works. All of this helped me to leave our meetings feeling a little more confident than when I arrived.

Thanks also to the musicians who gave readings of my portfolio works, the recordings of which are enclosed with this exegesis: the New Zealand String Quartet (Helene Pohl, Douglas Beilman, Gillian Ansell, Rolf Gjelsten), guitarist Jamie Garrick and the NZSM Orchestra.

I would also like to acknowledge the New Zealand School of Music for offering me an NZSM Scholarship for my Masters studies and thank the administrative staff at NZSM for their support.

Last but certainly not least, big time gratitude to my wife Liz for her love and patience while her sleep-deprived husband spent almost every waking minute of his at-home time toiling away on a large quantity of words and music. Luv $\mathrm{u}$ babe $\mathrm{xxx}$

This exegesis and portfolio is dedicated to Royce Galloway (Nana G) and Evelyn Jenkins (Nana J), who both passed away during my studies. 



\title{
CONTENTS
}

\author{
Abstract \\ Acknowledgements \\ Contents \\ 1 Introduction \\ $4 \quad$ Methodology
}

12 Previous and Related Research

Analysis of works

$17 \quad$ Nymphéa

49 Du cristal

$67 \quad$ Cendres

83 Analysis summary

91 Relating research findings to my creative work

97 Bibliography

99 Discography

Appendix

101 Original compositions for creative portfolio

148 CD tracklisting

CD containing recordings of portfolio compositions enclosed on inside back cover 



\section{INTRODUCTION}

At the heart of this exegesis is an exploration of how Saariaho succeeds in creating tension and release in three selected works - Nymphéa, Du cristal and Cendres. This is of particular interest to me due to Saariaho's avoidance of more conventional tensional devices usually used in $20^{\text {th }}$ century tonal music. Without goal-oriented harmonic tension based on consonance and dissonance in equal-temperament, Saariaho substitutes it with changes in harmonicity/inharmonicity based on an underlying harmonic field, as well as with timbral transitions between noisy and 'pure' sounds. This analysis also looks at how form is defined in these works through the use of either tensional trajectories or tensional stasis to produce an audible sectionalisation of each work, revealing their formal structures. Selected musical parameters are analysed to ascertain which of these parameters - or combinations of parameters - dominate tensional processes in these works.

The decision to focus on the work of Saariaho is the result of my own interest, as a composer, in spectral music. Throughout my undergraduate and postgraduate studies in composition, I have been most intrigued by the music of spectral composers such as Saariaho, Gérard Grisey and Tristan Murail. I have been drawn to the liminal harmonic states and timbral detailing that typify quintessential works of this compositional approach. I am attracted to the organic movement of harmonic material as it develops in spectral music, with pitch freed from the grid of the equaltempered chromatic scale. The use of quarter-tones and indefinite playing techniques (such as glissandi) allow pitch — and, by extension, harmony - to occupy this liminal space, allowing for the endless harmonic configurations that lie outside of traditional harmonic structures of common-practice tonality. The process-based approach to harmonic and timbral development can produce results that I may not have consciously thought of otherwise.

I also find the focus on timbral manipulation in spectral music interesting for the sense of 'internal' development it conveys (by 'internal' development I refer to the manipulation of instrumental timbre so that certain partials vary in amplitude over the duration of the sound, as opposed to discrete 'external' development such as changes in dynamics or pitch, or contrapuntal movement). I am interested in the potential for the development of timbral detail to become part of short or long-term teleological processes, or both. Historically, timbre (and the extended techniques 
associated with its manipulation) has been the musical parameter that has been slowest in its incorporation into Western musical notation, presently integrated in as elegant a manner as possible alongside the long-established noteheads, beams, tempo markings, articulations, time signatures, key signatures and staff lines. Yet timbre can exert a great deal of command over tensional states. Timbral tension is capable of sharing a close link with physical labour and strain (as demonstrated, for example, by the string playing in Nymphéa), just as high amplitude or a fast tempo does. In musical contexts where parametric processes unfold slowly, timbral transformation conveys a sense of microstructural life and activity. Spectral music's general avoidance of conventional motivic material that slots into a metric and equaltemperament grid allows the listener to be drawn to microstructural detail such as timbral development. Motif is subordinated, existing in the service of texture but occasionally drawn out as short-term ornamentation.

Though spectral composers acknowledge that the genre possesses a broad stylistic identity (insisting that the process of generating pitch material through analysis of sound spectra is generally the common feature, though there are still other possible spectral approaches besides analysis-based processes), a connection exists between the timbral detailing within spectral music's globalized, mass-oriented orchestrational techniques and the contrapuntal saturation found in the works of composers such as Varèse, Ligeti, Penderecki and Xenakis in the decades preceding the establishment of spectral music in the 1970s. This 'proto-spectralist' music shares with spectral music the organization of the ensemble into a 'sound mass', with an individual line occasionally being lifted above the contrapuntal web to provide a flicker of foreground interest. Looking further back we find the work of composers such as Ravel and Debussy, who prioritized colour in their ensemble textures, an early manifestation of the preoccupation with fused, resonant textures and stacked tertian structures of many spectral composers. Over the past few decades, these tertian structures have evolved to encompass quarter-tones that ordinarily would not blend with equal-tempered pitches, but find fusion within the naturally occurring harmonic spectra that found favour with early spectral composers.

Nymphéa, Du cristal and Cendres were selected for analysis due to their variety in ensemble size, instrumentation and their exhibition, to varying degrees, of the compositional techniques outlined in Saariaho's own research ${ }^{2}$. The decade-long

\footnotetext{
2 Saariaho, Kaija. “Timbre and Harmony: Interpolations of Timbral Structures.” Contemporary Music Review 2, no. 1 (1987): 93-133. doi:10.1080 / 07494468708567055.
} 
span (1987-1998) in which these works were written allows for a glimpse at how the influence of spectral composition techniques changed over the course of time in Saariaho's writing and can also reveal any enduring parametric changes that Saariaho calls upon to achieve certain tensional states. Indeed, by the late 1980s, Saariaho and her contemporaries were considered "post-spectralist". Metzer refers to Du cristal as Saariaho's last work in a period preoccupied with spectral and harmonic analysis ${ }^{3}$.

The methodology developed for this analysis involves tracing the movement of seven key parameters over the course of each work, as they move between states associated with low or high tension. The parameters are:

- rate of harmonic change

- dynamics

- spectral/ registral spread

- rhythmic activity

- $\quad$ sound/ noise

- spectral/harmonic density

- harmonicity/inharmonicity.

Values are assigned to each parameter and scaled to reflect their relative dominance or subordination alongside other parameters at points throughout each work. Previous research related to this analysis is addressed, with particular reference to Saariaho's discussion of her parametricised approach to composition at the time of writing. Relevant research regarding both musical tension and parametric interaction is also addressed. Other existing analyses of the selected works are acknowledged, with the differences in the focus of each analysis outlined.

The analyses of Nymphéa, Du cristal and Cendres are presented separately, with a final analysis summary drawing together features shared by the three works regarding the creation of tensional change, overall form and the use of 'foreground ornamentation'. Following the analysis section is a brief discussion of how Saariaho's approach to parametric interaction has influenced the composition of the works in my own creative portfolio. More generalised aspects of spectral composition that have been incorporated into my portfolio works are also described.

\footnotetext{
${ }^{3}$ Metzer, David. Musical Modernism at the Turn of the Twenty-First Century. Cambridge, New York: Cambridge University Press, 2009. 183
} 


\section{METHODOLOGY}

Seven musical parameters have been measured: dynamic profile, registral spread, harmonic density, rate of harmonic change, dominance of sound or noise, rhythmic activity and degree of harmonicity/inharmonicity. Measurements are taken at both the first beat of the bar and the downbeat closest to the middle of the bar, or only at the first beat of the bar where there is little or no parametric change between these two points.

The musical parameter that is most complicated in its measurement is harmonicity. I chose to base my calculations on Huron's ${ }^{4}$ (1994) interval class index of 12-tone equal-temperament consonance (Fig 1.1). Huron's index can be regarded as a rough approximation of the perceived consonance of typical equal-tempered interval classes. Huron does not provide a definition of consonance or dissonance but remarks that the perception of an interval's consonance or dissonance depends on the spectral content of the participating tones, their sound pressure levels and their pitch register ${ }^{5}$. While sound pressure (dynamics) and registral spread feature as measured parameters in this analysis, their effect on the perception of harmonicity/inharmonicity in the selected works generally lies outside my analytical scope. Instead, I will abstract away these complex details to preserve analytical simplicity, relying purely on the consonance/dissonance values Huron ascribes to each interval class as a measurement of total harmonicity/inharmonicity.

Huron's interval class index provides an index of numerical values that are applied to each interval class in Forte's six-element interval vector template. Complementary interval classes are given the same numerical value in Huron's index, as Forte's interval vector inverts interval classes larger than a tritone. The values in Huron's index are derived from results of three important studies in the perception of consonance and dissonance: Malmberg (1918), Kameoka and Kuriyagawa (1969), and Hutchinson and Knopoff (1979). The values established in each study were normalized, with each set of values having a mean of zero and a standard deviation of one. These previous studies apply individual index values to all 12 tones of the octave, whereas Huron applied the same numerical value to each set of interval

\footnotetext{
${ }^{4}$ Huron, David. "Interval-Class Content in Equally Tempered Pitch-Class Sets: Common Scales Exhibit Optimum Tonal Consonance." Music Perception: An Interdisciplinary Journal 11, no. 3 (April 1, 1994): 289-305. doi:10.2307 / 40285624.

5 ibid. 291
} 
classes. An interval class with a consonance value higher than zero is considered consonant, while an interval class with a consonance value lower than zero is considered dissonant.

\begin{tabular}{|c|c|}
\hline Interval class & Consonance value \\
\hline $\mathrm{m} 2 / \mathrm{M} 7$ & -1.428 \\
\hline $\mathrm{M} 2 / \mathrm{m} 7$ & -0.582 \\
\hline $\mathrm{m} 3 / \mathrm{M} 6$ & +0.594 \\
\hline $\mathrm{M} 3 / \mathrm{m} 6$ & +0.386 \\
\hline $\mathrm{P} 4 / \mathrm{P} 5$ & +1.24 \\
\hline $\mathrm{A} 4 / \mathrm{d} 5$ & -0.453 \\
\hline
\end{tabular}

Fig. 1.1. Huron's Interval Class Index of Tonal Consonance ${ }^{6}$

Huron's index, however, covers only 12-tone equal temperament, making it insufficient for measuring chords based on 24-tone equal temperament (found most frequently in Nymphéa and Du cristal). To address this shortcoming, I interpolated new index values for quarter-tone intervals by referring to the Plomp-Levelt curve ${ }^{7}$ (Fig. 1.2). One of the main reasons for employing the Plomp-Levelt curve in this analysis is because of the continuous values provided between semitones (in contrast to the discrete values in Huron's index), providing an approximate suggestion for index values for quarter-tone intervals. As with other consonance and dissonance indexes, the Plomp-Levelt curve is a model of the changing roughness, or dissonance, of an interval between two pitches depending on their ratio-based relationship. As the frequency interval increases, the interval is perceived as increasingly dissonant, though only up to a certain distance - known as the critical bandwidth - at which point perceived dissonance decreases. While Huron does not

\footnotetext{
${ }^{6}$ Huron, David. “Interval-Class Content in Equally Tempered Pitch-Class Sets: Common Scales Exhibit Optimum Tonal Consonance." Music Perception: An Interdisciplinary Journal 11, no. 3 (April 1, 1994): 289-305. doi:10.2307 / 40285624.

7 Plomp, R., and Levelt, W.J.M. “Tonal Consonance and Critical Bandwidth.” Journal of the Acoustical Society of America 38 (1965): 548-560.
} 
provide a definition of consonance or dissonance, Plomp and Levelt define the phenomena of perceived consonance or dissonance of intervals as the result of varying degrees of "beating" between adjacent frequencies, dependent on their frequency ratio. Beating is the audible result of small differences in the cycle speed of two or more pitch frequencies sounding simultaneously, and is the phenomenon to which the description of "roughness" is applied regarding the perception of dissonant intervals. Frequency ratios consisting of higher integers (e.g., 101:97) are generally perceived as being more dissonant than those containing smaller, more simple integers (e.g., 5:4). Plomp and Levelt produced a more detailed version of the curve to accommodate the perception of intervallic consonance between complex tones (tones containing harmonic overtone spectra such as those produced by musical instruments, as opposed to sine waves, which do not have an overtone series). This shows a general increase in the perception of consonance for intervals that map closely to the most simple, low-integer frequency ratios. The index values established in this analysis for quarter-tone intervals aim to reflect their general tendency to sound "rougher" relative to their neighbouring equal-tempered intervals, with some exceptions - while the intervals of 12-tone equal temperament map with sufficient closeness onto the simple just-intonation ratios to mostly be considered consonant, the majority of quarter-tones are often located in the higherinteger areas between the simpler just intonation points.

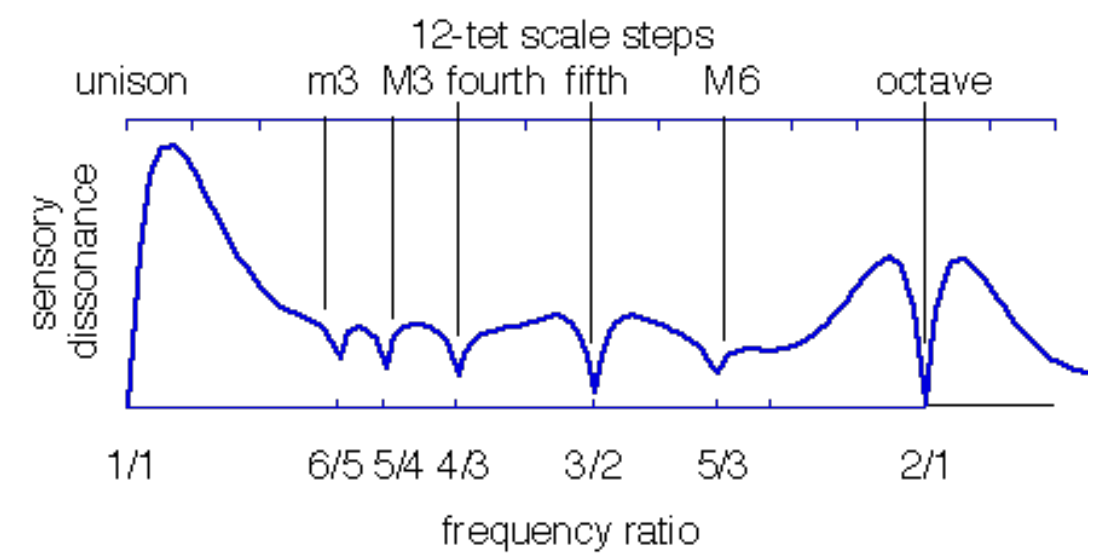

Fig. 1.2. The Plomp-Levelt curve for perception of intervallic consonance/dissonance, with incorporation of data for perception of consonance/dissonance of interval classes between two theoretical complex tones ${ }^{8}$

\footnotetext{
8 Plomp, R., and Levelt, W.J.M. “Tonal Consonance and Critical Bandwidth.” Journal of the Acoustical Society of America 38 (1965): 548-560., reproduced in Sethares, W. A. “Relating Tuning and Timbre." Experimental Musical Instruments 9, no. 2 (1993): 2330.
} 
In order to use the Plomp-Levelt curve to interpolate consonance values for 24-tet intervals from their 12-tet neighbours, I first mapped the existing Huron interval class index values onto the corresponding points for the 12-tet intervals on the curve. For example, the m3/M6 value 0.594 from Huron's index was applied to that interval's y-axis (sensory dissonance) position on the Plomp-Levelt graph, and so on for Huron's other 12-tet interval values. This provided some approximate numerical context for conferring consonance values to the curve points that corresponded with quarter-tone intervals - Plomp and Levelt provided either no or arbitrary numerical

\begin{tabular}{|c|c|}
\hline Interval class & $\begin{array}{c}\text { Consonance value } \\
\text { (quarter-tone consonance values in } \\
\text { bold derived from P-V C) }\end{array}$ \\
\hline $\mathrm{m} 2 \mathrm{~d} / \mathrm{M} 7 \$$ & -1.7 \\
\hline $\mathrm{m} 2 / \mathrm{M} 7$ & -1.428 \\
\hline $\mathrm{m} 2 \ddagger / \mathrm{M} 7 \mathrm{~d}$ & -0.9 \\
\hline $\mathrm{M} 2 / \mathrm{m} 7$ & -0.582 \\
\hline $\mathrm{M} 2 \$ / \mathrm{m} 7 \mathrm{~d}$ & -0.5 \\
\hline $\mathrm{m} 3 / \mathrm{M} 6$ & +0.594 \\
\hline $\mathrm{m} 3 \$ / \mathrm{M} 6 \mathrm{~d}$ & -0.4 \\
\hline M3/m6 & +0.386 \\
\hline M3 $\$ / \mathrm{m} 6 d$ & -0.4 \\
\hline P4/P5 & +1.24 \\
\hline $\mathrm{P} 4 \$ / \mathrm{P} 5 \mathrm{~d}$ & -0.4 \\
\hline $\mathrm{A} 4 / \mathrm{d} 5$ & -0.453 \\
\hline
\end{tabular}

Figure. 1.3 Interval class index used by author for measuring harmonicity/inharmonicity. Quarter-tones derived through Plomp-Levelt curve interpolation. Semitones derived from Huron's interval class index. 
values for the $y$-axis of their graph. The lowest y-axis value is 1.24 (P4/P5), at almost the lowest possible point of the y-axis, with the highest being greater than -1.428 (since the y-axis is measuring sensory dissonance, Huron's index values are obviously put in reverse numerical order on the Plomp-Levelt y-axis). The resulting interval class index, which covers a 24-tet octave, is shown in Figure 1.3.

The following is a demonstration of the harmonicity calculation process for harmonic material in the three analysed works:

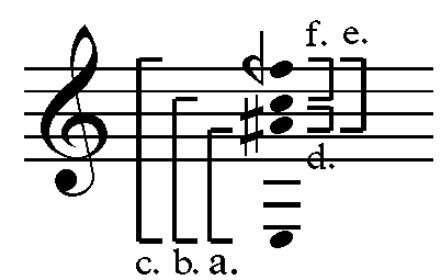

Fig. 1.4. Sample chord for calculation of harmonicity/inharmonicity, with constituent 12 and 24-tet intervals (chord example devised by author)

The consonance value of each interval within the sample chord (Fig. 1.4) is noted, with these values then added together to give a total consonance value (Fig. 1.5):

\begin{tabular}{|c|c|c|c|}
\hline Interval & $\begin{array}{c}\text { Pitch } \\
\text { classes }\end{array}$ & $\begin{array}{c}\text { Interval } \\
\text { name }\end{array}$ & $\begin{array}{c}\text { Consonance } \\
\text { value }\end{array}$ \\
\hline a. & $\mathrm{E}-\mathrm{A} \sharp$ & $\mathrm{A} 4 / \mathrm{d} 5$ & -0.453 \\
\hline b. & $\mathrm{E}-\mathrm{C}$ & $\mathrm{M} 3 / \mathrm{m} 6$ & +0.594 \\
\hline c. & $\mathrm{E}-\mathrm{Fd}$ & $\mathrm{m} 2 \mathrm{~d}$ & -1.7 \\
\hline d. & $\mathrm{A} \sharp-\mathrm{C}$ & $\mathrm{M} 2$ & -0.582 \\
\hline e. & $\mathrm{A} \sharp-\mathrm{Fd}$ & $\mathrm{P} 5 \mathrm{~d}$ & -0.4 \\
\hline f. & $\mathrm{C}-\mathrm{Fd}$ & $\mathrm{P} 4 \mathrm{~d}$ & -0.4 \\
\hline & \multicolumn{2}{|r|}{} & Total $=-2.941$ \\
\hline
\end{tabular}

Fig. 1.5. Process for obtaining consonance value of sample chord in Fig. 1.4.

The negative value obtained by combining the consonance values of each intervallic relationship within the chord indicates that this combination of pitches is likely to be perceived as more dissonant (containing more harmonic tension) than consonant. 
Harmonicity is the only parameter in this analysis that includes numerical values less than zero. Indeed, much of the harmonic material in the selected works is "inharmonic" according the standard of measurement applied here, meaning the graphed data for this parameter regularly appears beneath the zero value on the $y$ axis. To allow a clearer view of the relationship between harmonicity/inharmonicity and other parameters, it is presented in differing graphical ways. In the sectional analyses of Nymphéa and Cendres harmonicity/inharmonicity is presented on separate graphs whose y-axes display both positive and negative values. Du cristal, on the other hand, contains thick harmonic fields whose levels of harmonicity/inharmonicity are rarely consonant. This allows harmonicity/inharmonicity to appear on the same section graphs as other parameters, with consonance value placed on a secondary y-axis with its values inverted.

Dynamic profile values have been obtained by analysing amplitude levels of the works as .wav files and applying a value to the amplitude of each bar based on a scale of zero to 10 . A zero value reflects silence and a value of ten reflects maximum amplitude.

Harmonic density values are obtained by measuring the number of different pitches sounding at once. For example, if all players in a string quartet are performing double-stopped dyads with no pitches doubled in unison among them, the numerical value is 8 . If two players are performing identical dyads the harmonic density would then have a value of 6 , as there are now only six pitches sounding at once (Fig. 1.6). For each work the highest and lowest values of harmonic density are scaled so that the maximum value for harmonic density is equal to 10 . In this study, a chord is defined as two or more different pitches sounding simultaneously.

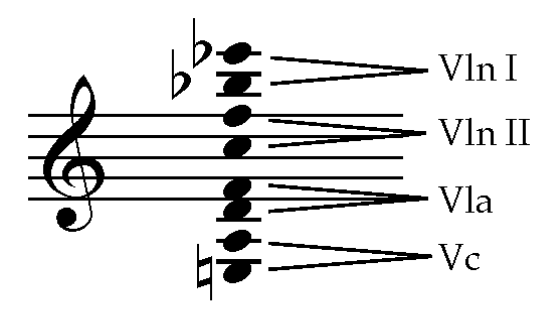

Harmonic density $=8$

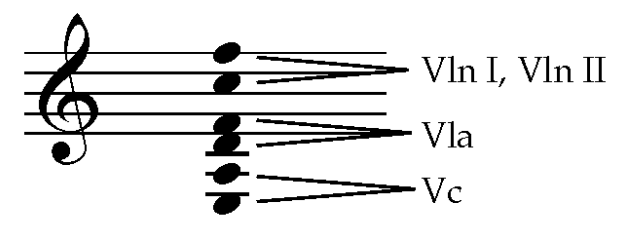

Harmonic density $=6$

Fig. 1.6. Process for measurement of harmonic density (chord example devised by author)

Values for registral spread are obtained by counting the number of semitones between the highest and lowest pitches in a chord. For example, a chord with a 
registral spread spanning three octaves would have a numerical value of 36 . As with harmonic density values for each work, the highest and lowest values of registral spread are scaled so that the maximum value for harmonic density is equal to 10 .

In assigning a numerical value to rhythmic activity, identifying the factors to be taken into account for this parameter made for a slightly more intuitive process. The primary criteria was the degree to which rhythmic activity acted as a foreground feature, either through the line of one player or through two, three or four-part contrapuntal material - essentially the exposure of a perceivable underlying pulse, and the importance of this device when it appears, relative to other parameters. A zero value is applied where there is no rhythmic material present (or such a high density of individual rhythmic material that no actual rhythmic activity is perceivable) and a value of 10 is given where the work is dominated by highly rhythmicized foreground material.

The dominant timbral quality of a bar is measured by referring to Saariaho's own sound-noise axis, which the composer has used as an alternative tensional device to harmonic consonance and dissonance - sound replacing harmonic consonance and noise replacing dissonance ${ }^{9}$. Noise - in which any sense of definable pitch is obscured due to frequency saturation - is given a value of 10, while purer sounds (for example, a violin played legato, with naturale bow position and without excessive bow pressure) are measured at zero.

To accurately calculate the rate of harmonic change (a change in the underlying harmonic field from which combinations of pitches are extracted) in each work, clock time is used as a measure of time as opposed to bar numbers, as musical time is of course subject to tempo fluctuations. Each work is analysed in overlapping 30second segments (0:00-0:30, 0:15-0:45, 0:30-1:00 and so on), with the number of changes in the underlying harmonic field recorded for each 30 -second segment.

Aside from harmonicity/inharmonicity in Nymphéa and Cendres and rate of harmonic change for all three works, all parameters are scaled between zero and 10, allowing for multiple parameters to appear on the same section graph. The result of this multi-parameter graphic representation is that section-based changes to parametric dominance and relationships are more clearly displayed. With the

\footnotetext{
9 Saariaho, Kaija. "Timbre and Harmony: Interpolations of Timbral Structures." Contemporary Music Review 2, no. 1 (1987): 93-133. doi:10.1080 / 07494468708567055.
} 
exception of clock time for the rate of harmonic change and overall tensional trajectory graphs, the x-axis value always shows bar numbers, and the y-axis the scaled value for the tensional state of each parameter. As previously mentioned, harmonicity / inharmonicity in Du Cristal appears on the same section graphs as other parameters, with consonance value placed on a secondary y-axis with its values inverted.

In addition to the graphic representation of the seven parameters outlined here, a general tensional trajectory line is superimposed over some graphs to clarify a section's formal function. The values of the tensional trajectory lines are not based on any calculation involving the dominant parameters in a given section. Rather, their values are based on my experiential perception of the tensional state in each section and is intended to be relative to the tensional trajectory across the entire work (the tensional trajectory across the entirety of each work is also shown at the beginning of each analysis).

The effect of chord spacing on the perception of harmonicity is not directly addressed in this analysis. Danner (1985) explores the effect of spacing on the perceived dissonance of a chord, finding that chords containing larger intervals between their constituent pitches are generally perceived as being markedly less dissonant than the same chord with its pitches more closely spaced ${ }^{10}$. This phenomenon may affect the perception of chordal harmonicity at certain points in the Saariaho works analysed here (especially given the prevalent inharmonicity of the harmonic material), but in this case it is generally out of the scope of the analysis. It can be confidently assumed that wide chord spacing has a leveling effect on the perception of harmonicity. For example, if a relatively consonant chord such as a major triad had its three pitches spread across four octaves, this would result in the triad being perceived as not necessarily dissonant, but as being somewhat less consonant than in its closer spacing. A clearer description of this effect could be that wider chord spacing results in a generally more ambiguous sense of harmonicity.

${ }^{10}$ Danner, Gregory. "The Use of Acoustic Measures of Dissonance to Characterize Pitch-Class Sets." Music Perception: An Interdisciplinary Journal 3, no. 1 (October 1, 1985): 103-22. doi:10.2307 / 40285324. 


\section{PREVIOUS AND RELATED RESEARCH}

Granot and Eitan (2011) have explored ways in which the interaction of selected musical parameters contributes to the perception of musical tension. One of the hypotheses of their research states that loudness is the musical parameter that has the most powerful effect on the perception of musical tension. This hypothesis was proved correct in their findings. In explaining their reasoning, the authors refer to the effect of loudness in extramusical environments, in which perception of this phenomenon serves as an instinctive biological warning. Changing loudness can indicate whether a particular sound source is approaching or moving away, allowing an organism to evaluate whether or not it is in danger. Granot and Eitan also maintain that another reason for loudness being linked with tension in a musical context is because it is "the main auditory manifestation of physical force" (2011: 241) ${ }^{11}$. This, of course, is also a sensation brought across from extramusical environments.

Cohen and Wagner (2000) address parametric interaction in musical tensional processes. One of the suggested reasons for the perception of increasing musical tension is the presence of an inverse relationship between the extent to which parametric changes correlate and the amount of information contained in the overall change. The authors suggest that when all parameters synchronise - that is, when all parameters simultaneously move in the same direction between high and low tension states - the overall informational change is actually minimal, lessening the overall amount of tension, and vice versa. The greater the amount of information, the higher the cognitive load, which itself affects tension (Cohen and Wagner, 2000) ${ }^{12}$. This analysis of Du cristal, Nymphéa and Cendres also looks to identify any instances of this type of nonconcurrent parametric interaction within these works.

Dibben (1999) looks at the perception of structural stability in atonal music. The results of two experiments provide insights that relate to questions concerning the

\footnotetext{
${ }^{11}$ Granot, Roni Y., and Zohar Eitan. "Musical Tension and the Interaction of Dynamic Auditory Parameters." Music Perception: An Interdisciplinary Journal 28, no. 3 (February 1, 2011): 219-46. doi:10.1525/mp.2011.28.3.219.

12 Cohen, Dalia, and Naphtali Wagner. "Concurrence and Nonconcurrence between Learned and Natural Schemata: The Case of J. S. Bach's Saraband in C Minor for Cello Solo." Journal of New Music Research 29, no. 1 (March 2000): 23.
} 
perception of form in Du cristal, Nymphéa and Cendres. Based on experimental results, Dibben suggests that listeners might hear atonal music "in terms of the relative structural importance of events and that listeners' hearing is greatly influenced by metrical and durational structure" (Dibben, 1999) ${ }^{13}$. Dibben goes on to posit the idea that salience, voice-leading and dissonance could be crucial elements that suggest relationships inferring prolongational structure in atonal music. What Dibben refers to as salience relates to the idea of "foreground ornamentation" mentioned earlier, a foregrounded detail in one or more musical parameters that serves to maintain shortterm interest while underlying macrostructural processes continue to unfold beneath.

The main catalyst for this analysis comes from Saariaho's own research and writing on tensional processes and the perception of form. In writing about the development of musical form, Saariaho (1987) has referred to Russian painter and art theorist Vassily Kandinsky's definition of form as "the external manifestation of inner meaning." Accordingly, this sense of inner meaning is realized by Saariaho at the level of musical parameters instead of the level of a work's overall formal structure. One of the parameters addressed by Saariaho is her sound/noise axis (in which "noise replaces the concept of dissonance and "sound" that of consonance (1987: 93) $)^{14}$, the composer's focus on this necessitating its inclusion as a measured parameter in this analysis. Saariaho explores the substitution of consonance and dissonance with pure sounds and noise, respectively. In Du cristal, Nymphéa and Cendres, Saariaho still relies on intervallic relationships of pitched material to generate tension, though not in a tonal setting. However, the sound/noise axis is overlaid as a means of augmenting the tensional possibilities of the works, particularly in Nymphéa. Saariaho regards the form of a work as something that, in the absence of overt harmonic rhythm, the listener perceives based on recognizable landmarks. The listener's memory of the work is simplified, so that it is remembered for its moments containing more salient features, as Dibben would describe them. Saariaho cites her work Verblendungen (1982-84) as the first work in which she

\footnotetext{
13 Dibben, Nicola. "The Perception of Structural Stability in Atonal Music: The Influence of Salience, Stability, Horizontal Motion, Pitch Commonality, and Dissonance." Music Perception: An Interdisciplinary Journal 16, no. 3 (April 1, 1999): 265-94. doi:10.2307/ 40285794.

14 Saariaho, Kaija. "Timbre and Harmony: Interpolations of Timbral Structures." Contemporary Music Review 2, no. 1 (1987): 93-133. doi:10.1080/07494468708567055.
} 
attempted to "construct forms of tension as well as structures of several levels"15. Trajectories were created for each parameter - polyphony, rate of harmonic progression, pitch range, dynamic profile, homophony, foregrounding of its tape part - with the intended result being a work whose form is derived from the interaction of these parameters, with "culminating points" that serve as memorable structural landmarks.

Howell (2011) has discussed Nymphéa as an example of how Saariaho controls teleological listening and the processes by which the composer builds musical narratives ${ }^{16}$. Regarding general formal structure, Howell maintains that Nymphéa can be divided into two identifiable parts (separated by a double barline that is directly preceded by a rare moment of silence). Howell then offers a more detailed breakdown of the formal structure of each part, describing them as the products of a series of developmental cycles, loosely fractal in nature, which the author compares to the action of a water lily opening (Nymphéa means water lily). In keeping with the botanical theme of the work, Hargreaves labels the developmental cycles as "growthdeath-decay" cycles and maintains that, as the work progresses, the cycles vary in duration, harmonicity, and their relationship to adjacent cycles, with some cycles joined together or appearing within another, larger cycle. The basis of my analysis differs from Howell's through its more linear division of the work into discrete sections (no overlapping sections) defined by tensional trajectories and states, as well as parametric combinations, which illuminate the form of the work.

Several analyses of $\mathrm{Du}$ cristal exist, with the perception of form being a common topic. The degree of depth to which the work is explored varies from author to author, with an unsurprising variety of conclusions regarding its formal structure. This variety has much to do with the difference in criteria by which form is judged in each analysis.

Hargreaves' (2011) analysis of Du cristal focuses on the "musical, semiotic and philosophical relationships" that exist within the work. Echoing Saariaho's thoughts on formal structure being perceived through the identification of "culminating points" of musical parameters, Hargreaves describes the formal structure of $D u$

\footnotetext{
15 Saariaho, Kaija. "Timbre and Harmony: Interpolations of Timbral Structures." Contemporary Music Review 2, no. 1 (1987): 93-133. doi:10.1080 / 07494468708567055.

${ }^{16}$ Howell, Tim, Jon Hargreaves, and Michael Rofe. Kaija Saariaho: Visions, Narratives, Dialogues. Burlington, VT, Farnham, Surrey: Ashgate, 2011. 81-105
} 
cristal as "an uninterrupted 16-minute sound, different parts of which come to prominence at different times" (2011:184) ${ }^{17}$. Hargreaves goes on to outline two ways in which Saariaho complicates the process of perceiving form in Du cristal. Firstly, Saariaho's simultaneous manipulation of multiple musical parameters (describing them as being in "an ongoing competition for prevalence"18) means that the form of the work is not realized through one clear parametric narrative. Secondly, the development of textural features in $\mathrm{Du}$ cristal's background material is such that it spreads thoroughly throughout much of this layer, obscuring larger structural patterns that lie beneath. Hargreaves cites Saariaho's scheme for pitch organization in $D u$ cristal, namely regarding pitch distribution and density, as an effective device for controlling the sense of tension and release during the work. The parameters Hargreaves focuses on are tempo, pitch and textural patterns, while also addressing Saariaho's casting of the orchestra's sections into register-defined bands. Hargreaves does not go so far as positing his own formal breakdown of Du cristal, instead outlining analyses by Metzer and Pousset alongside a "description of events" that take place over the work's duration.

Pousset stresses the repetitive qualities of $\mathrm{Du}$ cristal as a key to revealing its form, though we are not dealing, of course, with traditional literal repetition. Alluding to the symmetrical nature of the work's namesake, Pousset considers $D u$ cristal to be organised in a ranging ternary form - A B $\mathrm{A}^{\prime}$ - preceded by a slow introduction, with the second A section consisting of mutations of material found in the original $\mathrm{A}$ section, now ordered in retrograde ${ }^{19}$. While acknowledging the traditional role of tension and release in the continuation of forward movement in Du cristal (this being the main point of difference between Pousset's analysis and my own - the focus on tension and release as $D u$ cristal's primary formal device), Pousset cites repetition and equilibrium as the most important criteria by which to consider the formal coherence of $\mathrm{Du}$ cristal. Pousset's additional acknowledgment, like Hargreaves, of what Stoïanova (1994) describes as the network of "internal relations and temporal

${ }^{17}$ Howell, Tim, Jon Hargreaves, and Michael Rofe. Kaija Saariaho: Visions, Narratives, Dialogues. Burlington, VT, Farnham, Surrey: Ashgate, 2011. 177-201

18 ibid. 192

19 Pousset, Damien, Joshua Fineberg, and Ronan Hyacinthe. “The Works of Kaija Saariaho, Philippe Hurel and Marc-André Dalbavie-Stile Concertato, Stile Concitato, Stile Rappresentativo." Contemporary Music Review 19, no. 3 (January 1, 2000): 100-101 
equilibria of sonic materials and processes" ${ }^{20}$ in $\mathrm{Du}$ cristal perhaps accounts for the relative simplicity of his formal breakdown of the work, as a more detailed foray into its formal intricacies based on repetition and equilibrium may prove too cumbersome.

Metzer restricts his focus to the opening and closing sections of $\mathrm{Du}$ cristal, but also regards the work as consisting of three sections $(\mathrm{A}=\mathrm{bb} .1-126, \mathrm{~B}=\mathrm{bb} .127-299, \mathrm{C}=$ bb.300-373). Metzer judges the form of $\mathrm{Du}$ cristal through two focal points: the raising of the solo voices and how the voices assume expressive presence through the medium of flux ${ }^{21}$. Stating that $D u$ cristal contains recurring passages and sounds, Metzer suggests that the form of the work is articulated by the variations based on this recurring material. While Saariaho's pre-compositional sketches may indicate the repetition of material, it seems that very little of this repeated material is organized in such way as to be consciously perceived. This is where the value of a tension-based approach to defining form is useful, as the experiential perception of tension seems a more tangible route to understanding its structure. Focusing on parametric interactions and dominance further clarifies form, revealing how they combine over shorter durations to create tensional trajectories or states. Perception is, of course, unique to each listener, so the subjectivity of experiential perception must also be acknowledged.

20 Stoïanova, Ivanka. "A Work of Synthesis: Analysis of Amers" 1994. cited in Pousset. 101

${ }^{21}$ Metzer, David. Musical Modernism at the Turn of the Twenty-First Century. Cambridge, New York: Cambridge University Press, 2009. 186 


\section{ANALYSIS OF WORKS}

\section{Nymphéa \\ for string quartet and electronics}

This analysis discusses tensional processes employed in Saariaho's Nymphéa for string quartet and electronics by tracing changes to each of the parameters introduced in the Methodology section. Tension and release are used as guides for dividing the work into distinct sections, where the combined parametric changes suggest localised beginnings and endings that contribute to a sense of overall form. Important relationships between specific parameters are highlighted, as are Saariaho's methods of subverting expectations in the creation of tension and release by supressing or accentuating certain parameters. Saariaho's use of varying degrees of parametric desynchronisation - particularly with those parameters frequently used to provide "foreground ornamentation" in Nymphéa — are also discussed.

As expected, the rate of harmonic change in Nymphéa is mostly rather slow, though there are more active fluctuations during several passages throughout the work (Fig. 2.2). In particular, the rate of harmonic change can be seen to increase during the two most climactic passages in Nymphéa (bb.151-207 and bb.296-334), with these increases roughly lining up with increases in dynamic profile. An increase in the rate of harmonic change is a common tensional device employed in many forms of Western music, and it is interesting to find this device employed by Saariaho in this art music setting, especially since other foregrounded parameters such as sound/noise can obscure the rate of harmonic change in Nymphéa. For example, Saariaho's use of playing techniques such as extreme bow pressure means that any discernible pitches are buried beneath the resulting noise, with extended passages of extreme bow pressure sometimes masking the underlying accelerated harmonic changes.

The sound/noise parameter is key in controlling tension and release in Nymphéa. As Nymphéa navigates between pure tones and noise, it becomes apparent that it is almost never without some form of timbral manipulation adding a degree of noise to its overall sound. This can be seen in the restless bowing instructions prescribed for each player in the quartet, which constantly oscillates between sul tasto and sul ponticello bow positions. As a result, the timbral foundation of Nymphéa is infused with, at the very least, a small but near-constant amount of noise.

Rhythmic activity and sound/noise are the two parameters that are most 
consistently foregrounded, providing the moment-to-moment "foreground ornamentation", while also responsible for expressing larger synchronous and tensional changes, in Nymphéa. While harmonic development unfolds beneath, the interaction of these two parameters, especially in the first half of the work, seems to be one of alternating dominance of the foreground.

For instance, following the unison A that opens Nymphéa, a movement to the noisy end of the sound/noise continuum occurs, as all players employ surges of extreme bow pressure. From b.36, a clear polyrhythmic passage emerges, which then refocuses into a unified group of semiquavers at b.39. A hocketed rhythmic passage follows, centred microtonally around a unison G4, with the duration of some notes slightly extended. By the time the rhythmic material assumes the foreground, the noise content of the material has significantly receded due to the absence of extreme bow pressure, leaving the variations in bow position as the only noise-creating techniques. By b.50, rhythmic clarity has dissolved and noise has returned as the foregrounded feature, with extreme bow pressure used in the first violin part once again.

The second climax of Nymphéa takes place when the foregrounding of the rhythmic and sound/noise parameters are combined, which is significant for its rarity in Nymphéa and thus structurally important. At b.326, periodic slabs of extreme bow pressure are regularly passed around the quartet. Within the sustained wall of noise, each down-bow is audible, organized into a hocketed pulse. In terms of providing formal definition, this amalgamation of the two parameters serves as the eventual realization of something that had been briefly touched upon, but largely evaded up to this point - the combining of tensional high-points of rhythmic activity and sound/noise. The only other comparable amalgamation of these parameters occurs from bb.195-207, in which the quartet unites in rhythmic, accented stabs of extreme bow pressure. Harmonic parameters - harmonicity, registral spread, rate of harmonic change - are rendered temporarily irrelevant by the dominance of the sound/noise parameter being pushed to its extreme, especially in the latter of these two events, where the bow pressure is such that the notated pitches are barely audible. Much of the structural importance of the passages overwhelmingly dominated by noise comes from the tensional extreme they inhabit. As discussed in the Methodology, noise's saturation of frequencies goes beyond mere chromatic saturation, with much of the tensional impact derived from an implied loss of control over the production of sound, especially in combination with high amplitude, which is also a parametric feature of Nymphéa's climactic material. 
The harmonicity and harmonic density parameters are closely related for much of Nymphéa, with inharmonicity often increasing as harmonic density increases. This relationship is a fairly predictable one, given that the number of different intervallic relationships within a chord is likely to increase as the number of pitch classes in that chord increases. Importantly, only the minor third, major third and perfect fourth intervals are given positive numerical, or consonance, values in Huron's interval class index. Not surprisingly, the vast majority of Nymphéa's harmonic content is inharmonic. A strong contributor to the degree of inharmonicity in Nymphéa is the presence of quarter-tones, which have a high dissonance value in relation to equaltempered intervals. In scaling the harmonicity values for graphical representation alongside other musical parameters, this parameter is graphed using the secondary $y$-axis, with the values on this axis reversed so that high-points in its graphical representation indicate an increased degree of harmonic tension (or values that are below zero according to Huron's index), since this analysis is concerned with the modelling and comparison of tension through multiple parameters. Here, the scaled zero value on the secondary axis is 7.84 .

Harmonic density and inharmonicity rises and falls as Saariaho extracts varying combinations of pitches from the underlying harmonic fields. Harmonic tension rises and recedes in waves.

Aside from being perceivable in recorded performances, a sense of how Saariaho constructs form in Nymphéa can also be gained from following changes to the musical parameters charted in this analysis. As Howell (2011) has noted, Nymphéa is, at the most basic level, divided into two sections. This is indicated in the score by the double barline at the end of b.262, the only double barline to appear within the score.

\section{SECTION $1:$ bb.1-24}

The first section of Nymphéa introduces the sonic qualities that generally underpin the work: sustained pitches, with each part containing independent surges in dynamic profile and constantly changing bow position and pressure; a harmonic character that includes quarter-tones, with moments of rhythmic, "proto-melodic" material dominating the work's surface. For the purposes of this analysis, the term proto-melodic is used to describe a foregrounded sequence of pitches that lacks most of the properties one would associate with a melodic line. In particular, a protomelodic line 1) possesses little or no variety in pitch contour, 2) employs little rhythmic activity (that is, generates little rhythmic tension around an underlying 


\begin{tabular}{|c|c|c|c|c|}
\hline Section & Bars & Time & $\begin{array}{l}\text { Tensional } \\
\text { trajectory/quality }\end{array}$ & Main features \\
\hline 1 & $1-24$ & $0: 00-1: 16$ & low tension & $\begin{array}{l}\text { Introduces independent surges in } \\
\text { dynamic profile and constantly } \\
\text { changing bow position/ pressure; } \\
\text { gradual shift in dominant foreground } \\
\text { ornamentation parameter } \\
\text { (sound/noise to rhythmic activity) }\end{array}$ \\
\hline 2 & $25-38$ & $1: 17-1: 50$ & mid tension & $\begin{array}{l}\text { Louder dynamics and change in } \\
\text { attack profile, appearance first } \\
\text { "muted climax" chord with wide } \\
\text { registral spread, then narrowing to } \\
\text { single pitch }\end{array}$ \\
\hline 3 & $39-62$ & $1: 51-2: 26$ & mid to high tension & $\begin{array}{l}\text { first instance of rhythmic unison, } \\
\text { return of extreme bow pressure }\end{array}$ \\
\hline 4 & 63-104 & $2: 27-3: 59$ & low tension & "rest area", more parametric stability \\
\hline 5 & $105-150$ & $4: 00-5: 28$ & $\begin{array}{l}\text { mid tension to high } \\
\text { tension }\end{array}$ & $\begin{array}{l}\text { First main climax - wide registral } \\
\text { spread, "dynamic unison", increased } \\
\text { rate of harmonic change, first use of } \\
\text { repetitive material, foregrounded } \\
\text { rhythmic activity }\end{array}$ \\
\hline 6 & $151-207$ & $5: 29-7: 35$ & high tension & $\begin{array}{l}\text { Continuation of climax - more } \\
\text { unified playing, synchronized use of } \\
\text { extreme bow pressure, rhythmic } \\
\text { activity and sound / noise parameters } \\
\text { sharing the foreground (point of } \\
\text { arrival), increased rate of harmonic } \\
\text { change, but with contracted smaller } \\
\text { registral spread }\end{array}$ \\
\hline 7 & $208-243$ & $7: 36-9: 17$ & low tension & $\begin{array}{c}\text { Introduction of structurally } \\
\text { significant whispered syllabic } \\
\text { fragments, return to scattered bow } \\
\text { pressure }\end{array}$ \\
\hline 8 & $244-262$ & 9:18-10:18 & low tension & $\begin{array}{l}\text { Second appearance of "muted } \\
\text { climax" chord to conclude the first } \\
\text { half of Nymphéa, increased rate of } \\
\text { harmonic change but little tension }\end{array}$ \\
\hline 9 & 263-295 & 10:19-13:05 & low to high tension & $\begin{array}{l}\text { Parametric surges within controlled } \\
\text { increase in tension, gradual } \\
\text { synchronization of dynamic surges, } \\
\text { absence of foreground ornamentation }\end{array}$ \\
\hline
\end{tabular}




\begin{tabular}{|c|c|c|c|c|}
\hline 10 & $296-334$ & $13: 06-15: 08$ & high to low tension & $\begin{array}{c}\text { Major climax - rhythmic activity and } \\
\text { sound / noise parameters sharing the } \\
\text { foreground (point of arrival), high } \\
\text { amount of pitch instability }\end{array}$ \\
\hline 11 & $335-362$ & $15: 09-16: 39$ & low tension & $\begin{array}{c}\text { Proto-melodic material as foreground } \\
\text { ornamentation, third appearance of } \\
\text { "muted climax" chord at end of } \\
\text { section }\end{array}$ \\
\hline 12 & $363-389$ & $16: 40-18: 40$ & low tension & $\begin{array}{c}\text { Return of whispered material, shift in } \\
\text { dominant foreground ornamentation } \\
\text { parameter (rhythmic activity to } \\
\text { sound / noise) }\end{array}$ \\
\hline
\end{tabular}

Fig. 2.1. Formal outline of Nymphéa
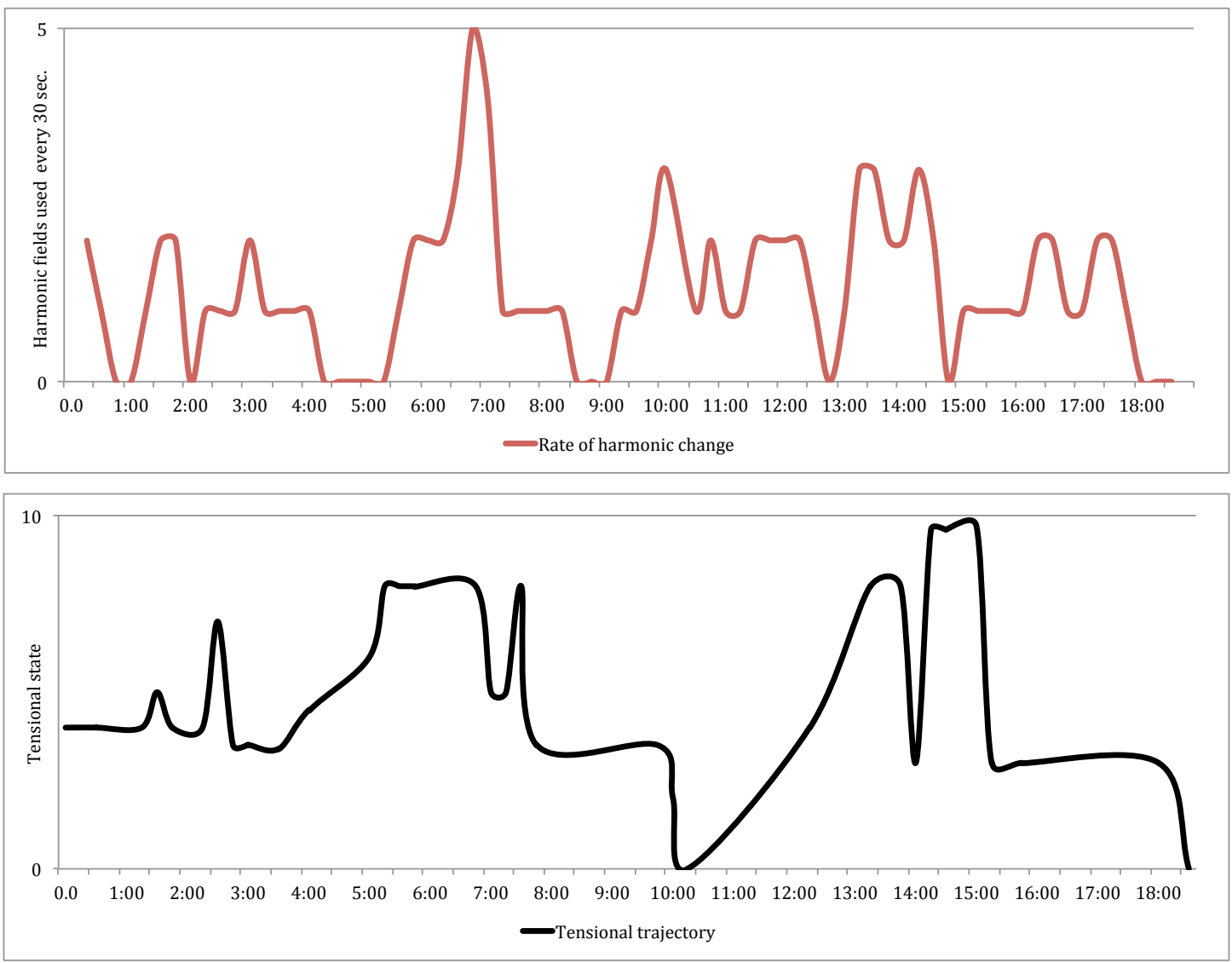

Fig. 2.2. Rate of harmonic change and overall tensional trajectory in Nymphéa. The overall tensional trajectory shown here is simply Nymphéa's constituent sectional tensional trajectories mapped end-to-end. Each sectional tensional trajectory is presented and discussed in the analysis that follows, with reference to the musical parameters that contribute most to that trajectory. All sectional tensional trajectories are based on the author's subjective perception of tensional change, using data from the analysis of parametric changes as a source of evidence. Graphs for Du cristal and Cendres have also been produced by the same method, and appear later in this exegesis. 
pulse) and 3) produces little in the way of tonal tension and release with its sequence of pitches.

The primary development in this section is a gradual shift in foreground material, from arhythmic surges of extreme bow pressure on all instruments (Ex. 1.1) to a proto-melodic line played in natural bow position by the second violin. The surges of extreme bow pressure initially overlap so as to create an almost unbroken line of noise amongst the purer tones. Across the first minute of the piece, however, the surges of extreme bow pressure become less frequent. The decreasing presence of extreme bow pressure occurs in contrast to the second violin's proto-melodic material (Fig. 2.3), which first emerges in b.8 as a three-note fragment, growing in length with each iteration until it becomes an unaccompanied line by b.23.

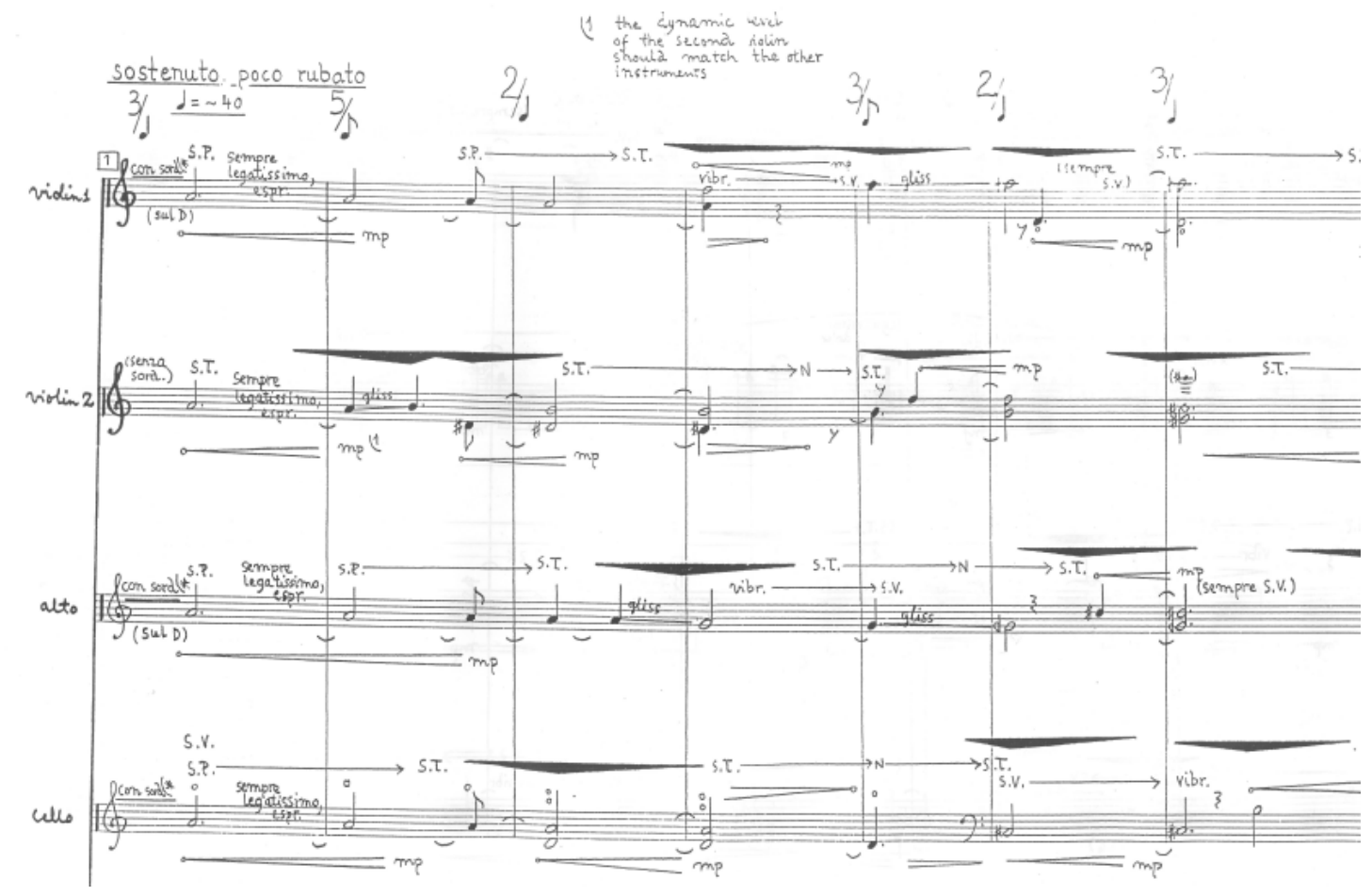

Ex. 1.1 Use of extreme bow pressure (notated by black lines) in the first section of Nymphéa. 

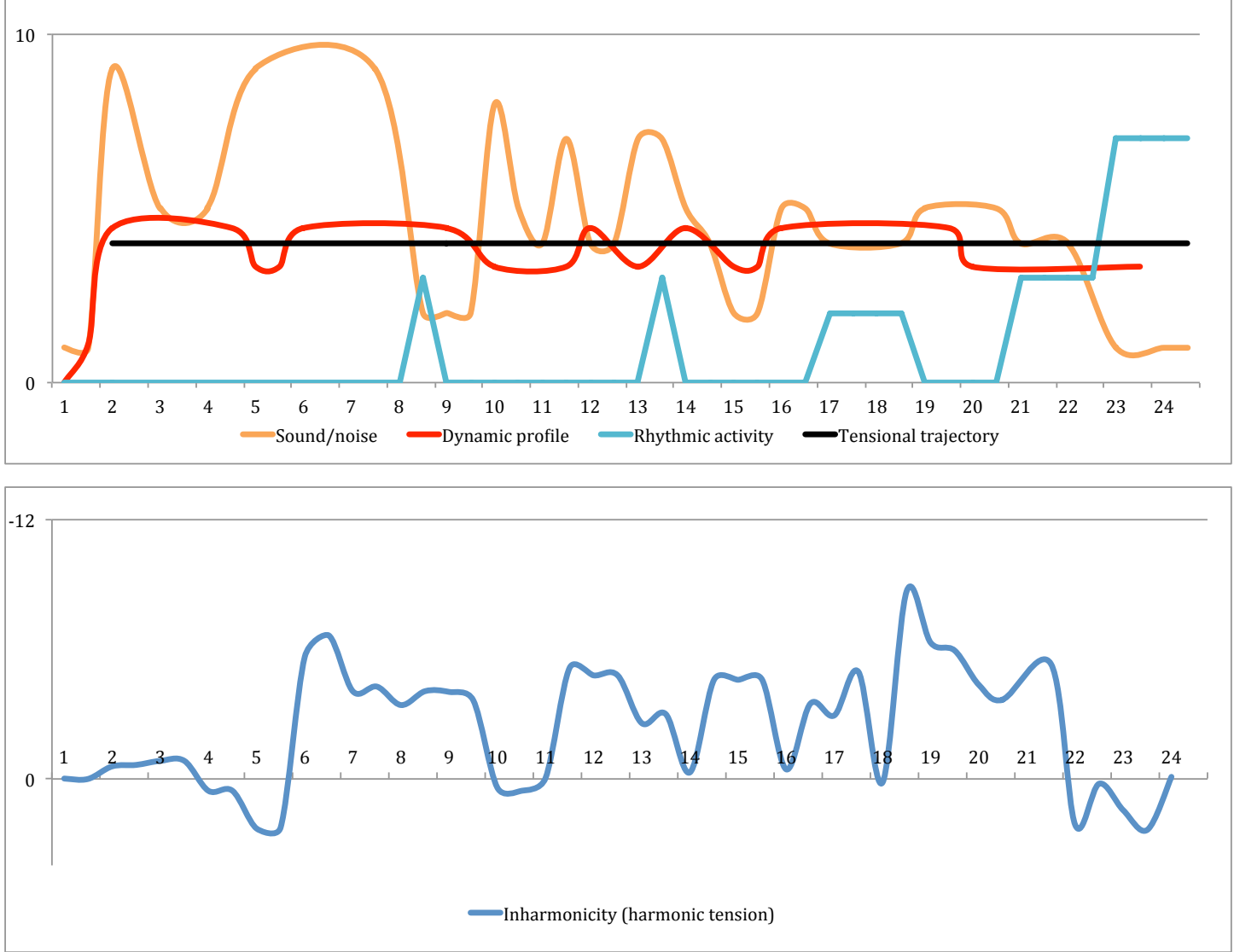

Fig. 2.3. Parametric changes in the first section of Nymphéa.

SECTION 2 : bb.25-38

The brief second section differentiates itself from the first in its use of parameters other than noise for generating tension, and for containing one of Nymphéa's strongest formal landmarks. Firstly, the attack profiles of the pitches now start at peak amplitude and recede, unlike the first section, in which pitches mostly grow out of, and recede back to, niente dynamics. The louder dynamics incorporated into the change in attack profile demonstrate the first parametric transformation through which Saariaho builds tension in this section (Fig. 2.4). The wash of pitches is once again arhythmic, though extreme bow pressure is momentarily absent. The decrease in tension from the stabilisation of the sound/noise parameter is somewhat neutralised by the change in attack profile and dynamics, which creates a more aggressive arhythmic character at the start of this section. Harmonic tension is also greater than that of the first section. 


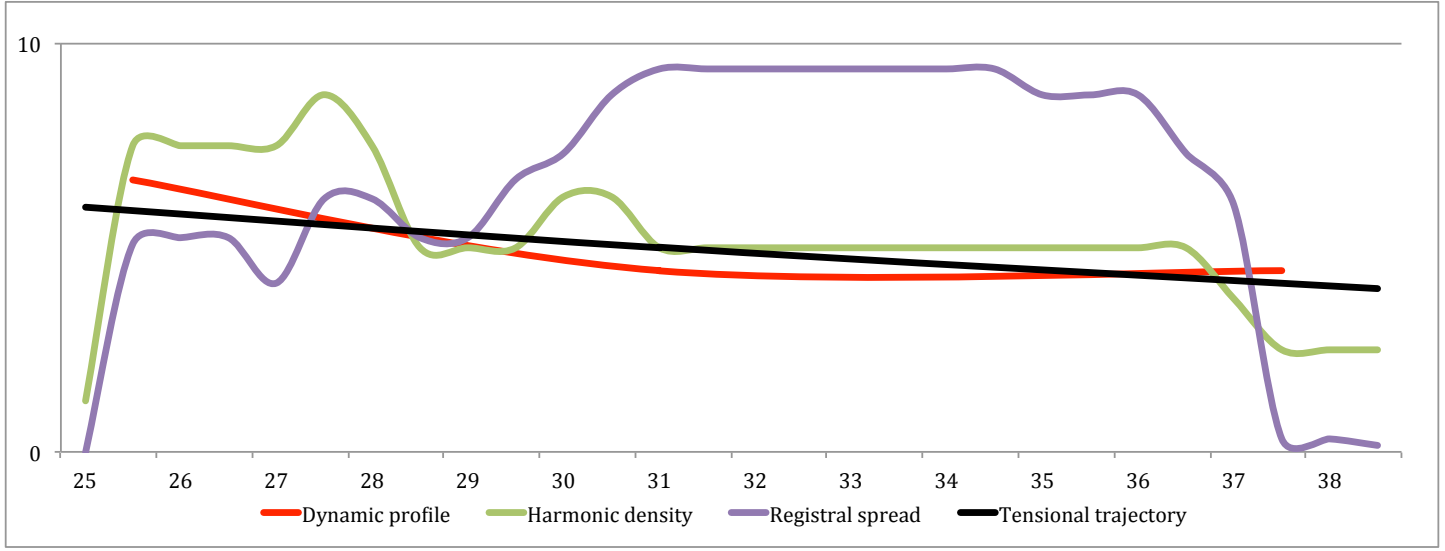

Fig. 2.4. Parametric changes in the second section of Nymphéa.

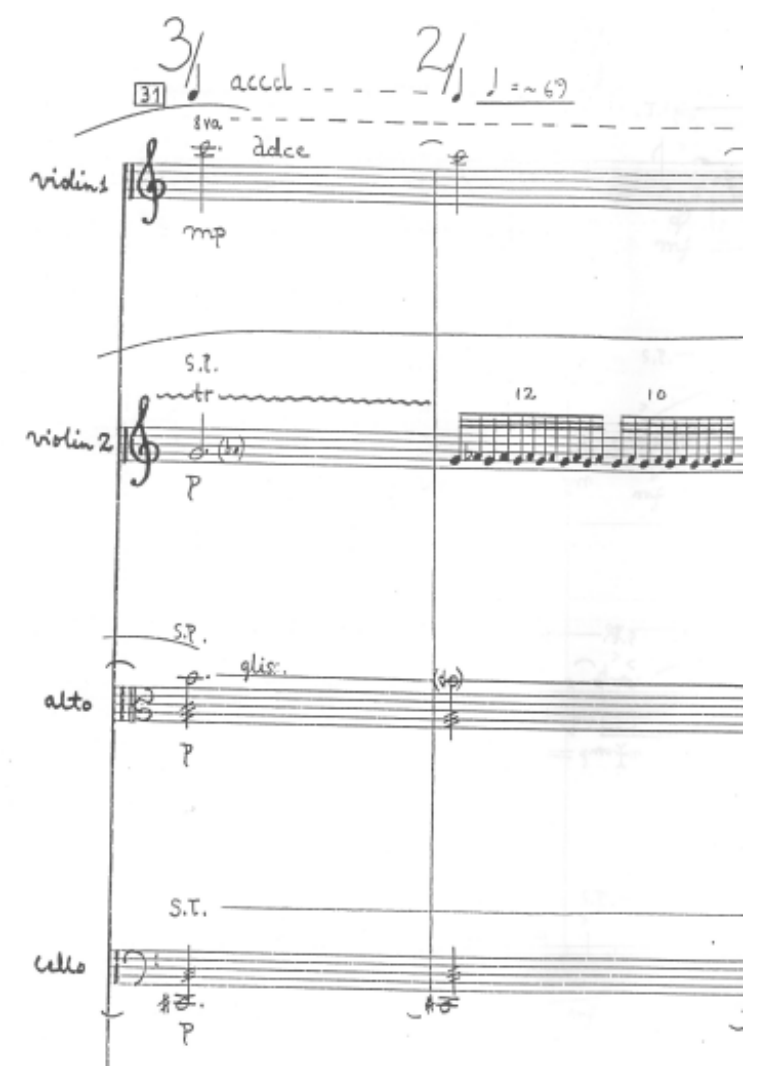

Ex. 1.2. First statement of $C \sharp$ chord, in the section section of Nymphéa.

The registral spread of the work expands from the confines of the middle-to-upper registers of the opening section, with the cello descending to a low $C \#$, while the first violin ascends to a $\mathrm{C} 7$ at b.31. This registral change coincides with changes in harmonic density and dynamic profile. All instruments revert to playing a single pitch (or a trill note in the case of the second violin) and the most noticeable change in Nymphéa up to this point occurs: the dynamic profile drops to $p$, with the viola and cello holding bowed tremolos whose "sustained instability" introduces a new 
tensional quality to the work. Pitches from a new harmonic field begin to emerge as the quartet reaches the sustained, widely spread chord at b.31, with this being the first of three moments in Nymphéa where this chord features (Ex. 1.2). While never identical in its constituent pitches (here they are C\#-B-G-C), it is distinguishable by the cello's low $\mathrm{C} \#$ played with a bowed tremolo. The purpose of this chord appears to be cadential and is discussed later in this analysis as it makes further appearances. This chord's formal purpose as a cadential event is reinforced by the change in the underlying harmonic field that also begins at this point. The registral spread contracts to G4 and its surrounding quarter-tones in preparation for the growth of a new harmonic field and new section of the work.

\section{SECTION 3 : bb.39-62}

The tensional trajectory of the third section is a moderate shift towards a higher state of tension, culminating in a crescendo. The section begins with some of the strongest foregrounding of rhythmic activity in the entire work, signalling another clear structural landmark (Fig. 2.5). In this section, however, tension is closely tied to registral spread, which is initially minimal, being centred around G4. Coupled with moderate dynamics, the result is a moment of rhythmic unison whose tensional and climactic potential is only partially fulfilled in its first appearance. This allows for tensional intensification of rhythmic unison as it reappears in the work.

As the quartet falls into rhythmic unison at b.39 (Ex. 1.3), playing a G4 in even semiquavers, there is an accompanying increase in tempo by way of metric modulation. The foregrounding of rhythmic activity continues as the semiquaver rhythm quickly splinters into a hocketed, syncopated rhythm. Quarter-tones surrounding G4 also return as a precursor to the registral spread extending upward and a more complex, arhythmic counterpoint returning that is reminiscent of the opening material of the second section. However, this passage is more restless due to its tempo fluctuations and the return of extreme bow pressure, which features in the first violin part. Independent dynamic surges in each part gradually build to a crescendo at b.62, at which point the tempo briefly drops back to lento, ushering in the next section. 

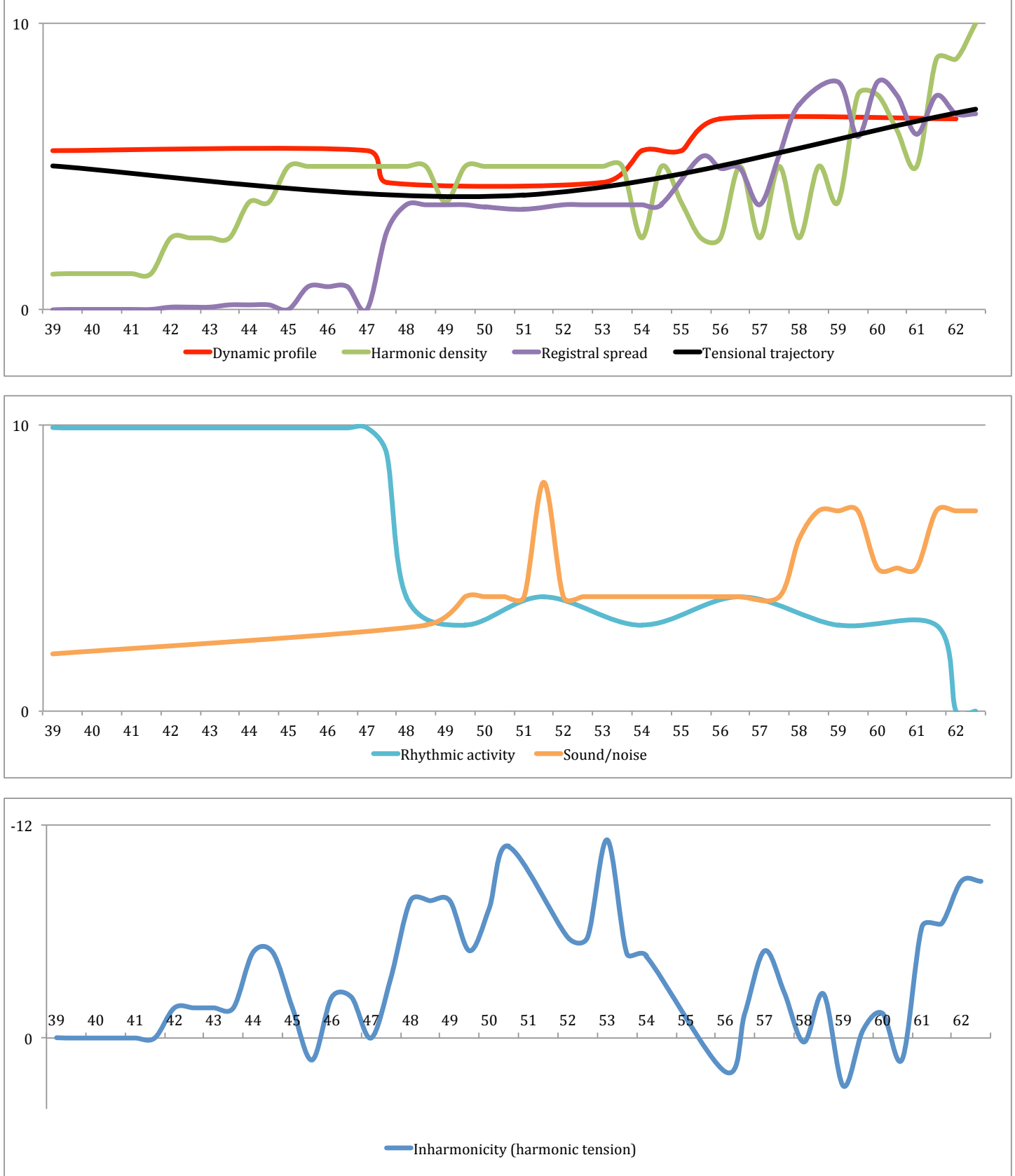

Fig. 2.5. Parametric changes in the third section of Nymphéa. 


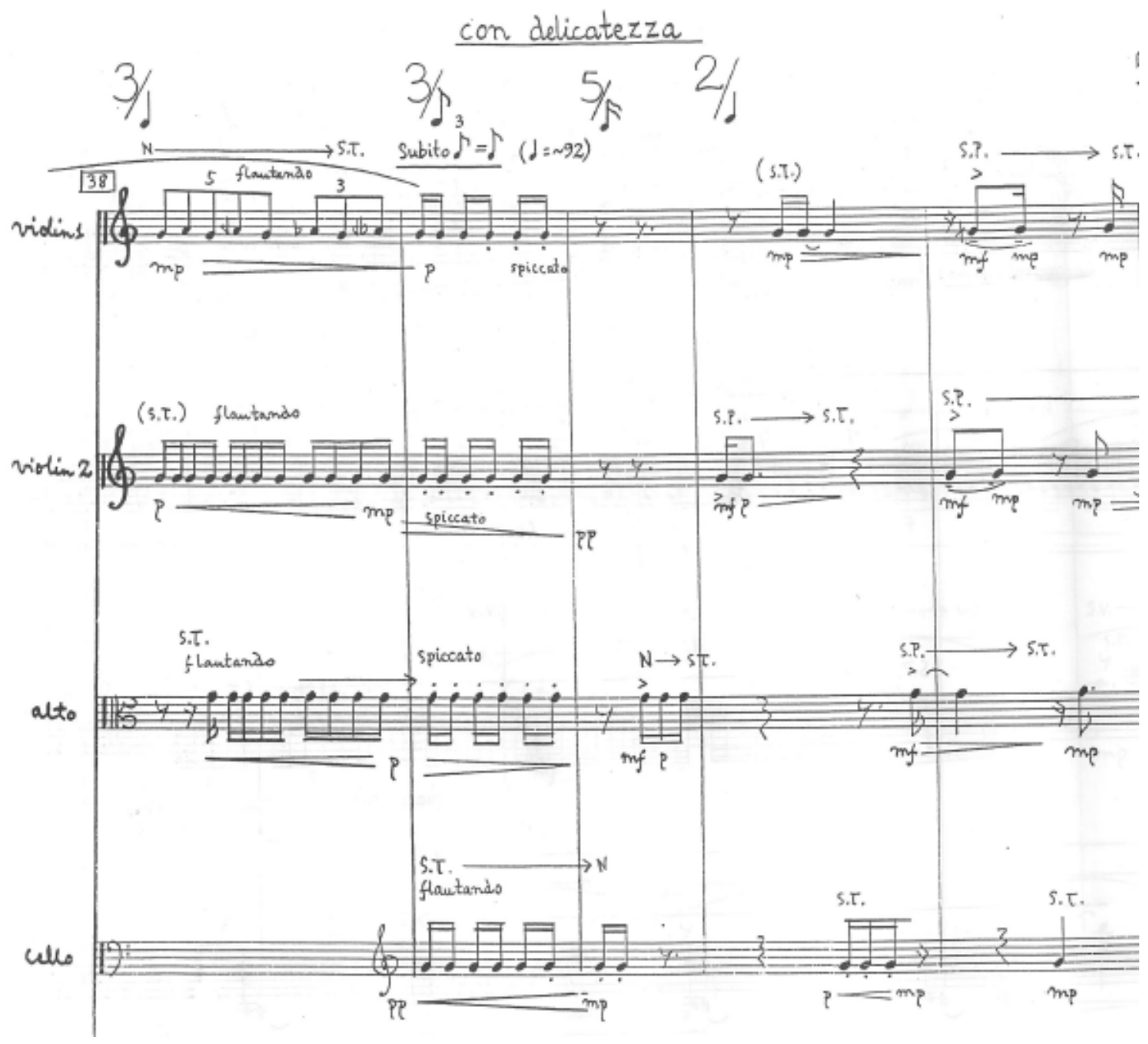

Ex. 1.3. Rhythmic unison in the third section of Nymphéa.

\section{SECTION 4 : bb.63-104}

Coming down from the crescendo, harmonic density increases from that of the previous section, though the fourth section is notable for passages in which the usually closely linked harmonic density and inharmonicity parameters diverge somewhat. For example, between bb.71-77 and bb.89-105 the degree of inharmonicity is relatively low despite a general increase in harmonic density from the third section (Fig. 2.6). Here, inharmonicity veers a little either side of the "zero value" of 7.84. Indeed, this section seems to develop into a type of rest area within the work, containing relatively less tension.

The overall dynamic profile remains quite constant through this section, as does registral spread. The arhythmic "wash of pitches" described in the second section returns for much of the fourth section, with extreme bow pressure being reintroduced as a prominent surface feature. Bow pressure is passed between instruments, again scattered irregularly between the players. The perception of 

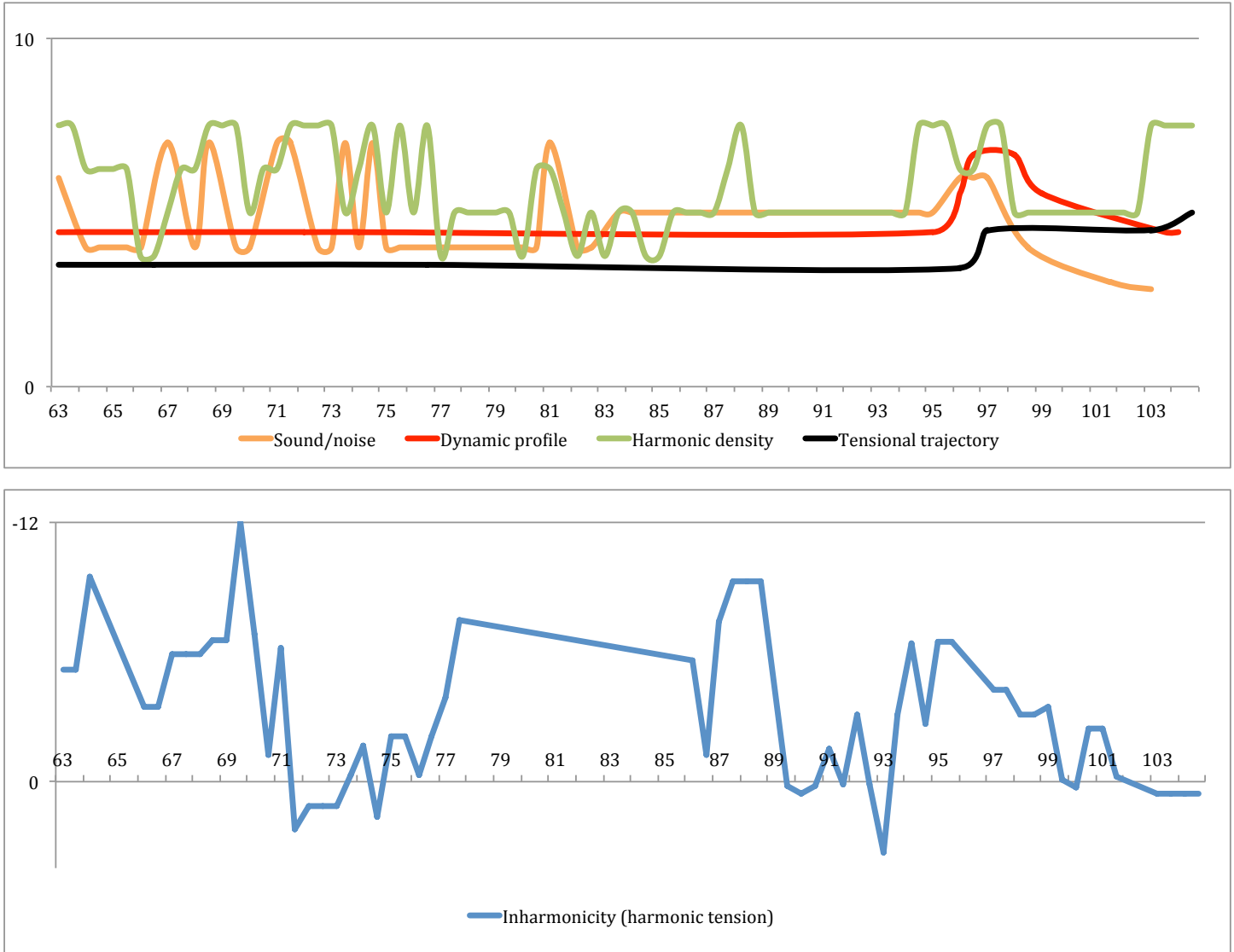

Fig. 2.6. Parametric changes in the fourth section of Nymphéa.

extreme bow pressure as a timbral motif in Nymphéa is reinforced through its frequent use in passages such as this. The amount of pressure and the density with which the technique is clustered between instruments in the work are major factors in altering levels of tension, hence the aforementioned irregular scattering of extreme bow pressure in this "rest area". It is applied in a more forceful and clustered fashion for highly tensional passages later in the work.

\section{SECTION 5 : bb.105-150}

The fifth section is a climactic passage, with the climactic material realized through both conventional devices found in classical music and through devices that are significant in the context of Nymphéa's soundworld. The most obvious parametric feature is the wide, cadential registral spread that remains throughout the section, indicative of a climactic moment, with particular use of pitches in the bass register suggesting a point of arrival (Fig. 2.7).

Following the crescendo at the end of the fourth section, all instruments are united at a forte dynamic, the loudest point of the work thus far (all instruments playing at the same dynamic simultaneously is rare up to this point in Nymphéa). This forte passage 

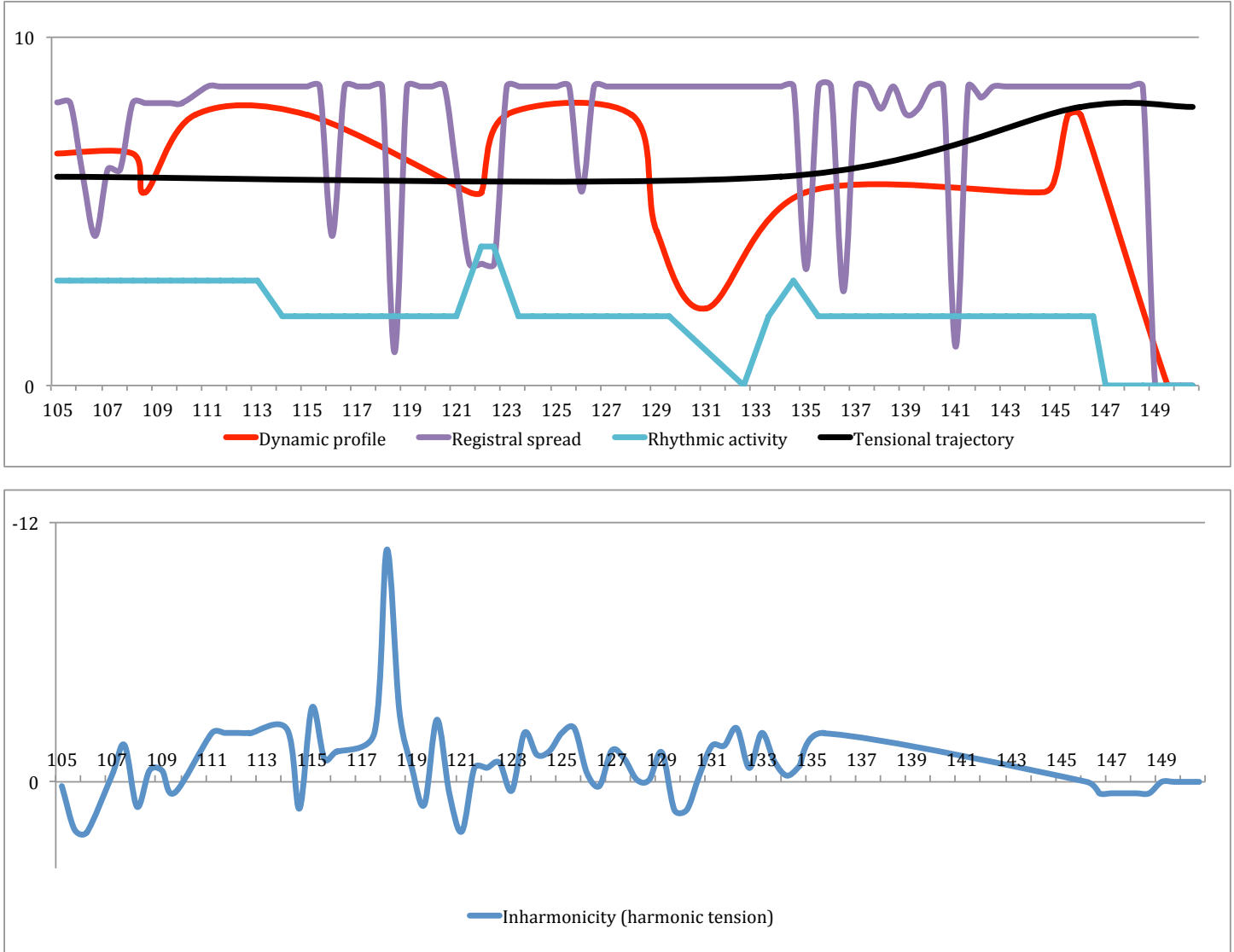

Fig. 2.7. Parametric changes in the fifth section of Nymphéa.

starting at b.111 is the peak of an unsteady, but general increase in the dynamic profile parameter from the beginning of the work. Also at b.111, the first violin and cello perform ascending and descending glissandi respectively, so that the first violin is playing repeated down-bows on A6 while the cello does the same on its low $\mathrm{D} \#$. The repeating of these pitches by the first violin and cello highlights the lack of harmonic change in this section. Up to this point, the rate of harmonic change has been very slow, but this section contains no harmonic change. Harmonic tension also fluctuates less in this section, again veering either side of the "zero value". This could be attributed to changes in the harmonic density parameter - in contrast to much of the preceding material, this section sees a prevalence of sustained single pitches being played on two to three instruments.

In the context of the overall form of Nymphéa, the use of techniques that contrast with what is found elsewhere in the work, such as sustained pitches, repetitive material and the foregrounding of rhythmic or melodic material, create distinctive points of focus that contribute to a clear formal structure. Another notable feature of this section that gives it a strong formal function is the change in foreground ornamentation, with the noise parameter subsiding and the rhythmic activity 
parameter coming to the foreground. The parameter of rhythmic activity comes to the foreground in two different forms (Ex. 1.4): firstly, through the proto-melodic material in the viola part, a fast wave-like melodic contour that also appears briefly in the violin parts, dovetailed between the three instruments; secondly, through the periodicity of the aforementioned sustained pitches in the violins and cello alongside the viola's proto-melodic material. Both of these rhythmic features - but especially the sustained pitches - are notable for their repetition, which contrasts with the often amorphous rhythmic context of Nymphéa. The scarcity of clearly repeated material in Nymphéa results in this section being perceived as structurally significant, reinforced by the expansive registral spread between the sustained pitches.

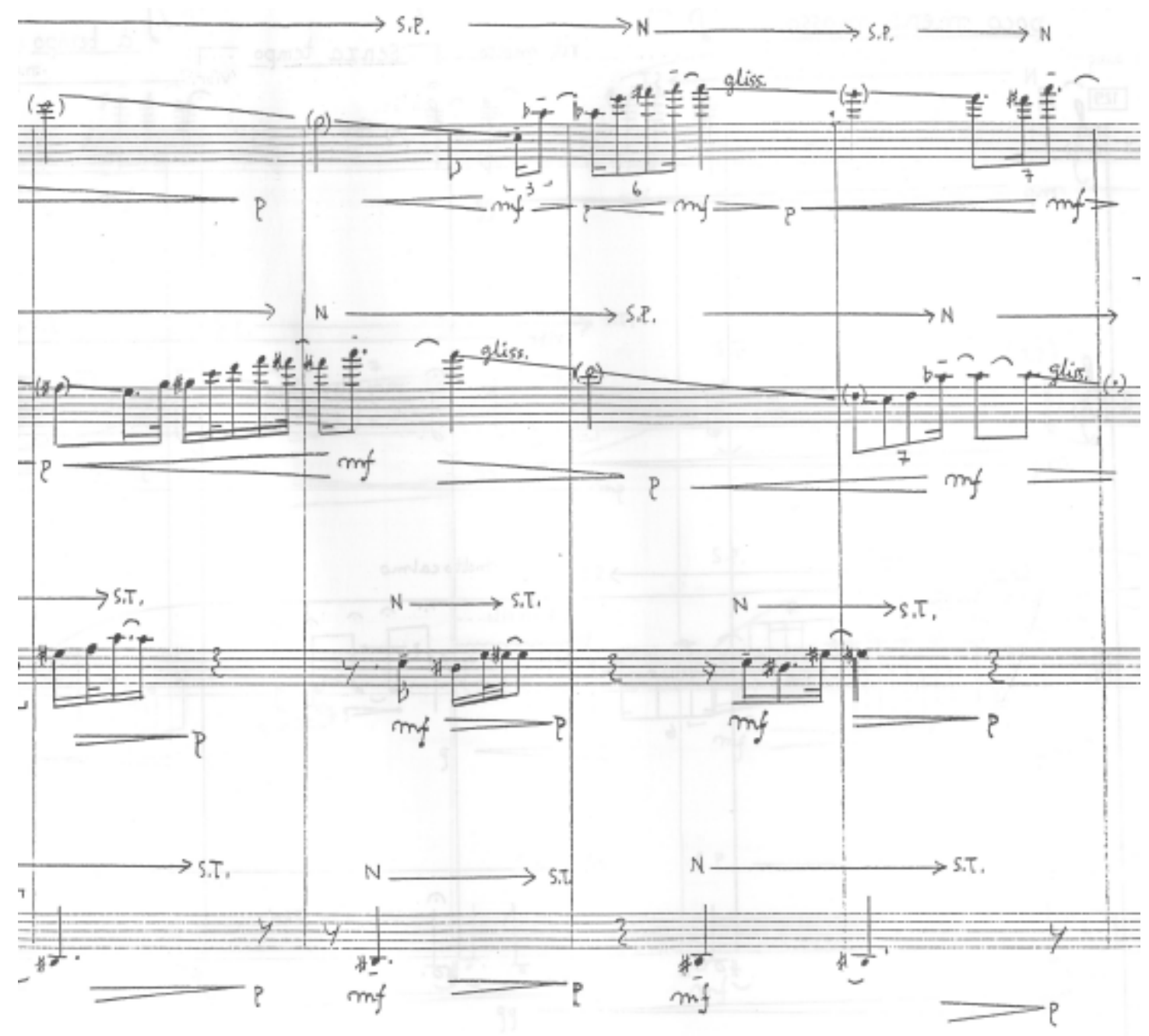

Ex. 1.4. Repetitive proto-melodic material (violins, viola) and sustained pitches (cello) in the fifth section of Nymphéa.

SECTION 6 : bb.151-207

While the sixth section is a continuation of the climactic function of the preceding section, the differing tensional processes employed in each of these sections 
necessitates them being regarded separately. The tensional quality of the sixth section is dictated more by changes to the sound/noise, harmonic density, dynamic profile and rate of harmonic change parameters than by changes to the inharmonicity parameter (Fig. 2.8). Though the degree of inharmonicity in this section generally increases and fluctuates more widely in comparison with the previous section - mostly due to the increase in harmonic density - it is overshadowed by the dominance of the dynamic profile and sound-noise parameters. After the overlapping niente lines in the violin parts at b.150 (another feature that creates a brief but clear separation between the fifth and sixth sections), the quartet unites in a bowed tremolo using extreme bow pressure that builds to fortissimo (Ex. 1.5). The noise produced by the bow pressure is such that it buries the actual pitches being fingered by the players. This united fortissimo is louder still than the forte passage in the fifth section, continuing the sense of climax. This passage is also the first time in the work that the surges of extreme bow pressure occur in unison across the whole quartet, rather than being staggered across individual instruments. As touched on in the discussion of the fourth section, this type of change in the organisation of bow pressure surges is significant due to its creation of a strong tensional process using noise and also due to the unity between the instruments functioning as a point of arrival in the formal structure of the work. Focus is also put on the unison surges of bow pressure by extending their duration for several bars, in contrast to their lasting only a few beats when played by a single player in previous sections.

For the first time in Nymphéa, the rate of harmonic change accelerates strongly. Between bb.153-189 the rate of harmonic change is at its fastest in the entire work. An increased rate of harmonic change is of course a common tensional device in classical music. In Nymphéa's atonal setting and the noise-dominated soundworld of this section, there is no goal-oriented aspect to this increased rate of harmonic change other than the implied sense of accelerated development, which is again reinforced through parametric unity between the players. Throughout this section the quartet moves together between waves of extreme bow pressure and more quiet, but animated, arhythmic flutters of notes. At the peak rate of harmonic change the quartet moves through a series of chords from different underlying harmonic fields, reaching each chord via synchronised glissandi. A unique feature of this section is the treatment of registral spread. Much of the section is restricted to a range of oneand-a-half octaves, with the lowest pitch rarely dropping below $\mathrm{C} 4$. The range is thinnest during the surges of noisy bowed tremolo, and widens to include the upper register for the material between surges. This constriction of the registral range 

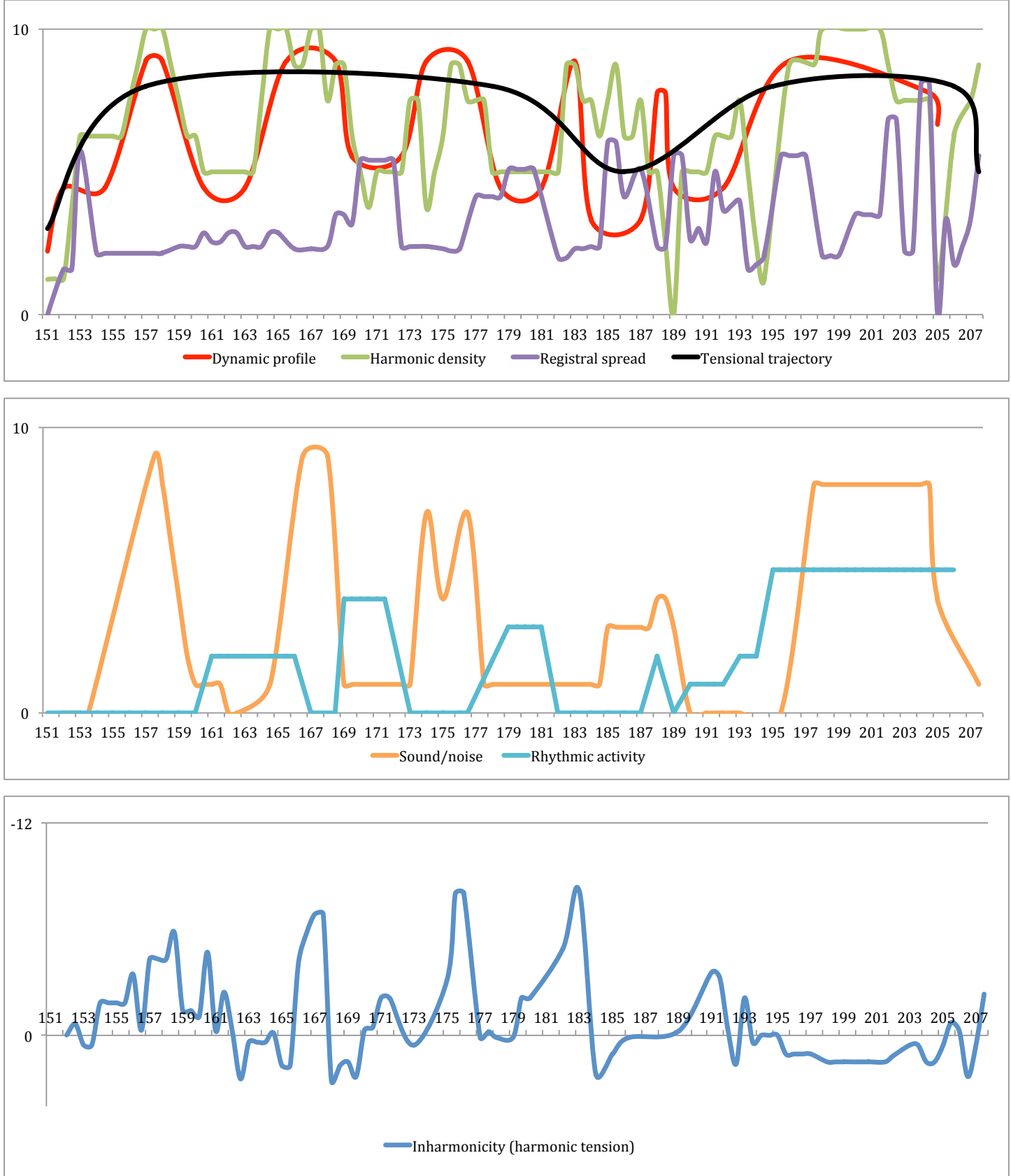

Fig. 2.8. Parametric changes in the sixth section of Nymphéa.

comes immediately after the very wide registral spread of the previous section, a clear parametric contrast between two sections that cover the first climax of Nymphéa. This parametric change highlights Saariaho's ability to generate tension and a sense of formal definition through varying the parameters used to achieve this. This section uses faster changes between states of tension and relative relaxation, evidenced by the changes between the various fortissimo bowed tremolos and the quieter material that lies between. Like the accelerated rate of harmonic change that follows, these changes add to the climactic sense of momentum. The section concludes with a high degree of rhythmic unison from bb.195-207, a passage that 


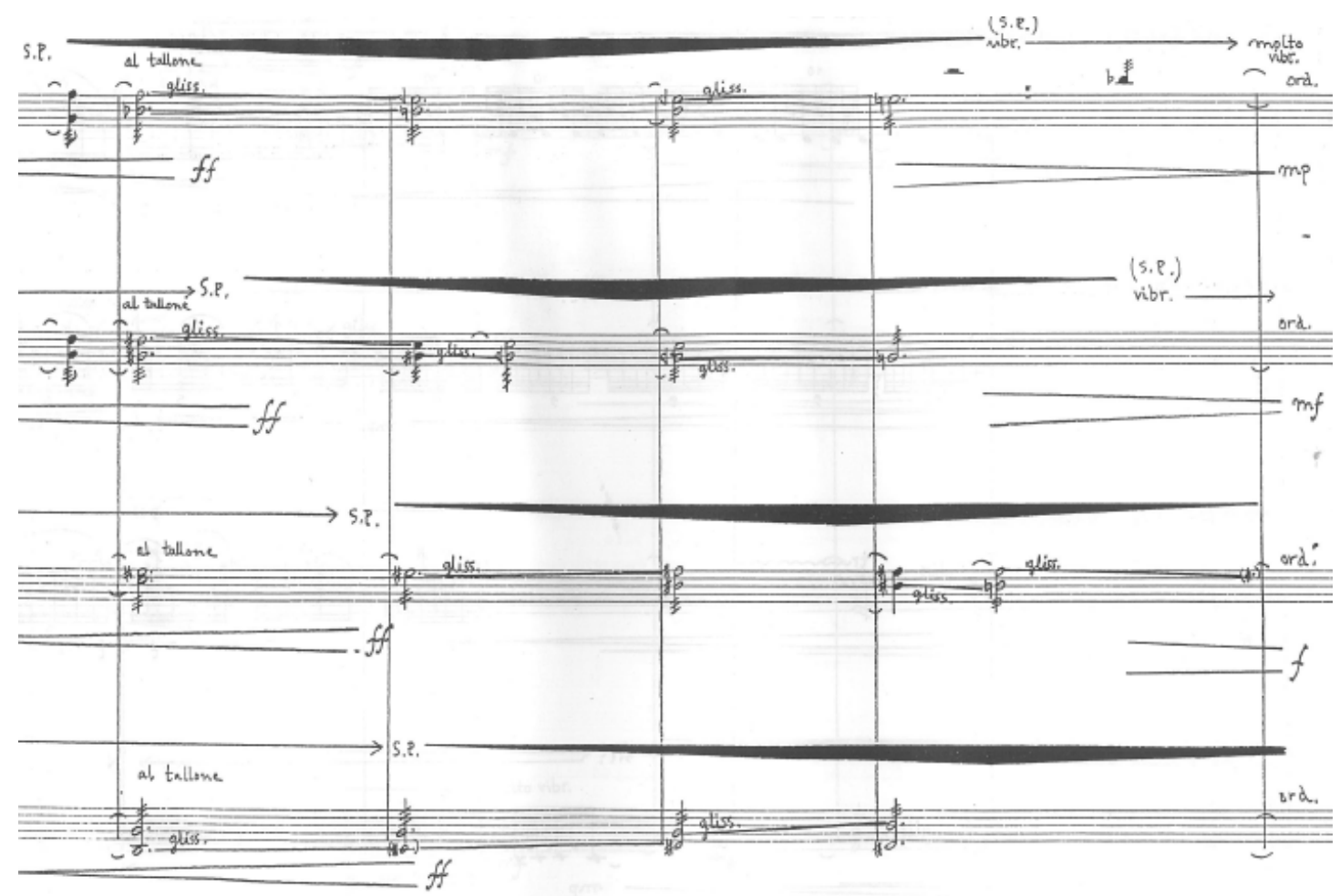

Ex. 1.5. United use of extreme bow pressure in the climactic sixth section of Nymphéa.

sees the rhythmic activity and sound/noise parameters sharing the foreground, with the quartet uniting in rhythmic, accented stabs of extreme bow pressure. As mentioned earlier, this parametric interaction contrasts with the alternating fashion in which these parameters have provided foreground ornamentation thus far, and is the only example of this type of parametric interaction in Nymphéa other than in the second climax of the work, where this interaction is drawn out further. The combining of these two parameters creates a clear point of arrival.

\section{SECTION 7 : bb.208-243}

The seventh section serves as another formal landmark due to its sustained low tension and introduction of new timbral material, and is notable for its manipulation of tension without relying on dynamic profile. The section begins with a haunting change in Nymphéa's aural tapestry as the players whisper syllabic fragments amid the bowed tremolos that connect with the end of the sixth section. The number of parameters in high-tension states is reduced in this section. By the start of this section the rate of harmonic change has dropped back to its pre-climax rate, and the dynamic profile is never louder than $m f$. The registral spread opens up once again (Fig 2.9), however - the bowed tremolos cover the same wide registral range of the fifth section, with the cello playing its open C-string for the first time in the work. 
This section is of interest for the way in which foreground ornamentation is managed through parametric changes. Given their unpitched nature, the use of spoken voice may be considered as a phenomenon that is quantifiable on the sound/noise parameter, as the voices bring a new timbral dimension to the work, immediately drawing aural attention. Along with the voices, the tensional processes at work in this section include the aforementioned bowed tremolos, now performed in a lower dynamic range. Surges of bow pressure have returned to their previous form of distribution, being scattered throughout the section, played by individual players for shorter durations. It is a moment, however, in which rhythmic material comes to the foreground that gives this section such a unique formal character. From bb.214-218 a short motif appears in the first violin part — six semiquavers alternating between $\mathrm{D}$ and $\mathrm{E} b$. This proto-melodic motif is played pizzicato, a technique that up to this point in Nymphéa has only appeared at one other time as a fleeting cluster in the second violin and viola parts in b.188. The pizzicato motif is then imitated in the viola part a major sixth lower, played arco by the first violin at its original pitches and played arco by the second violin a minor third lower. This short imitative exchange between members of the quartet is a clear departure from the dominant mode of discourse in Nymphéa. The pizzicato technique possesses an attack profile that contrasts with that of arco techniques, and the conspicuous response-like interaction between the parts contrasts with Saariaho's use of the string quartet in Nymphéa as a more globalised sound object with little in the way of prolonged focus on a single player.

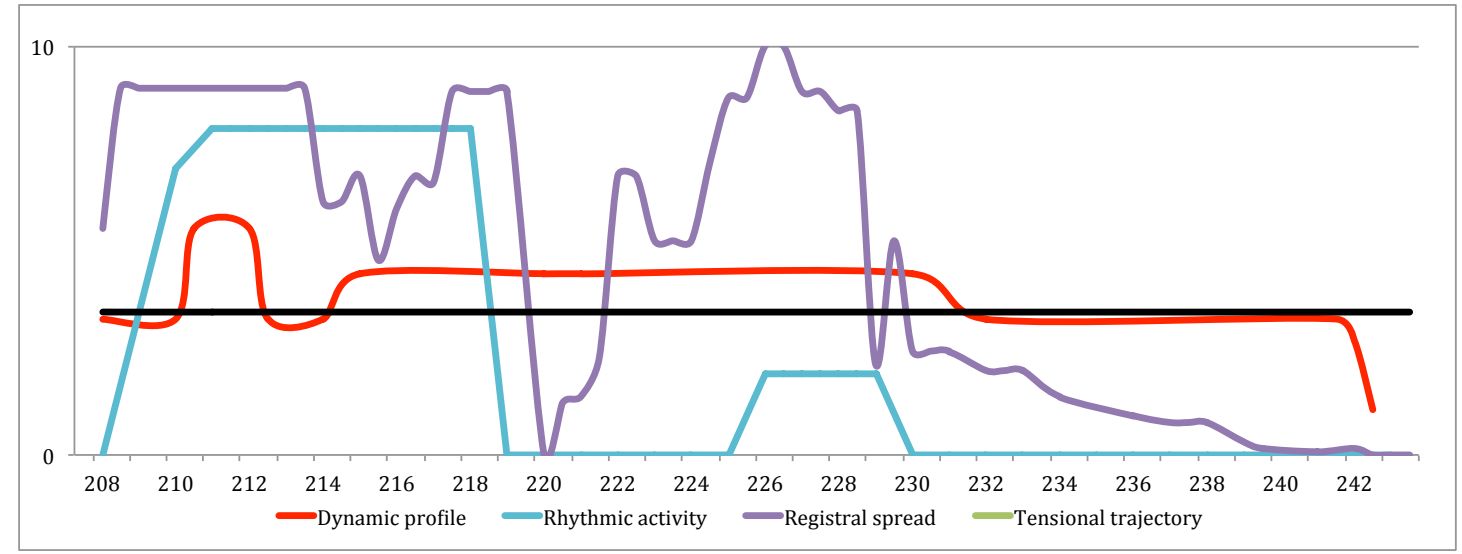

Fig. 2.9. Parametric changes in the seventh section of Nymphéa.

Following the pizzicato passage, the foreground ornamentation of the section is again dominated by scattered bow pressure surges and whispered syllabic fragments. It seems that the significance of this section lies in the structural importance of the whispered text in the overall form of Nymphéa, rather than the manipulation of tension. Given that it comes after the first climax of the work, this 
section's recession of the dynamic profile and rate of harmonic change parameters suggests another "rest area". Yet interest is maintained through the introduction of new sound elements. Following the parametric point of arrival in the preceding climactic sections, the introduction of voices and, briefly, imitative motivic material (some of which is played pizzicato), bring renewed interest to the work's surface material. These new elements can be seen as part of some type of coda symbolising the conclusion of one larger section of Nymphéa (indeed, the double barline that separates Nymphéa into its two parts is not far away at b.262), with the work breaking through to a new area that suggests a fresh timbral trajectory being established. The imitative pizzicato passage proves to be a stylistic and timbral non-sequitur, while the whispered voices go on to play a role in providing a sense of structural similarity between Nymphéa's two halves.

\section{SECTION 8 : bb.244-262}

The eighth section is made up of the remainder of Nymphéa's first half, which concludes at the double barline at b.262. The most obvious formal feature of this section is the timbral development derived from bowing on the bridge. This technique actually enters near the end of the previous section, at b.235, but remains through the implied separation between the two sections and is in all instruments by the start of the eighth section. Along with this timbral development, the trajectory of registral shape also provides clear start and end points for this section, articulating the overall form of Nymphéa (Fig. 2.10).

Starting with an F6 played as an artificial harmonic by the cello, the registral spread of this section steadily widens, retaining this upper reach while also steadily bleeding down to include the cello's low $\mathrm{C} \#$ by the end of the section. As mentioned earlier, such wide registral spacing of chordal material is often applied to reinforce cadential, climactic moments. Though we find this wide registral spread at the conclusion of the first half of Nymphéa, several other parametric changes that might be expected to accompany it are in fact subverted. The dynamic profile of this section remains at the same general level as the previous section and gradually tapers off to an eventual niente at the end, with the quartet playing bowed tremolos col legno tratto, which adds some significant wispy white noise to the strings' timbral character.

While the change in dynamic profile effectively suggests a winding down in this section, the rate of harmonic change increases - a change that, in conjunction with the increase in registral spread, gives a contrasting impression of a climactic event 

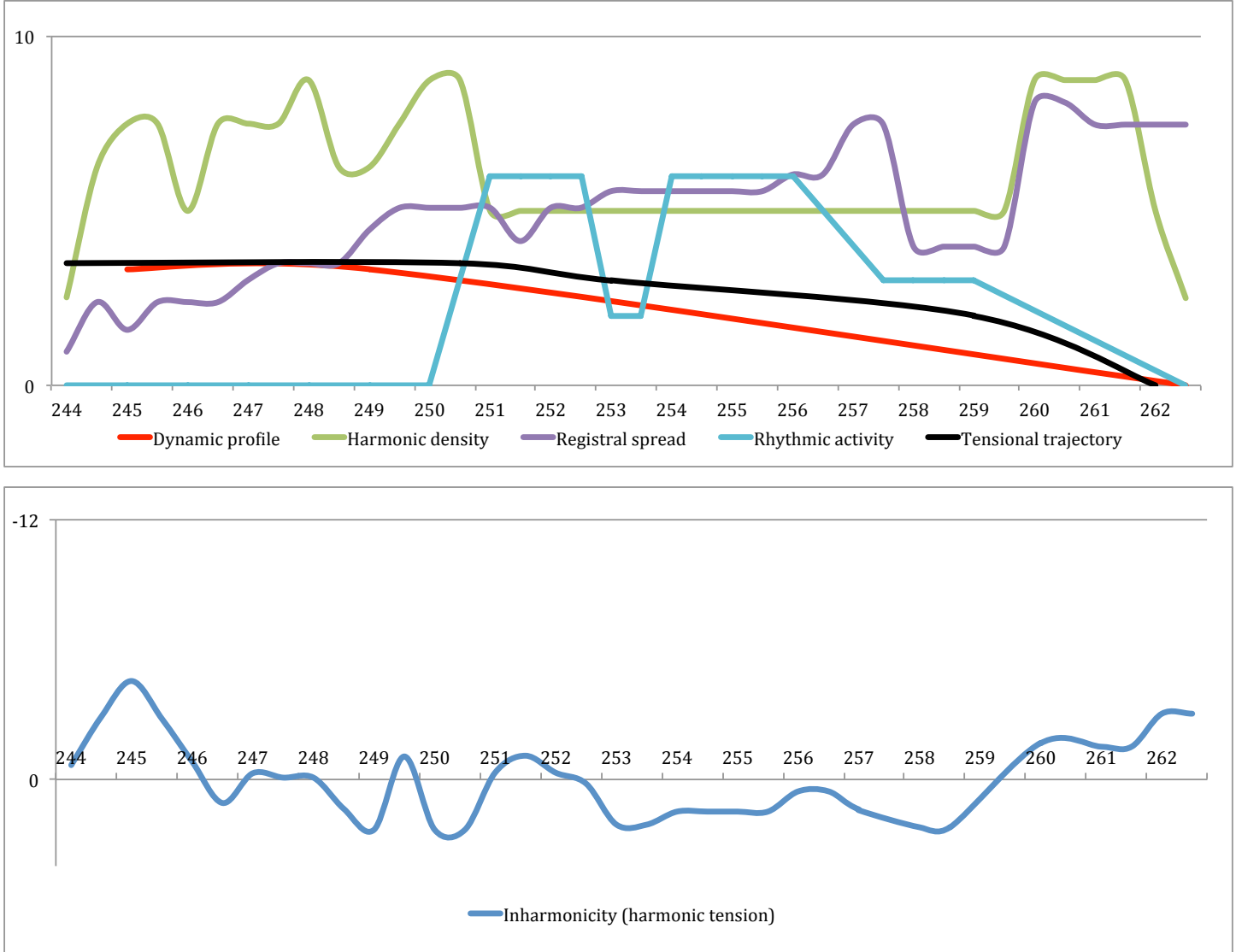

Fig. 2.10. Parametric changes in the eighth section of Nymphéa.

unfolding. Indeed, other techniques employed in the latter stages of this section suggest an active, yet muted, conclusion. The inharmonicity parameter in this section actually reveals little harmonic tension. In fact inharmonicity levels fall into "consonant" values for the majority of the section. Yet this is another one of the few instances in Nymphéa where the usually closely related inharmonicity and harmonic density parameters diverge. Double stopping is used extensively in the first half of this section, but harmonic tension remains low. As mentioned in the methodology, extreme registral spread has the effect of neutralising the perception of harmonic consonance and dissonance, diminishing the effect of both. This seems to apply to this section of Nymphéa, which does not exhibit any audible harmonic consonance. Additionally, the other ubiquitous method of disguising pitch in this work - the use of constantly changing bowing positions - constantly affects pitch perception, particularly the col legno tratto playing that diminishes the perceptibility of the pitches in the final few bars of the section.

Despite the focus here on qualities that relate to the sound/noise parameter, the parameter that comes to occupy the foreground most clearly in this section is rhythmic activity. Whereas the first half of this section is akin to the wash of pitches 
described in previous sections (but with the glassy overtones of the on-the-bridge bowing providing additional timbral interest instead of surges in bow pressure), the second half sees the quartet switch to rapid semiquaver patterns of similar contour that shift in and out of rhythmic unison. The subdivisions then increase to demisemiquavers at b.256, adding to the sense of tension and momentum also reflected in the rate of harmonic change, before dissolving into bowed tremolos for the final two bars of the section.

The final two bars of the section are significant for a rare moment of literal repetition due to the reprisal of the cadential $C \sharp$ chord of the second section (Ex. 1.6). Here the chord is initially denser than in the second section. While only the cello and viola are used, thinning out to $C \sharp-B-D \#-C$, with the upper and, more importantly, lower pitch tremolos in the second section, here all players do so. The low dynamic profile of the chord also remains, its muted cadential quality making it recognisable as material of some significance in the context of the work.

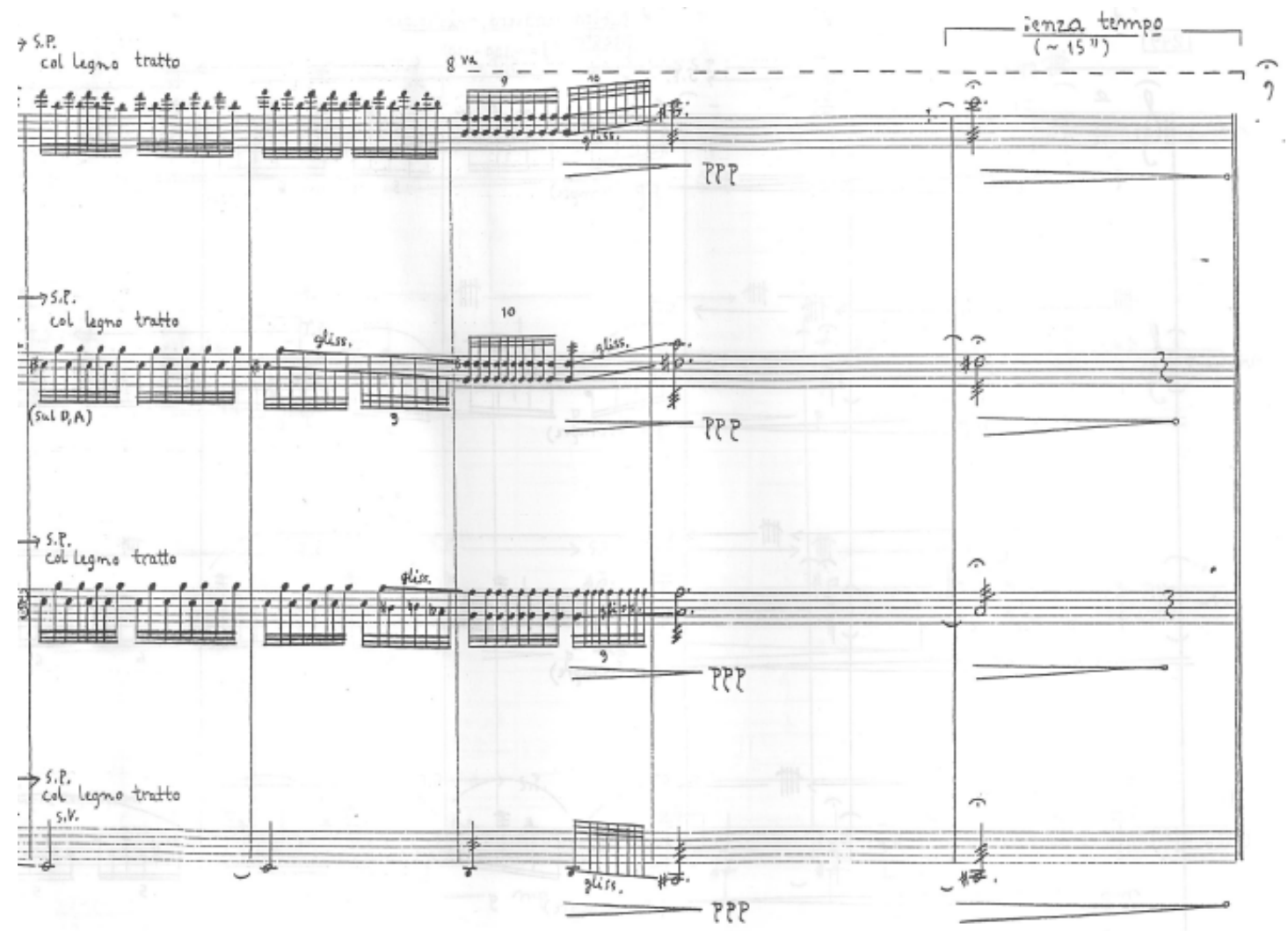

Ex. 1.6. Second statement of $C \#$ chord, in the eighth section of Nymphéa. 
SECTION 9 : bb.263-295

As the first section of Nymphéa's second half, the ninth section gradually accumulates tension in preparation for the climactic section that follows it. Musical parameters are tightly controlled in this section, with the reduction in the rate of parametric activity underscoring the audible change of pace following the first half of the work (Fig 2.11).

The use of inharmonicity as a tensional device is clearly demonstrated in this section, as Saariaho creates surges in inharmonicity whose peaks become gradually higher. Across the entire section, these undulations can be seen to follow an overall increase in harmonic tension. This control of harmonic tension, which places it within a limited bandwidth of inharmonicity over an extended duration, makes this section unique in the context of Nymphéa and certainly distinguishes it as the beginning of a new "movement". Like the inharmonicity bandwidth, harmonic density remains rather consistent throughout this section, with virtually no rests in any of the parts. The dynamic profile of this section also follows a similar trajectory to the inharmonicity parameter, rising and falling but maintaining a steady overall increase in its slow crescendo towards the next section. This is achieved to some extent through the periodic dynamic surges in the players' parts that, as with much of the first half of Nymphéa, are not synchronised. Over the course of this section, however, synchronisation is again used as a device for gathering force and momentum. The players' dynamic surges eventually begin to synchronise, and as the surges in the individual parts are also growing steadily louder, the overall dynamic profile reaches gradually higher peaks as the surges become more unified.

As with the parameters already discussed in this section, registral shape also remains generally consistent, with subtle changes unfolding over the duration of the section. Predominantly occupying the middle and low registers, this section also contains frequent flashes of artificial harmonics more than two octaves above the treble staff. As the dynamic surges become more synchronised, the registral spread grows through the use of artificial harmonics pushing further above the treble staff. The rate of harmonic change is also steady in this section, and overall slightly faster than the rate of harmonic change observed in the non-climactic sections of Nymphéa's first half. Between bb.287-295, the three dynamic surges - which, by this stage in the section, are closely synchronised between the players - all occur in conjunction with a sharp increase in registral spread that then decreases in tandem with the dynamic decrescendos. The three spikes in dynamic profile are of course more pronounced 

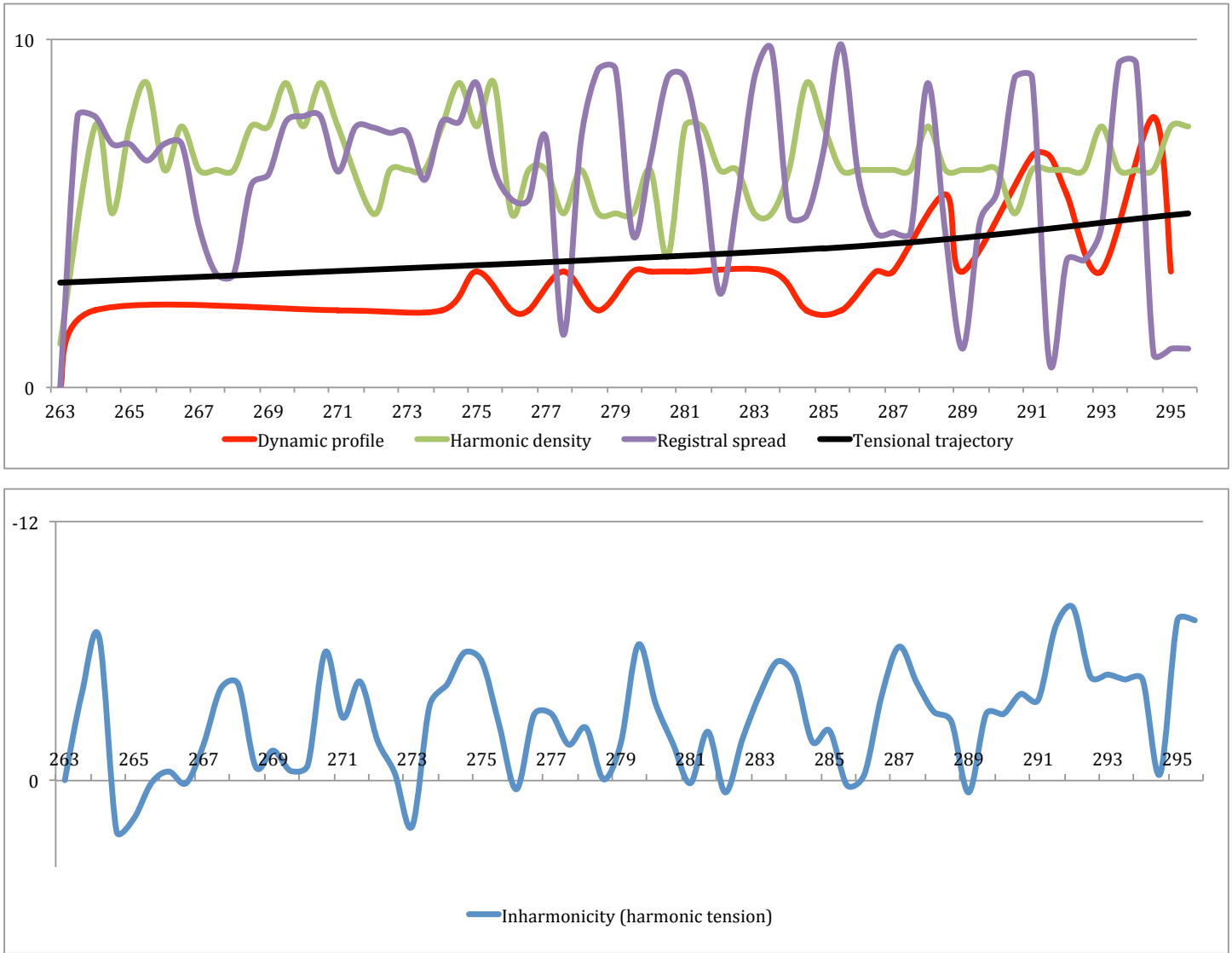

Fig. 2.11. Parametric changes in the ninth section of Nymphéa.

due to the closer synchronisation between the individual players. The final five bars of the section see its dominant playing style disturbed in preparation for the climactic section that follows, as in b.291 each player's crescendo coincides with a pitch that is played détaché, with the duration of notes also becoming longer and the vibrato instructions having disappeared. This is the first time such a clear tensional relationship between the dynamic profile and registral spread parameters is used in Nymphéa, highlighting Saariaho's heavy use of parametric desynchronisation elsewhere in Nymphéa. This parametric desyncronisation is a tensional device used for subverting potentially climactic passages, which in turn reinforces the tensional impact of true climactic passages in the work, where most parameters are synchronised.

Another obvious feature of this ninth section is the absence of foreground material based on changes to the sound/noise and rhythmic activity parameters, which quickly sets apart the two halves of Nymphéa. As an exception to what has preceded it, this section can be perceived as a point of contrast within the context of Nymphéa, marking a new approach to the foreground-background arrangement of musical elements in the wake of the first half of the work. Rhythmic activity is minimal 
throughout this section, with pitches flowing in a slow, arhythmic manner akin to the "wash of pitches" passages described in the first half of Nymphéa.

Without the surges of bow pressure and other variations of articulation lifting a single player out of the overall sound in the first half of the work, the ninth section sees the quartet organised as a more globalised texture. Interestingly, this is achieved through the work's most contrapuntal material. As a slower realisation of the "wash of pitches" described in earlier sections, here the registral extremes of high artificial harmonics or low cello pitches are the clearest features that remind the listener of the individual parts that comprise the ensemble. The quartet interacts in its most traditionally contrapuntal organisation in this section, yet it is articulated in such a way that the typical clarity of individual lines is often obscured by its languishing rhythmic character.

The timbral backdrop of this section retains a degree of familiarity due to the continuation of changes in bow position, whose movements between sul tasto and sul pont also gradually synchronise with the dynamic surges. In a departure from the way bow position is prescribed in the first half of Nymphéa, peaks in dynamic profile now coincide with reaching sul pont. In the first half of Nymphéa, peaks in dynamic profile coincide with naturale bow position. This contrary relationship between bowing position and dynamic profile, in which purity of pitch is compromised at the moment it reaches a dynamic peak, illustrates yet again the emphasis on desynchronisation and subversion of energetic profile in Nymphéa. Adding to this effect is a notable instruction in this section regarding vibrato that is overlying the bow position instructions. Like the bow position instructions, the vibrato instructions continually move between vibrato and senza vibrato, with peaks in dynamic profile coinciding with reaching senza vibrato. Here the decoupling of articulation and dynamics subverts their traditional relationship, frustrating the expressive capability of the material.

\section{SECTION 10 : bb.296-334}

The tenth section delivers the climax threatened in the ominous ninth section by employing material and tensional processes that contrast heavily with the ninth section. This section reprises many of the processes observed in the climactic material of the sixth section, pushing those processes to their extremes while also creating a structurally coherent link with the first half of Nymphéa (Fig. 2.12). Like the climactic material in the first half of the work, this section serves as a point of arrival once again in its use of parametric synchronisation, employing increased synchronisation 

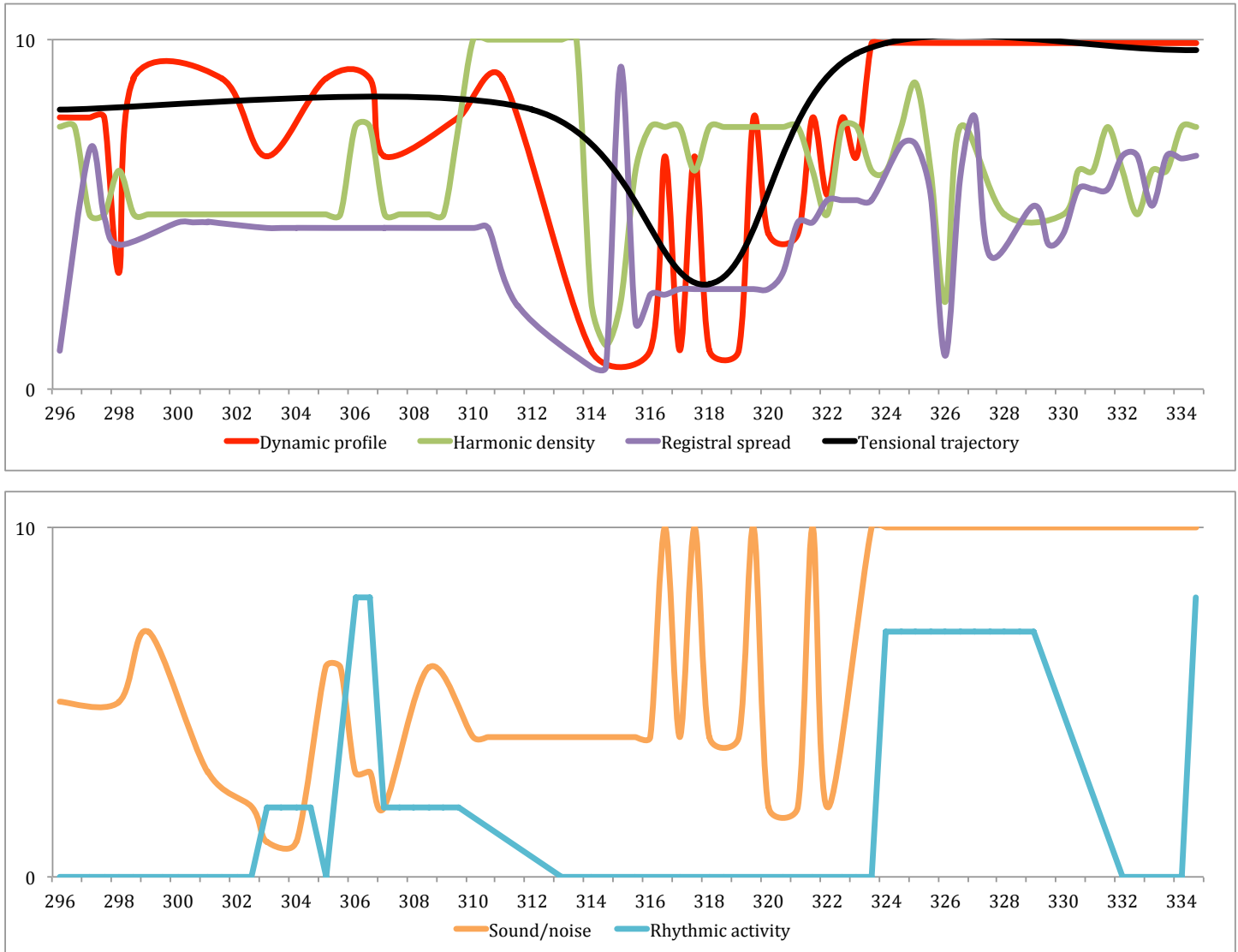

Fig. 2.12. Parametric changes in the tenth section of Nymphéa.

between the players to bring this climax into focus, while retaining a degree of flux as it jumps between a number of techniques and motifs (Ex. 1.7). Between bb.296-325 the quartet moves together briskly between 1) surges of extreme bow pressure played in polyrhythmic semiquaver and demisemiquaver glissandi patterns; 2) a version of the animated, arhythmic flutters of notes found in the climax of the sixth section, now transformed by heavily accented and staccatissimo playing; and 3) downward glissandi with extreme vibrato.

Though this section occupies a state of high tension due to its explosive rate of flux, in a formal sense it can also be considered a long-awaited release from the tension of the tightly controlled and consistent material of the ninth section. As with the sixth section, the tensional quality of the tenth section is dictated more by changes to the sound/noise, harmonic density, dynamic profile and rate of harmonic change parameters than by changes to the inharmonicity parameter. It is not possible to accurately measure inharmonicity in this section due to the extensive use of glissandi. At many points throughout this section, at least one player is performing a glissando technique, meaning that chordal material is not stable enough to enable extraction of distinct pitches for analysis. It is not within the scope of this analysis to 


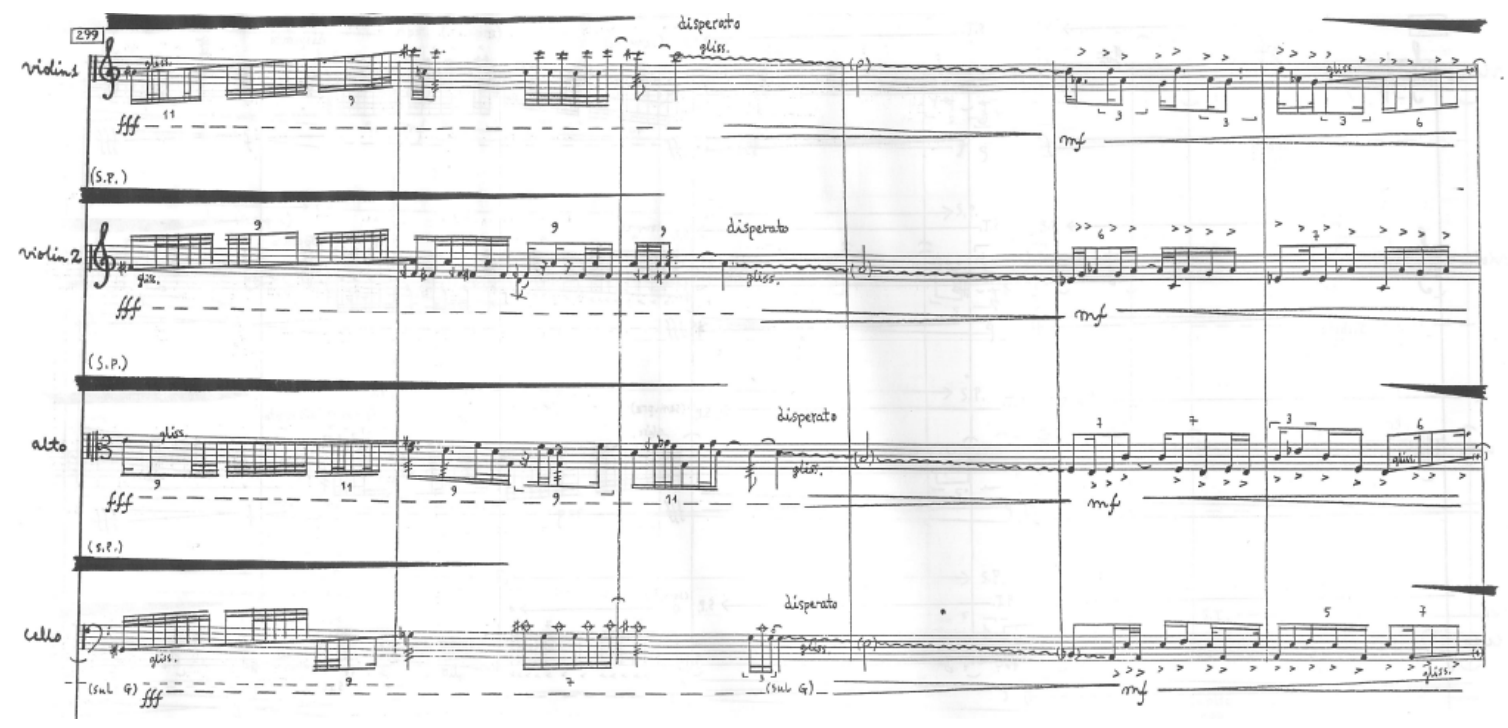

Ex. 1.7. Flux in articulations and techniques in the climactic tenth section of Nymphéa

develop a system for the measurement of inharmonicity of chordal material containing glissandi. It is possible, however, to acknowledge the pitch instability that results from glissandi techniques and their effectiveness as a pitch-based tensional process. Therefore, it is appropriate to shift focus in this section from inharmonicity to harmonic instability, which better describes the microtonal nature of the glissandi transitions between pitches. Harmonic instability still implies a tensional process concerning the degree to which a pitch, equal-tempered or not, remains static for its duration. This temporary reframing of inharmonicity obviously affects the accuracy with which the rate of harmonic change can be measured in this section as well, though there is enough harmonic material without glissandi to still allow fairly accurate identification of changes in the underlying harmonic field.

Having identified these obstacles to obtaining accurate measurement, it must be noted that a significant amount of the harmonic material in this section is ultimately overshadowed, as it is in the sixth section, by the dominance of noise. Periodic surges of extreme bow pressure return in this section, performed in unison by the entire quartet. Whereas in the sixth section these surges often contain glissandi, in the tenth section the surges are always combined with glissandi, in every part. All surges from bb.296-324 are also played sul pont, resulting in a combination of pitch instability and timbral instability combined with the most immediate and foregrounded parametric extreme - noise - which straddles both pitch and timbral instability.

The rate of harmonic change is accelerated in this section, though not quite to the extent of the climactic material in the first half of the work, but drops away significantly for Nymphéa's tensional apex starting at b.326. The passage that extends 
from b.326-334 is so dominated by noise that the rate of harmonic change is essentially irrelevant here. The tenth section shares with the sixth section the loudest dynamic profile of the whole work, with the surges of bow pressure being extended to their longest durations. From bb.326-334, the works's main climax - a hocketed pulse of ferocious, sustained down-bows (Ex. 1.8) - breaks free from the polyrhythmic tension and fast changes of material that have dominated thus far. This hocketed, down-bowed passage marks the strongest fusion of the two main foreground ornamentation parameters in Nymphéa, sound/noise and rhythmic activity. While the dominance of noise in this passage is such that the inharmonicity and rate of harmonic change parameters are rendered irrelevant, the other parameters - dynamic profile, harmonic density and registral spread - are employed in ways that typically serve to maximise the impact of climactic material. The extremely high dynamic profile and wide registral spread (between three and

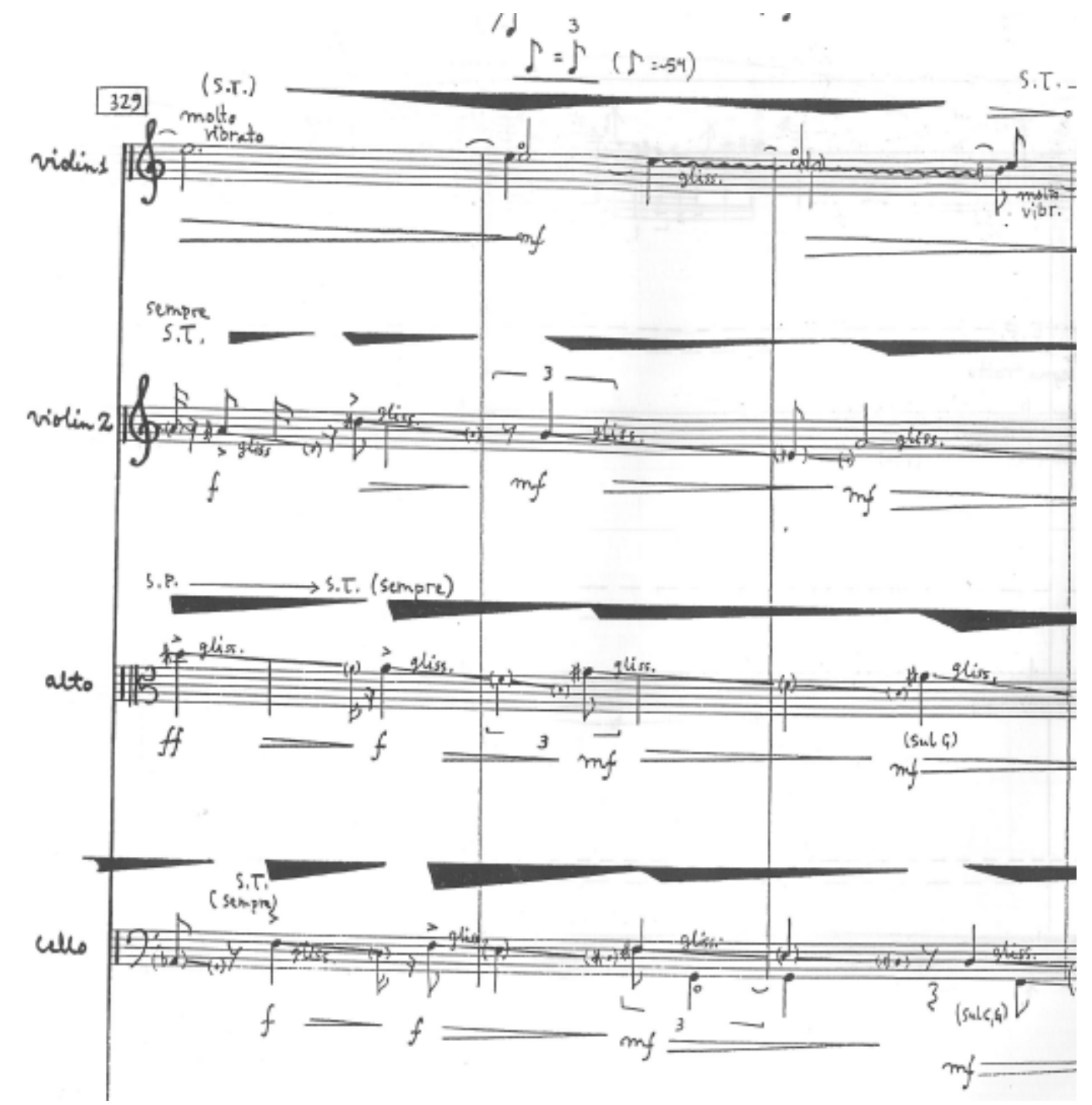

Ex. 1.8. Hocketed pulse of extreme bow pressure in the climactic tenth section of Nymphéa 
four octaves) combine with the foregrounded noise and rhythm to finally realise a climax that combines maximised timbral, rhythmic and dynamic parameters (with the noise parameter so extreme that it effectively consumes the inharmonicity and rate of harmonic change parameters), underlining the singular significance of this passage in the context of Nymphéa. The rhythmic parameter is adjusted between bb.328-334 to gradually release tension in this passage and eventually reach a point of rest. The durations of the sustained down-bows become increasingly extended and the dynamic profile decreases, and eventually the sense of rhythmic pulse is lost. Changes to slower tempi are also employed to this end.

\section{SECTION $11:$ bb.335-362}

The eleventh section continues the low-tension trajectory unfolding by the end of the preceding section. Several parameters are reorganised for this section, however, so that the low degree of tension is generated in a different way. We see the foreground ornamentation of this section (Fig. 2.13) dominated by the rhythmic activity of the proto-melodic material in the first violin, and a return to a more consistent use of material, as in the ninth section. The eleventh section begins with the first violin performing a repeated ascending figure, played legato. The bow position for the first violin's line is consistently naturale, a notably stable departure from the restless bowing instructions in the rest of the work. While the rhythm of the proto-melodic material differs slightly with every iteration, its general range and underlying harmonic field remains quite consistent. The sound/noise parameter is not foregrounded - despite the rest of the quartet playing slowly rising and falling glissandi figures, their col legno tratto bowing and piano dynamic relegates this material to a glassy atmospheric backdrop for the first violin's timbrally pure material. The first violin's proto-melodic material from bb.335-346 appears to be an extended recasting of the second violin's proto-melodic material that emerged in the

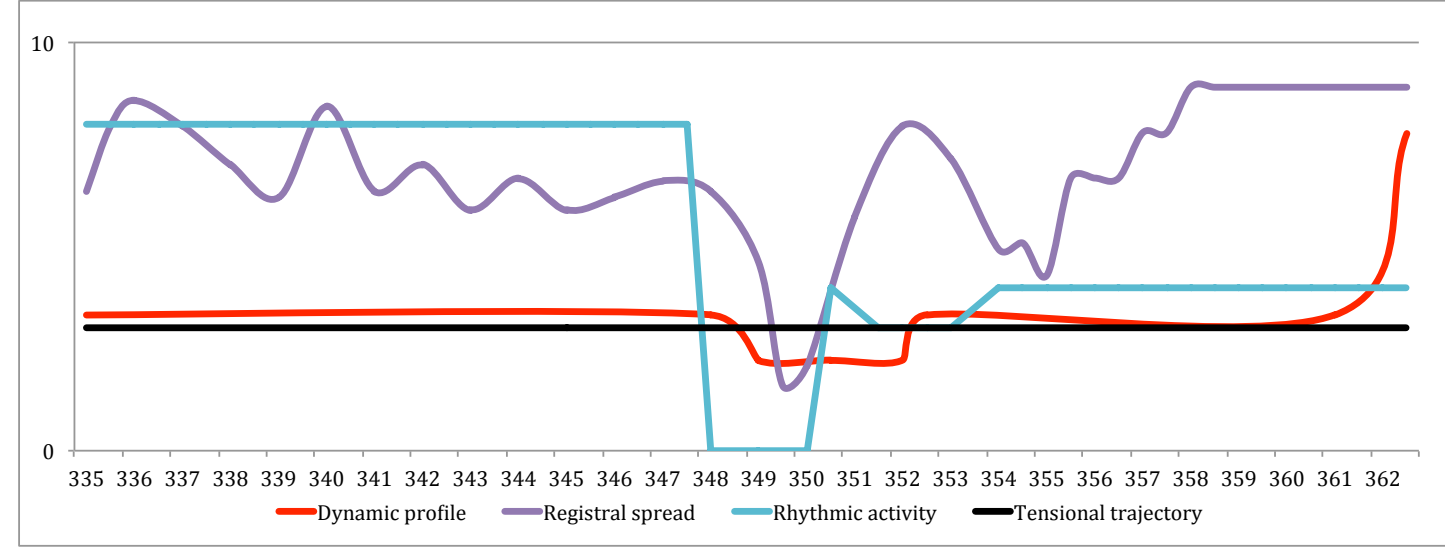

Fig. 2.13. Parametric changes in the eleventh section of Nymphéa. 
opening section of Nymphéa. As with the climactic content of the previous section, the return to material from an earlier section here reinforces a structural coherence that links the two halves of the work. Again, the presence of glissandi for much of this section imposes an obstacle for measuring harmonic tension and rate of harmonic change. Since the bowing techniques applied to all players excluding the first violin up until b.348 effectively mask their notated pitches, it is only the first violin that can be drawn upon for accurate information about the rate of harmonic change. Reliable measurement of the rate of harmonic change becomes possible from b.354, once glissandi no longer appear in any parts. The first half of this section, containing the first violin's proto-melodic material, displays very little harmonic change, reinforcing the sense of stasis created by the repetitive nature of the first violin's ascending lines. The rate of harmonic change accelerates slightly once the glissando material is replaced by more stable, pure pitches, but not enough to generate any sense of momentum. The dynamic profile of this section never rises beyond $m p$, which is assigned predominantly to the first violin only.

The final five bars of this section (Ex. 1.9) recall the muted cadential moments at the conclusion of other sections of Nymphéa - bb.31-37 (end of the second section) and bb.261-262 (end of the eighth section and first half of Nymphéa). Again, this material contains a low dynamic profile, wide registral spread and similar pitch material (C\#-

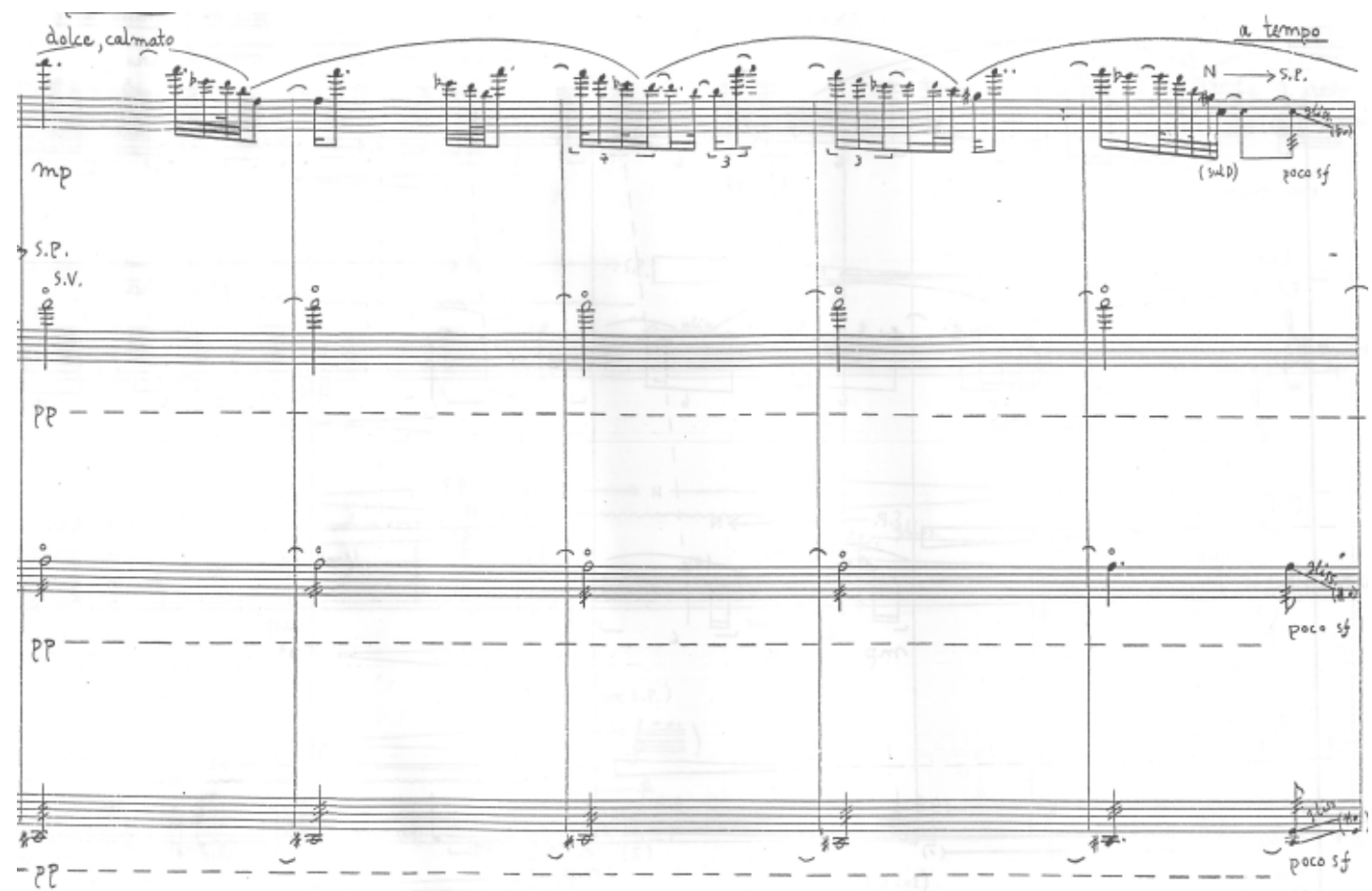

Ex. 1.9. Third statement of $C \sharp$ chord, in the eleventh section of Nymphéa. 
G-A), with the most identifiable and important pitch of course being the cello's low $\mathrm{C} \#$, played tremolo. Though the harmonic density of the chords based on the low $\mathrm{C} \#$ differs with each occurrence, it can be reliably inferred that these pitches are derived from a common underlying harmonic field. When considering that in addition to the ubiquitous tremolo technique, the chords based on the low $\mathrm{C} \#$ also share common dynamic and registral parametric features, it appears that Saariaho is using recognisable repetition of this harmonic material at structurally important points (early in the work, at the conclusion of its first half and near the end of the second half) to tie the work together through quasi-cadential points of arrival that reveal Nymphéa's home key, or home harmonic field.

\section{SECTION 12 : bb.363-389}

The final section of Nymphéa continues the decline in energy towards silence, while reprising particular types of foreground ornamentation that illuminate formal similarities between the two halves of the work (Fig. 2.14). The section begins with the return of whispered material, as used near the end of the first half of the work. The only variation in this second appearance is that the syllabic fragments are now full lines of text, taken from But there has to be more by Russian poet Arseniy Tarkovsky. Lines are whispered in full, though some syllables are drawn out across several beats. The syllables that are drawn out are also the same syllabic fragments used in the first half of Nymphéa, their source now revealed.

The use of the whispered text near the conclusion of both halves of Nymphéa adds a further structural landmark and creates a sense of formal logic for the work. As mentioned in regard to the seventh section, the whispered text has value as a timbral refresher that draws the attention of the listener. This also applies in the second half of the work, with the whispered text following sections that have pushed the extremes of the sound/noise parameter to the foreground for an extended period (tenth section), with rhythmic activity also featuring.

Rhythmic activity occupies the foreground of the early part of the twelfth section, alongside the whispered text, with the cello playing a passage of rapid but crisp microtonal contours initially covering less than an octave. Here we have another example of climactic material subverted - the cello line, like the whispered text and the accompanying upper register pitches held by the violins, are played at low volume. The combination of low and high pitch material — with nothing occupying 

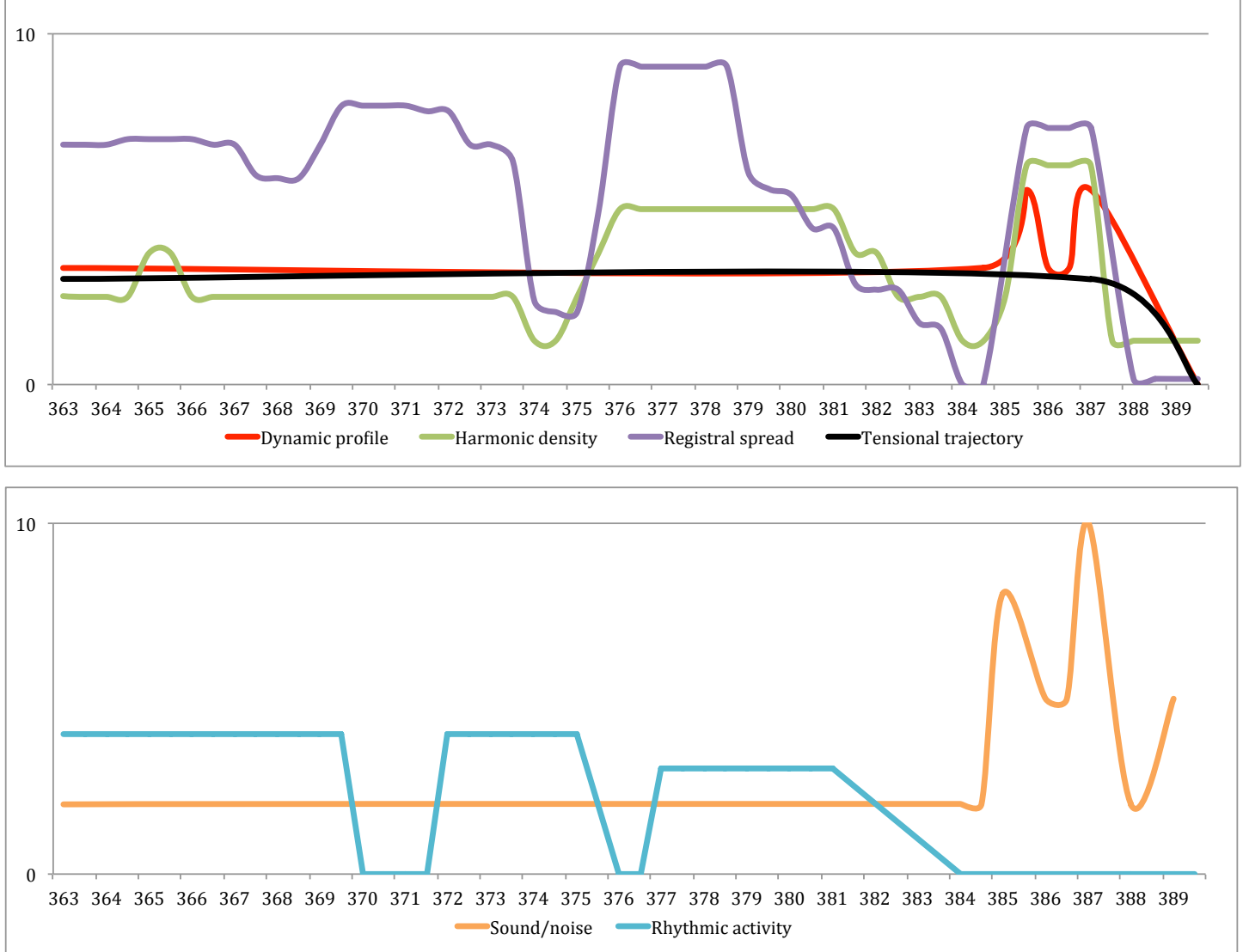

Fig. 2.14. Parametric changes in the twelfth section of Nymphéa.

the treble register of this spread - generates tension, but this can be considered registral tension as opposed to harmonic tension, as the great distance between the low and high pitches lessen the audible intervallic relationships that we interpret as consonant or dissonant. The fast playing in the cello line also conveys a sense of momentum, but the effect is subverted by the quiet dynamics and the avoidance of clear melodic or tonal direction in the line. Additionally, the rate of harmonic change remains slow throughout this section, becoming gradually slower following the conclusion of the whispered text passage at b.380.

Also decreasing in this section is harmonic density, which remains relatively low throughout, in contrast to the thicker harmonic material that dominates the second half of Nymphéa. This reduction in harmonic density is another means of reducing tension as the work winds down. As seen throughout the work, and especially in the first half, the sound/noise and rhythmic activity parameters often alternate in their role of providing surface material in Nymphéa. This is seen again in the twelfth section, once the whispered text and cello line conclude. The sound/noise parameter now comes to the foreground for the final few bars of Nymphéa, with two sustained 
surges of extreme bow pressure played without tremolos by the cello. The rest of the quartet accompanies the cello with high artificial harmonics, again using registral tension of wide harmonic spacing in addition to harmonic tension. The degree of inharmonicity is rendered unstable due to the quartet playing trills. The effect of the trills is reminiscent of the glissandi discussed in the tenth section, which also generates tension through harmonic instability. The closing bars of Nymphéa suspend this harmonic tension and instability, while the other parameters descend to their zero values. Eventually the cello is left alone, avoiding release to the end with a trill flickering away into silence.

In summary, Saariaho creates a coherent, tension-based formal discourse in Nymphéa by relying on a core group of parametric relationships and combinations, while also using non-literal repetition of selected material. Synchronisation - of rhythmic activity, dynamics or noise - is key to any one parameter dominating the material, its importance coming from its relative scarcity in the overall context of the work. Noise and rhythmic activity are clearly the parameters that Saariaho uses to construct foreground ornamentation, while traditionally tension-related parameters such as inharmoncity and dynamic profile also feature. The dominance of noise in climactic passages is such that it obscures the perception of an accelerated rate of harmonic change, Saariaho instead pairing noise with rhythmic activity to create the 'rhythmicised noise' that heightens Nymphéa's climactic passages. 


\section{ANALYSIS OF WORKS}

\section{Du Cristal}

for orchestra

Where Nymphéa relies on changes in the foregrounded sound/noise parameter for generating tension and release, $D u$ cristal primarily uses the dynamic profile and inharmonicity parameters to achieve this. Additionally, where foreground ornamentation in Nymphéa is provided through foregrounded activity in the rhythmic and sound/noise parameters, Du cristal relies purely on rhythmic activity to provide microstructural interest as the work unfolds. Rhythmic activity is manipulated in two main ways to reinforce formal structure in Du cristal. Firstly, it is used in a similar fashion to Nymphéa, with rhythmic unison being an important device for creating points of arrival in the work. The orchestra occasionally aligns with a perceivable rhythmic grid, changing the work's relationship to time by generating brief temporal momentum. Secondly, rhythmic activity is used as a device for creating passages that change the listener's perception of the orchestra in this work as a global sound object, turning attention to the numerous pockets of individual activity and contrapuntal lines that can populate its thick texture. Saariaho uses multiple layers of polyrhythmic material to create activity that is nested within dense orchestral textures, varying the degree to which this polyrhythmic material comes to the foreground. In these instances it is impossible to perceive an underlying rhythmic grid, but attention is turned to the individual lines that emerge from the sea of sustained pitches that comprise a timbre chord.

\section{SECTION 1 : bb.1-36}

The first section of $\mathrm{Du}$ cristal displays the slow parametric changes that typify much of the work (Fig. 3.3). It consists of one harmonic field, with certain combinations of pitches from within this harmonic field being illuminated at different times, as described by Hargreaves (2011). Harmonic tension is manipulated through variation of the pitch combinations.

As with the rate of harmonic change, the changes in dynamic profile in this section are also slow. However, the early moments of the work are notable for their loud dynamics - opening the work at a fortissimo dynamic provides a strong and obvious parametric contrast to the silence from which it originates, but the intent behind this loud dynamic is that it serves as a starting point for the trajectory of the dynamic 


\begin{tabular}{|c|c|c|c|c|}
\hline Section & Bars & Time & $\begin{array}{c}\text { Tensional } \\
\text { trajectory/quality }\end{array}$ & Main features \\
\hline 1 & $1-36$ & $0: 00-1: 51$ & high to low tension & $\begin{array}{l}\text { Transition out of sustained, } \\
\text { globalized sound-mass with } \\
\text { introduction of short } \\
\text { arhythmic phrases for some } \\
\text { instruments }\end{array}$ \\
\hline 2 & $37-64$ & 1:52-2:59 & $\begin{array}{c}\text { low tension, crescendo } \\
\text { at end }\end{array}$ & $\begin{array}{l}\text { "rest area", gradual increase in } \\
\text { dynamic profile, pitch } \\
\text { instability techniques used for } \\
\text { crescendo }\end{array}$ \\
\hline 3 & 65-107 & $3: 00-5: 16$ & $\begin{array}{l}\text { rest area, larger } \\
\text { crescendo at end }\end{array}$ & $\begin{array}{l}\text { Another gradual increase in } \\
\text { dynamic profile, very wide } \\
\text { registral spread, long absence } \\
\text { of any foregrounded } \\
\text { ornamentation, concludes with } \\
\text { parallel parametric changes } \\
\text { towards high tension }\end{array}$ \\
\hline 4 & $108-140$ & $5: 17-7: 04$ & high tension & $\begin{array}{l}\text { High dynamic profile, } \\
\text { harmonic density and registral } \\
\text { spread }\end{array}$ \\
\hline 5 & $141-244$ & 7:05-10:31 & high to low tension & $\begin{array}{l}\text { Rhythmic activity parameter } \\
\text { as a tensional device } \\
\text { (percussion solo), infrequent } \\
\text { harmonic tension, high } \\
\text { dynamic profile }\end{array}$ \\
\hline 6 & $245-277$ & 10:32-11:34 & low to high tension & $\begin{array}{l}\text { Rise in harmonic tension, } \\
\text { though climax uses reduction } \\
\text { of registral spread to one pitch }\end{array}$ \\
\hline 7 & $278-329$ & 11:35-14:11 & low to high tension & $\begin{array}{l}\text { More synchronized } \\
\text { relationship between increases } \\
\text { in dynamic profile and } \\
\text { inharmonicity / harmonic } \\
\text { density, use of pitch instability } \\
\text { to add tension ahead of } \\
\text { following section }\end{array}$ \\
\hline 8 & $330-353$ & $14: 12-15: 31$ & $\begin{array}{l}\text { high tension to low } \\
\text { tension }\end{array}$ & $\begin{array}{l}\text { Climactic passage using } \\
\text { rhythmic activity, and } \\
\text { dynamic profile. Low } \\
\text { inharmonicity but extreme } \\
\text { registral spread. }\end{array}$ \\
\hline 9 & $354-368$ & $15: 32-16: 40$ & low tension & $\begin{array}{l}\text { Focus on percussion } \\
\text { synchronization. Extreme } \\
\text { registral spread but low } \\
\text { dynamic profile. }\end{array}$ \\
\hline
\end{tabular}

Fig. 3.1. Formal outline of Du cristal 

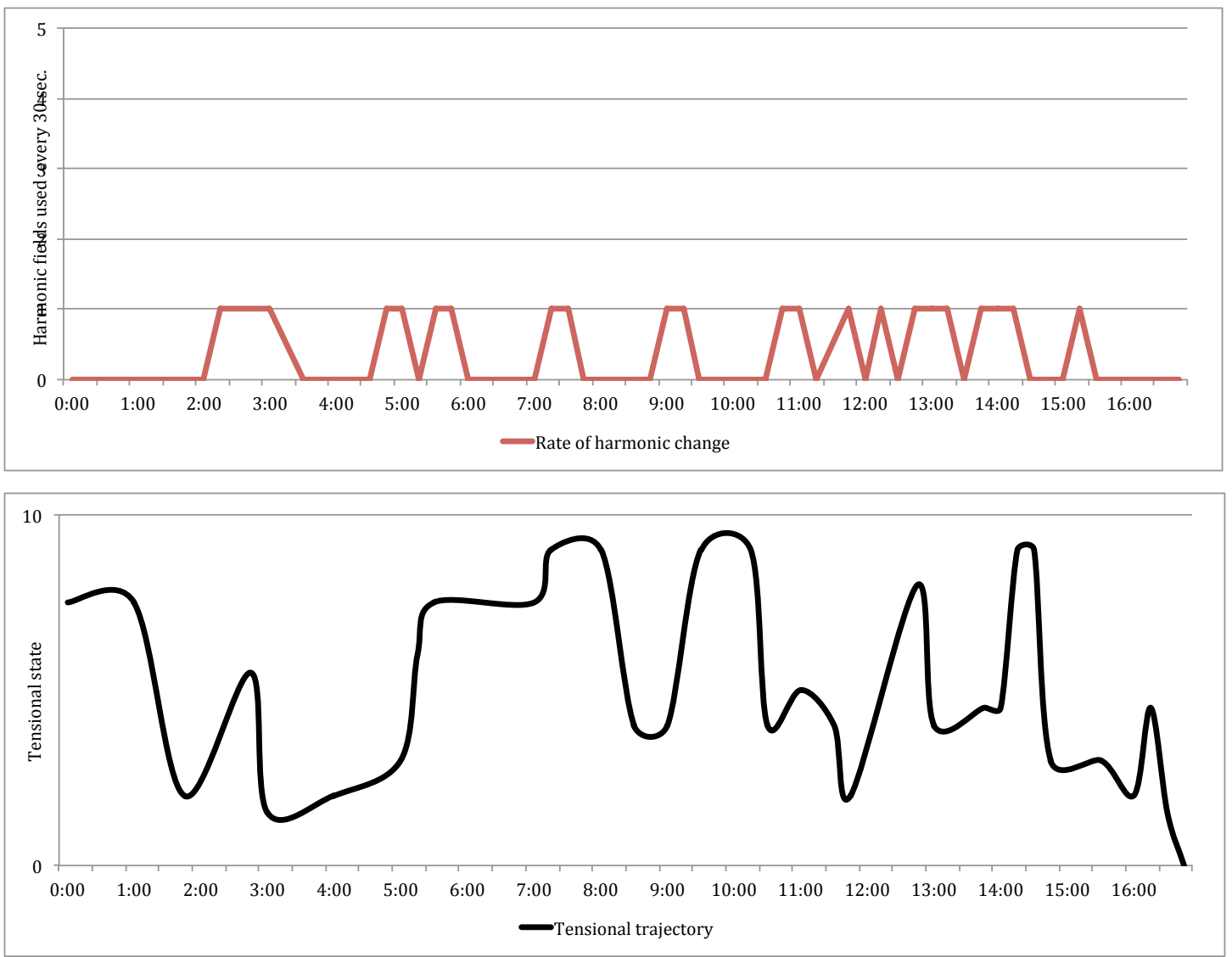

Fig. 3.2. Rate of harmonic change and tensional trajectory in $\mathrm{Du}$ cristal

profile parameter towards the $p$ dynamic reached at the end of the section. The overall form of this section is a gradual shift from high tension to low tension, with the trajectory in dynamic profile being the most crucial parametric change in creating this shift.

Additionally, rhythmic activity is utilized with differing relationships to the underlying meter to assist this section's tensional transition. Firstly, a modest

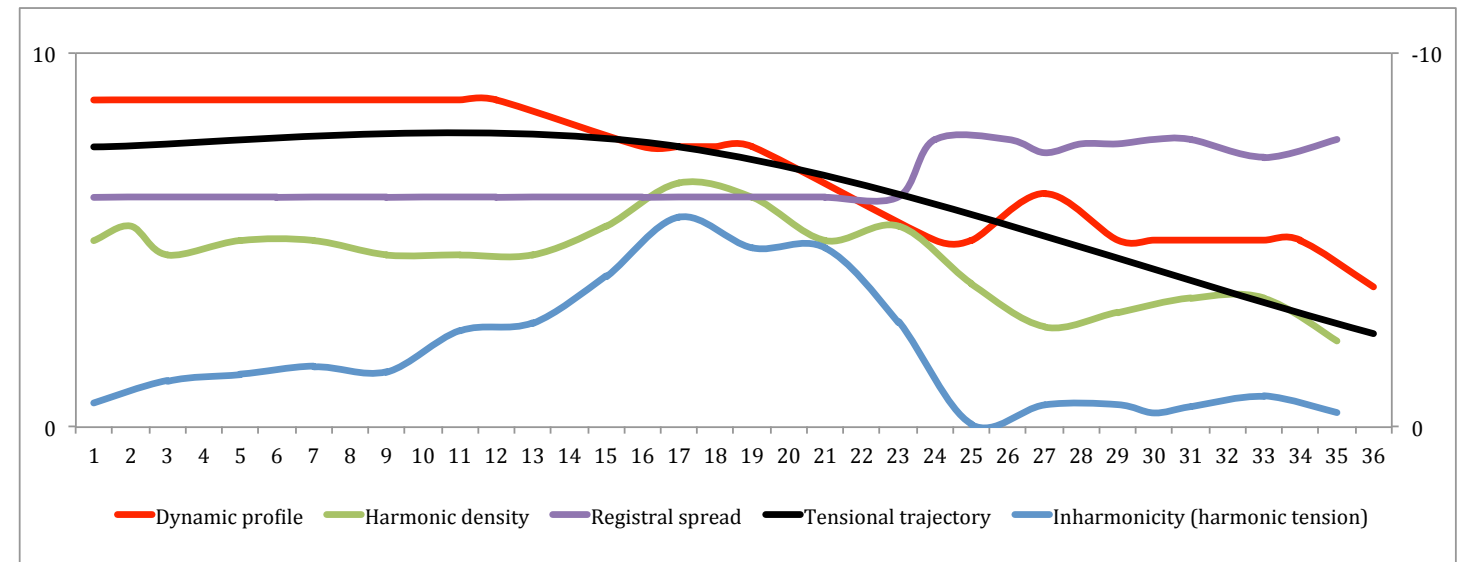

Fig. 3.3. Parametric changes in the first section of Du cristal. 
amount of rhythmic momentum is generated between bb.1-19 through an F6 played in repeated semiquavers passed from glockenspiel to piccolo and clarinet (though initially introduced by the unpitched triangle). The high registral placement of this pattern precludes the domination of any rhythmic drive but does support an overall state of forward movement. As the section progresses, rhythmic activity is utilized to transition out of the sustained, globalized sound-mass of the opening timbre chords, with short arhythmic phrases or trills from woodwind and string instruments being highlighted momentarily, beginning to pull attention away from the textural to the contrapuntal, as individual phrases gradually overlap and dovetail. As with the repeated semiquavers that preceded them, these flickers of activity from individual instruments provide the foreground ornamentation in this section, yet the cumulative effect of the freer playing is reminiscent of the arhythmic quality found in Nymphéa. The general formal trajectory of this section can be described as moving from a high-tension global sound-mass toward a medium-tension state in which increased individual rhythmic activity draws more attention to individual lines within the orchestral texture.

It is notable that while registral spread remains static until b.23, harmonic density has increased by b.17, filling in the chordal material with additional pitches. As found in Nymphéa, the increase in harmonic density leads to a parallel increase in inharmonicity. In Du cristal, harmonic tension steadily rises from the opening of the work through to b.17, with the fortissimo dynamic remaining in place until around this point also. From bb.17-36, the tension of this section begins to unravel. The harmonic density and inharmonicity parameters drop, stabilising at b.26 with lower values than those found at the opening of the work. Meanwhile, the gradual drop in dynamic profile starting at b.13 contributes to the overall tensional transition of the section. The already wide and static registral spread begins to fluctuate slightly from b.23 and becomes wider still, most notably through the introduction of the low $\mathrm{C}$ on the piano. The increase in registral spread combined with the gradual decrease in harmonic density makes for wider spacing between pitches, particularly in the middle register, which enhances the contrasting spaciousness of this half of the section with the sustained density of the first half.

\section{SECTION 2 : bb.37-64}

The second section is an extension of the tensional state reached at the end of the first section and largely serves as a rest area, similar in function to those described in the analysis of Nymphéa. While harmonic density and inharmonicity are less than that of 
the first section and fluctuate by small amounts, the underlying harmonic field undergoes a gradual transformation in preparation for a new harmonic field in the following section (Fig. 3.4).

Foreground ornamentation in this section is initially supplied by short overlapping phrases in the woodwind instruments' upper registers, the variety of metric subdivisions in each part again producing an arhythmic mesh of pitches. The woodwind phrases thin out, with the pitched percussion, harp, piano and synthesizer entering at b.52 in a more unified motivic statement (the harp, piano and synthesizer notably playing in unison). The piano and harp are brought out of the contrabass register for use in this motivic statement, with the subsequent constriction of registral spread to three and a half octaves - the smallest registral spread in the work thus far - setting the section up for a gradual re-expansion of registral spread, as the section builds to a crescendo in anticipation of the third section.

Another parameter assisting the gradual increase in tension at the end of the second section is dynamic profile. The dynamic profile of this section follows a clear trajectory from $p$ at b.37 to fff at b.64. From b.55 the first change in the underlying harmonic field becomes detectable. A degree of harmonic flux occurs as slow glissandi are introduced to some string parts, travelling toward pitches found in the underlying harmonic field in the following section. The pitch instability of the glissandi enhances the tensional quality of the crescendo. bb.62-64 contain an accumulation of extreme bow pressure in the now extensively divided string section, which dominates the orchestration at this point. While the noisier extremes of the sound/noise continuum (achieved through extreme bow pressure) strongly intensify the tensional state created within Nymphéa's smaller ensemble, the non-tremolo bow

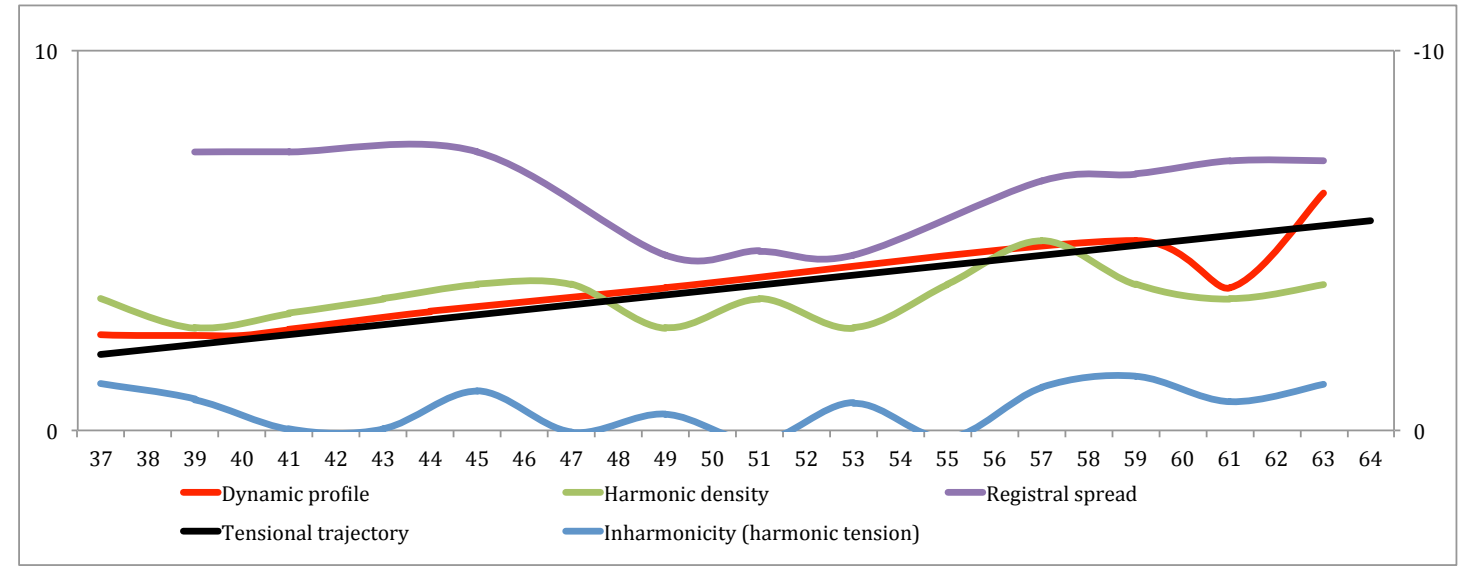

Fig. 3.4. Parametric changes in the second section of Du cristal 
pressure employed at this point in $\mathrm{Du}$ cristal does not cut through the other strings played ord, the glockenspiel, the horn and the rolls on the bass drum and timpani. The noise of the bow pressure seems to serve more as a device for supporting the unpitched timbral quality of the bass drum and, to a lesser degree, the timpani, in the heightened tensional state at the end of this section.

\section{SECTION 3 : bb.65-107}

The tensional profile of the third section bears some similarity to that of the second section - a trajectory from low to high tension — with the main difference being that certain parameters are pushed to further extremes, providing this section with a clear identity in the context of the work (Fig. 3.5). Dynamic profile is again used as a primary driver of the tensional trajectory in this section, with other parameters contributing as the work builds towards the climactic passage in the fourth section.

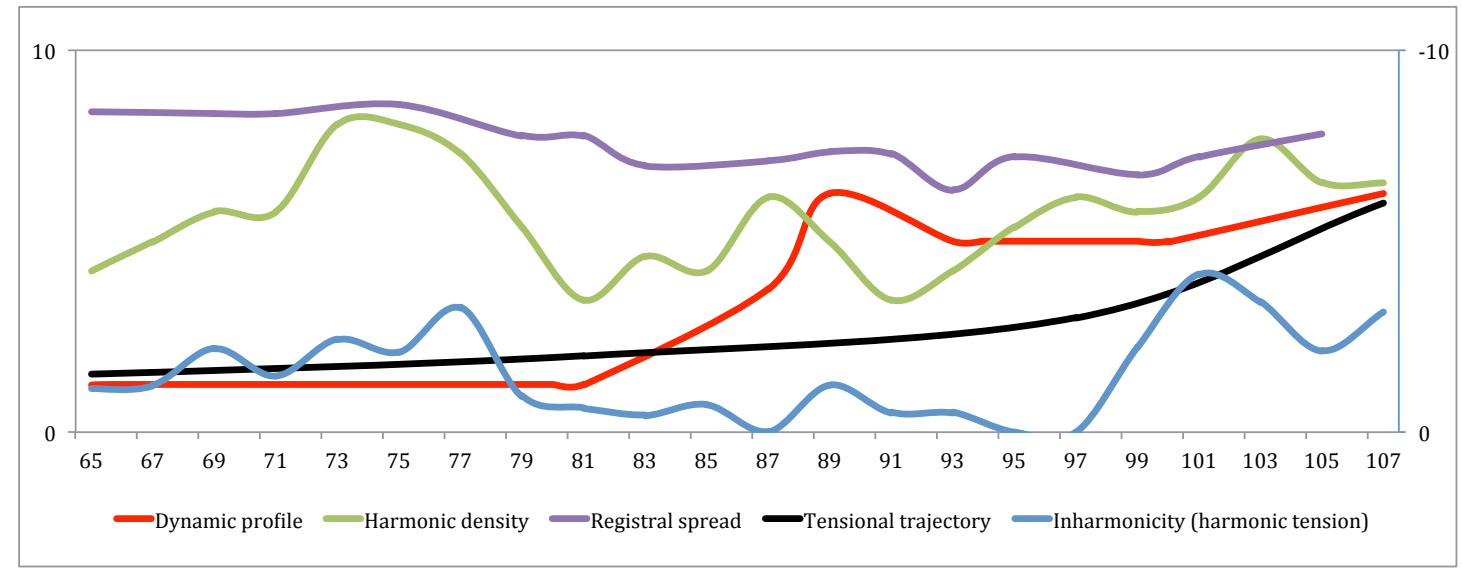

Fig. 3.5. Parametric changes in the third section of $D u$ cristal

A prolonged period of release opens the third section, as the crescendo of the preceding section dissolves. Dynamics are reduced to $p$, with the extensively divided string section (accompanied by the synthesizer) remaining in place. As also observed in Nymphéa, Saariaho employs a somewhat subversive combination of parametric extremes. Extremely wide registral spread and high harmonic density - two parametric extremes traditionally associated with climactic material - are combined with quiet dynamics and a minimal rate of harmonic change. The result is a period of stasis, even in the context of the gradated parametric development found in $D u$ cristal. On closer inspection, until b.75 the registral spread of this section is heavily weighted towards the upper reaches of the string instruments' registers, reaching more than two octaves above the treble staff. The remaining pitches are widely spread, extending beneath the bass staff. There is a small amount of noise in this passage due to the timbral quality of pitches in the upper registers of the violins and 
violas, where tonal purity becomes increasingly thin and glassy. This registral skew and associated timbral effect is the primary source of any tension in this passage. There is also a slight increase in inharmonicity in this passage, though, as discussed in the analysis of Nymphéa, the voicing of chords at registral extremes diminished the intensity of consonance and dissonance, another example of parametric subversion in Saariaho's writing.

As already mentioned, the parameter that most clearly reinforces the low tensional state of this passage is the low dynamic range, which remains in place until b.78. Though Du cristal is less consistent than Nymphéa in its employment of foreground ornamentation, it is worth mentioning that the degree of stasis generated in this passage is also reliant on the absence of any foregrounded material. Like the ninth section of Nymphéa, this absence of foregrounded material in this passage of $D u$ cristal's third section assists in creating a clear structural landmark, given its contrast to the material that has preceded it.

Foreground ornamentation reappears at b.78, coinciding with the onset of other underlying parametric changes as the third section starts to accumulate tension leading into the fourth section. Glockenspiel, vibraphone, crotales and synthesizer draw the listener in, returning with high-register polyrhythmic/arhythmic material before a trilling piccolo line is added (b.88), along with harp and piano lines that mimic the rhythmic character of the synthesizer (b.94). Harmonic density decreases as the foreground ornamentation returns, and starts to gradually increase for the remainder of the section. Inharmonicity also decreases at the same point, but remains low for a longer period, allowing for a more dramatic increase occurring from b.97. By this point, the registral spread has filled out, with more pitches populating the middle and low registers, making the increase in harmonic tension more noticeable due to the closer registral proximity of the pitches. Also occurring at this point in the section is the beginning of a change to a new harmonic field, adding a sense of harmonic flux to the ongoing rise in tension. The transition to the new harmonic field takes place across the next 15 or so bars, straddling the boundary between the third and fourth sections marked by peaking swells on the bass drum, timpani and tamtam at b.108. From b.96 until the end of the section Saariaho revisits the use of extreme bow pressure in the string section, though again the noise generated by this technique is embedded in the background as it is overpowered by the more cleanly played material in the other sections of the orchestra. The conclusion of this section displays a clear convergence of parameteric changes that move toward higher states of tension, marking the first parametric "point of arrival" in Du cristal. 
SECTION 4 : bb.108-140

The fourth section marks the beginning of a longer passage of high-tension, climactic material in Du cristal. Building on the tensional trajectory of the previous section, the fourth section sees some parameters reach new peaks, with tension maintained in preparation for further intensification of tensional energy in the fifth section (Fig. 3.6).

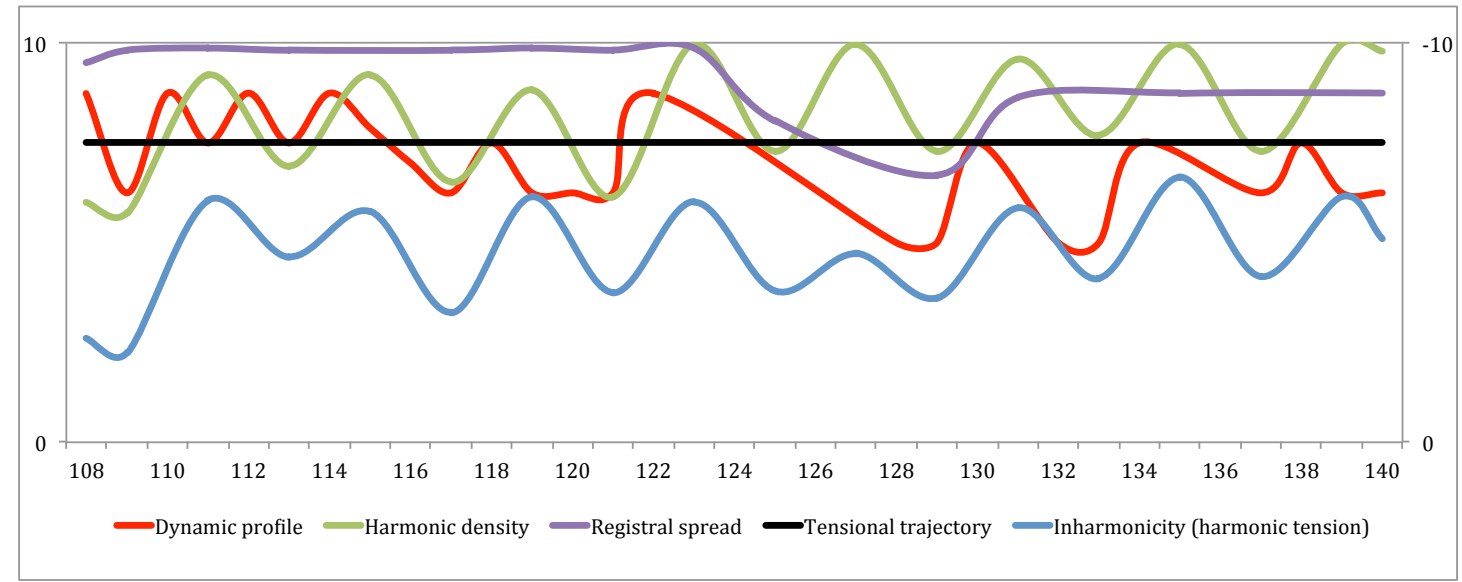

Fig. 3.6. Parametric changes in the fourth section of Du cristal

The opening moments of the section see harmonic density reach its highest peak thus far as the entire orchestra is active by this point, filling out thick chords. Density rises and falls with periodic surging chords in the brass choir that act as foreground ornamentation at the outset of this section. The increase in harmonic density coincides with an expansion of registral spread to almost seven octaves - the widest spread so far in the work, surpassed by only a couple of later passages. As mentioned previously, the transition to the fourth section coincides with a transition in the underlying harmonic field, which is complete by around b.113. Inharmonicity rises and falls along with harmonic density, often increasing past the previous peaks of inharmonicity reached during the decay of Du cristal's opening chord. Again, inharmonicity and dynamic profile are the two main parameters generating tension in this section. The consistent $f-f f f$ dynamic range makes this section the loudest since the opening dozen bars of $\mathrm{Du}$ cristal. It is the chordal surges from the brass choir that take the role of foreground ornamentation in this section, despite the eventual sprinkling of high-pitched percussion around these surges. The attack profile of the brass surges transform during this section, from swift crescendos to sudden attacks at forte or louder, an attack profile not employed since the work's opening series of chords. In combination with the high degree of harmonic tension, the sudden attack profile of the brass chords jumping out from the backdrop of high string harmonics 
and trilling woodwinds maintains the high-tension state of this section in anticipation of the continued escalation of tensional energy — with its notable foregrounding of rhythmic activity — in the fifth section.

\section{SECTION 5 : bb.141 - 244}

The fifth section includes the peak of the longer climactic passage that has been unfolding over the previous section, with the foregrounding of the rhythmic activity parameter as a tensional device, replacing inharmonicity alongside dynamic profile (Fig. 3.7).

Dynamic profile reaches its highest peak of the entire work in the fifth section, with timpani (later joined by roto-toms) featured in a soloistic manner for much of the section, often playing at $f f$ or louder, with each percussive phrase separated by chordal bursts from the orchestra. Though the timpani's material is fairly consistent in its rhythmic character, the constant triplet, quintuplet and septuplet subdivisions obstruct the perception of any underlying metric pulse, generating a high amount of rhythmic tension. While rhythmic activity and dynamic profile are foregrounded in this section, inharmonicity and harmonic density decrease markedly. The vast majority of the section contains a minimal amount of harmonic tension - the lowest amount in the work thus far. It could be argued, however, that wide registral spread comes into play here with regards to perception of consonance/dissonance, as discussed earlier, increasing the perception of inharmonicity due to the distance between pitches compromising the ability to perceive consonant intervallic relationships within chordal material.

Registral spread is at its most unstable thus far, with both upper and lower registral extremes quickly varying between one and two octaves between bb.141-201. Prior to this, the registral extremes in $D u$ cristal had remained rather stable, in keeping with the prevalence of sustained pitches that dominate the textural fabric of the work. The instability of registral spread here contributes to the general sense of flux generated by the timpani's arhythmic phrases. Extreme bow pressure is employed at several dynamic peaks in this section, though again it does not cut through the other sections of the orchestra, serving instead as a timbral backdrop as opposed to a foregrounded source of tension as seen in Nymphéa.

The start of the fifth section is also marked by a change in the underlying harmonic field. Again, the transition between harmonic fields is gradual, stretching across a 

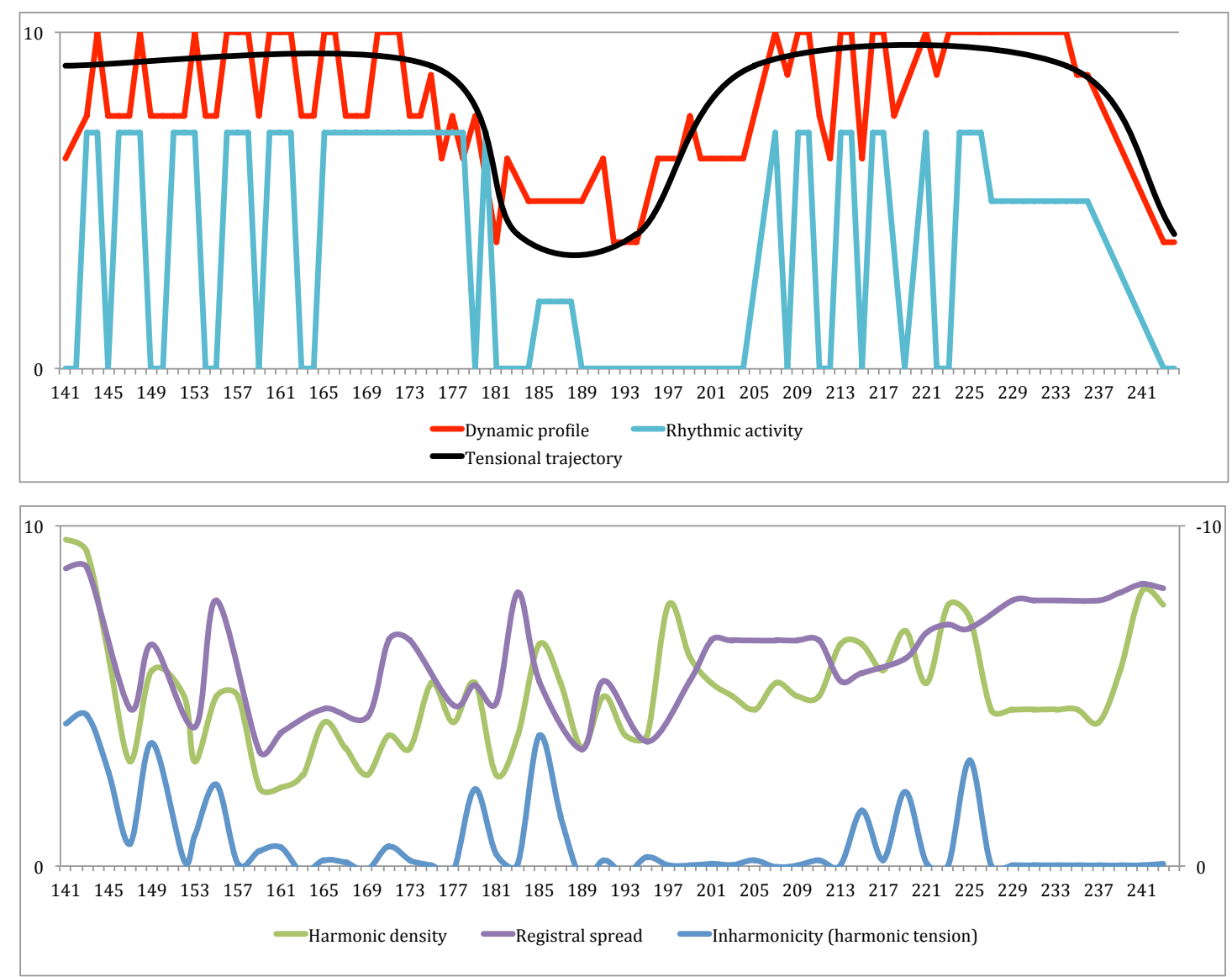

Fig. 3.7. Parametric changes in the fifth section of $D u$ cristal

dozen bars, including the final bars of the fourth section. A second harmonic change takes place in the fifth section, between bb.191-199, by which time the timpani/rototom phrases have temporarily ceased and a brief, low-tension rest period (bb.183204) has ensued. The dynamic profile decreases, with foreground ornamentation being occupied by a brief return of polyrhythmic phrases from the harp, piano and synthesizer similar to that described in the third section. Ascending, overlapping polyrhythmic phrases then populate the woodwind choir from b.196, gradually reinstating rhythmic instability as the section builds to a crescendo ahead of the timpani and roto-toms' resumption at b.205. Throughout the section, harmonic density steadily increases, but inharmonicity generally remains at the same low level.

At b.227 Du cristal arrives at one of its few passages of sharper rhythmic focus, a clear formal landmark for the work. The timpani and roto-toms depart and the orchestra unites in a continuous pattern of semiquavers, with each instrument repeating the same note or notes. Even in this moment of rhythmic unity, Saariaho ensures that its edges remain blurred by varying the articulations of these notes across the orchestra, using accented, tenuto to staccatissimo markings. Between bb.227-243 this metric grid of semiquavers propels the work along, with varying 
combinations of instruments taking up the rhythmic pattern while others temporarily drop out or hold brief sustained notes. Here we see Saariaho once again using synchronisation to create a unique point of arrival in a work - in this instance, using rhythmic unity at the end of an extended climactic passage containing rhythmic activity that, up to this point, has operated without a strong sense of temporal momentum by not working around a clear pulse.

Throughout this semiquaver passage, registral spread expands into the bass register, so that by the end of the section the material covers six octaves. In contrast, the dynamic profile begins to drop back from b.236, reaching $m p / m f$ by the end of the section. By this point, the semiquaver pattern has lost much of its tensional impact due to the ritardando starting at b.241 and the contamination of the semiquaver pattern with overlaid sextuplet subdivisions.

\section{SECTION 6 : bb.245-277}

As also seen in the third section, the sixth section follows a general trajectory from low to high tension, with dynamic profile again used as a primary driver of the tensional trajectory. Inharmonicity returns as an influential tensional parameter, with this section being unique in its more active variation in the degree to which each of these parameters influences the tensional process. This section also uses the minimisation of registral spread as a component in the generation of tension (Fig. $3.8)$.

The transition to the sixth section is marked by a change in harmonic field and a sharp rise in harmonic tension - an interesting contrast to the very low amount of inharmonicity in the climactic, high-tension fifth section. The sustained and repetitive quality of the pitch material means that inharmonicity remains at a constant level until b.260, when harmonic density begins to steadily decrease. By the end of the section, harmonic density has been reduced to one unison pitch - Ab4 in the treble staff - played by most of the orchestra's pitched instruments. This unison pitch is brought to one of the strongest crescendi in the entire work, made all the more significant as a structural arrival point due to its strong contrast with the dense harmonic context that dominates $\mathrm{Du}$ cristal. Aside from the novelty of this brief sparseness in density, this section is also notable for the expansiveness and stability of its registral spread up until its final bars. Registral spread reaches seven octaves, the widest spread of the entire work. Much like the opening section, the registral extremities of much of the sixth section remain static, with pitch movement taking place within these registral boundaries. An example of this embedded pitch 

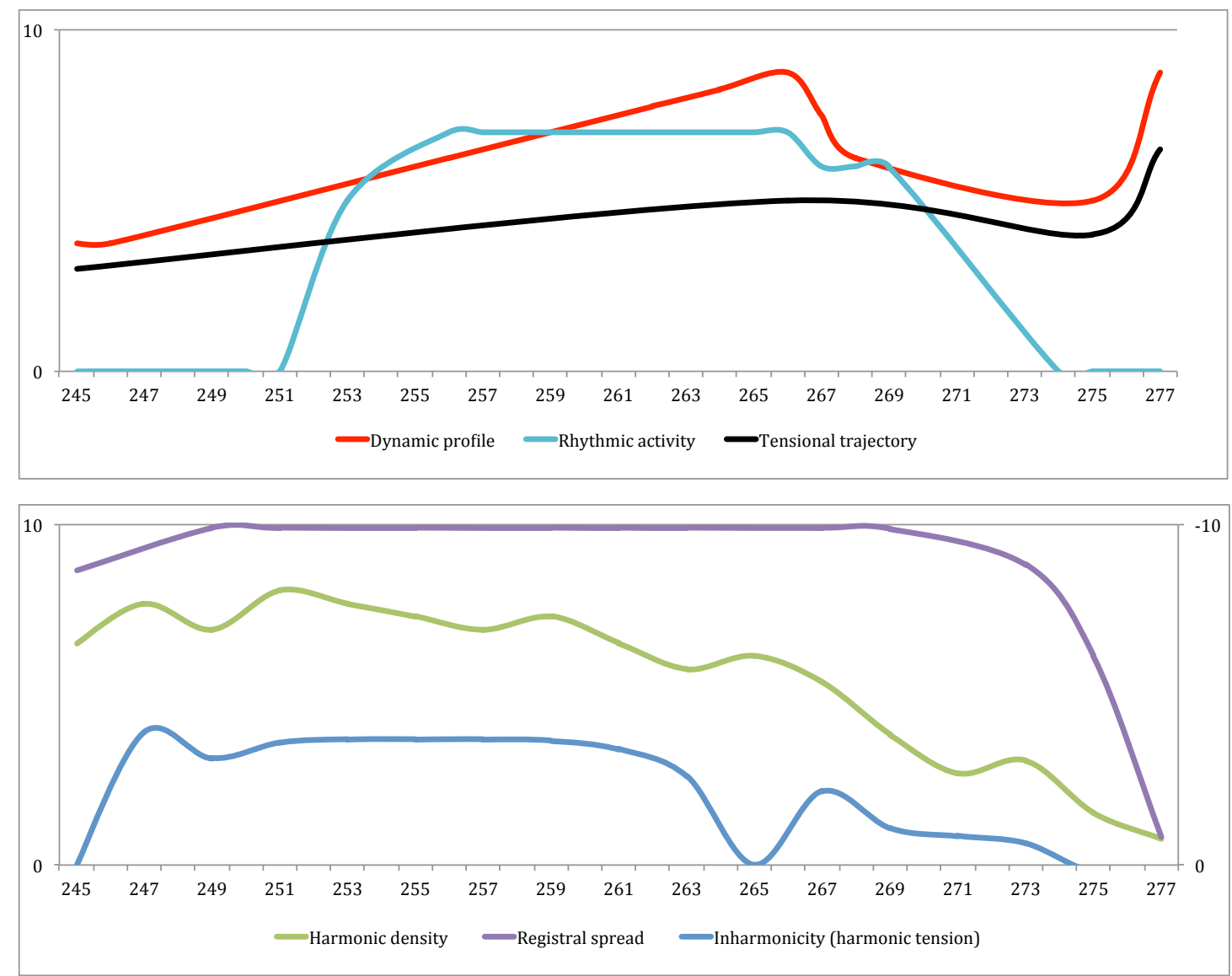

Fig. 3.8. Parametric changes in the sixth section of $\mathrm{Du}$ cristal

movement is the foreground ornamentation based on rhythmic activity in the percussion section.

At b.253 the marimba emerges from the arhythmic mesh of contrapuntal activity with a repeated rhythmic motif built on quintuplet subdivisions. It is then joined by the bass drum, timpani and roto-toms, each playing a different repetitive figure based on triplet subdivisions. A simple repeated motif is played by the synthesizer, piano, harp and vibraphone, based on the same tuplet grid as the bass drum. The interlocking percussive material itself does not generate a great degree of tension. The mid-tempo nature of the bass drum's crochet tuplets acts as the dominant pulse in this passage and is not fast enough to generate any sort of momentum-based tension. This section relies on the aforementioned increase in dynamic profile for this, with the rhythmic activity serving as foreground ornamentation while the two main parametric changes, dynamic profile and harmonic density, converge to create the section's tensional climax. 
SECTION 7 : bb.278-329

The seventh section follows a familiar low-to-high tension trajectory, this time in preparation for Du cristal's final climax in the following section. Dynamic profile and inharmonicity are again the main parameters affecting tensional fluctuations, sharing a close relationship in this section's surges in tension (Fig. 3.9).

This section also starts with a change in harmonic field in its opening bars, reinforcing the sense of transition to a new phase in the work. The seventh section contains the most harmonic flux of the entire work, with two more changes to the underlying harmonic field occurring. Though inharmonicity is initially relatively high in this section (containing the highest peaks of inharmonicity in the entire work between bb.278-300), tension is initially minimized through the low dynamics that follow the crescendo at the end of the previous section. Rhythmic activity appears frequently, organized in a similar fashion to the short, arhythmic phrases described in the first section. It is the periodic increases in dynamic profile and inharmonicity / harmonic density that
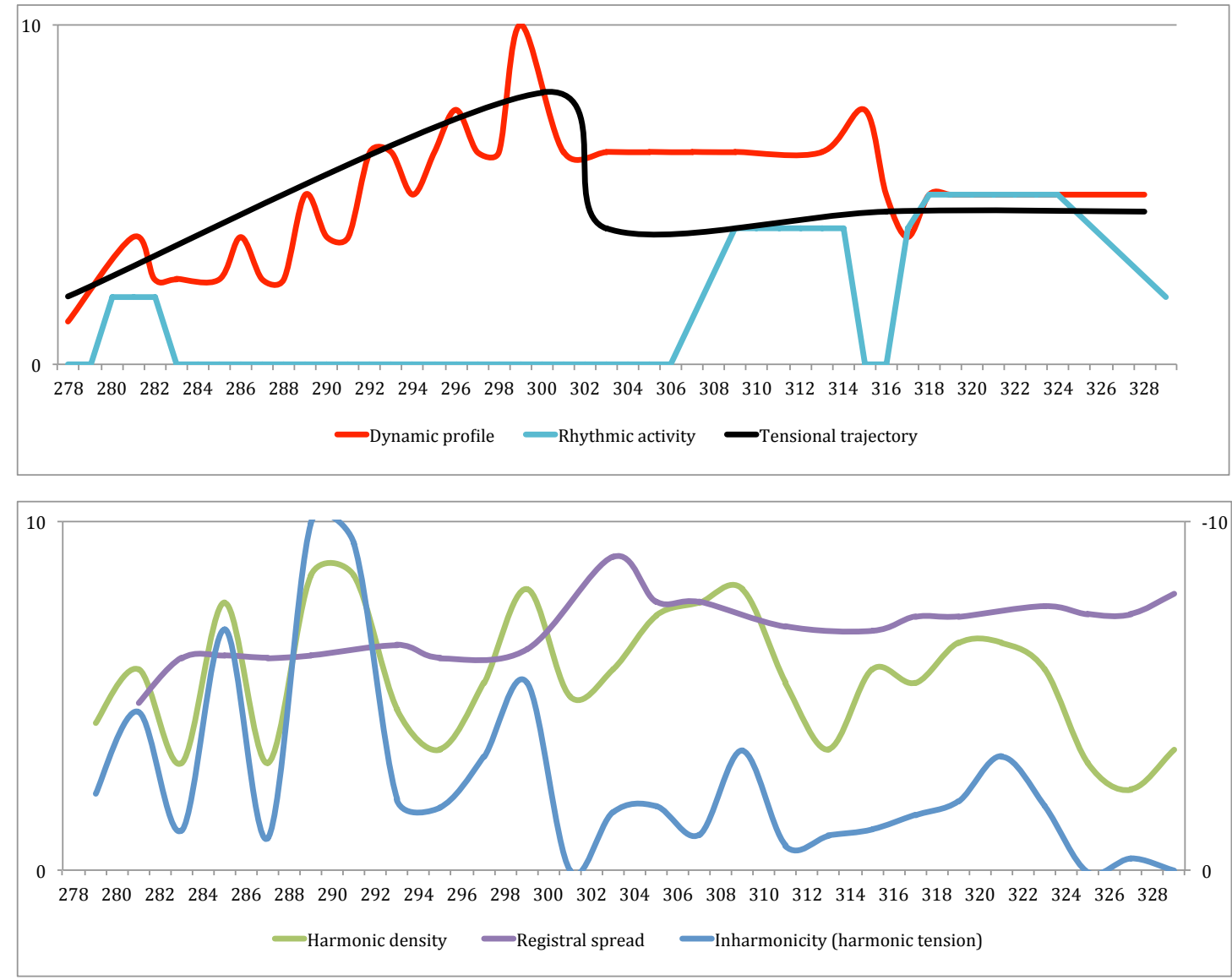

Fig. 3.9. Parametric changes in the seventh section of $D u$ cristal 
enhance the tensional qualities of the rhythmic activity. The dynamic surges take place within a larger overall increase in dynamic profile that culminates at bb.299300 with one of the loudest crescendi of the entire work - a sustained statement of the same chord that opens $D u$ cristal, signaling a change in the underlying harmonic field.

From the opening bars of this section the use of glissandi in the string section increases, until practically the entire string section is doing so by the time the large crescendo arrives. The amount of pitch instability, and subsequent harmonic flux, created by string glissandi contributes to the tensional trajectory in approaching the large crescendo. The more synchronized relationship between surges in dynamic profile and harmonic density/inharmonicity make this section somewhat unique, and reminiscent of the close relationship between dynamic profile and registral spread in the ninth section of Nymphéa, whose form is also based on a trajectory from low to high tension in anticipation of climactic material. Following the sustained pitches from the crescendo at bb.299-300, rhythmic activity returns as foreground ornamentation, but now with a foregrounded repetitive semiquaver grid in the upper register of pitched percussion. Though harmonic density remains the same as earlier in this section, harmonic tension is decreased. One further crescendo arrives at b.315, though its tensional impact is lessened due to a decrease in harmonic tension and an overall fall in dynamic profile following the main crescendo. Emerging from this crescendo is more rhythmic activity, now transformed by a mesh of short ascending phrases in the woodwind choir that grows increasingly polymetric, also underlined by another change in harmonic field. The loss in rhythmic stability is combined with another surge in dynamic profile to generate a high degree of tension immediately before $D u$ cristal's last climactic passage in the following section.

\section{SECTION 8 : bb.330-353}

The penultimate section of $\mathrm{Du}$ cristal contains the final major climax of the work, with dynamic profile and rhythmic activity dominating the tensional trajectory. The overall form of this section follows a transition from high to low tension, as both rhythmic activity and dynamic profile subside, creating a rest period ahead of the work's final section (Fig. 3.10).

The crescendo at the end of the previous section bursts into a rhythmic passage that marks the beginning of the eighth section. The dynamic profile leaps to $f f$ and the familiar insistent semiquaver rhythm returns, though in this instance the rhythmic 

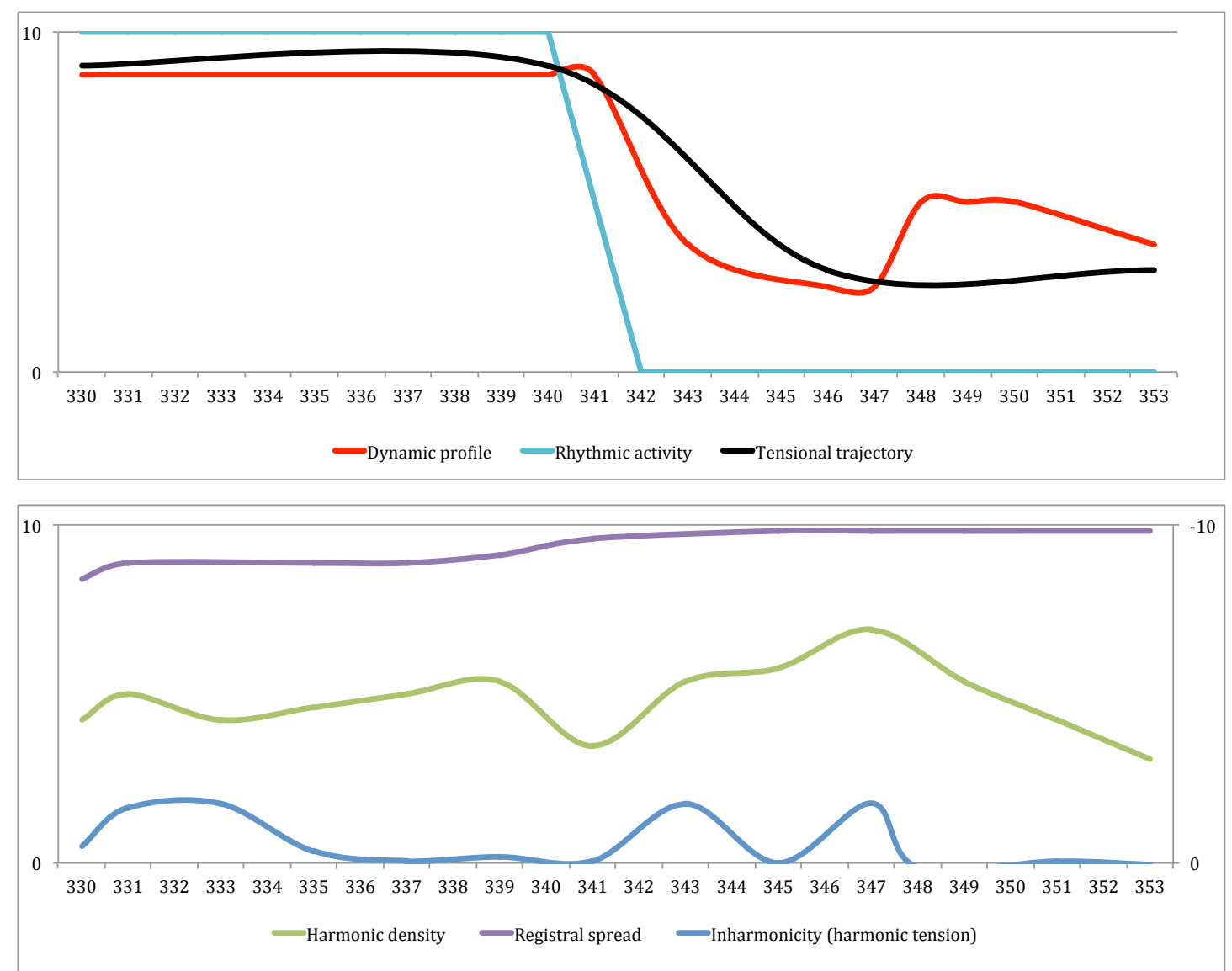

Fig. 3.10. Parametric changes in the eighth section of $D u$ cristal

material is quickly passed around the percussion section, most notably between the xylophone, doubled by marimba and piano, and roto-toms, doubled by timpani. As found in a handful of passages in Du cristal, this passage sees the percussion section and the rest of the orchestra share the same metric grid, momentarily bringing the work into sharp focus. This passage is the most dynamic and foregrounded iteration of the orchestra's metric synchronisation, as the two groups of doubled percussion instruments quickly trade small groupings of semiquaver patterns to create an almost unbroken stream of semiquaver beats. Rhythmic activity is also reinforced in this passage through bursts of brief sustained notes from other instruments, particularly the brass section. The overall effect is one of high rhythmic tension, as the simple underlying metre is subverted due to the unpredictable passing of rhythmic fragments between the two groups of doubled percussion instruments and the additional unpredictability of the brass and woodwind bursts.

While harmonic density is only slightly less than that of the previous section, inharmonicity falls to some of its lowest levels of the entire work. This is another example of Saariaho subverting parametric relationships, once again not relying on inharmonicity to generate tension. The transition to the eighth section is again 
marked by a change in the underlying harmonic field. It is apparent that changes in the underlying harmonic field in Du cristal, which, in the atonal context of this work can be difficult to perceive, are supported by parallel changes in other parameters to give these harmonic transitions structural significance.

Once the rhythmic material fades away, the remainder of the eighth section serves as a low-tension rest area dominated by the extensively divided string section. This passage shares the subversive combination of parametric extremes noted in the third section's string-dominated rest area, with typically climactic parametric features such as wide registral spread and high harmonic density juxtaposed with quiet dynamics. Between its registral extremes (the widest of the entire work along with the sixth section), however, this passage also contains more internal movement than its earlier counterpart, with glissandi in many string parts generating a muted degree of harmonic flux and a multitude of short phrases creating another dense polymetric mesh. Nevertheless, the low dynamics restrain the material, providing a platform for the segue into the quiet suspense of Du cristal's final section.

\section{SECTION 9 : bb.354-368}

The final section of $\mathrm{Du}$ cristal is unique for its tensional process, relying on repetition as a means of sustaining tension as the work winds down, with only the string and percussion sections remaining. Synchronisation is also turned into a foreground feature, becoming a final structural point of arrival for the section and the work as a whole (Fig. 3.11).

A slight increase in harmonic tension occurs at the beginning of the section but this increase is not sufficient to stand out as strongly inharmonic in the overall context of $\mathrm{Du}$ cristal. Furthermore, inharmonicity immediately decreases throughout the section. Also gradually decreasing is dynamic profile, adding to what would usually be a release of tension. Tension remains, however, due to the percussive material occupying this section's foreground ornamentation - a slow pulse played on the bass drum, with each beat quickly echoed by a high $\mathrm{C}$ on the crotales. The extreme registral spread of the string section remains unchanged from the previous section, contributing to the climactic quality of the harmonic material. The feeling of suspension is enhanced through the absence of glissandi in this section, leaving pitches hanging, with trills being the only form of pitch movement. Although a reliable periodicity exists in the bass drum's rubato pulse, it is a descriptive stretch to regard it as rhythmic activity. Still, the periodicity of the bass drum/crotales pulse must be acknowledged as a tensional device, its repetition sitting alongside the 

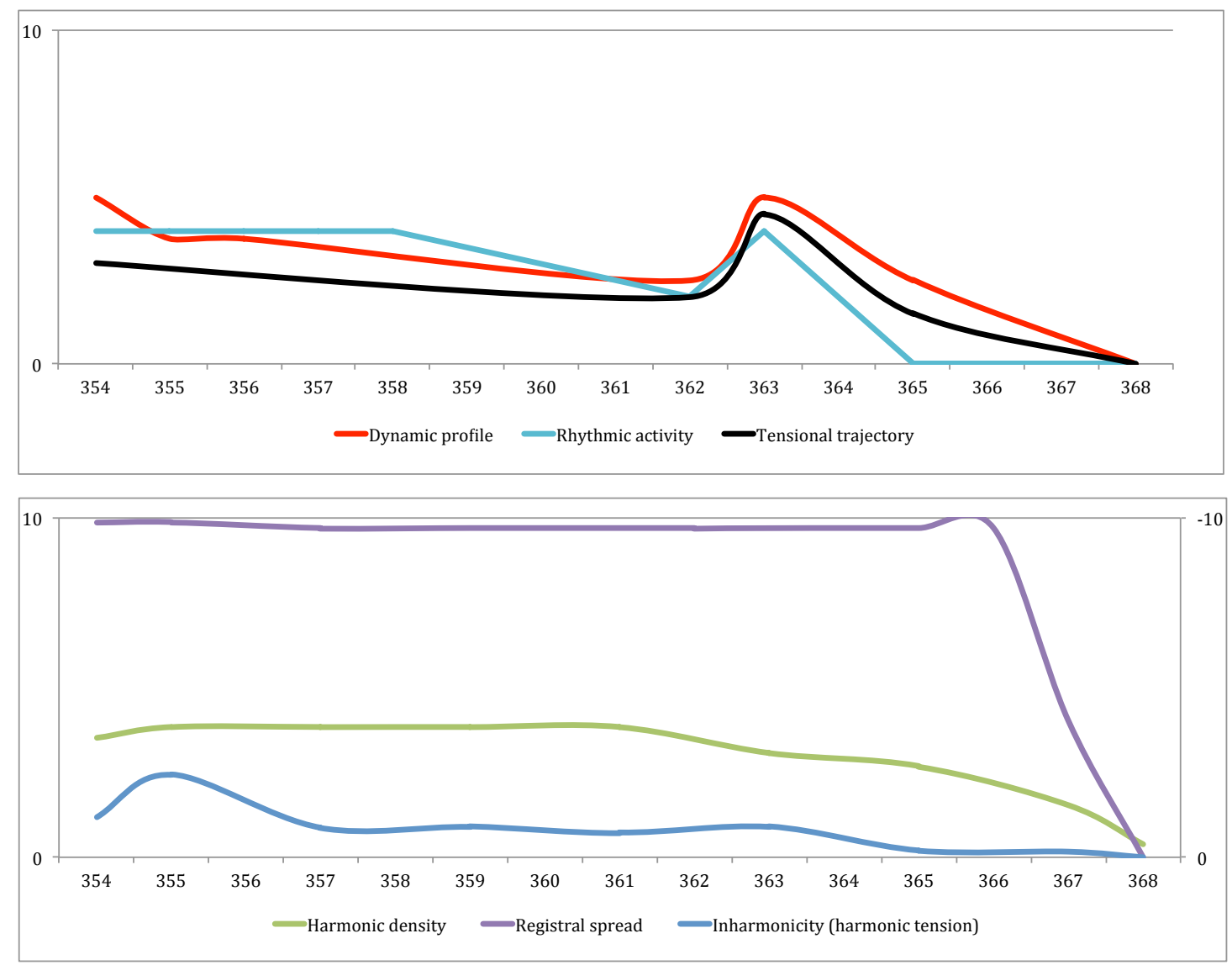

Fig. 3.11. Parametric changes in the ninth section of $D u$ cristal

shimmering strings as the final section exists suspended in time. It is rhythmic synchronization in its most minimal form that finally brings closure to $\mathrm{Du}$ cristal. After the desynchronized bass drum/crotales pulse is repeated for almost a minute, the final two pulses see the two instruments synchronise (b.364), falling quietly on the same beat.

To summarise, given that the sectionalisation of the works in this analysis is based on the identification of small to mid-scale tensional trajectories that take place within their overall durations, the relatively small number of discrete sections identified in the analysis of $\mathrm{Du}$ cristal reveals the slow rate at which tensional changes tend to take place in the work. That the transitions to new sections in $D u$ cristal often coincide with a transition to a new underlying harmonic field suggests that harmonic change is not employed in varying speeds to generate tensional changes in Du cristal, but provide harmonic variety. This approach to harmonic change differs from Nymphéa in that while it is common for a new section to start with a new harmonic field, the rate of harmonic change is also used within a section as a device for reinforcing short-term tensional changes. 
As with Nymphéa, parametric desynchronisation dominates Du cristal. Saariaho avoids combining the tensional extremes of many parameters at once, choosing to subvert the climactic potential of a passage. Structurally, both Nymphéa and Du cristal use rhythmic synchronisation to underscore climactic points of arrival.

Changes in the sound/noise parameter do not greatly affect the overall tensional state in the orchestral context of $\mathrm{Du}$ cristal, where techniques such as extreme bow pressure are now confined to just one section of a larger ensemble. Saariaho does not attempt to augment the presence of noise in $\mathrm{Du}$ cristal by incorporating extended techniques into other instrument parts, perhaps because incorporating noise-based techniques into other instrument parts would compromise the conceptual realization of the work. Speculation aside, the absence of noise as a tensional device is the primary parametric point of difference from Nymphéa.

Without the sound/noise continuum to rely on for creating tensional change, inharmonicity assumes the role of the parameter most closely tied to changes in tensional state, alongside dynamic profile. The sheer density of Du cristal's harmonic material results in far higher levels of inharmonicity than Nymphéa. It is difficult, however, to quantify and compare the two works and identify one work that is more "inharmonic" than the other, as both works possess only extremely small amounts of harmonic material that reach beyond a zero value for inharmonicity, residing instead in a constant state of inharmonicity. As discussed, wide registral spread surely plays a role in distorting the perception of harmonic tension in Du cristal - perhaps more so than in Nymphéa - due to some intervals spanning multi-octave distances.

On top of the dual role of rhythmic activity in Du cristal as 1) a structural point of arrival (tutti) and 2) as provider of contrapuntal detail that contrasts with the work's globalized textures, there are moments in Du cristal that see rhythmic activity cast as an overtly tensional device while serving as foreground ornamentation, such as the climactic timpani/roto-tom solo passage in the fifth section (where inharmonicity is, incidentally, rather low). 


\section{ANALYSIS OF WORKS}

\section{Cendres}

\section{for alto flute, cello and piano}

Composed eight years after Du cristal and 11 years after Nymphéa, Cendres (1998) displays a detectable stylistic departure from the other two analysed works. Cendres is, however, still able to be divided into sections based on tensional states or transitions between two or more tensional states (Fig. 4.1). Cendres is distinguishable from the other two analysed works due to the differing use of several parameters, while its shorter duration necessarily allows for less of the gradual parametric change employed in Nymphéa and Du cristal.

Given the shorter duration of Cendres and the faster tensional transitions that take place within the work, the need for foreground ornamentation - material that provides moment-to-moment interest while larger formal and tensional processes unfold - is somewhat reduced. As with $D u$ cristal, noise plays little part in controlling tensional states, occasionally serving as foreground ornamentation but not in the overpowering manner observed in Nymphéa. Harmonic density is also arguably used as foreground ornamentation in passages involving solo instruments.

Of the three analysed works, the use of rate of harmonic change as a large-scale tensional device is most audible in Cendres (Fig. 4.2, 4.3). While the rate of harmonic change increased in Nymphéa's climactic passages, the overpowering noise produced by extreme bow pressure and other bowing techniques often obscured pitch content. In Cendres, the relatively pure quality of its pitch content allows changes in the underlying harmonic field to be more easily perceived, though pitch instability often keeps inharmonicity levels in a constant state of flux. The use of rhythmic unison as a structural point of arrival is present in Cendres, a parametric role that stylistically links all three works.

\section{SECTION 1 : bb.1-24}

The opening section of Cendres follows a clear trajectory from low to high tension, with the parameters that contribute most to this tensional change being dynamic profile and inharmonicity. While the minimal harmonic density of Cendres' opening bars necessarily results in the foregrounding of one instrument at a time, once the entire trio is playing no one instrument provides foreground ornamentation. This is similar to the globalised textural material found in much of Nymphéa and Du cristal. Though material that could be considered foreground ornamentation is elusive in 


\begin{tabular}{|c|c|c|c|c|}
\hline Section & Bars & Time & $\begin{array}{l}\text { Tensional } \\
\text { trajectory/qual } \\
\text { ity }\end{array}$ & Main features \\
\hline 1 & $1-24$ & $0: 00-1: 43$ & Low to high & $\begin{array}{c}\text { Low harmonic density initially. Increases } \\
\text { in dynamic profile, registral spread and } \\
\text { inharmonicity. }\end{array}$ \\
\hline 2 & $25-66$ & $1: 44-4: 11$ & High to low & $\begin{array}{l}\text { Pitch instability techniques, introduction } \\
\text { of rhythmic activity via polymetric } \\
\text { passages, gradual reduction of tension } \\
\text { via transition to more consonant } \\
\text { harmonic material. }\end{array}$ \\
\hline 3 & $67-94$ & $4: 12-5: 08$ & $\begin{array}{l}\text { Low to high, } \\
\text { with } \\
\text { fluctuations in } \\
\text { between }\end{array}$ & $\begin{array}{l}\text { Rhythmic unison at tensional high- } \\
\text { points, frequent alternation between two } \\
\text { parametrically distinct types of material, } \\
\text { especially in terms o harmonic tension. }\end{array}$ \\
\hline 4 & 95-136 & $5: 09-7: 08$ & $\begin{array}{l}\text { Low / mid } \\
\text { tension }\end{array}$ & $\begin{array}{l}\text { Rhythmic activity via polymetric } \\
\text { material, predominantly low harmonic } \\
\text { density, smaller registral spread and } \\
\text { lower dynamic profile. }\end{array}$ \\
\hline 5 & $137-154$ & $7: 09-8: 20$ & $\begin{array}{l}\text { Low to mid, } \\
\text { with three } \\
\text { distinct } \\
\text { tensional surges }\end{array}$ & $\begin{array}{l}\text { Repeated figure appears in flute and } \\
\text { cello. Low harmonic density, accelerating } \\
\text { rate of harmonic change. }\end{array}$ \\
\hline 6 & $155-168$ & $8: 21-9: 00$ & High tension & $\begin{array}{l}\text { Wide parametric and tensional } \\
\text { fluctuations, highly accelerated rate of } \\
\text { harmonic change. }\end{array}$ \\
\hline
\end{tabular}

Fig. 4.1. Formal outline of Cendres

this section, when it does appear it is often through changes in the sound/noise parameter, as each instrument employs some form of extended technique that alters timbral quality. Additionally, harmonic density can be said to assume the role of foreground ornamentation in the opening bars of the work, as the textural sparseness of the material draws attention. There is also little foregrounded rhythmic activity in the first section. As with Nymphéa and Du cristal, rhythmic activity that indicates an underlying pulse is used sparingly but often contributes to the illumination of formal landmarks in the work. 

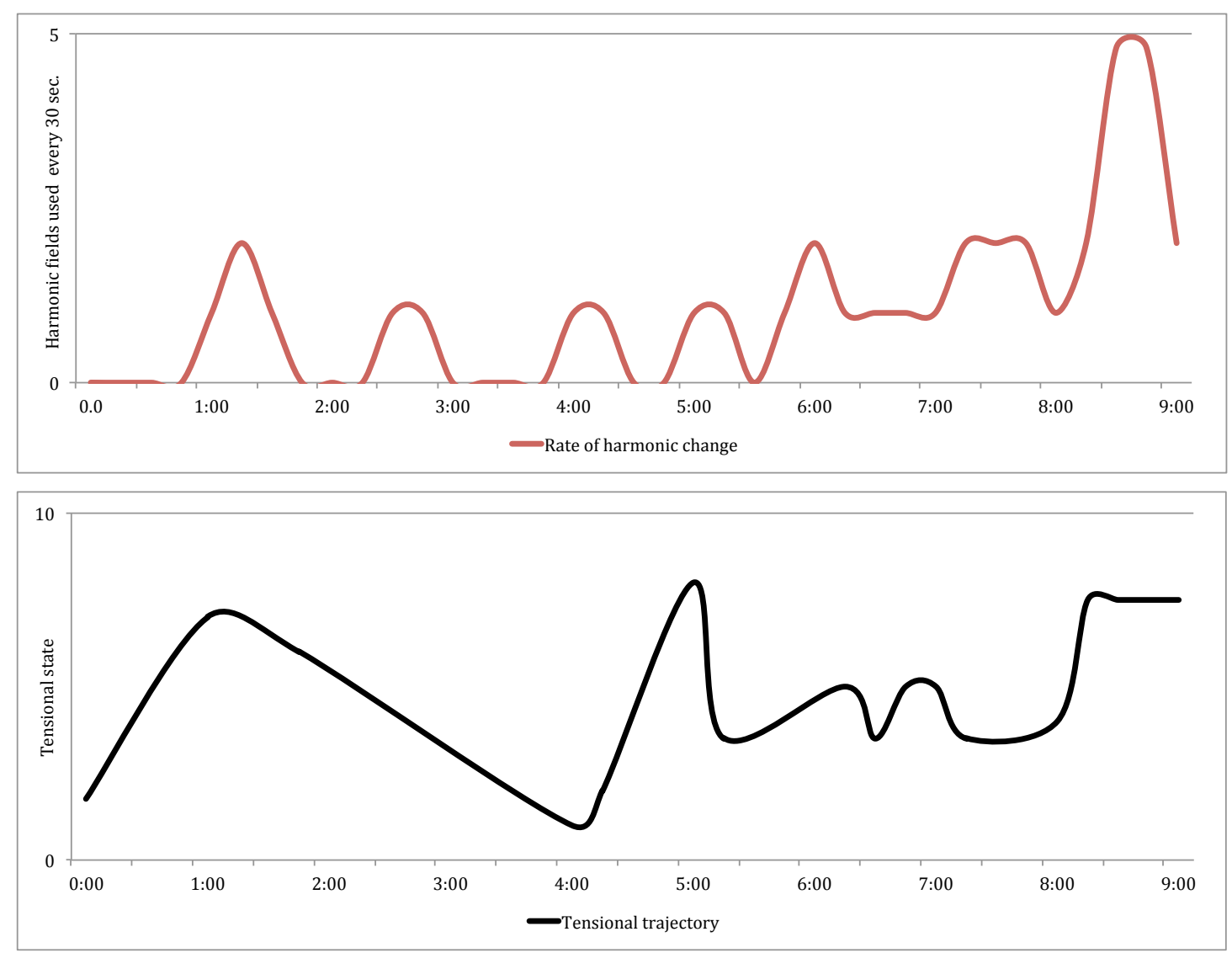

Fig. 4.2. Rate of harmonic change and tensional trajectory in Cendres
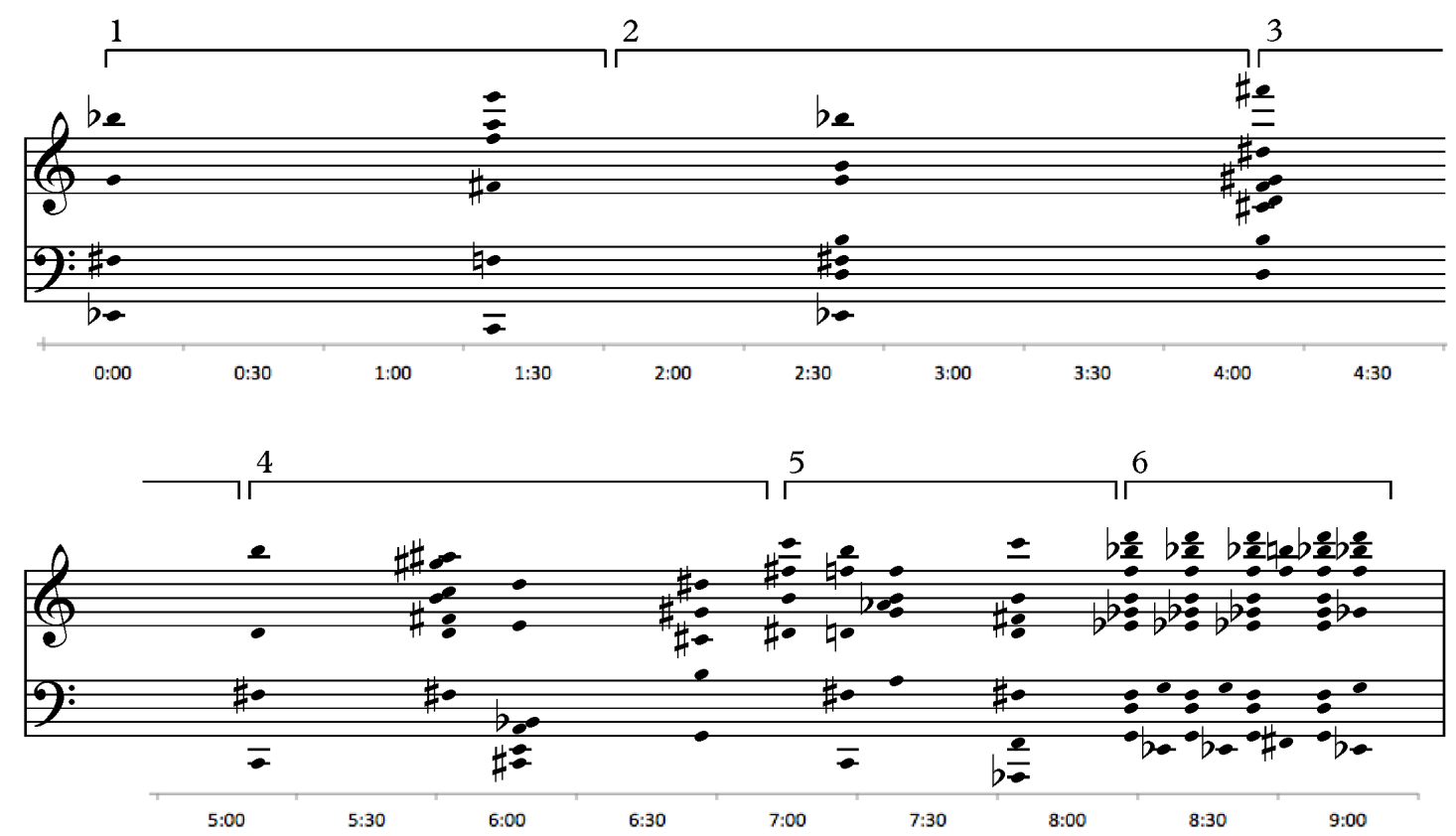

Fig. 4.3. Sequence of harmonic fields in Cendres, mapped against clock time and sectional breakdown. 
This first section of Cendres is notable for a relatively high number of parameters changing in parallel as the tensional transition takes place (Fig. 4.4). The work opens with a single pitch from the piano (minimal harmonic density and registral spread), played mp (low dynamic profile). Meanwhile, there is no change in the underlying harmonic field until b.12, by which time these parameters have increased to produce a slightly stronger degree of tension. It is the change in harmonic material that significantly transforms the amount of tension in this section, introducing strongly inharmonic material for the first time in the work. Previously, harmonic material has been mostly consonant. Fast and resonant piano runs, containing chromatic passing notes that are not part of the underlying harmonic field, now contribute to the sense of denser harmonic material being used.

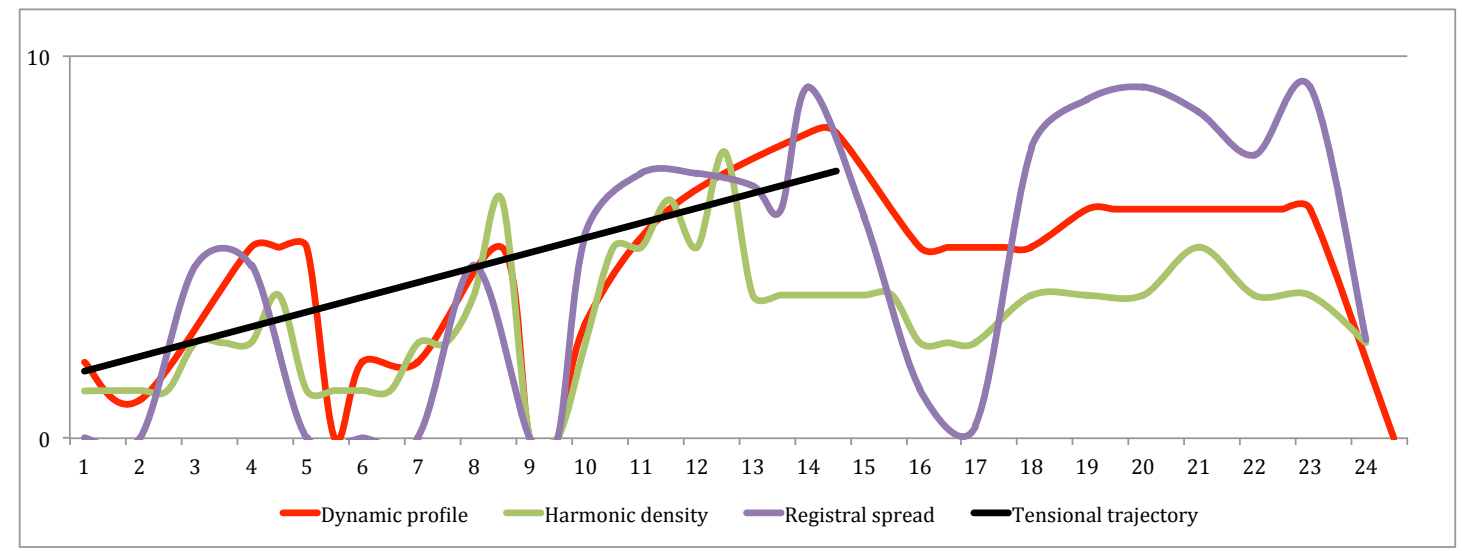

Fig. 4.4. Parametric changes in the first section of Cendres

The more synchronised parametric change in this section is demonstrated a few bars later, between bb.15-17, when a brief period of release occurs. Dynamic profile decreases, registral spread significantly decreases to less than an octave and inharmonicity decreases. Foregrounded rhythmic activity appears for the first time at this point also, as the players pass a repeated three-note demisemiquaver pattern to one another in bb.16-17. As mentioned, this period of release is a brief interruption of the overall trajectory of this section from low to high tension - dynamic profile and inharmonicity return to their former levels and registral spread in particular expands to its widest range yet, adding to the sense of climactic tension at the end of the section. Pitch instability also features strongly in the final bars of the section through the repeated use of glissandi in the flute part alongside trilling in the cello and piano parts.

The parallel parametric changes also roughly coincide with the first change in the underlying harmonic field. The rate of harmonic change increases as a new 
underlying field emerges with the release of tension at bb.15-16, with another change in harmonic material used a few bars later with the transition back to the high-tension conclusion of the section.

Although a degree of noise is present in the opening material of this section, it is not sufficient to act as a source of tension, functioning more as foreground ornamentation. The Eb2 that opens Cendres, played on piano and then cello, incorporates extended techniques on both instruments, introducing foreground ornamentation via timbral manipulation. The piano's Eb2 in the opening bar is played by plucking the string inside the piano, producing an attack profile resembling a pizzicato articulation on a string instrument. The following Eb2 from the cello is played sul pont (gradually transitioning to naturale), while trilling with harmonic finger pressure to produce G4 (the fifth partial of the harmonic series based on Eb2). The breath tones played on the flute serve as foreground ornamentation when it enters at b.17.

\section{SECTION 2 : bb.25-66}

The second section follows an opposing trajectory to the first section, moving from high to low tension. As with the first section, parameters often share parallel relationships with one another, with more contrasting material in terms of high and low tension occurring during the overall tensional process of the section (Fig. 4.5). Dynamic profile and inharmonicity are again the primary parameters used to generate tension, with the pitch instability of techniques such as trilling and glissando also continuing to affect tension.

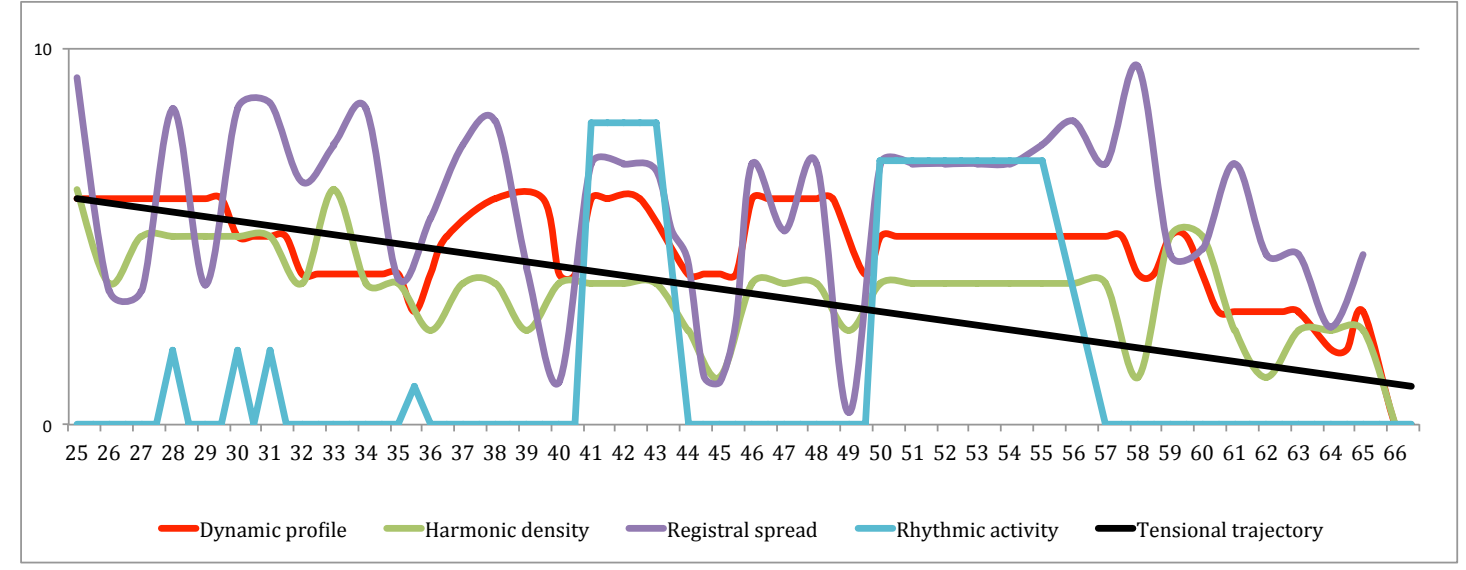

Fig. 4.5 Parametric changes in the second section of Cendres 
The second section begins with the most dominating use of noise thus far in Cendres, as the flautist uses loud breath tones, mouthing a series of phonemes through the instrument. The use of excited human breath certainly adds dramatic tension to the beginning of the section - the sound of human breath, not being controlled through embouchure and transformed into pure pitch, instils a more instinctive sense of tension for the listener, not unlike the effect of an increase in dynamic profile as discussed in the methodology section. Whereas pitch-based tension and release is to some extent a learned interpretation of sound, animated unpitched vocal material and high amplitude of a sound call on the immediacy of our biological reaction to extramusical environmental phenomena.

Harmonic tension varies widely between inharmonicity and more consonance throughout most of this section, but pitch instability is the more relevant tensional device employed. The large amount of trilling and glissandi that occupy the instrument parts in this section makes reliable calculation of harmonic tension difficult. At almost any point in this section at least one of the instruments is performing a trill, a glissando or a fast ascending run comprised of pitches outside of the underlying harmonic field, causing much of the section to be dominated by harmonic flux.

Although the general trajectory of the section is from high to low tension, this is interrupted on several occasions by the freezing of certain parameters in combination with repetition of material by the whole trio, breaking away from the arhythmic, harmonically unstable material that dominates the section. In bb.41-42 each instrument switches to a repeated figure, temporarily stabilising registral spread, dynamic profile and harmonic density. The most noticeable parametric change, however, is the sudden prominence of rhythmic activity created by the polymetric nature of the repeated material. This is the first instance across the three analysed works that the use of rhythmic activity as foreground ornamentation is manifested in this style. When the ensemble unites using rhythmic activity in Nymphéa and $D u$ cristal, all instruments repeat the same rhythmic material, with little or no pitch variation in the individual lines.

The repeated polymetric material that follows from bb.50-56 (Ex. 2.1) provides even more contrast to the surrounding material due to its relative lack of harmonic tension. The strongest source of tension in the two passages of rhythmic activity is the push and pull of the polymetric material as the distance between the respective downbeats of the flute and cello patterns incrementally change. Like the material in 

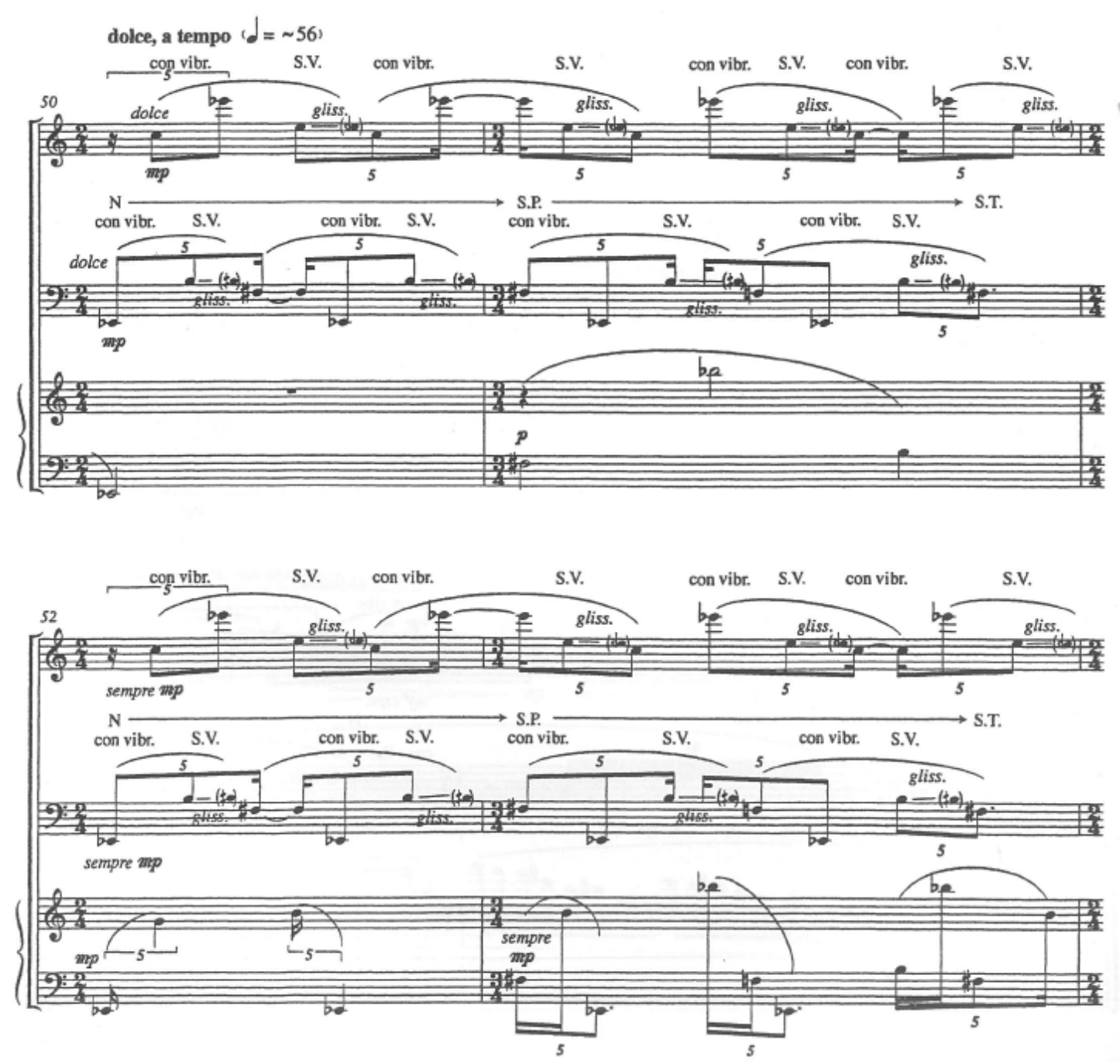

Ex. 2.1. Polymetric material in the second section of Cendres

bb.41-42, this short passage sees the parameters freeze in another structural non sequitur before the work reverts back to its stylistic character, as though these tensional departures might never have happened.

Despite the numerous ascending runs superimposed over the pitch material, this section sees little actual change to the underlying harmonic field. The section retains the harmonic field from the end of the first section, transforming amongst the extended series of piano runs from bb.35-40 and emerging with a new underlying field for the first of the short repetitive passages at b.41. Following the second repetitive passage, the transition to a low-tension state is completed through harmonic density gradually thinning out, accompanied by a decrease in dynamics. The harmonic field is ultimately reduced to the consonance of Eb2 and G4, revealing that this has been a return to the harmonic field that opens Cendres. 


\section{SECTION 3 : bb.67-94}

While following an overall trajectory from low to high tension, the brief third section contains several large tensional fluctuations throughout. Rhythmic activity is harnessed in the same manner seen in Nymphéa and Du cristal, with the ensemble synchronising to create rhythmic unison in passages of high tension. Dynamic profile is again closely tied to tension. The behaviour of the inharmonicity parameter is of interest in this section due to its unusual relationship with harmonic density.

The transition between the second and third section is marked by the full bar rest at b.66 and a new underlying harmonic field starting at b.67. The same harmonic field remains in place for the entire section. A significant amount of tension is generated in this section through the frequent alternation between two parametrically distinct types of material. The first type of material is typical of what has preceded this section - arhythmic, with frequent odd-numbered beat subdivisions, set against sustained and trilled notes - and is associated more with moments of lower tension in this section. The second type of material found in this section uses rhythmic unison in the form of repeated semiquaver patterns, with minimal harmonic density and registral spread (Ex. 2.2). The material containing rhythmic unison also contains the most inharmonic material, and is used for moments of higher tension in the section. This section contains the most foregrounded rhythmic activity and rhythmic unison thus far in the work, signalling a formal point of arrival.

The semiquaver pattern is more pervasive nearer the end of the section, providing a sense of tensional momentum. The structure of the section is reinforced by the cadential use of the $\mathrm{C} 2$ in the final chord, acting as a point of arrival for the section. There is little tension derived from inharmonic material in the third section, with the majority of harmonic material actually measuring as consonant (Fig. 4.6). The

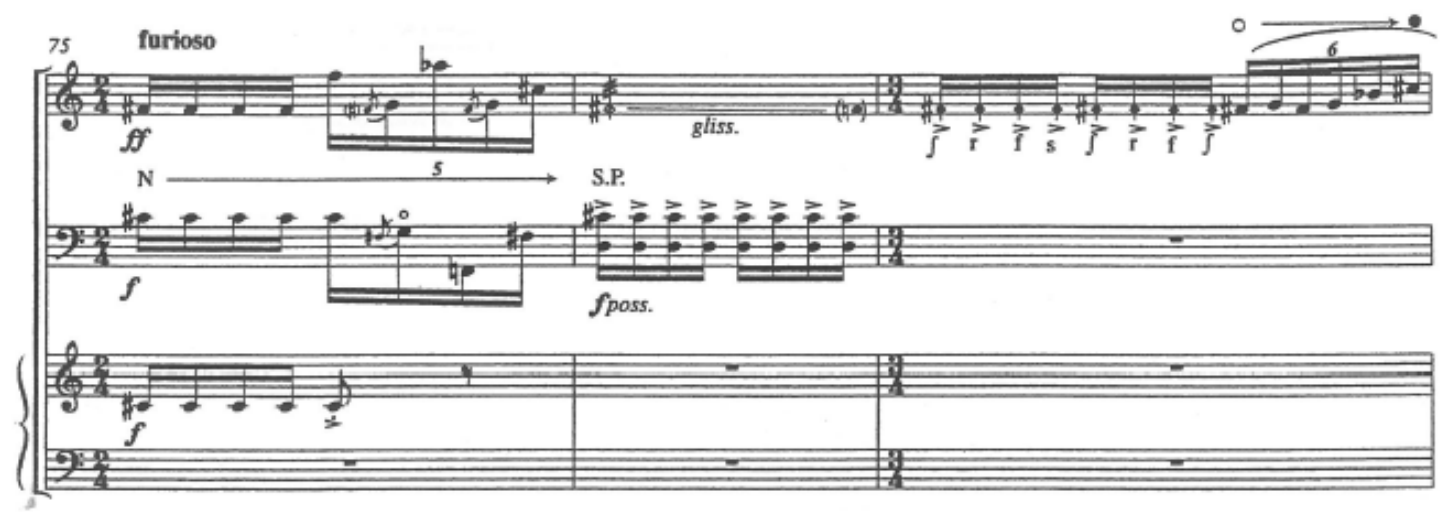

Ex. 2.2. Rhythmic unison in the third section of Cendres 

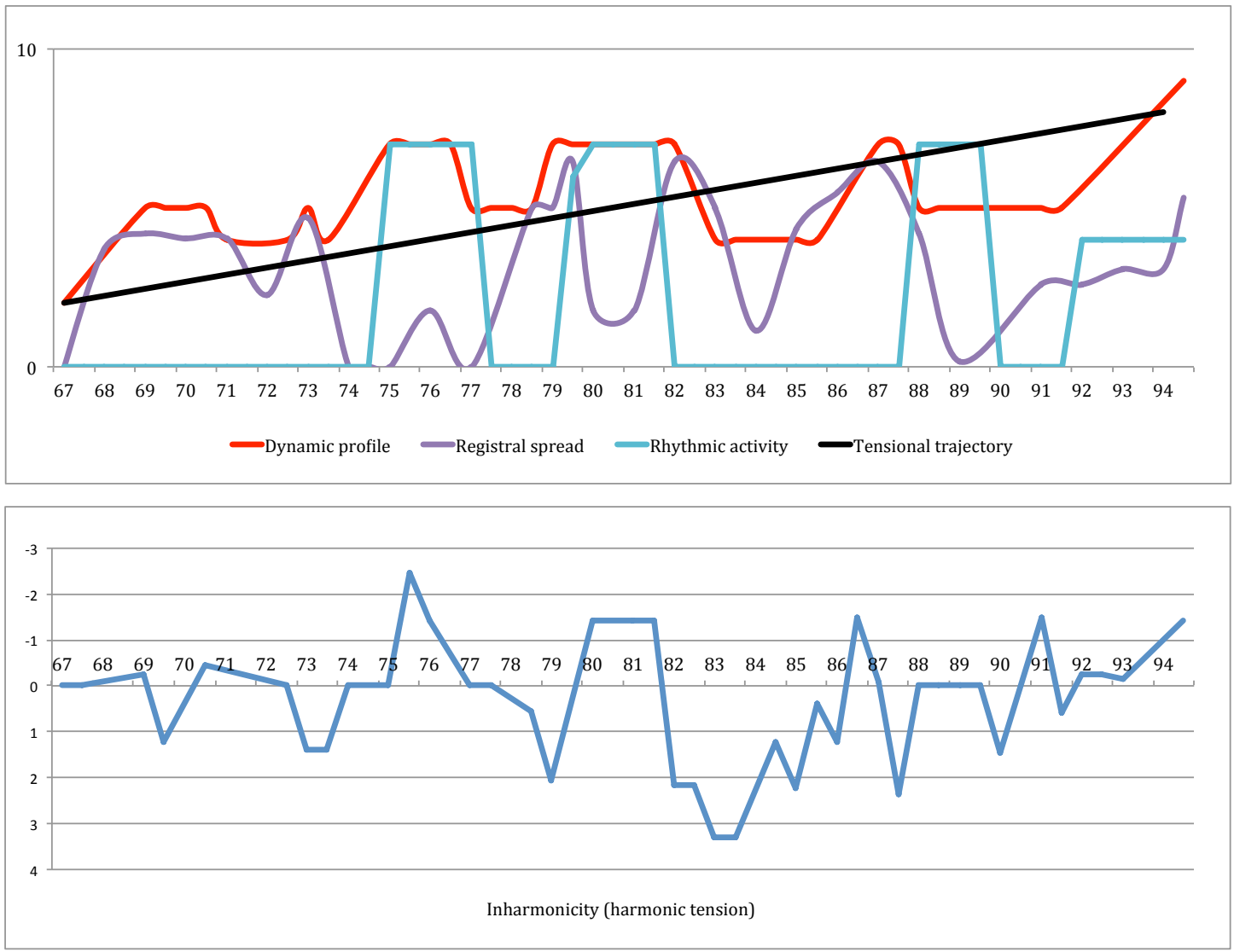

Fig. 4.6. Parametric changes in the third section of Cendres

relationship between harmonic density and inharmonicity in this section is of interest due to this lack of harmonic tension even in the section's more dense harmonic material - a contrast with the usual relationship between these two parameters in Nymphéa and Du cristal. Three of Cendres's largest spikes in harmonic density occur in this section, in the form of three thick piano chords at b.73, b.79 and bb.82-83. Each of these chords, however, measure as consonant. This consonance compliments the mostly sustained note durations occurring with these chords, supporting moments of small-scale tensional release in the section. Contrasting with this is the inharmonicty of the high-tension rhythmic material that emphasises the small-scale movement between higher and lower states of tension during the section. The overall transition from low to high tension in this section is reinforced by the prevalence of the inharmonicity associated with the high-tension material in the final few bars.

One explanation for the relative consonance of this section's harmonic material could be the absence of quarter-tones in much of Cendres, meaning that the occurrence of highly dissonant intervallic values between equal-tempered and quarter-tone pitches is reduced. Pitch instability also features in this section, predominantly in the form of trilling, which again makes the calculation of inharmonicity difficult in some bars. 


\section{SECTION 4 : bb.95-136}

Following the frequent tensional fluctuations and high-tension conclusion of the third section, the fourth section displays more tensional stability, particularly through occupying a smaller dynamic range. Although most of its material can be considered low to mid tension, there is enough tensional and parametric variation, including two short dynamic surges, to keep this section from being considered a "rest area" of the kind described in analyses of Nymphéa and Du cristal (Fig. 4.7). Tensional changes are again driven by movement in the dynamic, inharmonicity and rhythmic activity parameters. The change to a new harmonic field around b.108 marks the beginning of a slightly accelerated rate of harmonic change in Cendres, though in this section the acceleration is not sufficient to create tension through any sense of harmonic flux.

The fourth section retains the predominantly low harmonic density of the third section, evading any sense of vertical mass that might suggest climactic material. In fact, it is rare in this section for the whole trio to be playing at the same time, with the only clear increases in density occurring in bb.115-118, where the piano's chordal material thickens or the cello plays double stops, and b.125, which reprises the thick piano chord found in the third section. The amount of inharmonicity is also similar to the third section, although this section is more consistently inharmonic from its beginning at b.95 until b.108, where the change to less consistent inharmonicity roughly coincides with a change to a new underlying harmonic field. As also observed in the third section, harmonic density does not share a parallel relationship with inharmonicity. Both of this section's peaks in harmonic density - bb.115-118 and b.125 - coincide with almost entirely with consonant pitch collections, subverting the typical tensional relationship between these two parameters. Pitch instability is also employed regularly in this section, appearing again in the form of trilling and glissandi. The pitch instability generated by these techniques continues to play an important role in the tensional quality of Cendres by producing an almost constant state of restlessness within the harmonic fabric of the work.

As with harmonic density, the registral spread of the fourth section often restricts the cadential and tensional range. Of the six sections that make up Cendres, the fourth section contains the least amount of fluctuations of registral spread, being predominantly confined to the middle and upper registers. The absence of pitch material in the lower bass register is the most noticeable feature regarding registral spread in this section, contributing to its structural identity as a predominantly lower-tension area in the overall context of the work, without a strong climactic 
event. The bass register is used in the opening four bars, producing the widest registral spread of the section (four octaves), but Saariaho subverts its climactic potential by avoiding rhythmic activity, limiting harmonic density and using a low dynamic profile. According to calculations, some of the harmonic material in the opening four bars is consonant. This consonance is neutralised to a significant degree by the wide registral distribution of the constituent pitches, producing the more consistent harmonic tension referred to in the previous paragraph.

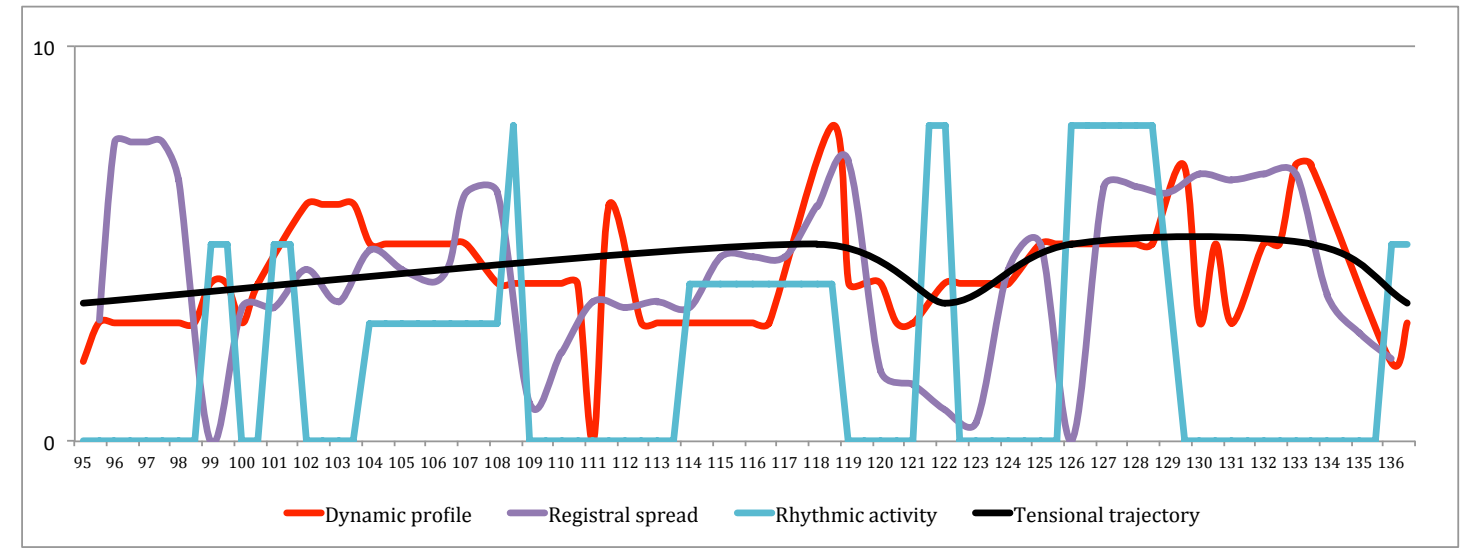

Fig. 4.7. Parametric changes in the fourth section of Cendres

In this section, rises in tension are achieved by combining increased rhythmic activity with high dynamic profile, along with inharmonicity that is generated to some degree through the expansion of registral spread. The use of rhythmic activity as a tensional device is somewhat unique in this section, as rhythmic unison between the players is not used, though an underlying metric grid is still revealed. The first rise in tension, between bb.115-18, sees the cello as the sole source of rhythmic momentum, playing a quintuplet semiquaver pulse over tremolos in the piano part. The second rise in tension, in bb.126-129, sees both the flute and piano playing consistent semiquavers, though after the four semiquavers on a unison $\mathrm{C} \sharp 4$ on the first beat of b.126 (the only example of rhythmic and pitch unison in this section), rhythmic unison is made evasive through the use of opposing beat subdivisions in the flute part while the cello holds the initial semiquaver subdivision. In both of these examples Saariaho creates momentum, and subsequently tension, through the use of a repetitive pulse, though tension is controlled - or curbed - through not having rhythmic activity dominate the material through complete rhythmic unison. The result is that the climactic impact of the material is diminished and is not convincingly perceivable as a clear point of arrival in the formal structure of the work. 
Again, no one parametric feature is foregrounded in a fashion that could be considered foreground ornamentation. Rather, the short, expressive phrases that emerge from this section's sparse textures provide a relatively conventional foreground role, such as the cello line in bb.108-109 and bb.121-122, and the flute line in bb.119-120. The repetition of phrasal material, such as the aforementioned cello lines, serves more as a structural, formal device, providing coherence for the section as opposed to providing small-scale detail while larger parametric trajectories unfold (as observed in Nymphéa and Du cristal).

\section{SECTION 5 : bb.136-154}

As with the fourth section, the fifth section contains more controlled tensional fluctuations, this time in preparation for the climactic sixth and final section of Cendres. The section is comprised of three small-scale trajectories from low to midtension, with the third small-scale tensional trajectory breaking into the high-tension material that opens the sixth section (Fig. 4.8). Dynamic profile and inharmonicity are again the drivers of tensional change in the section. Rhythmic activity is foregrounded in low-tension passages in this section, in contrast to its typical use in the three analysed works as an additional, structurally significant device for hightension passages.

Beginning each low-to-mid tension trajectory in the fifth section is a bar of short ascending and descending glissandi in the flute and cello parts. Found in bars 136, 147 and 152, the flute and cello material is identical in all three bars (Cendres is the only work of the three containing identical repetition of motivic material). The flute's unbroken line of six quavers at $d=50$ provides a rhythmic steadiness that lacks the momentum of the foregrounded rhythmic material in Cendres that is typically based on much faster semiquaver subdivisions. In combination with the $\mathrm{mf} / \mathrm{mp}$ dynamic markings, this material provides a low-tension foundation from which tension increases in subsequent bars before ebbing back to the same low-tension motif.

The rate of harmonic change in this section is at its fastest thus far in the work, as the mid-tension material between bb.138-146 contains changes to two different harmonic fields before reverting back to the harmonic field carried over from the end of the fourth section for the second statement of the low-tension flute and cello material. Though the rate of harmonic change increases in this section, it is really the cyclic pacing of the repeated small-scale tensional trajectories that generates the sense of accelerating forward movement - the first small-scale tensional trajectory occupies bb.136-146, while the second occupies bb.147-151 and third b.152 until 


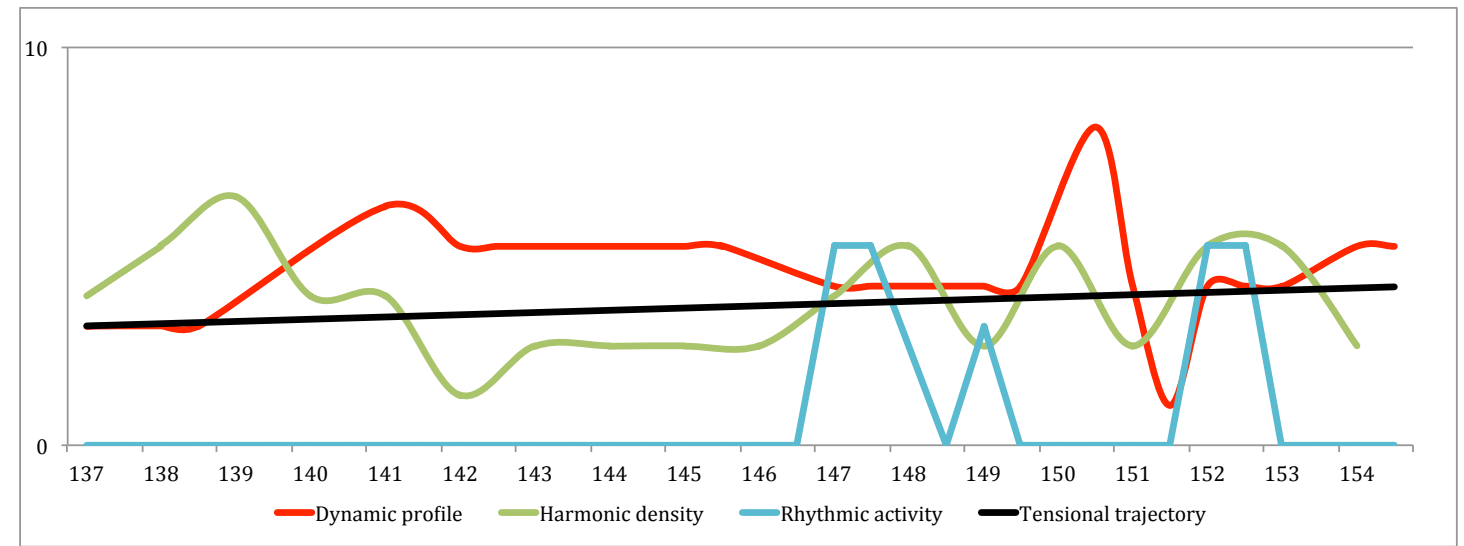

Fig. 4.8. Parametric changes in the fifth section of Cendres

b.155, when the high-tension final section erupts and harmonic flux truly becomes a strong tensional device. The underlying rate of harmonic change in the fourth section is actually rather constant beneath the increasingly shortened small-scale trajectories involving other parameters such as dynamic profile and inharmonicity.

As in other low-tension sections in Cendres, harmonic density remains fairly low throughout this section, increasing by one or two pitches whenever the piano extends its range below the bass clef, greatly extending registral spread. Low harmonic density again supports the low-to-mid tensional state, and also diminishes the climactic impact of this section's expansions of registral spread, maintaining a wide spacing between pitches reminiscent of the "muted" climactic material in Nymphéa.

\section{SECTION 6 : bb.155-168}

The brief final section of Cendres is the tensional high-point of the work, achieved as much through the quick changes between states of high and low tension as through the high-tension material itself. The accelerating rate of harmonic change reaches its peak in this section, contributing to the contrast between high and low tension material. The dynamic profile and inharmonicity parameters also fluctuate greatly in this section, maximising the sense of flux.

The section opens with the full trio interrupting the piano's gradual dynamic surge from the end of the previous section, drastically increasing the tensional state with an arhythmic flurry of pitches from a new harmonic field, played forte with a mixture of trilling and glissandi in the flute and cello and a brisk phrase comprised of demisemiquavers in the piano part. The following bar sees an immediate tensional change, achieved through several simultaneous parametric changes in a relatively 
conventional manner. Harmonic density reduces down to single pitches from the flute and cello, their dynamic markings dropping to $m f$ and $m p$ respectively. Perhaps the most striking parametric change is harmonic, with the pitch content reprising the sustained major third on $\mathrm{E} b$ from the work's opening harmonic field. Also contributing to the sense of flux here is the sudden reduction in registral spread from the three and a half octaves in b.155, the Eb major dyad in b.156 is spread across a major tenth in the bass clef.

Similarly contrasting material follows for the remainder of the section. Aside from b.164, however, the full trio no longer plays at the same time, instead alternating between solo piano and flute and cello, with the high-tension material simply a repeat of the piano's short phrase from b.155 (Ex. 2.3). The flute and cello, dividing

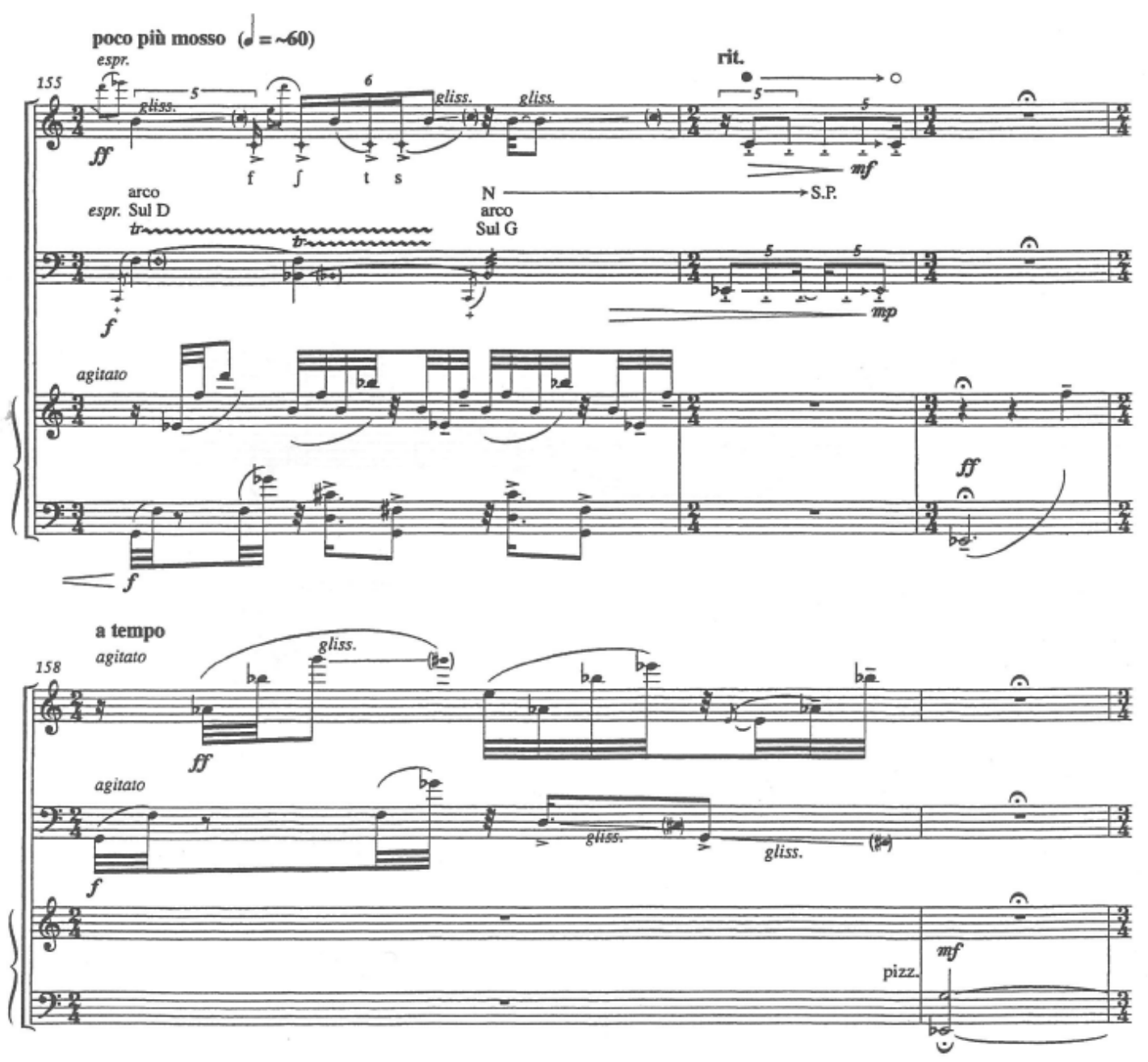

Ex. 2.3. Repeated material in the sixth section of Cendres 
the piano's hands between them, use glissandi to further increase tension through pitch instability. This instrumental variation is another device for maximising flux, and subsequently tension, via constant timbral alternation. A side effect of this section's instrumental alternation is that harmonic density remains very low, in another apparent parametric subversion of climactic material (Fig. 4.8). The overpowering tensional flux is, however, such that the low harmonic density is somewhat negated. This negation is also achieved through the predominantly wide registral spread (another powerful climactic device) in this section, realised by the wide intervallic leaps used in each part.

The short phrase repeated throughout this section is deceptively rhythmic - this is made clear when it appears in the solo piano part at bb.161-163 (the only time the phrase appears in the piano part unaccompanied), with the sharper, more percussive attack and timbral homogeneity of the piano providing clearer rhythmic focus than the flute/cello iterations peppered with glissandi. Here, rhythmic activity is briefly brought to the foreground in a unique incarnation: there is metric consistency in the demisemiquaver subdivision, which is free of any of the metrically subversive tuplet,
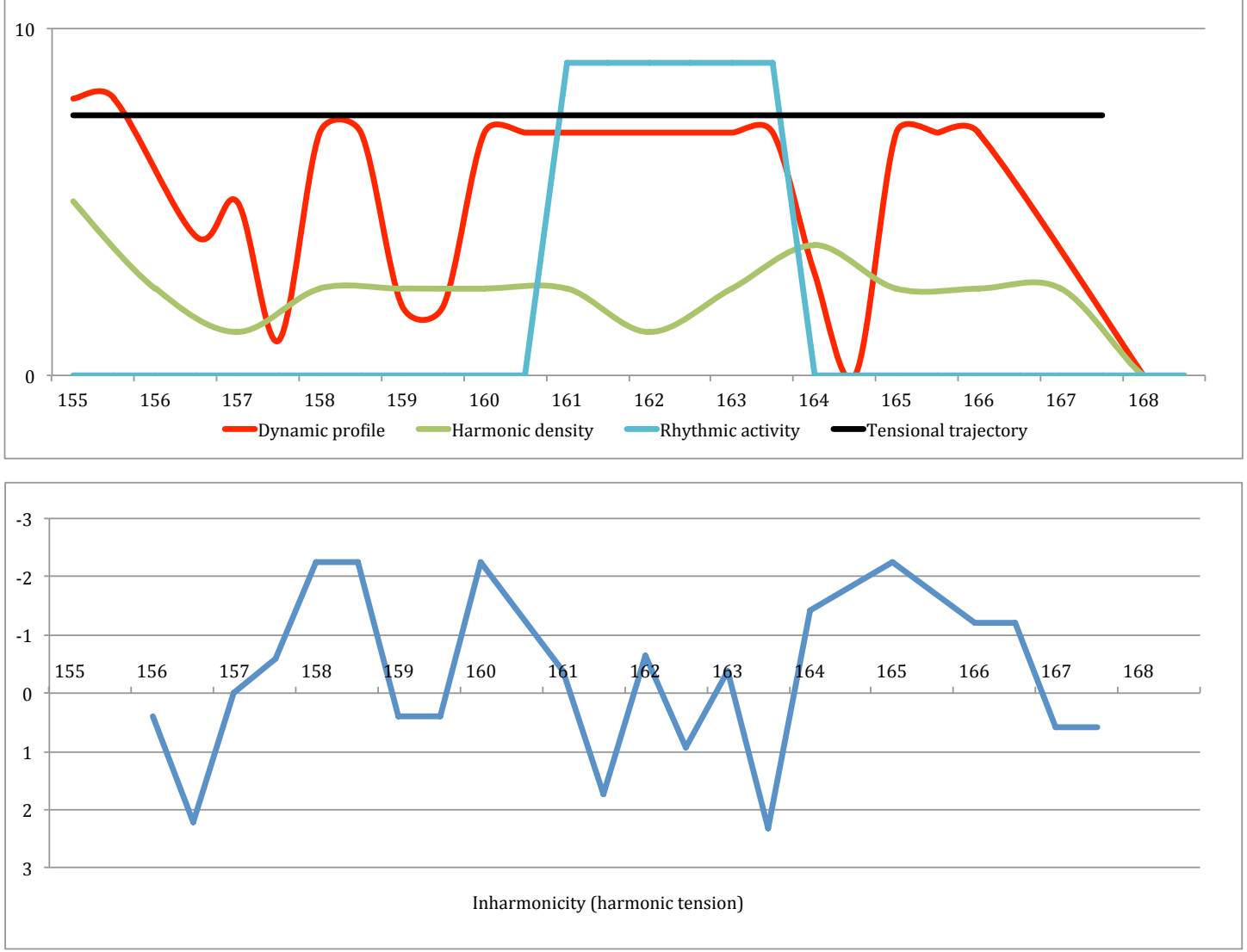

Fig 4.8. Parametric changes in the sixth section of Cendres 
quintuplet or septuplet subdivisions that have typically accompanied such material elsewhere in the work. Here, in this brief snatch of time, is a slight loosening of Saariaho's grip on rhythmic behaviour in Cendres, with sense of freer rhythmic play, without venturing into syncopation. Its brevity precludes it from becoming a climactic point of arrival of great structural significance - it seems, instead, to be just one of several small-scale ingredients that contribute to contrasting character of this section in the context of its overall scheme.

Continuing with reflection on the formal, structural significance of this section in the overall context of Cendres, we should return to the aforementioned observation that this short section is essentially comprised of alternations between two contrasting types of tensional musical material, which presents in itself an obvious contrast to the rest of the work. The clearest impression of a long-term parametric trajectory in Cendres is found when reviewing the consistent acceleration of the rate of harmonic change across the duration of the work, which reaches its apex with the frequent change of harmonic field in the final 14 bars of the work. In this light, the sixth section appears to function as the parametric climax for the rate of harmonic change, while appearing in other regards as a coda or structural non-sequiter of the kind referred to in the discussion of Nymphéa. 


\section{ANALYSIS OF WORKS}

\section{Summary}

I will now discuss the findings from the analyses of Nymphéa, Du cristal and Cendres, with a highlighting of the main similarities and differences in Saariaho's use of various parameters, and combinations of parameters, to change and maintain tensional states across the three works. A description of how perceivable form is created through these parametric changes is also given, along with a discussion of the similarities, differences and functions of foreground ornamentation across the three works.

Starting with a broad perspective of these works, I will discuss musical form as it relates here. The perception of form for these works clearly does not occur through the traditional analytical method of identifying sections that contain literal repetition of a previous section, perceivable through repeated chord progressions or changes in key. While changes in the underlying harmonic field commonly coincide with the beginning of a new section, it is, first and foremost, the cycles of tension and release that define the formal character of these works. It should be noted that all three works contain at least one instance of chordal material being repeated at a later point in the work. While they provide rare landmarks of coherence and familiarity, these literal repetitions are too fleeting to define the formal character of the works in any way. The sections that comprise the overall form of each work - whether these sections navigate trajectories from one tensional state to another or maintain a constant tensional state throughout - are distinguishable by their unique combinations of parametric properties, providing variation across the duration of each work and reinforcing an overall formal structure.

By changing which parameter, or combination of parameters, drives tensional change, Saariaho retains variety as the works unfold, allowing for sections that contain similar tensional states but through different parametric combinations. This technique is behind the muted climactic material that features, in varying quantities, in each work, whereby one parameter seems out of step with the tensional trajectory of its surrounding parameters by being held at its low-tension extremity, subverting what would otherwise be a more high-tension passage (as observed in the eighth sections of Nymphéa and Du cristal and the fifth section of Cendres). 
The first parameter to be discussed is rhythmic activity. There is a clear relationship between rhythmic activity, in the form of rhythmic unison, and states of high tension in all three works (making rhythmic activity most associated with states of high tension). Saariaho reliably uses rhythmic unison as a point of arrival, heightening climactic material through the forward momentum generated by the whole ensemble playing repeated pitches, typically of very short duration such as semiquavers. Much of the impact of rhythmic unison in these works is due to its strong contrast with the material that typically surrounds it - rhythmic activity, in which an underlying pulse is perceivable, is absent for the vast majority of each work. An underlying metric grid is revealed only occasionally - on these occasions, the temporal dimension of the music is engaged in a more active (rhythmic) fashion, giving the impression of acceleration to the processes unfolding in the works and heightening the sense of tension and momentum.

Of all the parameters traced through the selected works, rhythmic activity is also the most versatile. It is employed not only in the form of rhythmic unison for passages of heightened tension, but as more "playful" foreground ornamentation that provides moment-to-moment interest while underlying tensional trajectories unfold.

Occasionally, freer rhythmic material is employed as a source of tension, as observed with the soloistic percussion material in Du cristal's climactic fifth section. Here, the percussive material functions as both foreground ornamentation and the primary source of tension in the section, due to its high amplitude. Along with sound/noise, rhythmic activity is the main parameter used for foreground ornamentation in Nymphéa, and it is the primary parameter used for foreground ornamentation in $D u$ cristal. A freer type of rhythmic activity is also applied in Nymphéa when it appears as the proto-melodic material that acts as foreground ornamentation, though this typically appears in non-climactic passages.

Cendres differs from Nymphéa and Du cristal because of its use of looping polyrhythmic and polymetric material that lasts for several bars, for example in its second section. These occasional snatches of rhythmic material do not develop to become an important feature in the work, nor are they part of climactic material, instead serving as non sequiturs of sorts, brief moments of rhythmic contrast.

The rate of harmonic change is another defining feature of the selected works. In considering the relationship between the rate of harmonic change and the perception of form in these works, the coincidence of changes in the underlying harmonic field 
with a transition to a new section of tension and release shows that harmonic change is important to Saariaho for reinforcing a sense of structural development and forward movement on a sectional level, and less as a moment-to-moment tensional device via accelerating its rate of change. While rate of harmonic change appears to be a parameter that is used to support a handful of short-term tensional changes in Nymphéa and Du cristal, it follows a long-term trajectory for the duration of Cendres, moving from an initially slow rate of harmonic change to the frequent shifts between harmonic fields in its final section.

Across the three works, however, rate of harmonic change is very rarely fast enough to create a genuine sense of flux and serve as a source of high tension. The only sections in which Saariaho uses an accelerated rate of harmonic change to build tension are the sixth section of Nymphéa, which contains the first major climax of the work, and the final, climactic section of Cendres. As mentioned in the analysis of the sixth section of Nymphéa, however, the noise generated by extreme bow pressure obscures the increased rate of harmonic change taking place. It is more common for Saariaho to use a slow rate of harmonic change to support periods of low tension or stasis in these works, such as in third section of Du cristal.

Inharmonicity is also a key parameter in the production of tension across all three works. While Du cristal's harmonic material is measured as entirely inharmonic, Nymphéa and Cendres contain brief flickers of more consonant material, though it is only in Cendres that we find what may be termed intentional consonance, in the harmonic material based on the Eb2 that opens the work. Registral spread plays an important role in the perception of inharmonicity. As mentioned in the analyses of the selected works, wide spacing between a chord's constituent pitches can compromise the perception of its intervallic relationships, resulting in the consonance or dissonance of harmonic material becoming less audible. This effect certainly comes into play in each of these works, arguably a device employed by Saariaho to give the impression of fluctuation in the degree of inharmonicity, creating a type of harmonic ambiguity. While inharmonicity is an important tensional parameter here, the most climactic, high-tension sections in these works are not always the most inharmonic. It is, unsurprisingly, the dynamic profile parameter that truly defines climactic material in these works. Du cristal is by far the most inharmonic of the three works, based on the measurements of inharmonicity. This is largely due to passages of high harmonic density, often containing dissonant quarter-tone intervals. The climactic fifth section, however, with its thunderous percussive material, contains some of the least inharmonic material of the entire 
work, mostly due to it containing far less quarter-tones. It seems that since these works constantly dwell in inharmonicity, Saariaho must make use the tensional extremes of other parameters such as rhythmic activity and dynamic profile to realise tensional peaks.

Also tied to the aforementioned prevalence of inharmonicity in the three works is Saariaho's use of pitch instability to generate tension, which leads to instability of the intervallic relationships within harmonic material in the context of ensemble works. This is achieved through extensive use of trills, glissandi and, in the case of strings, constantly shifting bow positions. This method of producing tension through pitch and harmonic instability is evident in the prevalence of these playing techniques in Nymphéa. Glissandi are used in the flute and cello parts throughout Cendres, while all three instruments regularly employ trills. The cello's changing bow positions in Cendres are reminiscent of Saariaho's string writing in Nymphéa. Du cristal also features this type of pitch instability in the string section, while trills are used extensively in the woodwind section. The value of these playing techniques as a source of tension lies in their small-scale level of pitch activity in a harmonic context that often contains sustained pitches and a slow rate of harmonic change. The flutter of a trill and the timbral subtleties of a change in bow position add instability and liveliness to pitch material; the slow, extended string glissandi in Du cristal contribute to tension through producing motion and anticipation of their final harmonic destination, and through the unique microtonal harmonic hues that result from such incremental harmonic transitions.

The combination of parametric extremities that dominates climactic material across the three works is rhythmic activity (unison) and dynamic profile. Registral spread and harmonic density vary greatly with each appearance of rhythmic unison/high amplitude climactic material, assumedly dependent on Saariaho's desire to maximise the climactic nature of the material. Wide registral spread is by no means strictly attached to climactic material, with several examples demonstrating the striking effect of condensing the registral spread of the ensemble to a small range - see the third section of Cendres (major $7^{\text {th }}$ ) or even the climactic unison Ab4 that concludes the sixth section of $\mathrm{Du}$ cristal (the rhythmic unison in this case involves tied, long note values across several bars).

The final section of Cendres is the only example of Saariaho using flux between contrasting tensional states itself as a source of tension, releasing the work from the more measured trajectory-based navigation of tension and release. As mentioned in 
the analysis of Cendres, while the work can be divided into sections based on tension and release (allowing an overall formal structure to be perceived), it displays less gradual tensional transitions than Nymphéa and Du cristal. Cendres displays a more occurrences of several parametric changes occurring in parallel and demonstrates Saariaho diversifying her methods of generating tension, with Cendres' final section being the most extreme example of this approach.

Parametric synchronisation is the main device through which points of arrival are created in the three selected works. The impact of synchronisation in these works is due, of course, to the vast amount of parametric desynchronisation that dominates them - individual players often have dynamic surges that are independent of the rest of their ensemble, one string player will be playing sul pont while others play naturale, several players will be performing rhythmic material that uses differing beat subdivisions, and so on. Saariaho uses parametric synchronisation to bring the works into sharper focus for high-tension passages by coordinating parallel changes in the rhythmic activity and dynamic profile parameters specifically, with the addition of the sound/noise parameter in the case of Nymphéa. All players will share a crescendo, or align themselves with the same repeated semiquaver pattern, or, in the case of Nymphéa, use extreme bow pressure for a type of timbral tutti. The works then dissolve back into desynchronised webs of arrhythmic material with lone dynamic surges that briefly push a player above the global texture before it is reabsorbed. Synchronisation, of course, provides a final sense of resolution in $D u$ cristal using rhythmic unison, with the bass drum and crotales beating out of step with one another until the final bars of the work, in which their final two beats are synchronised.

Foreground ornamentation differs widely between the three works, both in terms of how often it is used and the parameters that are used to provide it. While the sound/noise parameter and the rhythmic activity parameter provide foreground ornamentation for much of Nymphéa, there is less use of foreground ornamentation in $\mathrm{Du}$ cristal, which relies purely on rhythmic activity, and very little in Cendres. The key question regarding the use of foreground ornamentation in these works is why it is used, or not, in a particular section or work. It seems that an ensemble's size and timbral homogeneity play a role in Saariaho's use of foreground ornamentation, as does her desire to emphasise periods of stasis or activity.

The statement that Cendres contains very little foreground ornamentation is explainable due to the criteria mentioned above regarding ensemble size and timbral 
homogeneity. Cendres' main difference from Nymphéa and Du cristal stems from its relative restlessness: the active quality of its quick alternation between foregrounded instruments, and lack of focus on creating globalised sound mass (although its opening bars, and brief snippets thereafter, give a nod to the fused textures that typify spectral music). The quick alternation of foregrounded material occurs between instruments with distinct timbral differences — piano, cello and flute providing moment-to-moment variation of timbral foregrounding, occasionally involving slight changes to the sound/noise parameter through the flute's breath tones or a change of the cello's bow position. Cendres' overall form simply makes less use of stasis than Nymphéa and Du cristal. Its smaller ensemble size and quick alternation between foregrounded instruments allows for less separation between the micro- and macrostructural.

As touched on earlier, the rhythmic activity parameter is used in varying ways in these works. Some passages in Du cristal contain polyrhythmic material as foreground ornamentation, though Saariaho often places this material in the treble register and above (such as the pitched percussion material in the latter half of the third section), which keeps it from commanding any kind of temporal momentum, but also moves the overall material away from stasis through providing active foreground material. The use of surges of extreme bow pressure by individual players in sections of Nymphéa serves a similar purpose, providing moment-tomoment interest by breaking away from timbral homogeneity of the string quartet. Points of arrival in Nymphéa and Du cristal are also of interest for the way that some of this material blurs the role of foreground ornamentation, making it a source of tension, with the parameter providing the foreground ornamentation being pushed to its high-tension extremity. This is of interest because, while supplying moment-tomoment interest, foreground ornamentation is not often the primary source of tension. This blurring of roles is observed with the sound/noise and rhythmic activity parameters in Nymphéa's climactic material. Elsewhere, the previously mentioned percussion material of $\mathrm{Du}$ cristal's climactic fifth section sees surface material also play this dual role by becoming the primary source of tension.

To conclude, it is clear that Nymphéa, Du cristal and Cendres can be divided into sections based on tensional processes that illuminate their overall formal structures. The parametric changes that combine to create these tensional processes vary, both between the works and within each work. Inharmonicity and the rate of harmonic change were initially the two parameters given the most attention when analysing the tensional processes in these works, primarily due to the primary points of 
difference in spectral and post-spectral composition being the use of slowly developing timbre chords and non-tonal harmonic character. Analysis of these works by Saariaho, however, reveal an equal - or even greater - reliance on rhythmic changes for creating moments of high tension. This is most obvious through the use of rhythmic unison in all three works to create points of arrival, providing temporary perceptibility of pulse. Rhythmic unison always occurs in tandem with loud dynamics that reinforce the significance of the material. Inharmonicity is also common to high-tension material in each work, though not with the same regularity as rhythmic unison and loud dynamics. As these works rarely shift out of inharmonic chordal material (particularly Nymphéa and Du cristal), it seems that Saariaho makes use of rhythmic unison as a further device for accentuating climactic material. Parametric synchronisation is also a device that links the three works, as several parameters will move to high-tension extremes simultaneously for climactic passages, which also involves all players moving in parallel. The dominance of desynchronisation - of both parameters and players - in these works again makes for a contrasting point of arrival when synchronisation occurs.

A slow rate of harmonic change is common across all three works as a means of supporting low-tension passages, while Cendres is the only work that uses an accelerated rate of harmonic change to build tension. While at least a small element of noise is present in each work, Nymphéa is the only work that truly harnesses noise as a source of tension. Although fleeting, Cendres is the only work to embrace harmonic consonance, allowing for more audible contrast in harmonic tension. Regarding foreground ornamentation, Nymphéa's proto-melodic material and $D u$ cristal's polyrhythmic material share the use of rhythm as foreground ornamentation that subverts the underlying meter enough to avoid contributing a sense of momentum.

Stylistically, Saariaho's organic approach to musical form, based not on literal repetition but on tensional states and trajectories and variety in parametric dominance, link her with other post-war composers that developed dense polyphonic textures from which details could emerge, such as the vast polyphonic and contrapuntal webs constructed by 'proto-spectral' composers such as Ligeti. The rarity of stable pitch and rhythmic material evokes organicism of the kind espoused by Wishart $(1996)^{22}$, who writes of the tendency for lattice-oriented music to be

\footnotetext{
22 Wishart, Trevor. On Sonic Art. Vol. 12. Amsterdam: Harwood Academic Publishers, 1996.
} 
produced by composers in the West, with notated music fixed to the crossing lines of equal-temperament pitch and discrete durational units. 


\section{RELATING RESEARCH FINDINGS TO MY CREATIVE WORK}

To conclude this exegesis, the final section acts as a segue between the subjects covered in the analysis and the original compositions submitted as part of my accompanying portfolio. I will point to aspects of Saariaho's compositional approaches that I have incorporated in the writing of the three works in my portfolio, String Quartet No. 3, The Way Out Is Through for orchestra, and Yōkai for guitar. As stated in the Introduction, spectral music is a stylistically broad approach, where the process by which compositional materials are derived is as much of a defining feature as any kind of similarity between the works that result from this process. I will give a brief description of the processes used to derive my compositional materials, with reference to phenomena such as parametric interaction, formal clarity, foreground ornamentation and the varying degrees of 'spectralist' compositional method in each work.

\section{String Quartet No. 3}

The first of the three works written for my portfolio, String Quartet No. 3 works with the distortion of harmonic spectra. In this case the harmonic spectrum used as a starting point is the harmonic spectrum based $\mathrm{C} 2$, the lowest open string of the cello. A range of new harmonic spectra were then generated through stretching or compressing the constituent frequencies of the original spectrum by various coefficient values, but retaining $\mathrm{C} 2$ as the fundamental pitch. The work then proceeds to move through spectra that are increasingly stretched, until the first climax is reached. The passage of lower tension that follows is made up of a progression of increasingly compressed spectra. The passage from the second climax through to the end of the work consists of a progression of spectra that are once again increasingly stretched.

In establishing the overall form of String Quartet No. 3, I worked with a parametricised plan as outlined by Saariaho $(1987: 107)^{23}$. The end result in String Quartet No. 3, however, is a high amount of parallel parametric change, in which many parameters simultaneously follow the same tensional trajectory. It is interesting to note Cohen and Wagner's findings regarding the perception of

\footnotetext{
23 Saariaho, Kaija. "Timbre and Harmony: Interpolations of Timbral Structures."
} Contemporary Music Review 2, no. 1 (1987): 93-133. doi:10.1080 / 07494468708567055. 
increased musical tension in relation to parametric change, whereby the cognitive load - and, by extension, tension - put onto the listener is actually increased when perceiving parameters moving in divergent tensional directions ${ }^{24}$. Perhaps Saariaho subscribed to this approach with the greater independence of her parametric trajectories. As observed in the analyses of Nymphéa and Du cristal in particular, passages of parametric divergence are employed, producing the muted climactic material found in some sections.

In the general absence of noise-based tensional processes in String Quartet No. 3, I made a conscious effort to use harmonicity/inharmonicity as a dominant source of tension and release in the work. This was achieved by extracting pitch collections from each distorted spectrum that contained intervallic relationships of varying harmonic tension. Also related to the use of inharmonicity in String Quartet No. 3 is my employment of pitch instability (another featured tensional device found in the analysed works), not only through timbral manipulation but through techniques such as glissandi, wide vibrato and extensive trilling that keep the moment-tomoment harmonic material in a near constant state of motion in passages of higher tension.

Though not a new technique in the context of my previous approaches to timbral character in my instrumental writing, Saariaho's timbrally detailed string writing also informed my approach to String Quartet No. 3. Though the timbral character of my string quartet is generally purer than that of Nymphéa, I attempted to instill an internal activity and sense of movement to the pitch material that does not move in a traditionally contrapuntal fashion, by incorporating shifts in bow position.

I also incorporated proto-melodic material as a form of foreground ornamentation in String Quartet No. 3, in the first violin part between bb.64-73. At this point in the work, harmonic density has decreased from the claustrophobic double stopping that initially dominates the work, providing an opportunity for introducing some contrasting performative techniques to the material. I aimed to create active, yet nonteleological foreground ornamentation that sat above the spectral transition gradually unfolding. Saariaho, of course, employs proto-melodic material as

${ }^{24}$ Cohen, Dalia, and Naphtali Wagner. "Concurrence and Nonconcurrence between Learned and Natural Schemata:The Case of J. S. Bach's Saraband in C Minor for Cello Solo." Journal of New Music Research 29, no. 1 (March 2000): 23. 
foreground ornamentation in Nymphéa - for example, in the violin's fragmented ascending runs in the first section of the work.

\section{The Way Out Is Through \\ for orchestra}

While the pitch material of String Quartet No. 3 is derived from a series of distortions applied to harmonic spectra, the pitch material for The Way Out Is Through comes from a more literal transcription of inharmonic spectra evolving through time (Fig 3.1). The sound source is a controlled swell played on a 22-inch ride cymbal, in which amplitude moves from very low to very high, with the cymbal then left to vibrate until any remaining sound was virtually inaudible. Two microphones were used to record the swell, with one microphone positioned above the cymbal and the other positioned directly underneath. The use of two vantage points for capturing the sound of the swell is due to the difference in the range of frequencies that project from the upper side of the cymbal in comparison to the underside (the underside projects lower frequencies far more strongly than the upper side). A spectral peak analysis was then performed at 13 different sample points during both microphone recordings, comprehensively covering the arc of the swell, with the ten strongest frequencies of each sample analysis rounded to the nearest quarter-tone (any frequencies that lay outside of the range of orchestral instruments was omitted).

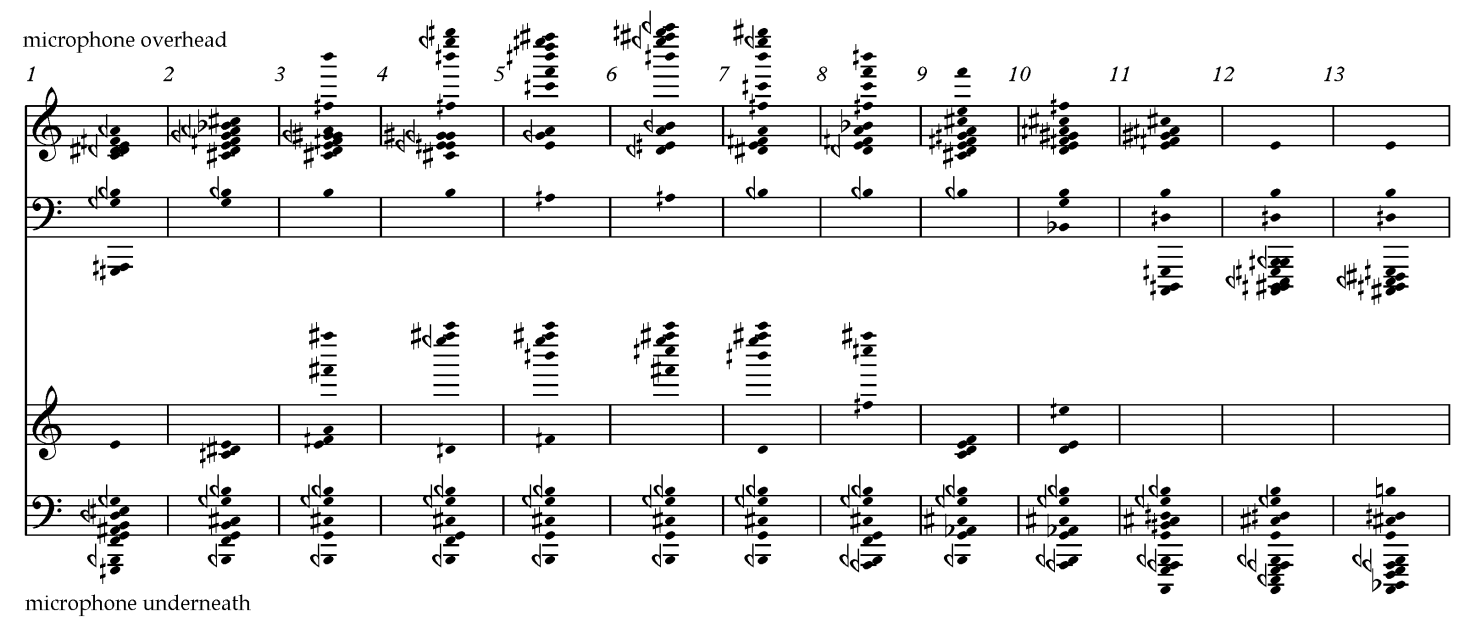

Ex. 3.1. Pitch material used for The Way Out Is Through, extracted from spectral peak analysis of a ride cymbal swell.

The form of The Way Out Is Through is clearly an extended arc-like tensional trajectory, based on the energy profile of the cymbal swell, with a brief percussion 
interlude momentarily interrupting the process at its tensional peak. I employ several techniques found in the analysed Saariaho works to provide microstructural interest while long-term processes unfold beneath.

As with String Quartet No. 3, parallel parametric changes dominate the first section of The Way Out Is Through, following a strict process that applies brief moments of "swelling" to several parameters, in a microstructural swell figure that interrupts the low-tension, more timbrally detailed material that dominates. Brief, parallel increases in dynamic profile, registral spread and harmonic density comprise these swells, along with a purer timbral quality, as the strings revert to naturale bow positions. Even the low-tension material contains small-scale swells in dynamic profile, though these swells are not synchronized across the orchestra. This material and the more synchronized multi-parameter swells gradually grow in intensity over several minutes to reach a tensional peak at the mid-point of the work (echoing the peak of the ride cymbal swell).

Changes in registral spread in The Way Out Is Through echo that of the cymbal swell, with the widest spread occurring at the peak of the swell (tutti material at bb.56-74) and pitches in the bass register dominating the decay of the swell. For climactic effect, the first half of the work employs a gradual expansion in registral spread that begins with a small cluster of mid-register pitches, omitting pitches in the bass register at the onset of the swell, introducing them once the controlled expansion of registral spread eventually encompasses them.

Again, while not a new technique in the context of my previous compositional output, I have added short-term timbral changes to slowly developing material, adding microstructural life and activity as described in the Introduction. This takes the form of constantly changing bow positions in the string parts of The Way Out Is Through. These oscillating bow positions often coincide with dynamic surges, creating a more marked timbral transformation, with the string player having to apply more bow pressure to achieve a given dynamic when playing in the somewhat counterproductive sul tasto position, as found in the first half of the work.

I employ parametric synchronization of the whole orchestra as a point of arrival in The Way Out Is Through, with the orchestra briefly uniting for three thick, high amplitude chords at bb.69-73, with all players entering on the same beat, before sliding back into the staggered, arhythmic surges that form the foundation of the work. Parametric synchronization, and particularly rhythmic synchronization, is the 
primary parametric device used by Saariaho to herald a significant formal point of arrival in her works, particularly in Nymphéa and Du cristal.

Pitch instability is incorporated as a tensional device, particularly in the high-tension final bars of the first section (bb.51-60), with trilling, wide vibrato, fluttertongue and glissandi featuring strongly. As mentioned in the description of String Quartet No. 3, this tensional device found in each of the selected Saariaho works helps to keep moment-to-moment pitch and harmony in a near constant state of motion in passages of higher tension.

Snatches of non-teleological foreground ornamentation of the kind observed in $D u$ cristal are also employed in the latter half of The Way Out Is Through, with polyrhythmic material in the pitched percussion and harp parts sitting atop sustained string lines sliding to pitches within new harmonic fields, with more extended durations applied to the subtle dynamic surges from the woodwind and brass sections.

\section{Yōkai}

for guitar

In a departure from the analysis-based sourcing of pitch material used for the two preceding works, the handful of harmonic fields used in Yōkai were created by adding pitches around those used for the work's motivic material. One of the objectives of writing Yōkai was to work with pitches of fixed register, whereby each pitch class within a harmonic field rarely appears in more than one register. This approach can result in modal instability as any given octave range within a harmonic field seems to suggest a different scale or mode. Yōkai also differs from the other two works in my portfolio for its exclusive use of equal-tempered pitches.

While the tensional processes in Yōkai are predominantly driven by changes in the dynamic profile and inharmonicity parameters, Yōkai is the only portfolio work in which I employed an audibly accelerating rate of harmonic change as a tensional device. This occurs during the work's final climactic passage, from bb.77-101, with its shifting between fragments or elaborations of earlier motivic material and harmonic fields. Here, the harmonic flux in the final section of Cendres provided an influence to embrace more agile harmonic restlessness. 
To provide moments of contrast to the fixed register pitch organisation in Yōkai, ascending and descending runs found throughout the work incorporate pitches and pitch transpositions from outside the underlying harmonic field. This device is observed in Cendres, particularly in the piano's ascending runs that seem to act as a type of 'chromatic refresher', or contributor of additional harmonic tension, superimposed over the underlying harmonic field.

Form is perceivable in Yōkai as much through literal repetition of motivic material as through tensional trajectories, a departure from the dominance of tensional trajectories in the perception of form in Nymphéa and Du cristal and, again, more reminiscent of Cendres, which employs some literal repetition of material. 


\section{BIBLIOGRAPHY}

Berry, Wallace. Structural Functions in Music. Englewood Cliffs, N.J: Prentice-Hall, 1976.

Cohen, Dalia, and Naphtali Wagner. "Concurrence and Nonconcurrence between Learned and Natural Schemata:The Case of J. S. Bach's Saraband in C Minor for Cello Solo." Journal of New Music Research 29, no. 1 (March 2000): 23.

Danner, Gregory. “The Use of Acoustic Measures of Dissonance to Characterize PitchClass Sets." Music Perception: An Interdisciplinary Journal 3, no. 1 (October 1, 1985): 103-22. doi:10.2307/ 40285324.

Dibben, Nicola. "The Perception of Structural Stability in Atonal Music: The Influence of Salience, Stability, Horizontal Motion, Pitch Commonality, and Dissonance." Music Perception: An Interdisciplinary Journal 16, no. 3 (April 1, 1999): 265-94. doi:10.2307/40285794.

Farbood, Morwaread M. "A Parametric, Temporal Model of Musical Tension." Music Perception: An Interdisciplinary Journal 29, no. 4 (April 1, 2012): 387-428. doi:10.1525/mp.2012.29.4.387.

Fineberg, Joshua. “Spectral Music.” Contemporary Music Review, 19, no. 2 (August 2000): 15. doi:10.1080/07494460000640221.

Granot, Roni Y., and Zohar Eitan. "Musical Tension and the Interaction of Dynamic Auditory Parameters." Music Perception: An Interdisciplinary Journal 28, no. 3 (February 1, 2011): 219-46. doi:10.1525/mp.2011.28.3.219.

Howell, Tim, Jon Hargreaves, and Michael Rofe. Kaija Saariaho: Visions, Narratives, Dialogues. Burlington, VT, Farnham, Surrey: Ashgate, 2011.

Huron, David. "Interval-Class Content in Equally Tempered Pitch-Class Sets: Common Scales Exhibit Optimum Tonal Consonance." Music Perception: An Interdisciplinary Journal 11, no. 3 (April 1, 1994): 289-305. doi:10.2307 / 40285624.

Johnson-Laird, Phil N., Olivia E. Kang, and Yuan Chang Leong. “On Musical Dissonance." Music Perception: An Interdisciplinary Journal 30, no. 1 (September 1, 2012): 19-35. doi:10.1525/mp.2012.30.1.19. 
Lerdahl, Fred. “Calculating Tonal Tension.” Music Perception 13, no. 3 (1996): 319-63.

Metzer, David. Musical Modernism at the Turn of the Twenty-First Century. Cambridge, New York: Cambridge University Press, 2009.

Murail, Tristan. "Spectra and Sprites." Contemporary Music Review 24, no. 2-3 (April 1, 2005): 137-47. doi:10.1080/07494460500154806.

Plomp, R. \& Levelt, W.J.M. "Tonal Consonance and Critical Bandwidth." Journal of the Acoustical Society of America 38 (1965): 548-560.

Pousset, Damien, Joshua Fineberg, and Ronan Hyacinthe. “The Works of Kaija Saariaho, Philippe Hurel and Marc-André Dalbavie — Stile Concertato, Stile Concitato, Stile Rappresentativo." Contemporary Music Review 19, no. 3 (January 1, 2000): 67-110. doi:10.1080/07494460000640371.

Reigle, Robert, and Paul Whitehead (eds.). Spectral World Musics: Proceedings of the Istanbul Spectral Music Conference. 1st ed. Istanbul: Pan Yayınc1lık, 2008.

Rose, François. "Introduction to the Pitch Organization of French Spectral Music." Perspectives of New Music 34, no. 2 (July 1, 1996): 6-39. doi:10.2307 / 833469.

Roy, Stéphane. "Functional and Implicative Analysis of Ombres Blanches." Journal of New Music Research 27, no. 1-2 (June 1, 1998): 165-84. doi:10.1080/09298219808570743.

Saariaho, Kaija. “Timbre and Harmony: Interpolations of Timbral Structures.” Contemporary Music Review 2, no. 1 (1987): 93-133. doi:10.1080 / 07494468708567055.

Sethares, W. A. “Relating Tuning and Timbre." Experimental Musical Instruments 9, no. 2 (1993): 23-30.

Wishart, Trevor. On Sonic Art. Vol. 12. Amsterdam: Harwood Academic Publishers, 1996. 


\section{DISCOGRAPHY}

Saariaho, Kaija. Cendres. Wolpe Trio, Kaija Saariaho: Chamber Music. Kairos 0012412KAI (2004) CD.

Saariaho, Kaija. Du Cristal. Los Angeles Philharmonic Orchestra/Esa Pekka-Salonen, Kaija Saariaho: Works for Orchestra. Onedine ODE1113-2Q (1993) CD.

Saariaho, Kaija, Nymphéa. Kronos Quartet, CD. Kaija Saariaho - Los Angeles Philharmonic Orchestra, Esa-Pekka Salonen; Kronos Quartet; Petri Alanko, Anssi Karttunen - Du cristal ...à la Fumée / Nymphéa. Onedine ODE 804-2 (1989) CD. 
APPENDIX 
String Quartet No.3

Brad Jenkins 



\title{
String Quartet No. 3
}

\author{
Duration $8^{\prime} 30^{\prime \prime}$
}

\section{Performance notes}

Change bow direction ad lib during long tied passages. Players should not try to synchronize bowing unless the ensemble shares a crescendo. All pitches connected by a slur, including those that occur within double stops, should be played as legato as possible.

All glissandi start at the beginning of the note on which they are notated.

All bowed tremolo are to be played as fast as possible.

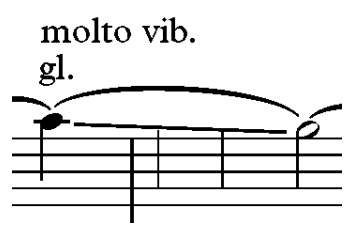

Strong vibrato to be used, producing a wavering in pitch while performing glissando.

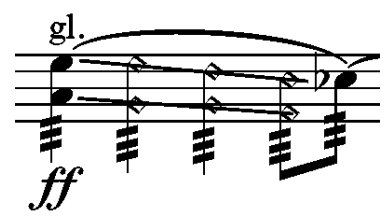

Touch harmonic pressure to be used on the string between beginning and end points of glissando. 

$d=69$ Con moto
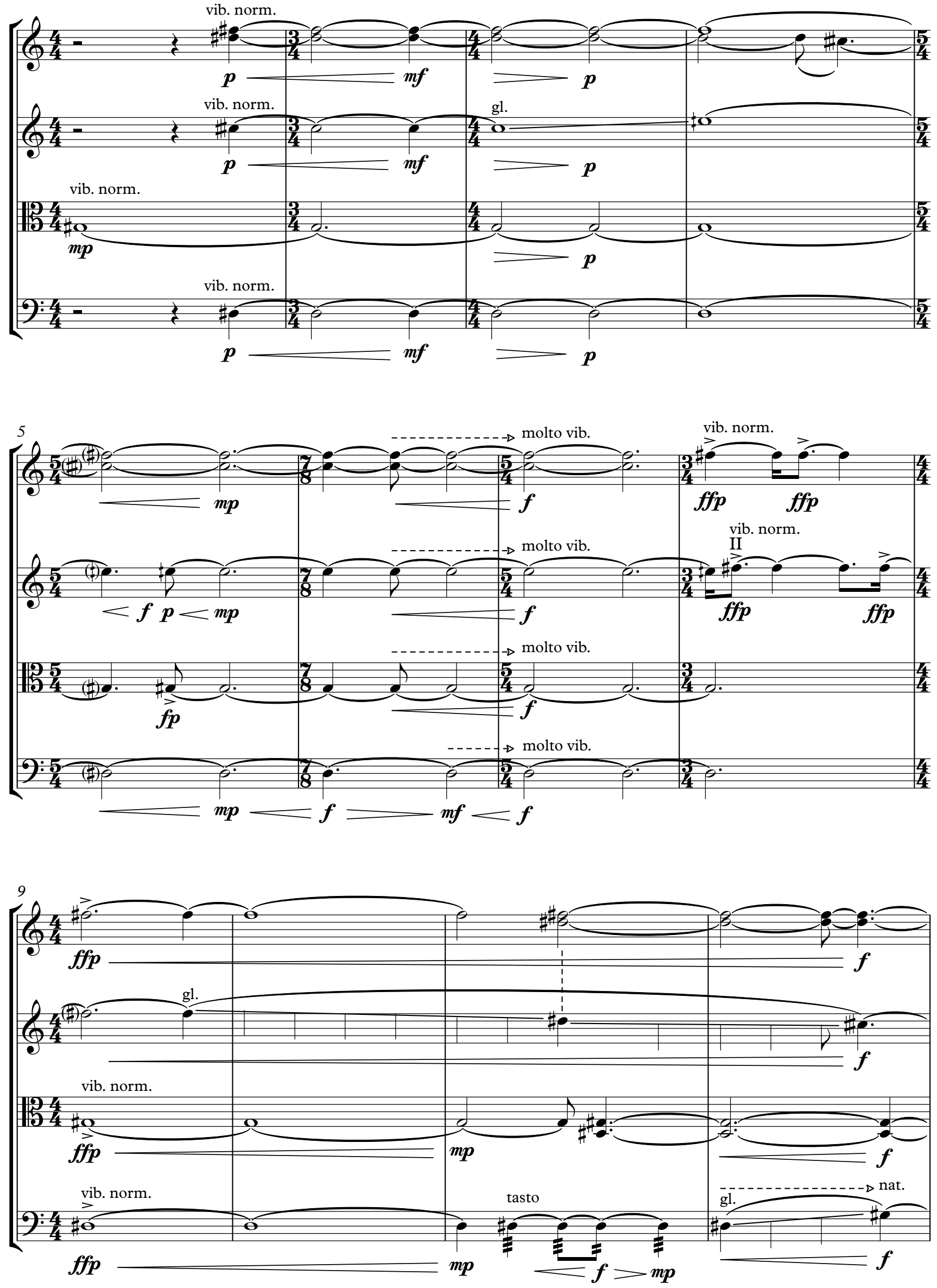

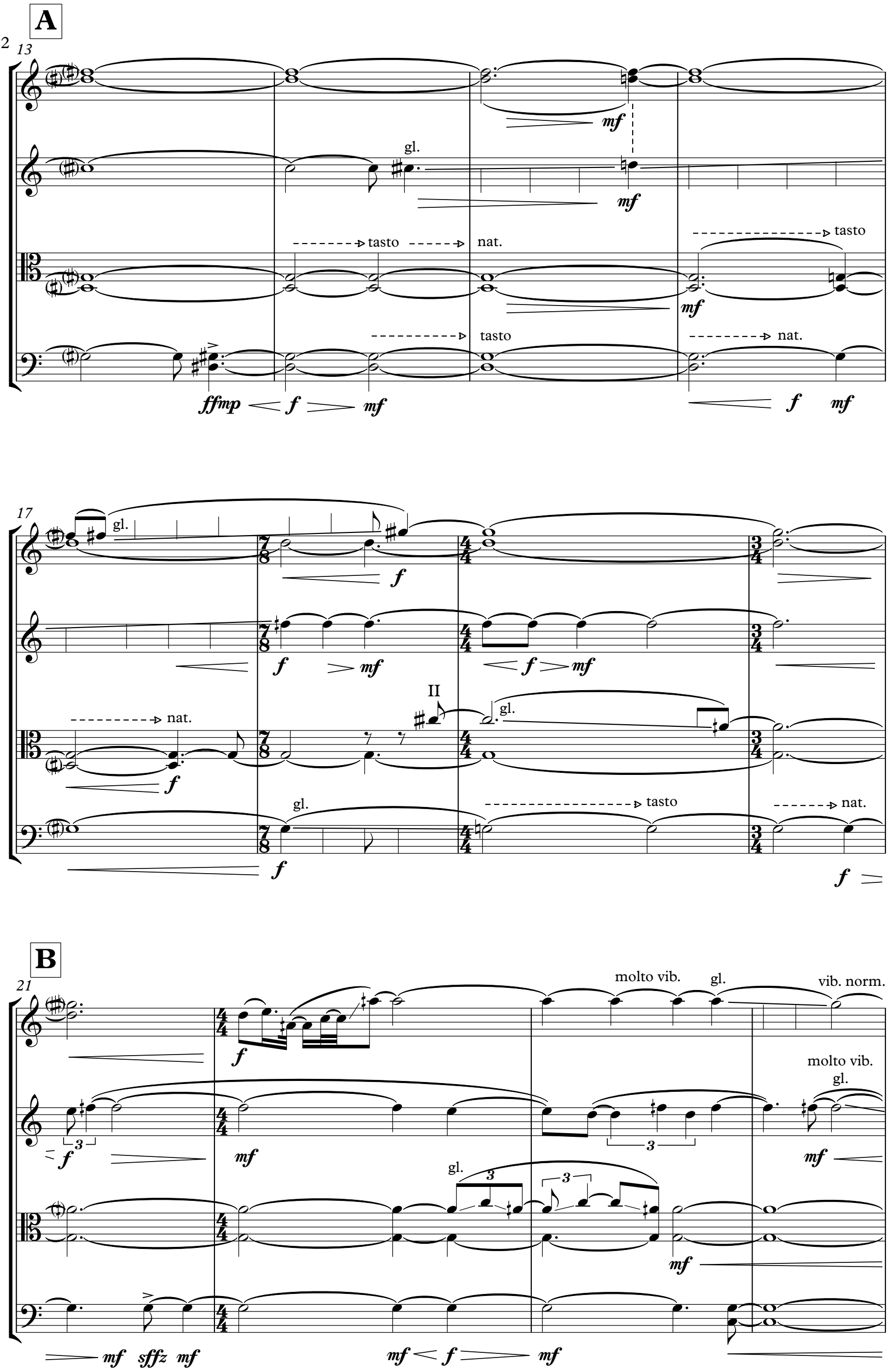


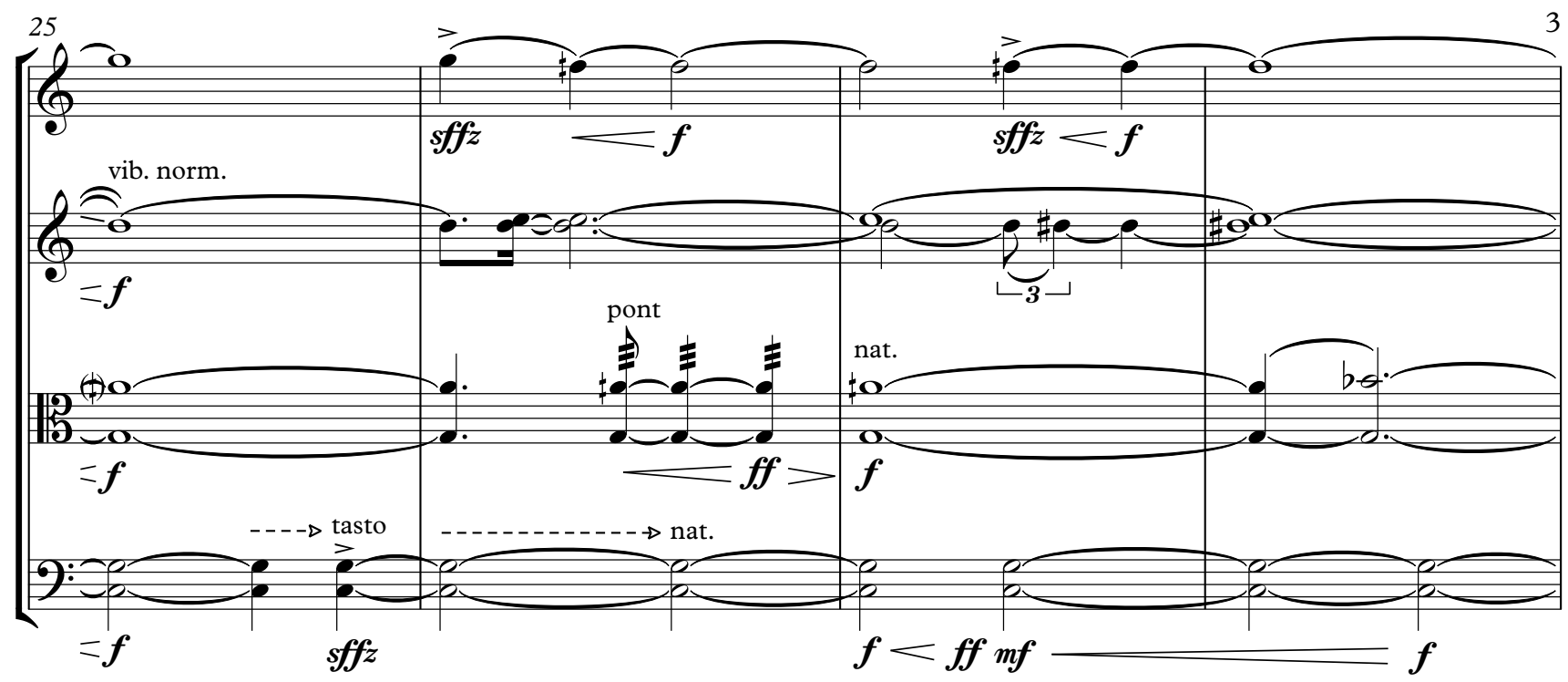

C

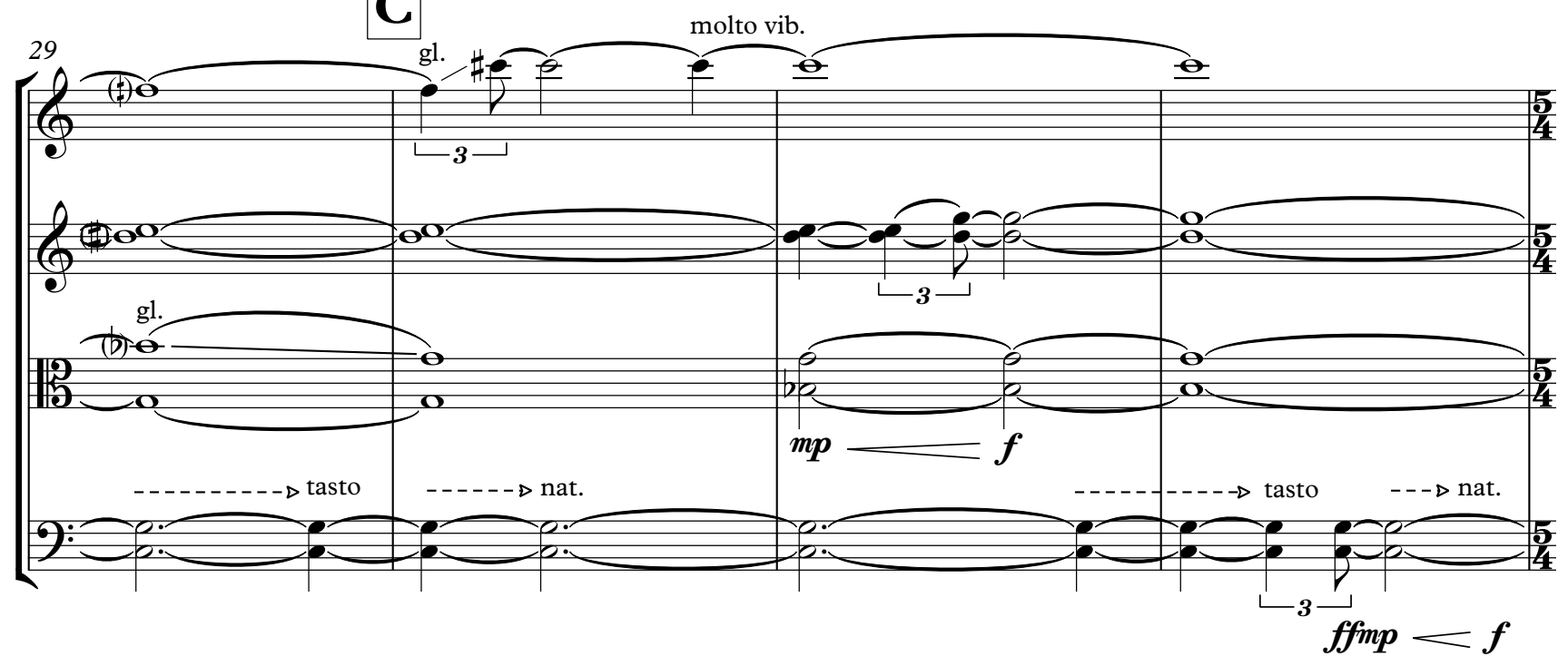

vib. norm.

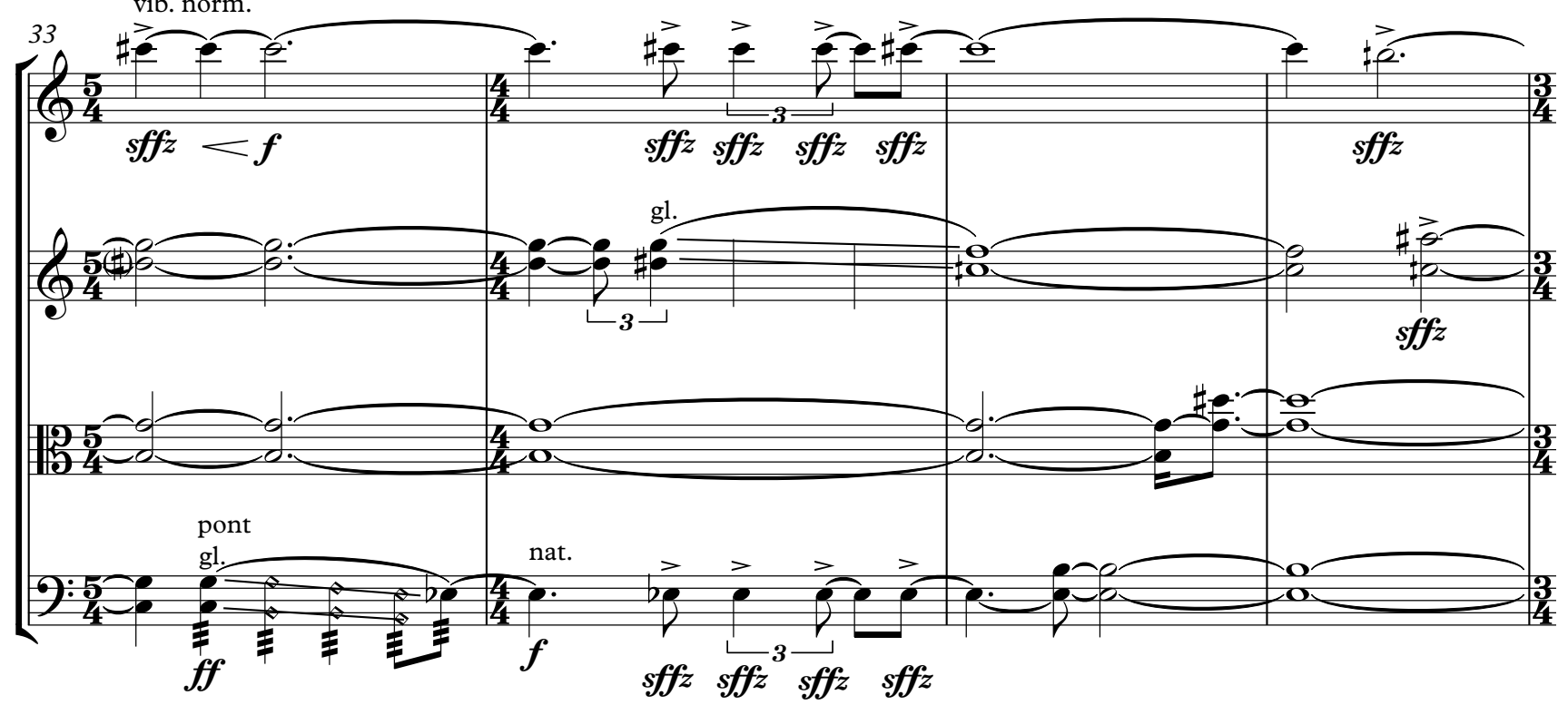


D
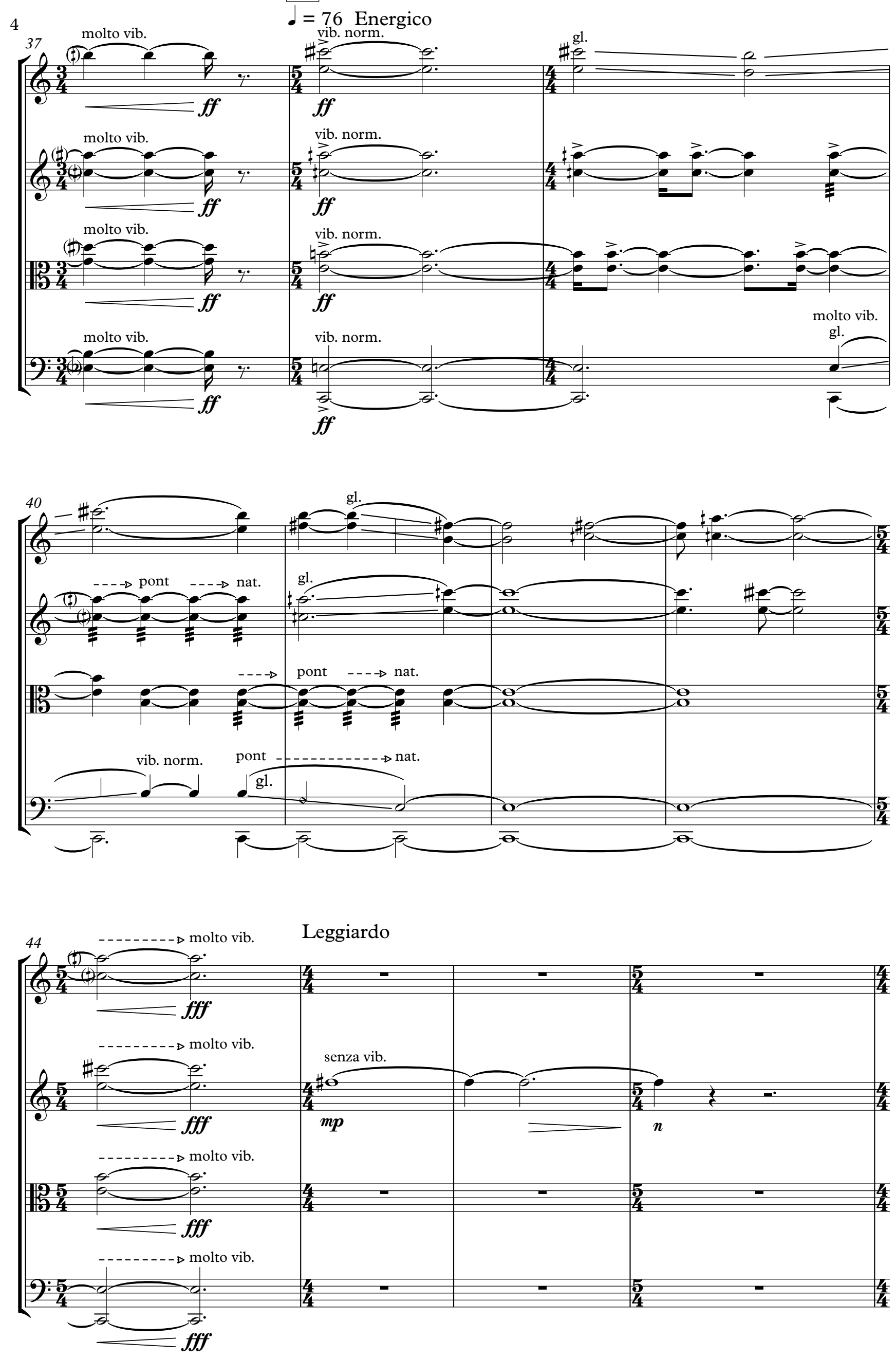

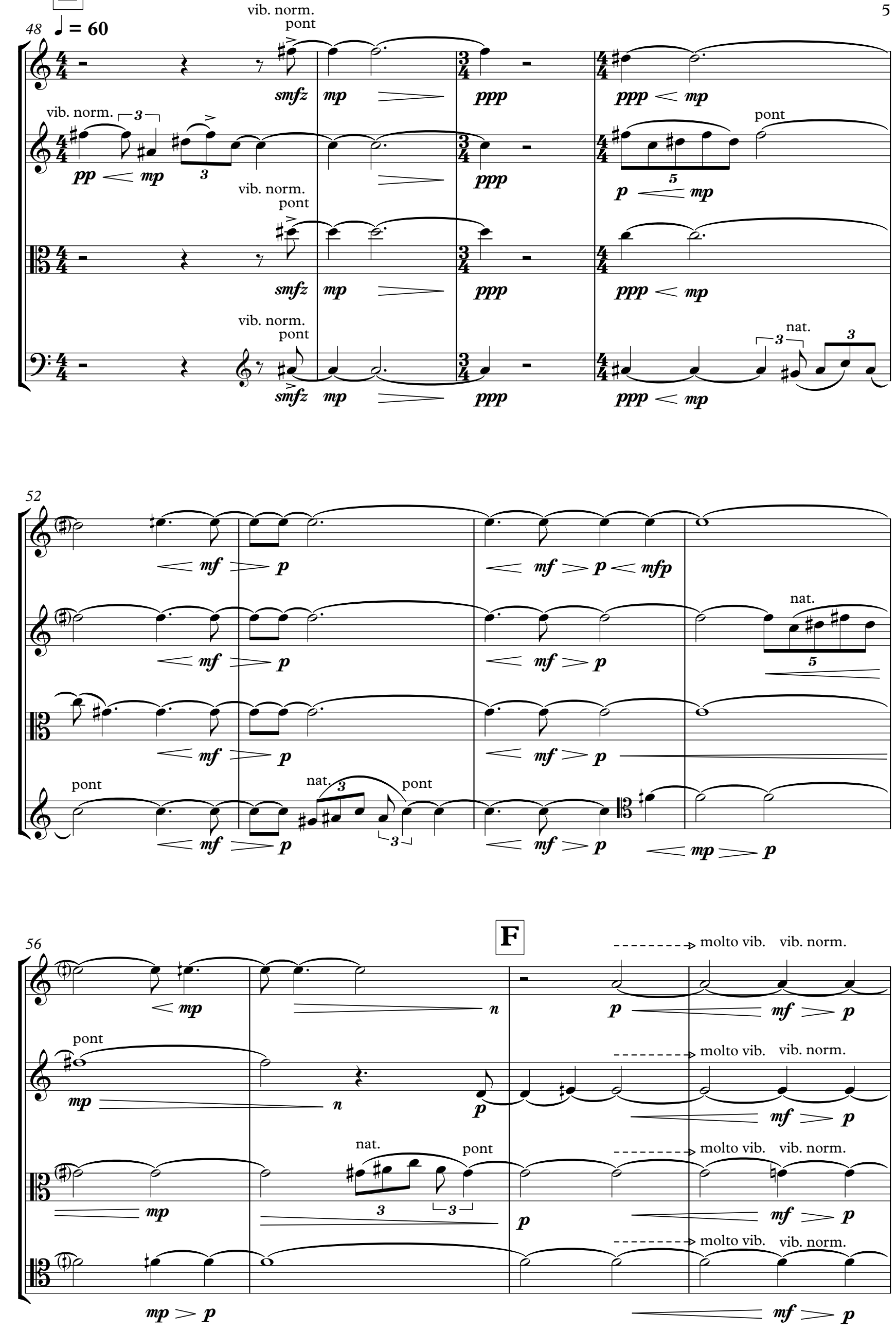

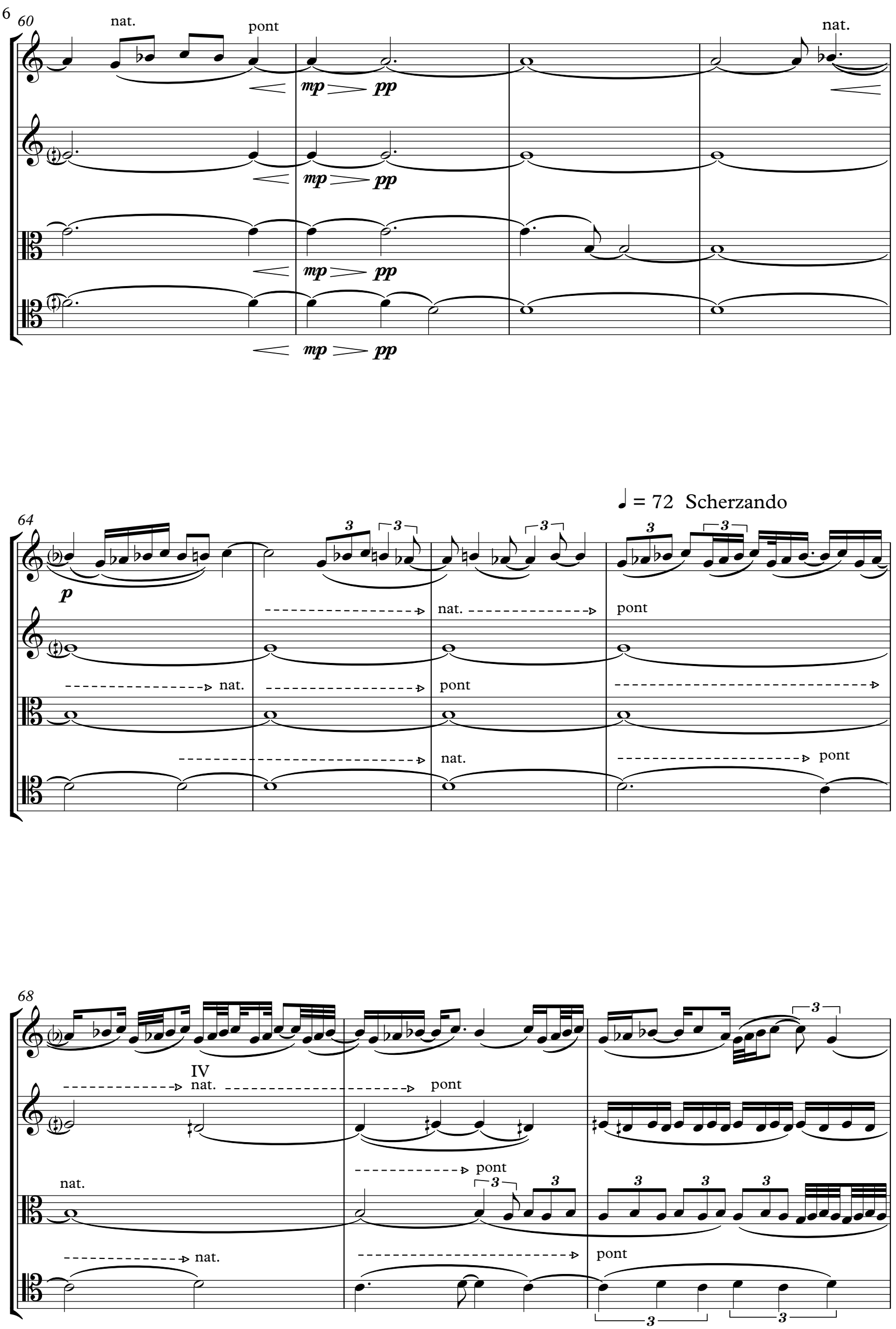


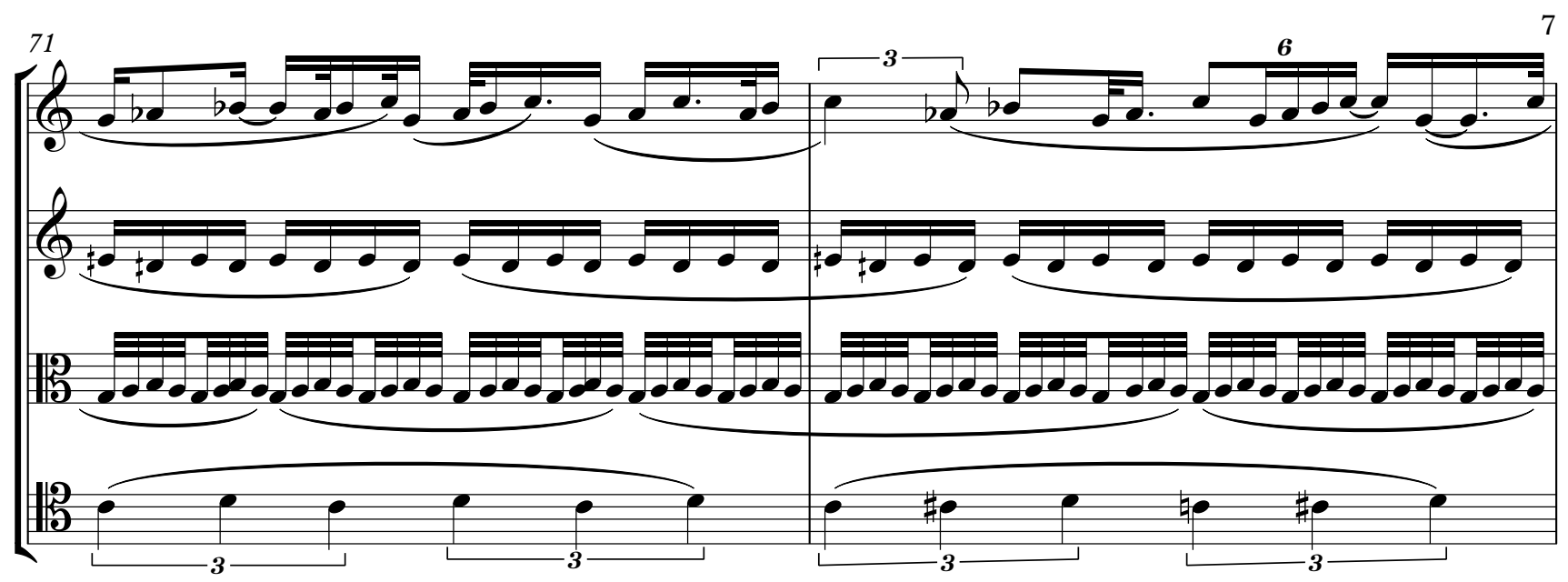

G
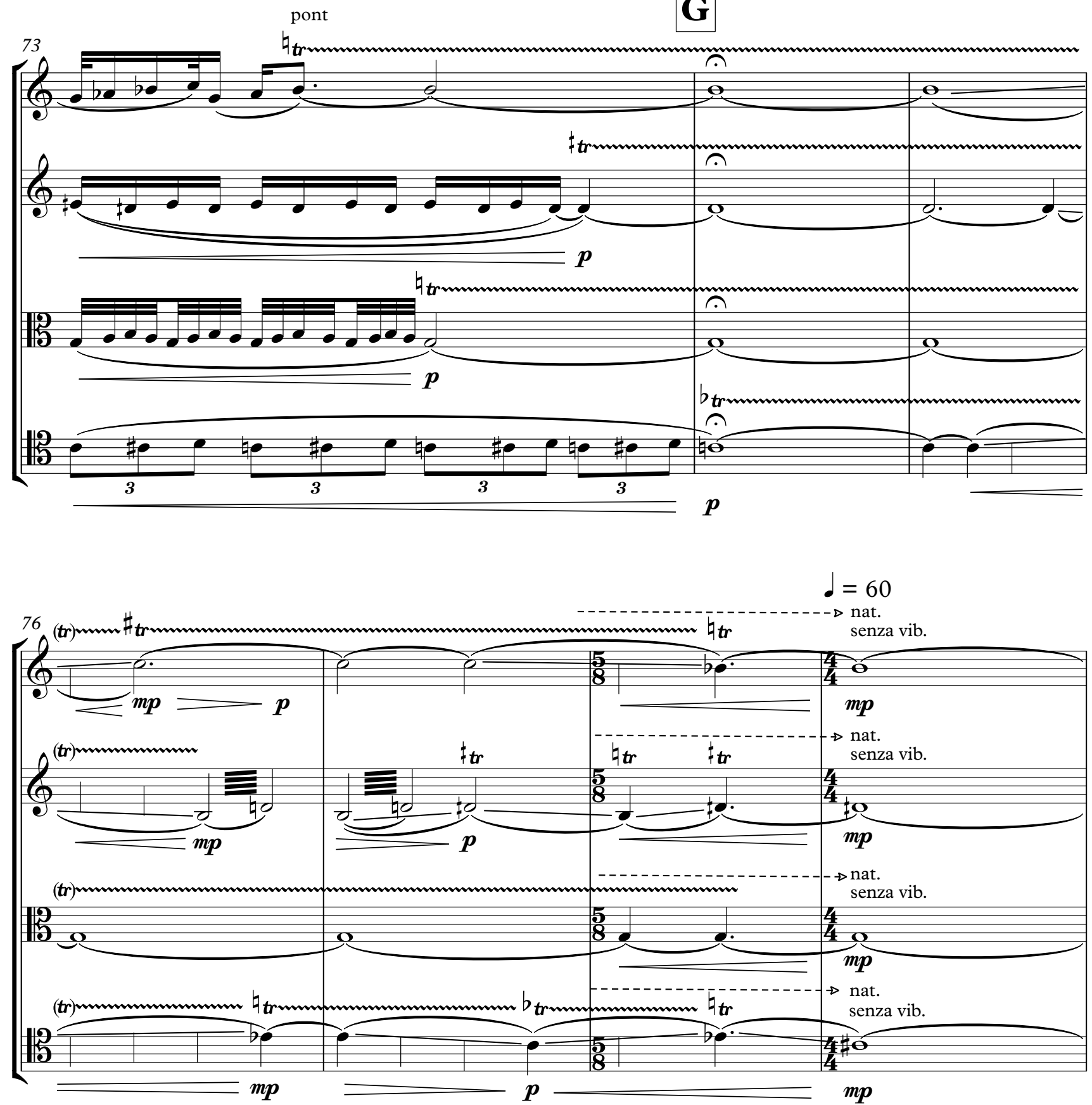

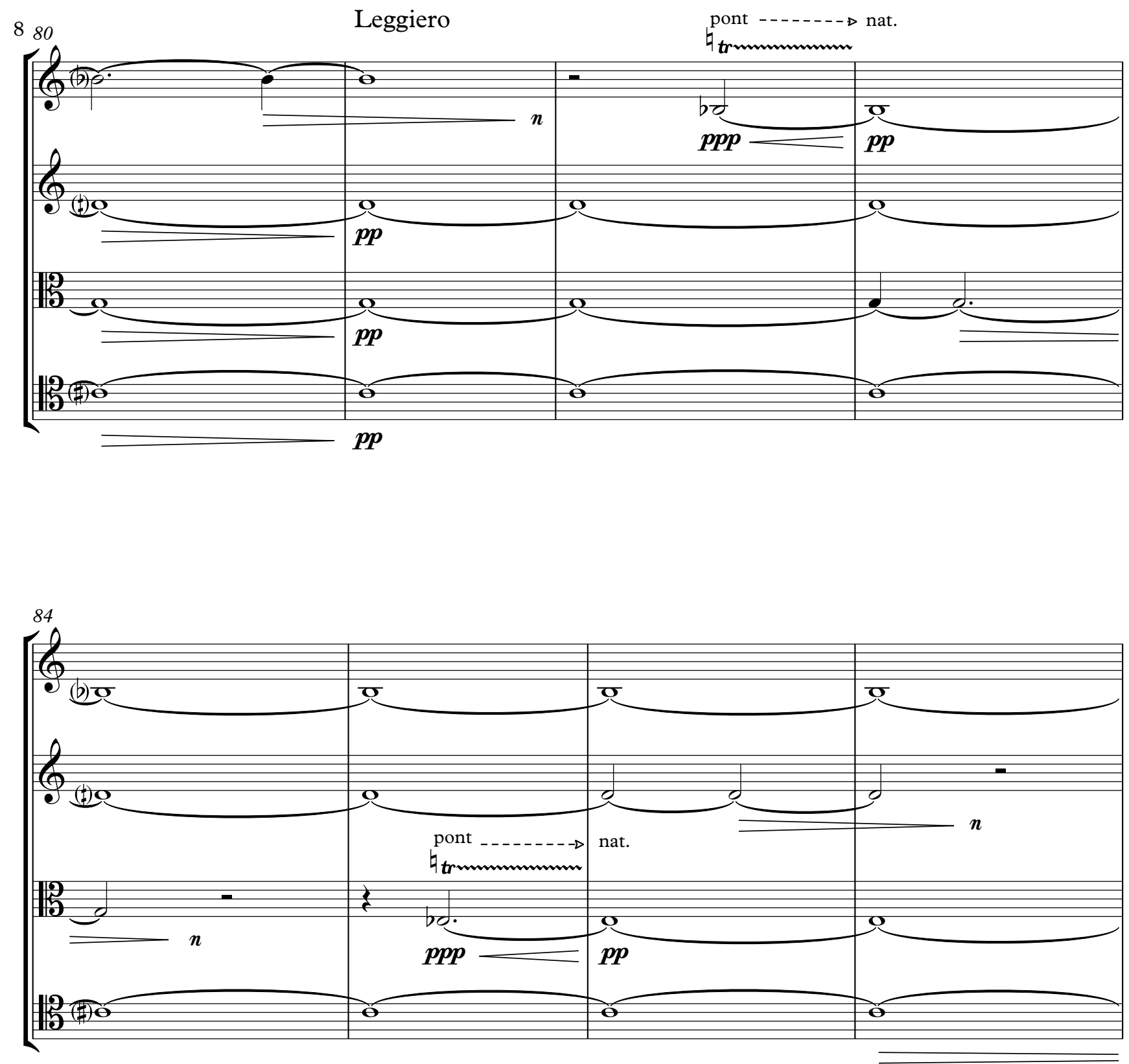

H

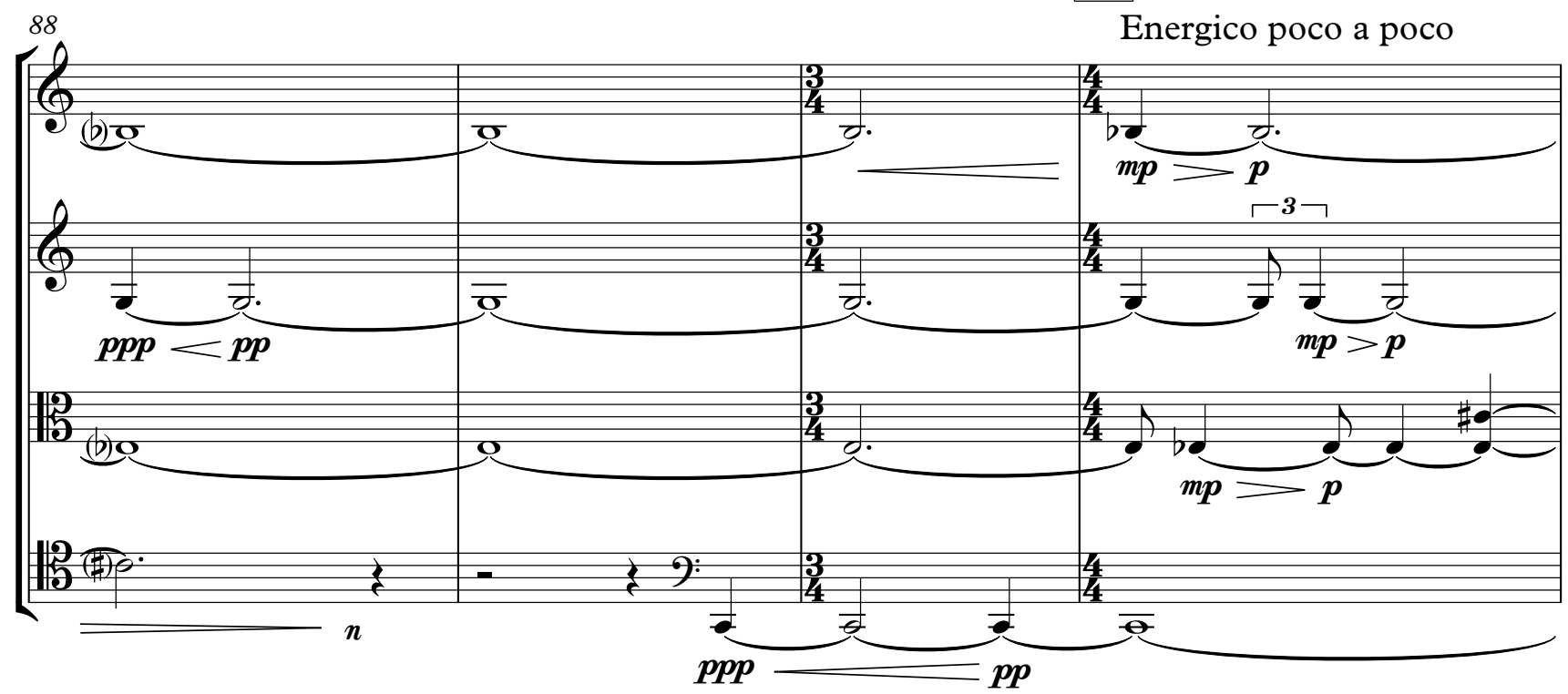



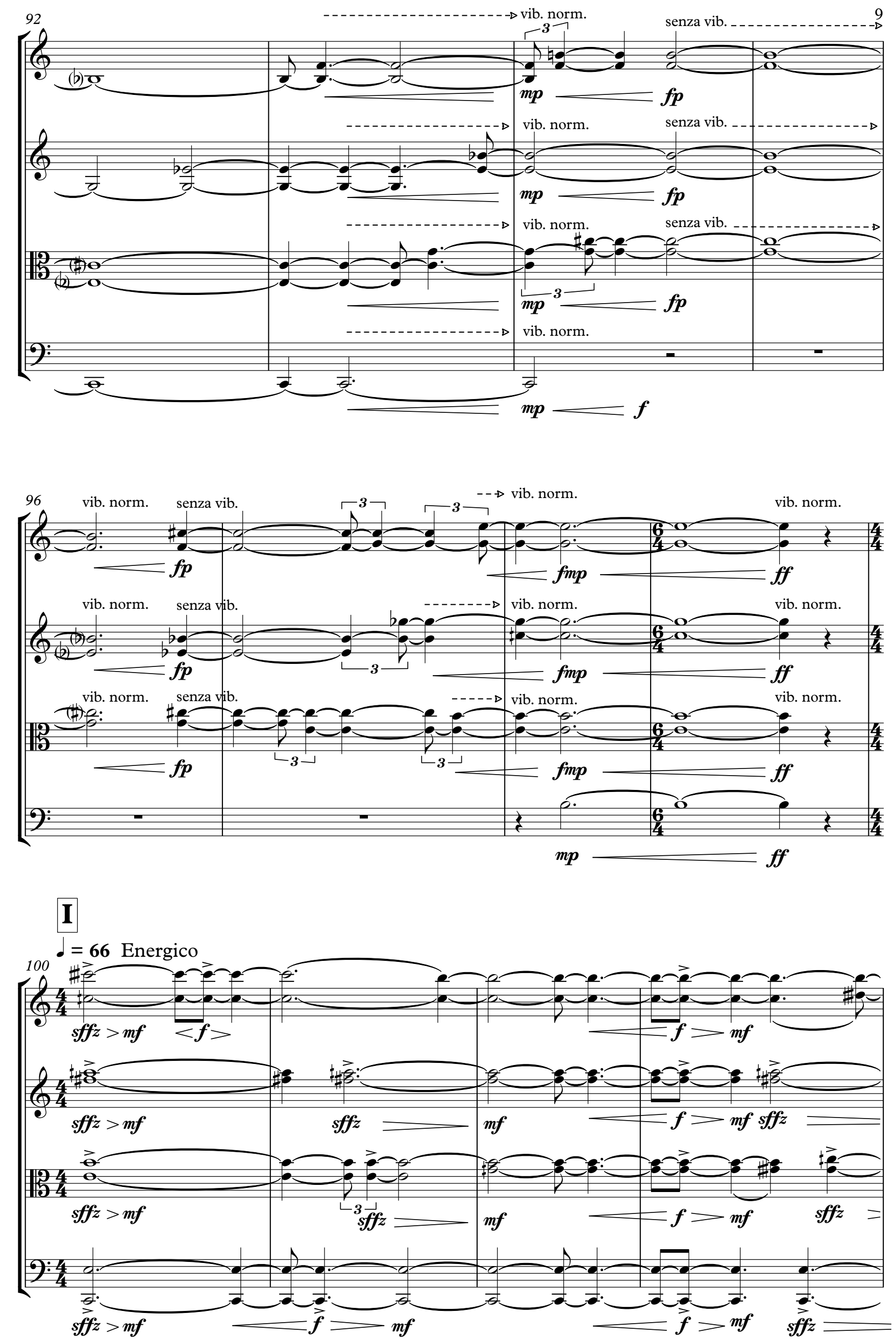
Energico, furioso

poco accel. .
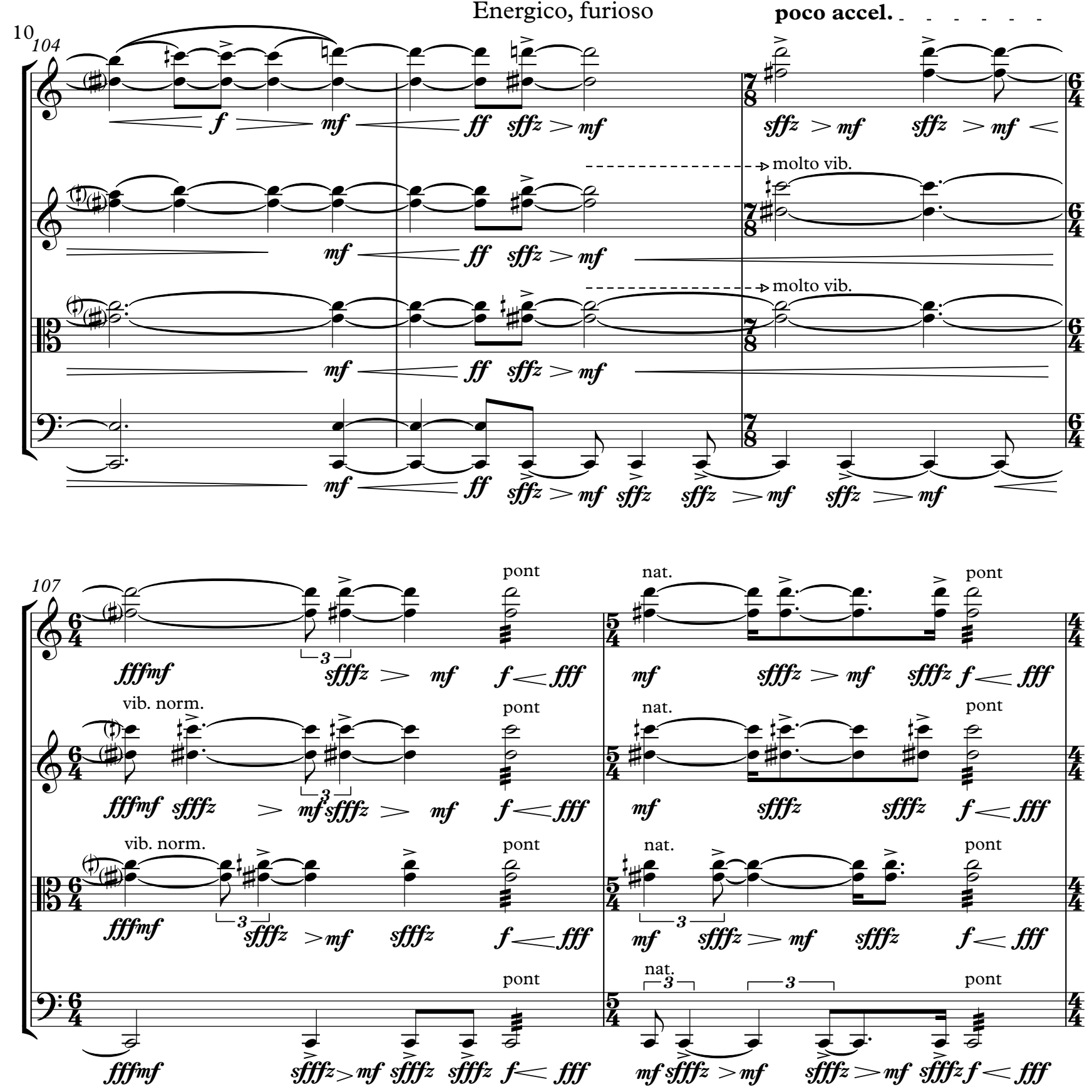

$\mathrm{J} d=66$ Grazioso

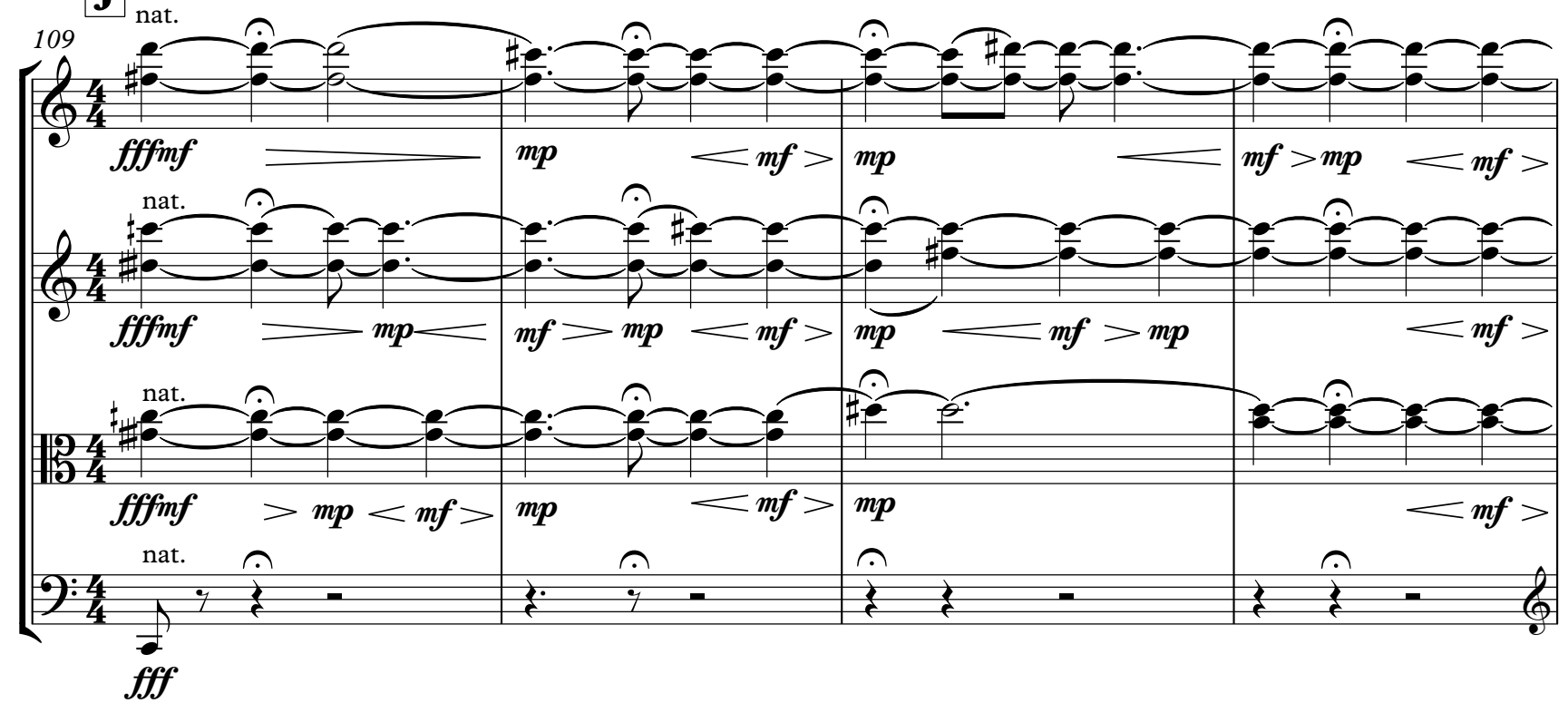



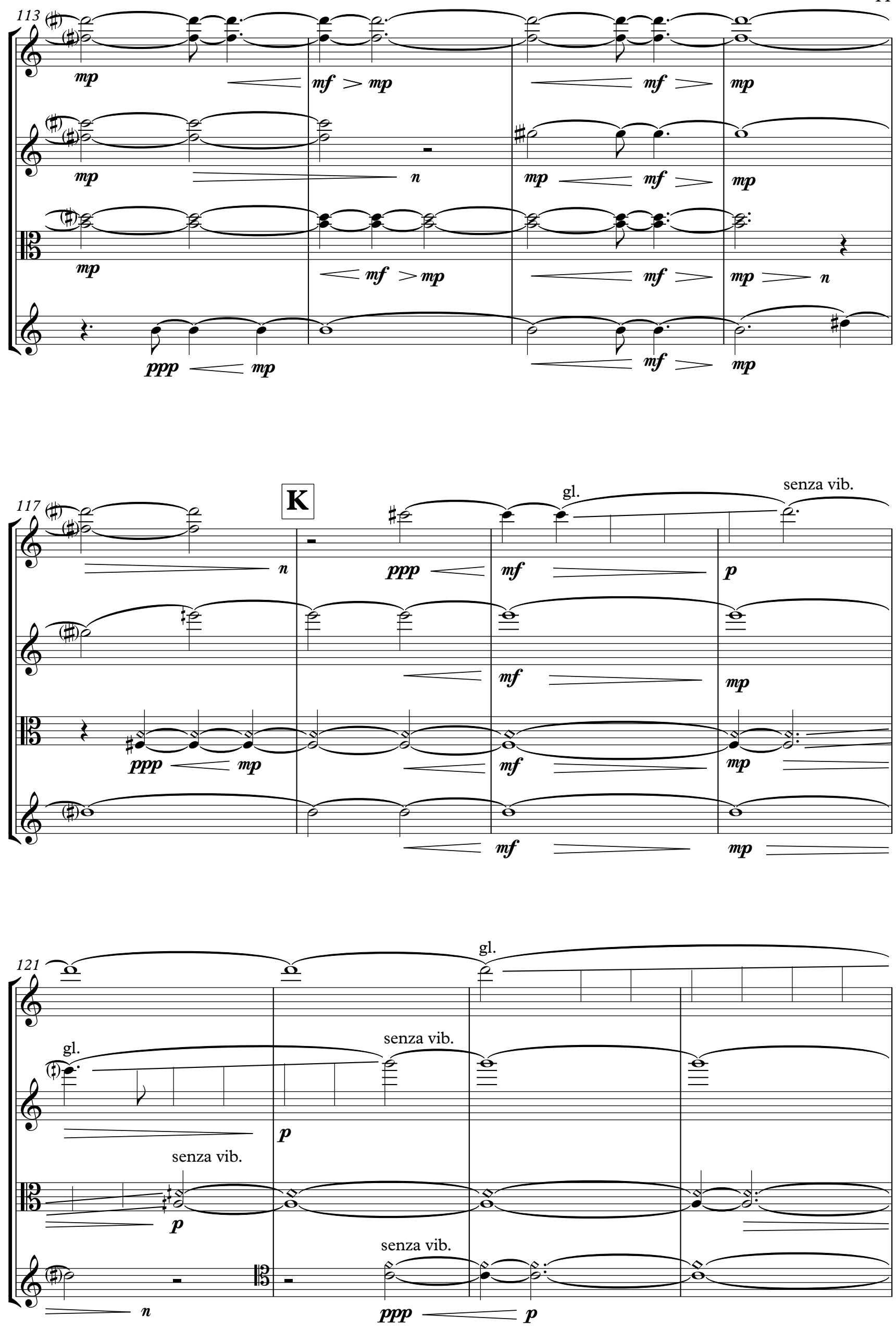

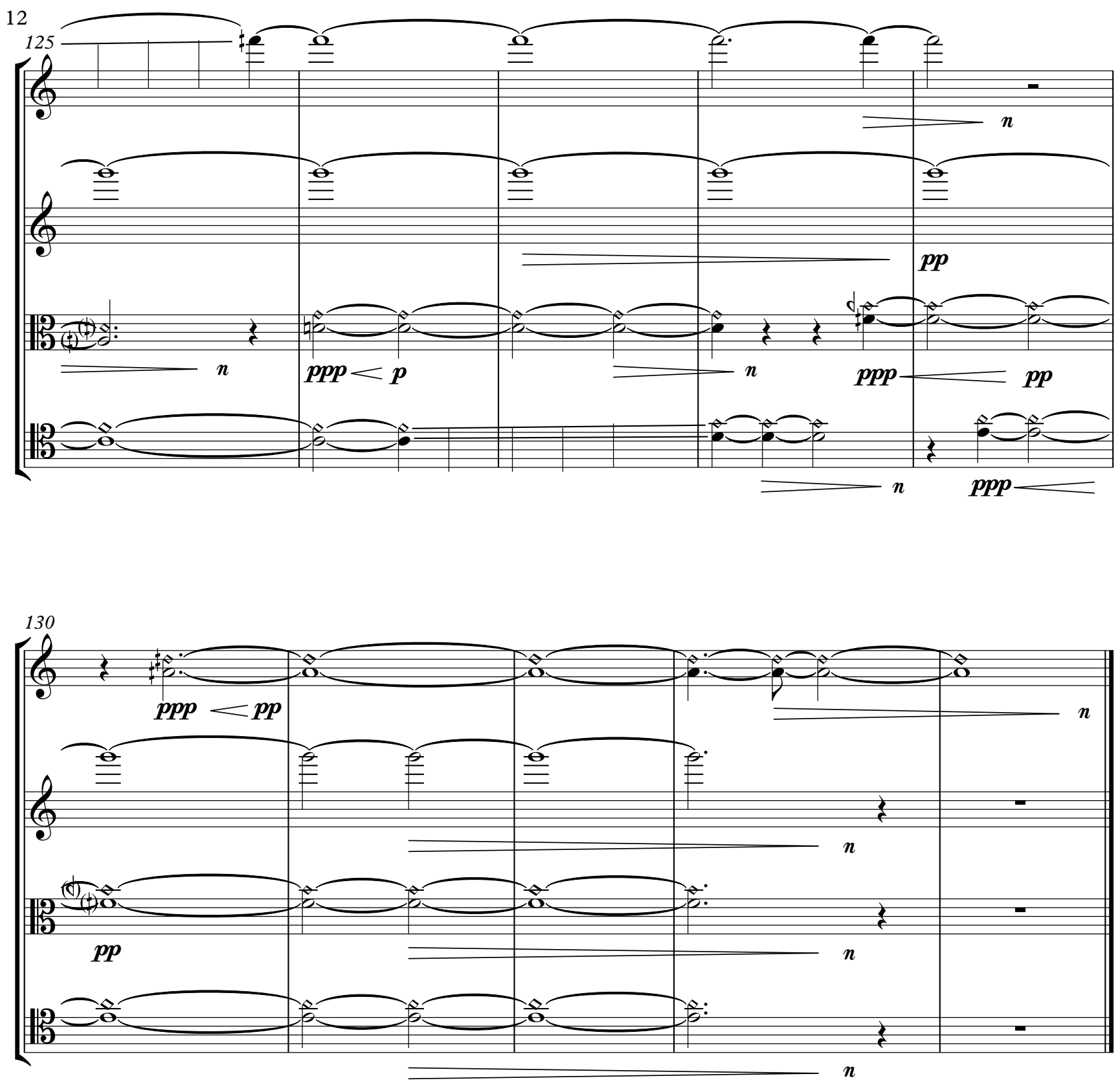


\section{The Way Out Is Through}

for orchestra

Brad Jenkins 



\title{
The Way Out Is Through
}

Duration 9'

\section{Instrumentation}

\author{
3 flutes (1 piccolo double) \\ 3 oboes \\ 3 clarinets in B-flat \\ 3 bassoons (1 contrabassoon double) \\ 4 horns in $\mathrm{F}$ \\ 3 trumpets in $\mathrm{C}$ \\ 2 tenor trombones \\ bass trombone \\ tuba
}

3 percussion

(32", 28" and 25" timpani, marimba, glockenspiel, vibraphone,

2 suspended cymbals, triangle, bass drum, tam-tam)

harp

strings 


\title{
Performance notes
}

\section{General}

\author{
Transposed score \\ $\$$ Play the notated pitch a quarter-tone sharp. \\ Play the notated pitch a quarter-tone flat.
}

Trills on all instruments are to be of a semitone interval. It is at the player's discretion as to whether the trill uses the pitch a semitone above or below the main pitch. For trills occurring on quarter-tones, players are free to use either a quarter-tone or semitone trill.

All glissandi start at the beginning of the note on which they are notated.

Where glissando lines do not lead to a destination pitch, the player is free to decide on the destination pitch of the glissando, though the glissando should continue for the entire notated duration and not stop prematurely. Trombonists may want to give themselves maximum possible slide length for glissandi by playing starting pitches at the lowest available position.

\section{Percussion}

Marimba is to be played with soft and hard mallets as indicated.

Tremolo in the marimba, timpani, tam-tam and bass drum parts indicate unmeasured rolls.

The two suspended cymbals should be of differing sizes, so that a timbral difference between the two is audible.

Suspended cymbals are to be played with mallets.

Tam-tam is to be played with standard tam-tam beater.

Triangle is to be played with a standard beater.

Beater for the bass drum is at the player's discretion.

Glockenspiel is to be played with brass mallets.

Mallets for the vibraphone are at the player's discretion. 


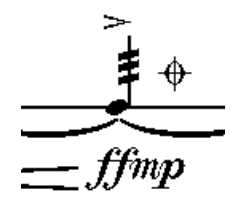

The indicated dynamic expression is to be achieved by quickly grabbing the cymbal with the hand following the cymbal swell so that the cymbal continues to sound but the amplitude of the swell is quickly reduced. An alternative to this method is to use the mallet heads to dampen the cymbal.

\section{Strings}

$\longrightarrow$ tasto $\longrightarrow$ nat.

Player is to gradually change between the indicated bowing positions.

All bowed tremolos are to be played as fast as possible.

min

Play with very wide vibrato for the duration covered by the vibrato line.

\section{Harp}

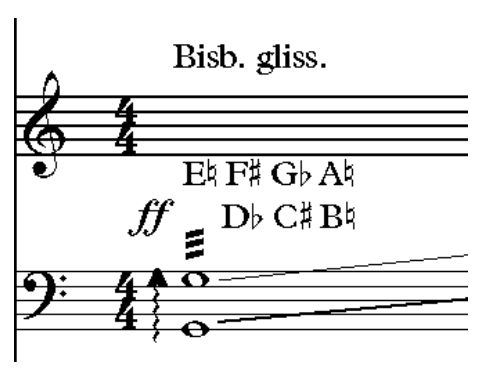

Moving bisbigliando glissando - play several fast glissandi one after another with alternating hands. The fingers slide over the indicated interval as it moves upwards in register.

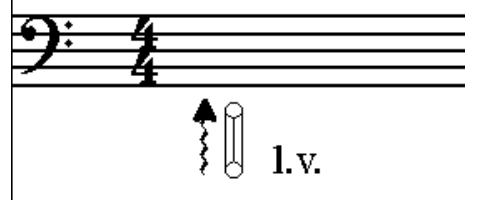

Thunder glissando - a single fast and loud glissando played by the left hand on the lowest strings of the harp. The strings are played forcefully so that they rattle against one another creating a metallic thunder-like sound. 

• = 44 Delicato
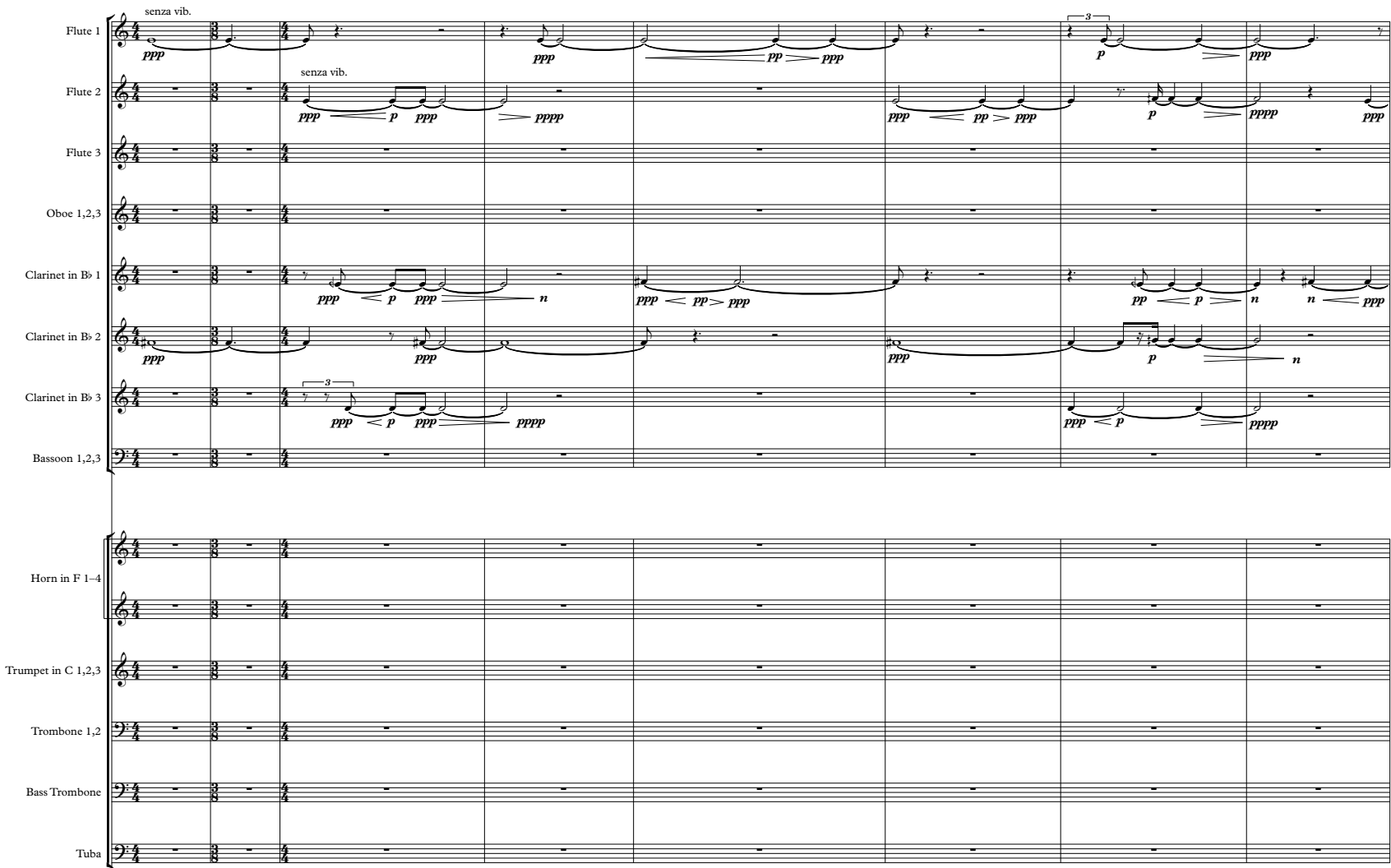

Perc. 1

Perc. 2 Sus. Cymbal

Marimba
Soft mallets

$\frac{1}{p p p}$

20

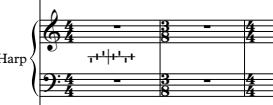

.$=44$ Delicato

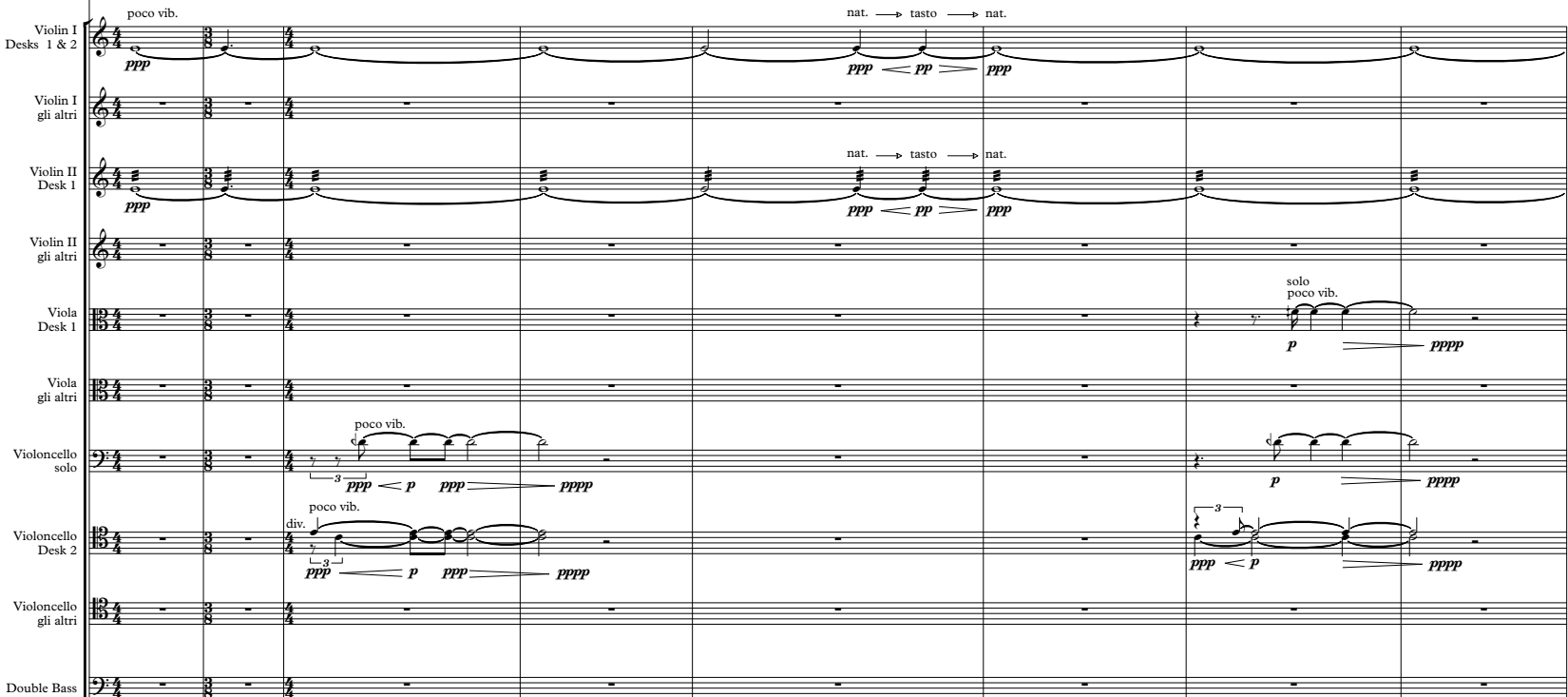




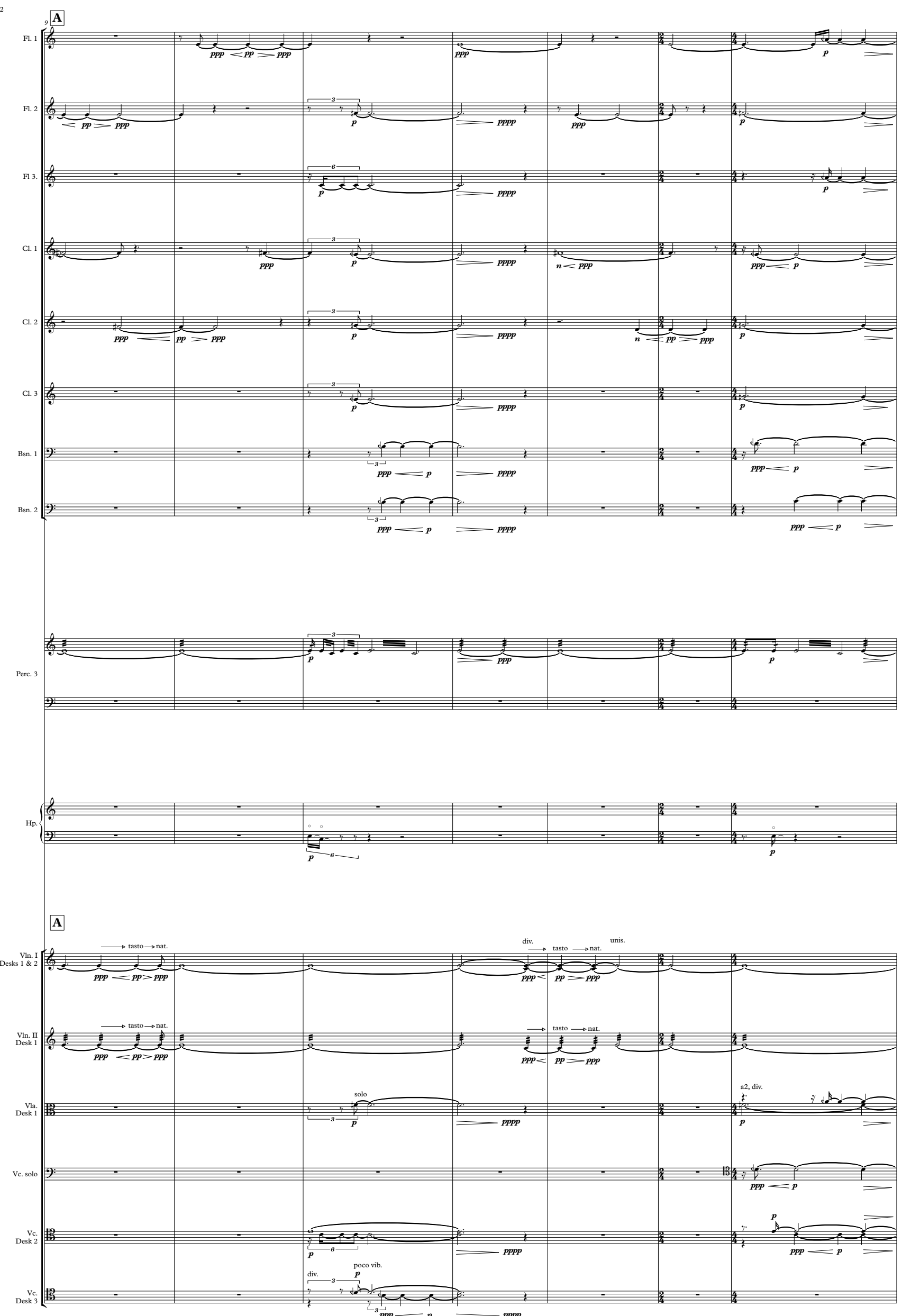



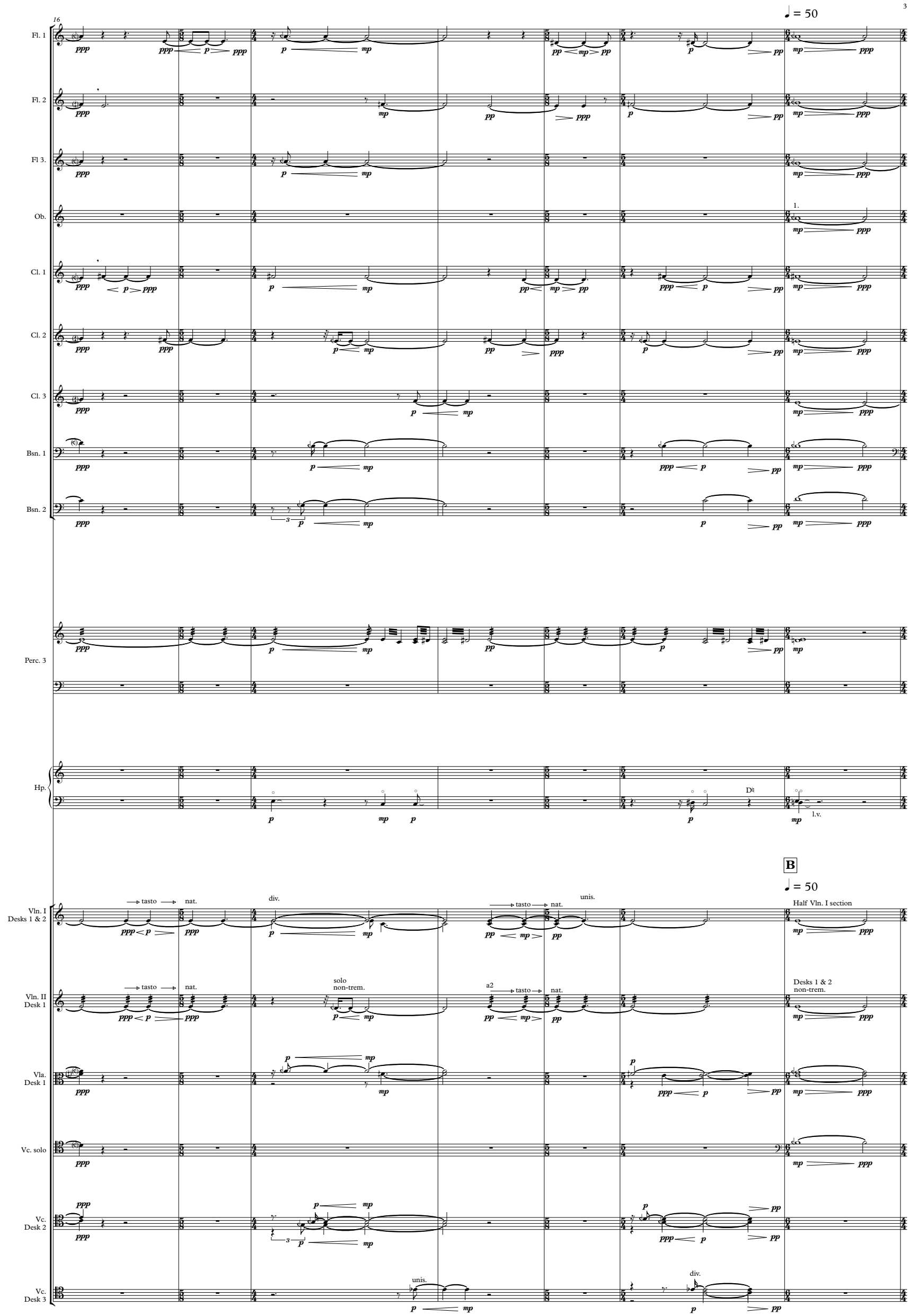


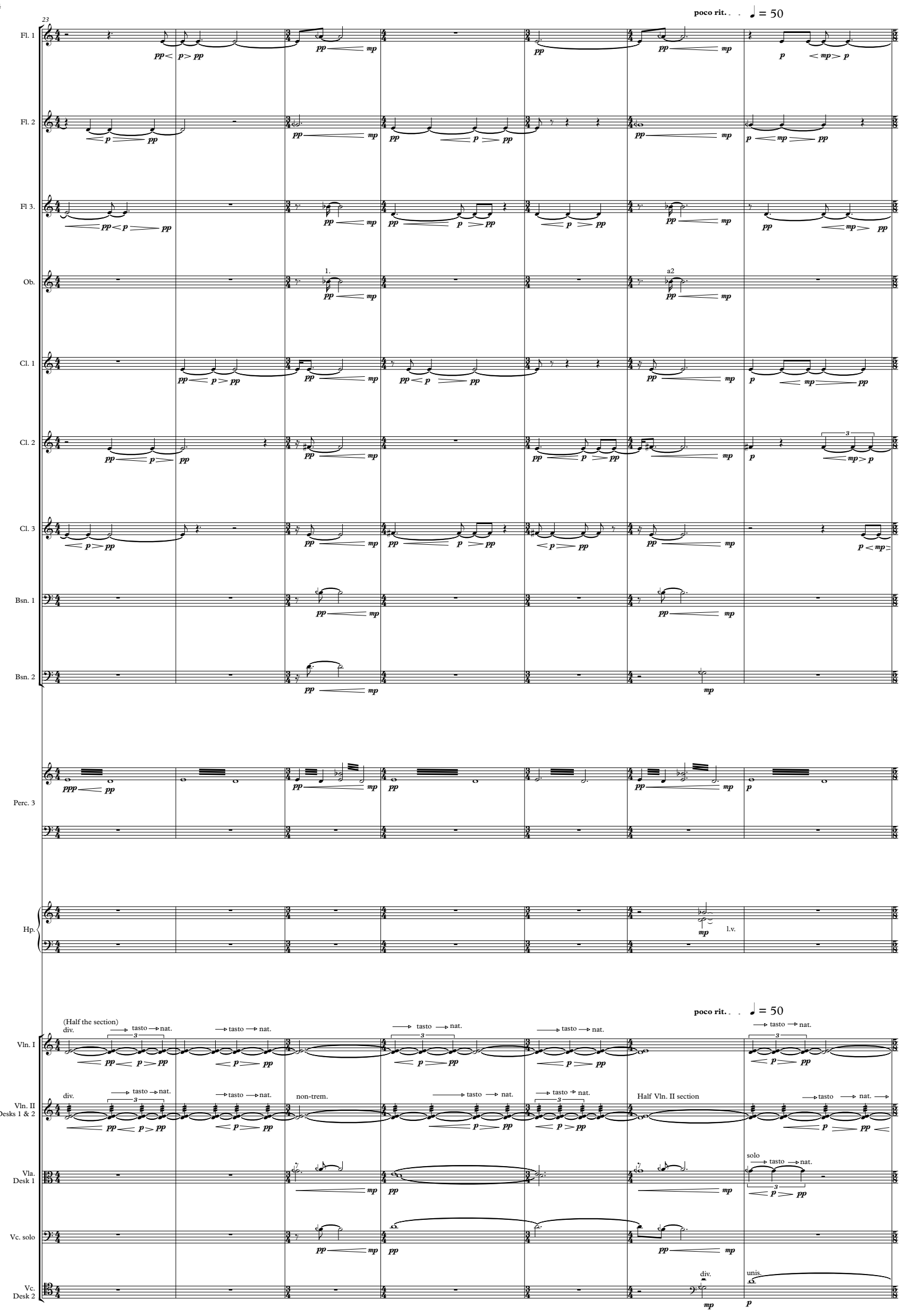


C
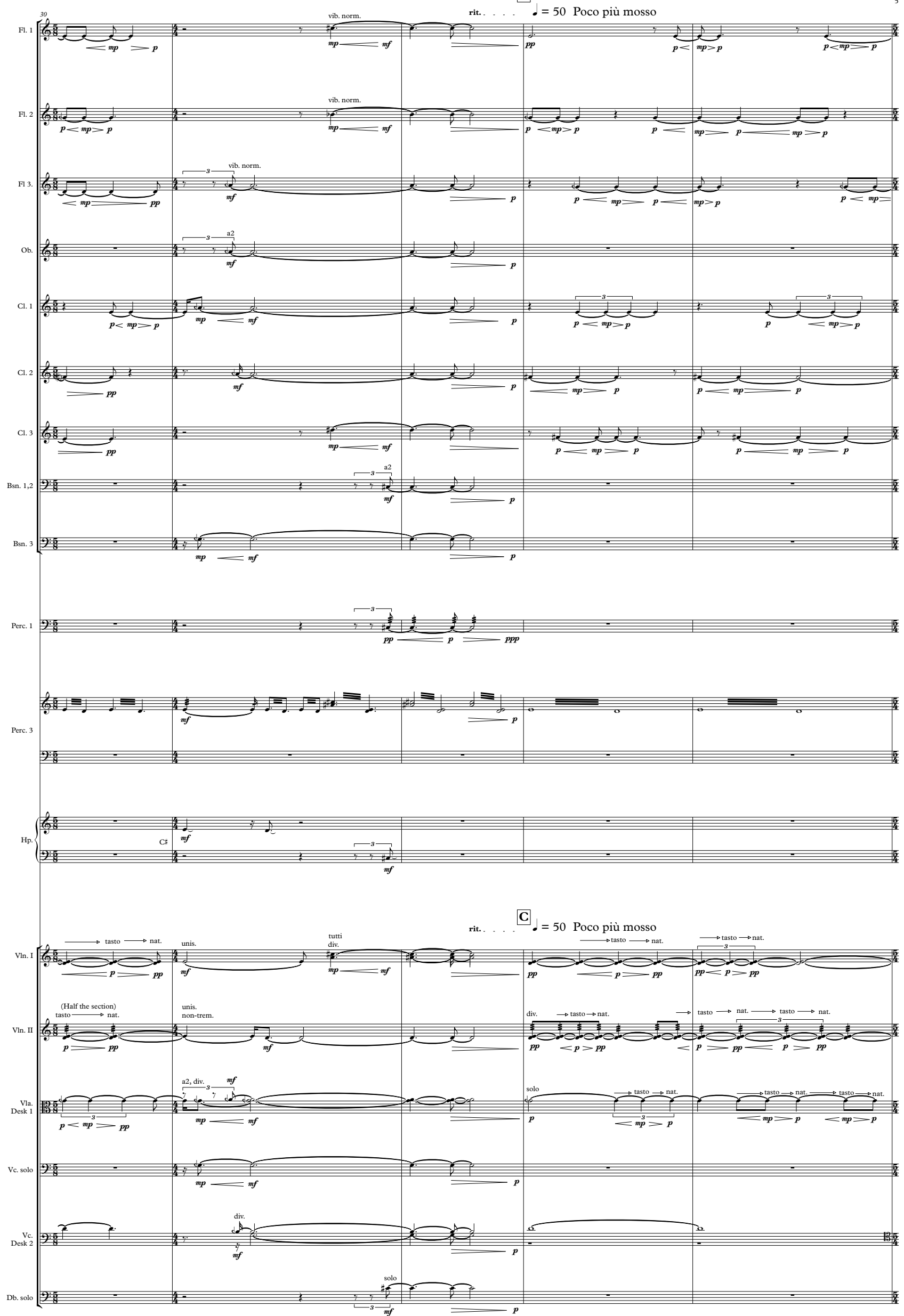


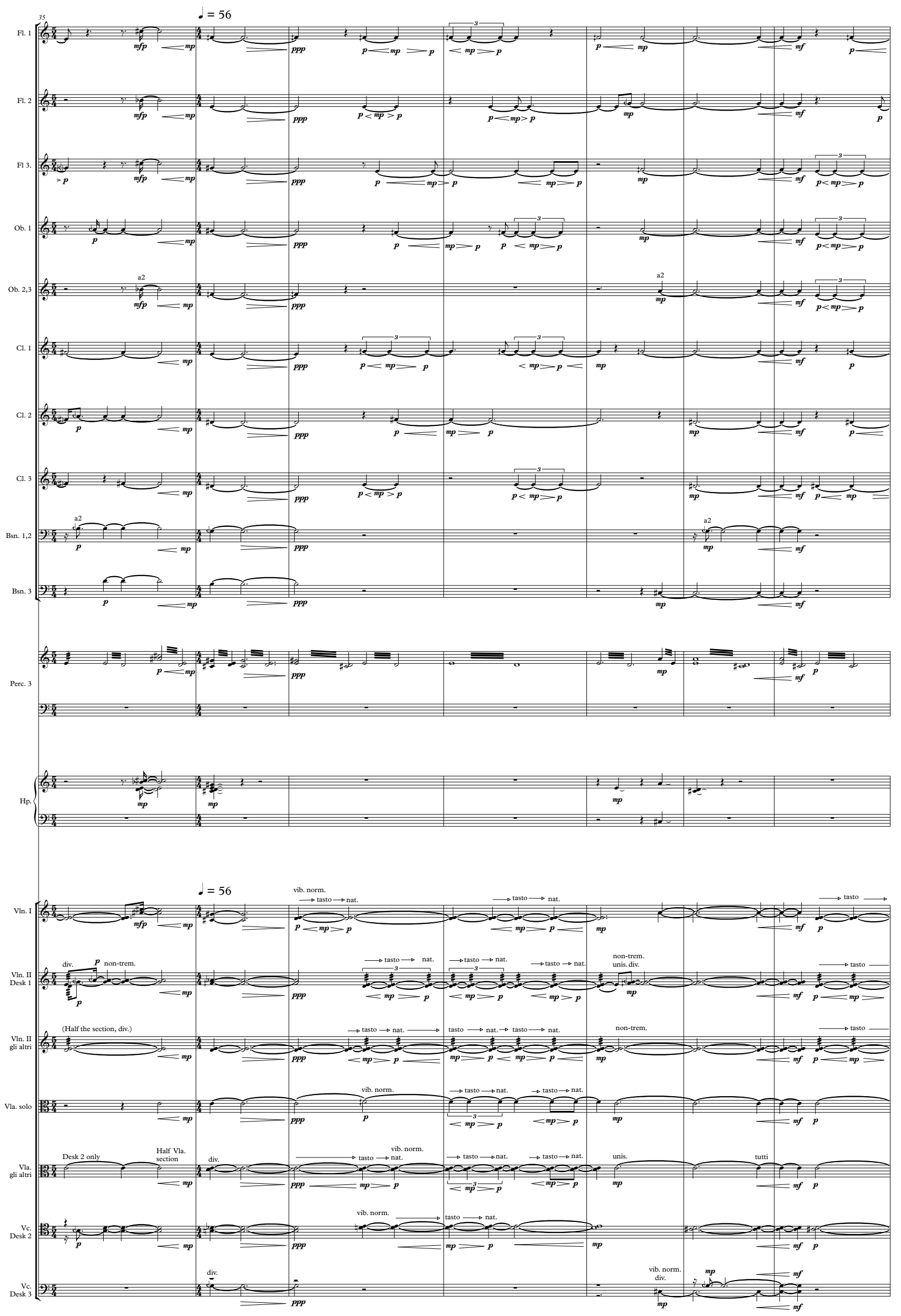




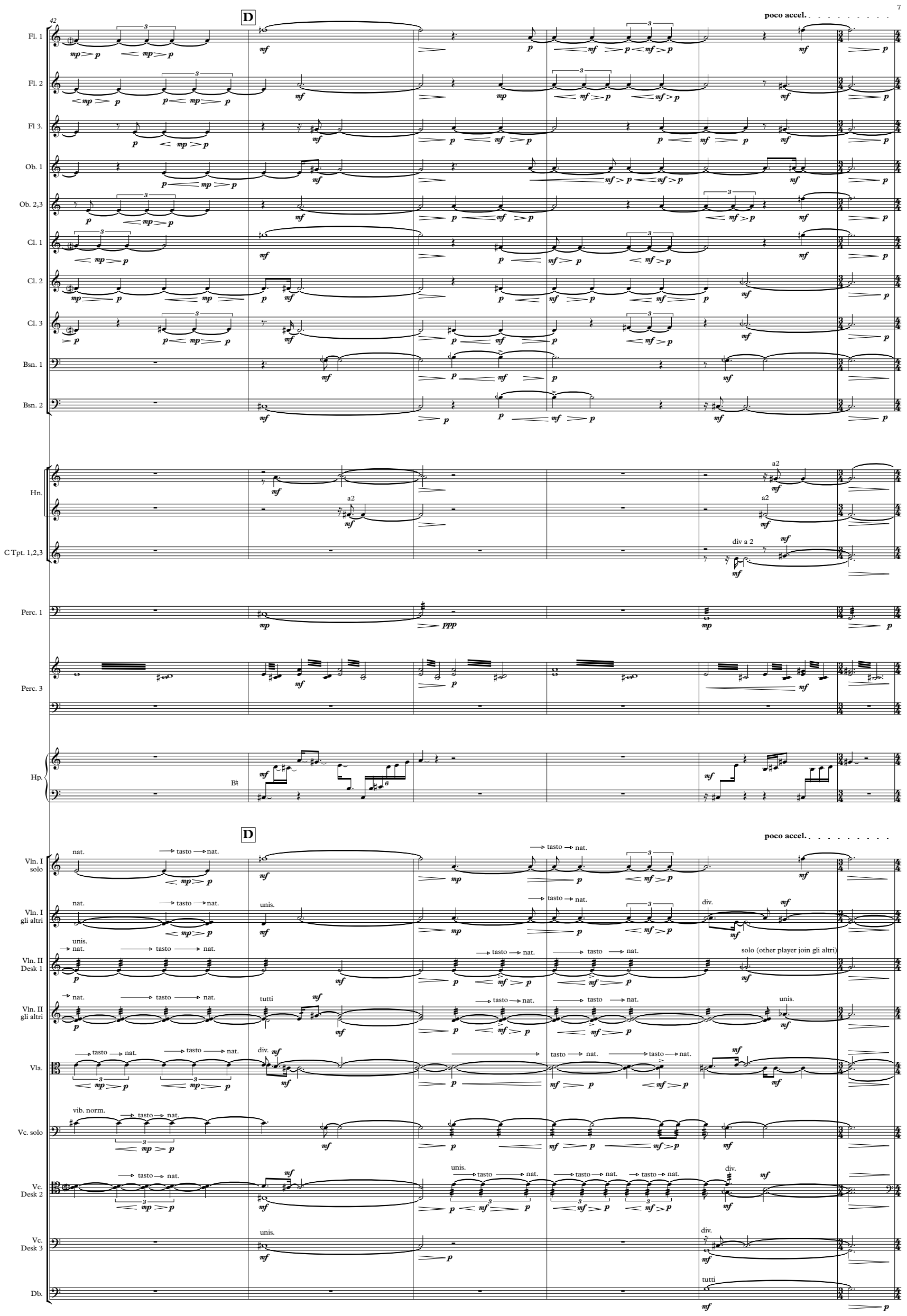




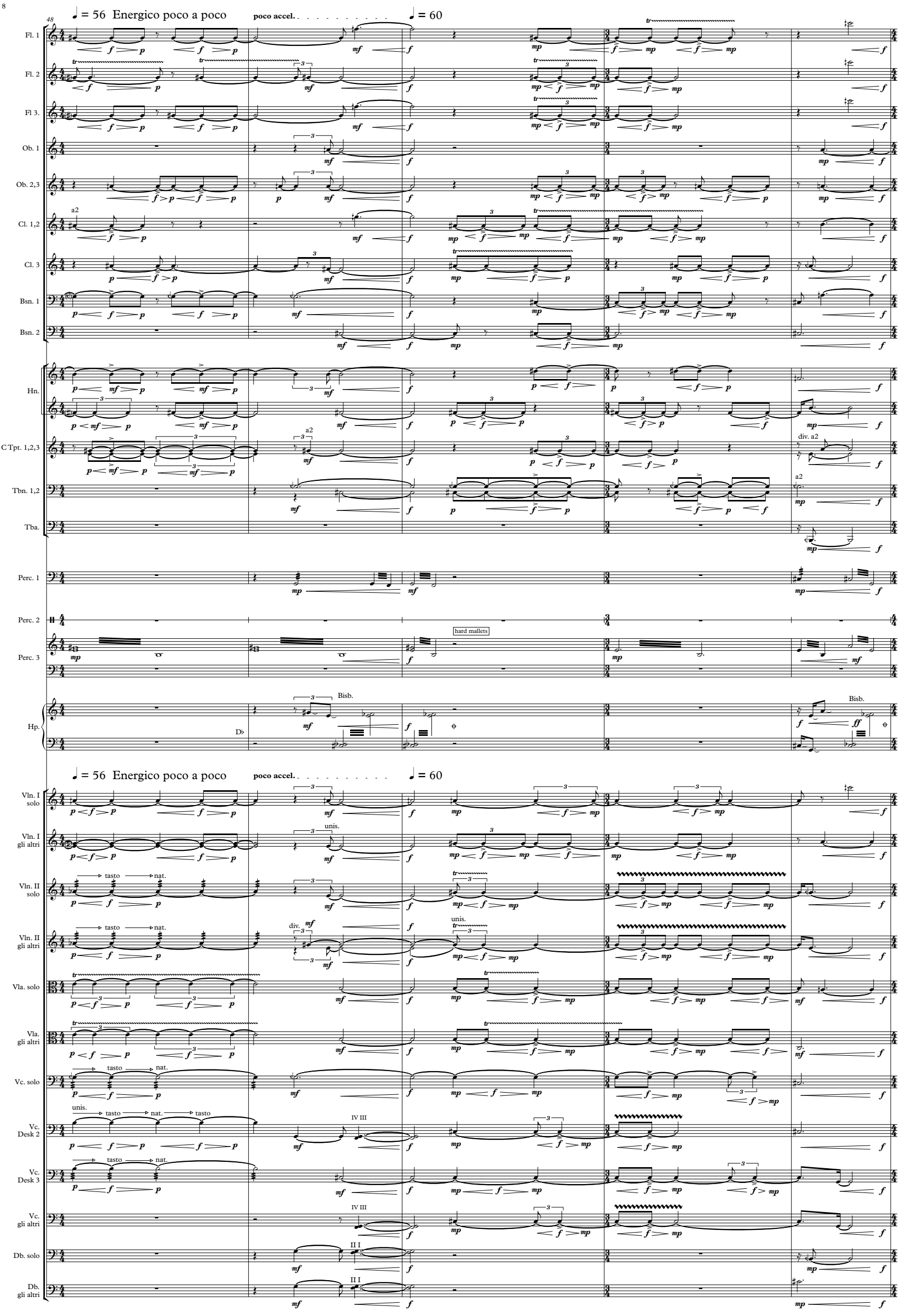


$\mathbf{E}$

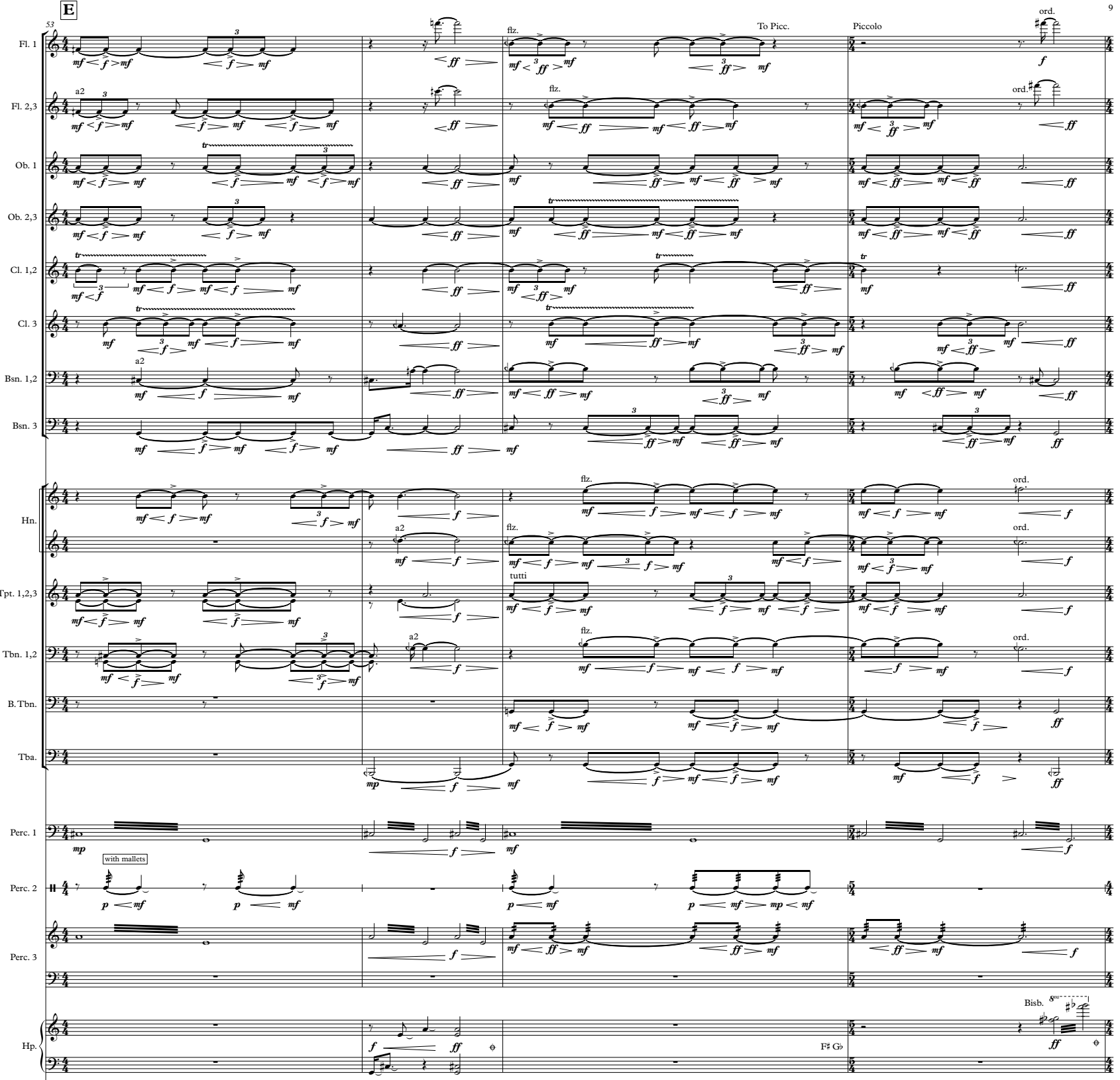

E

Solo

VIn:

Vlin

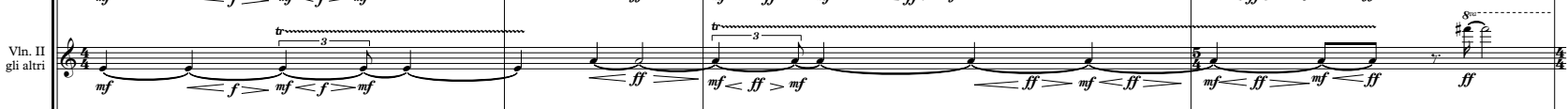

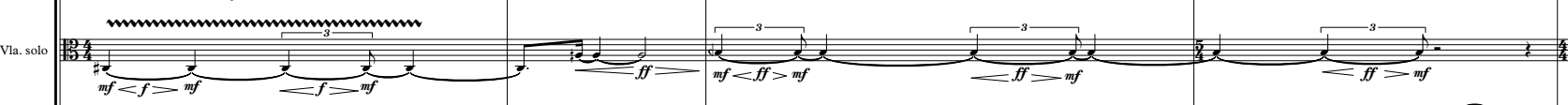

gil altri

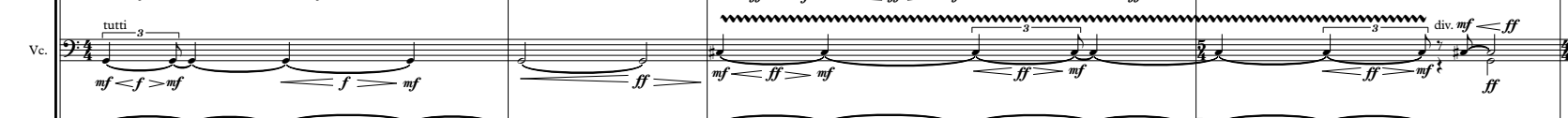

Db. solo

gil altri 

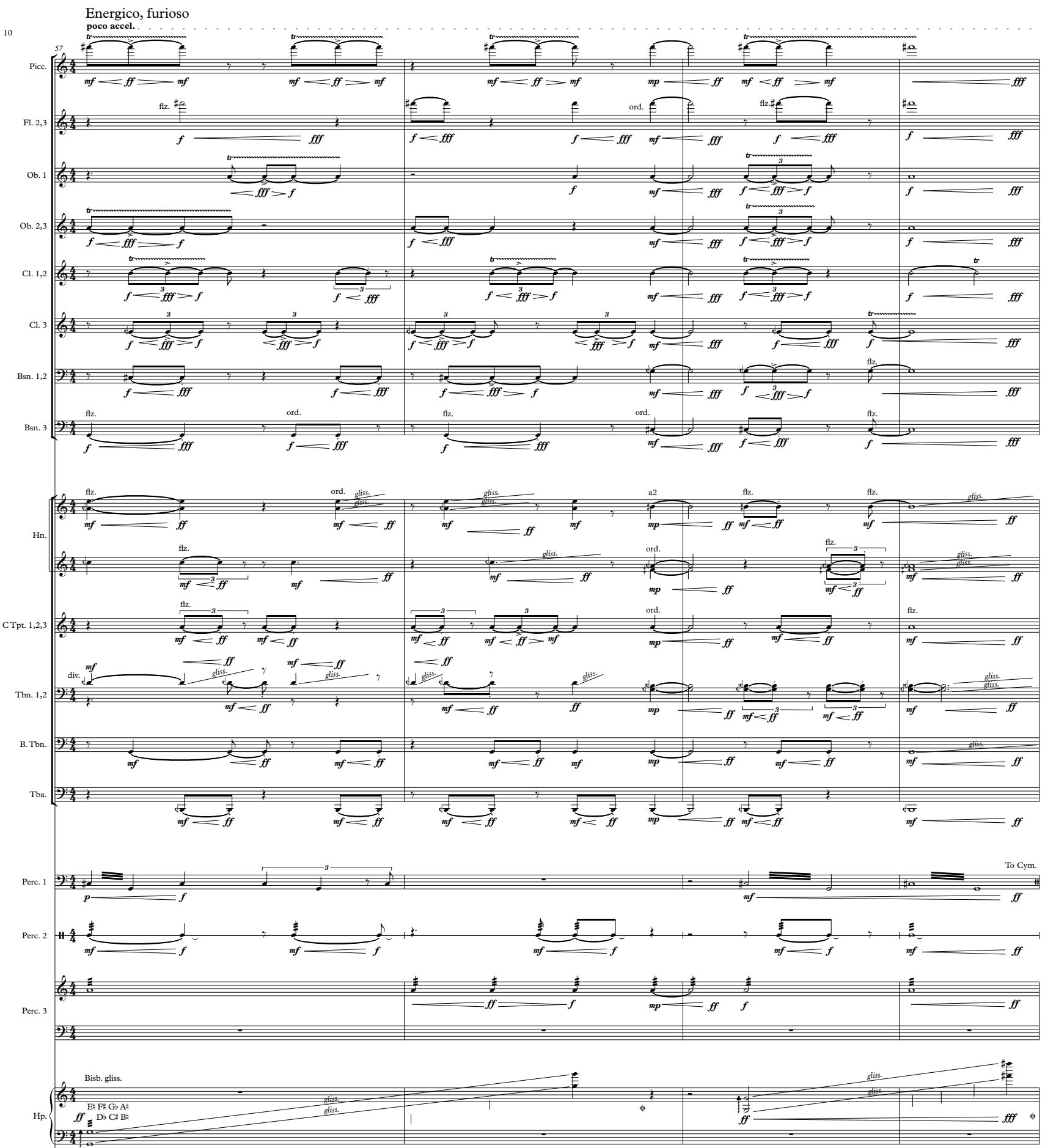
Energico, furioso

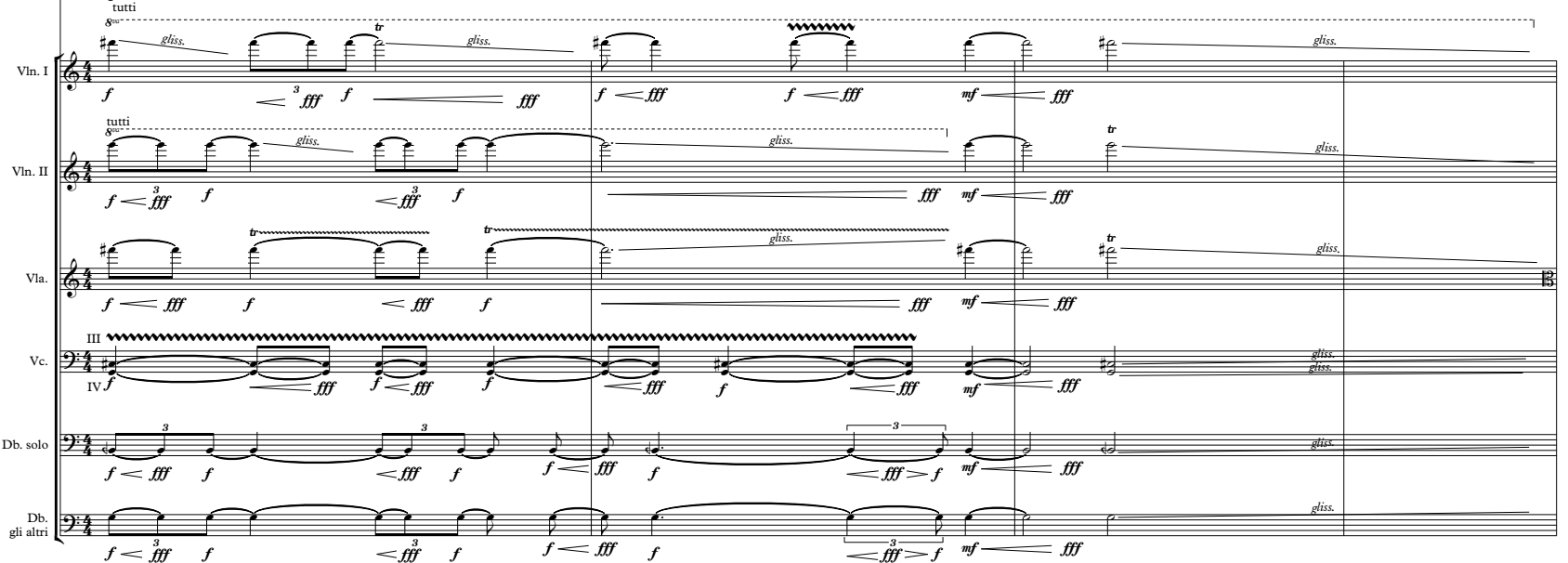




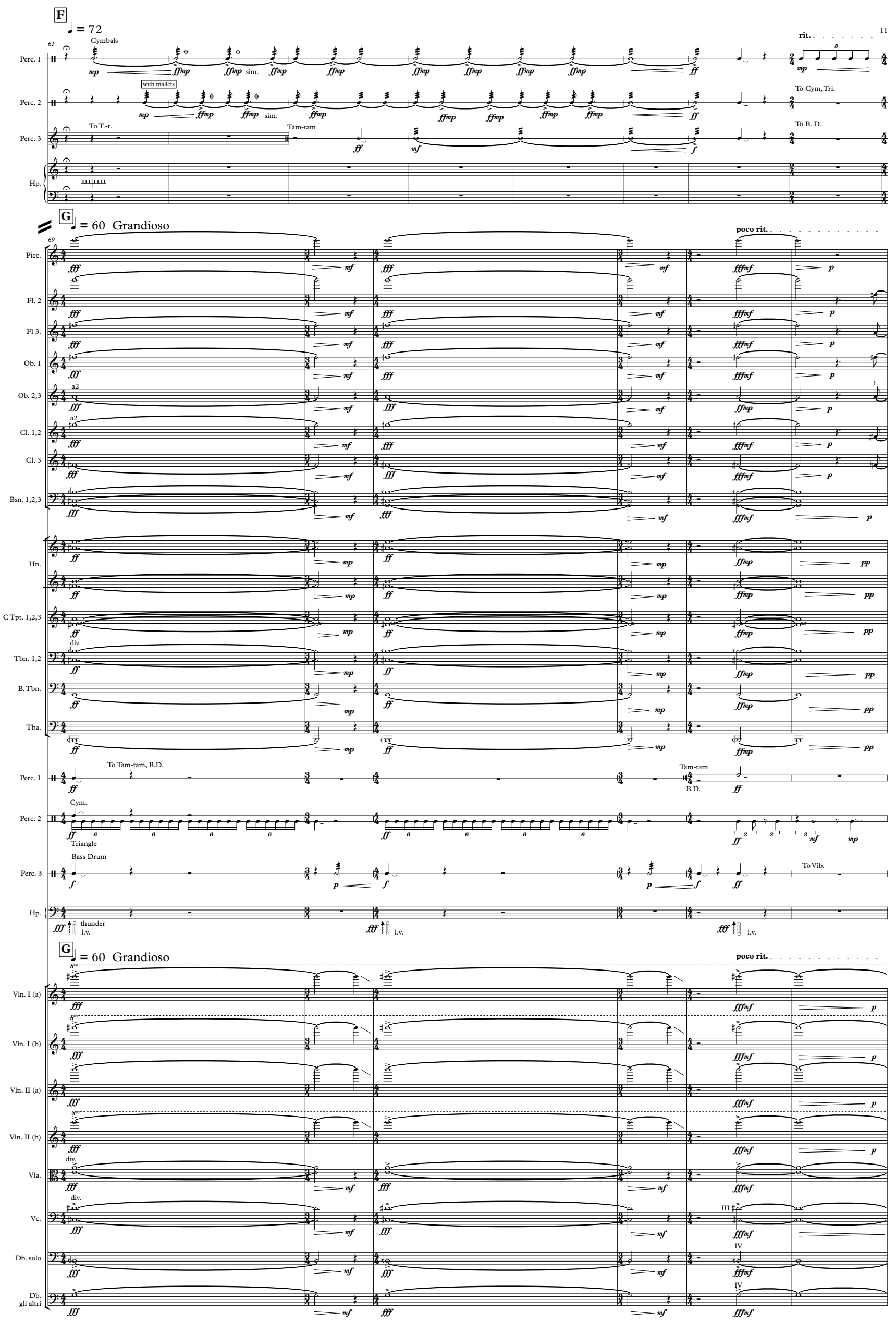



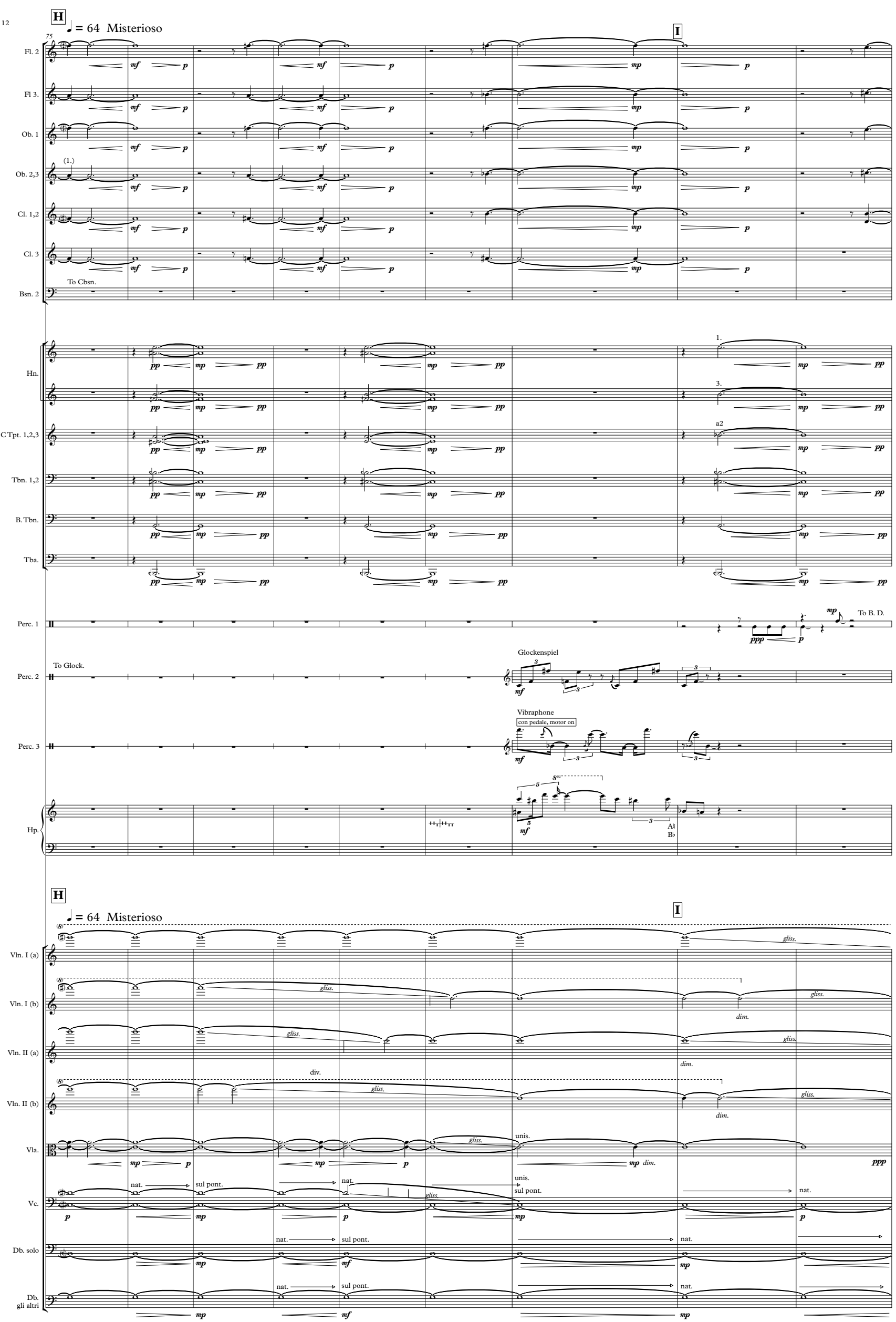

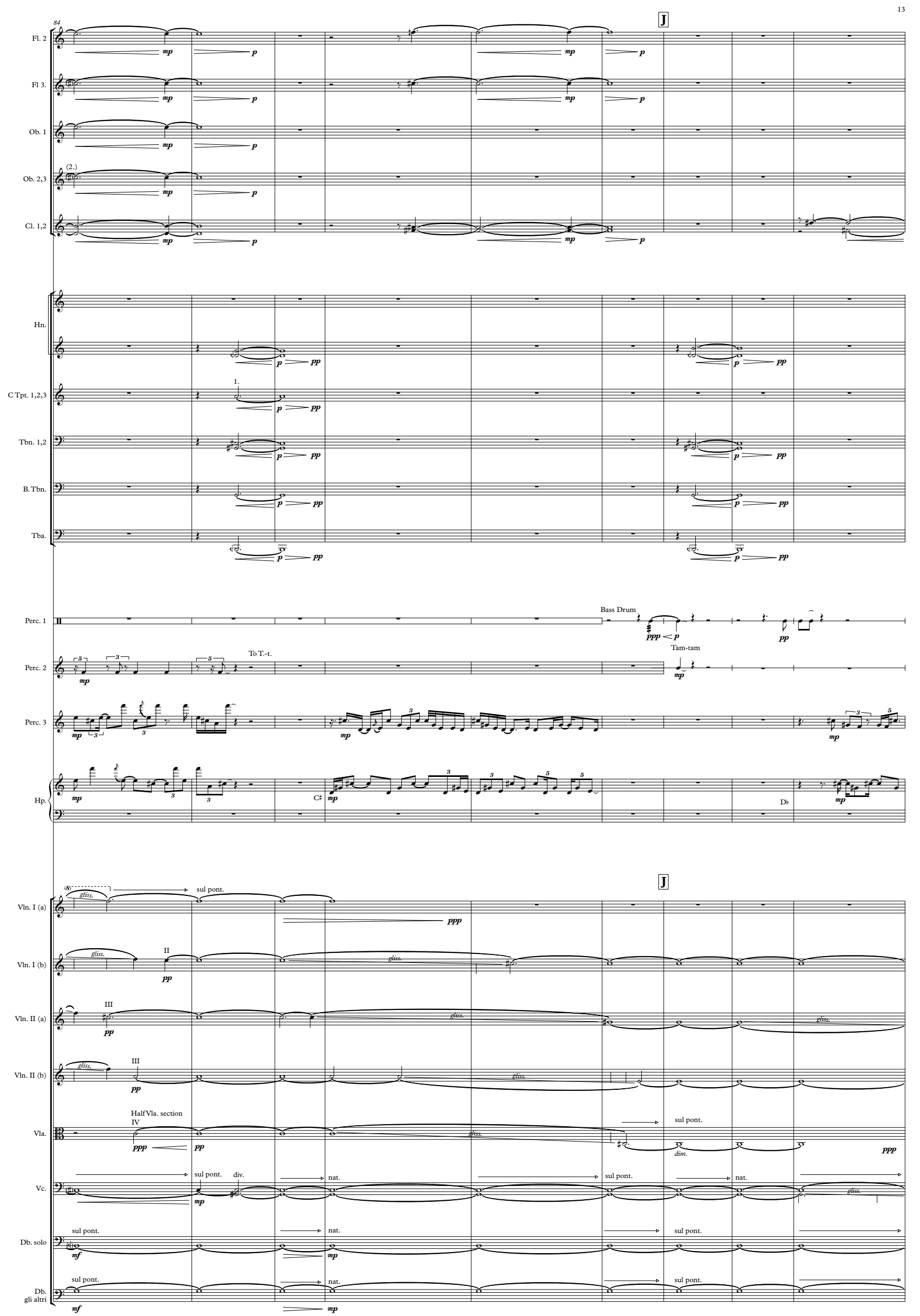


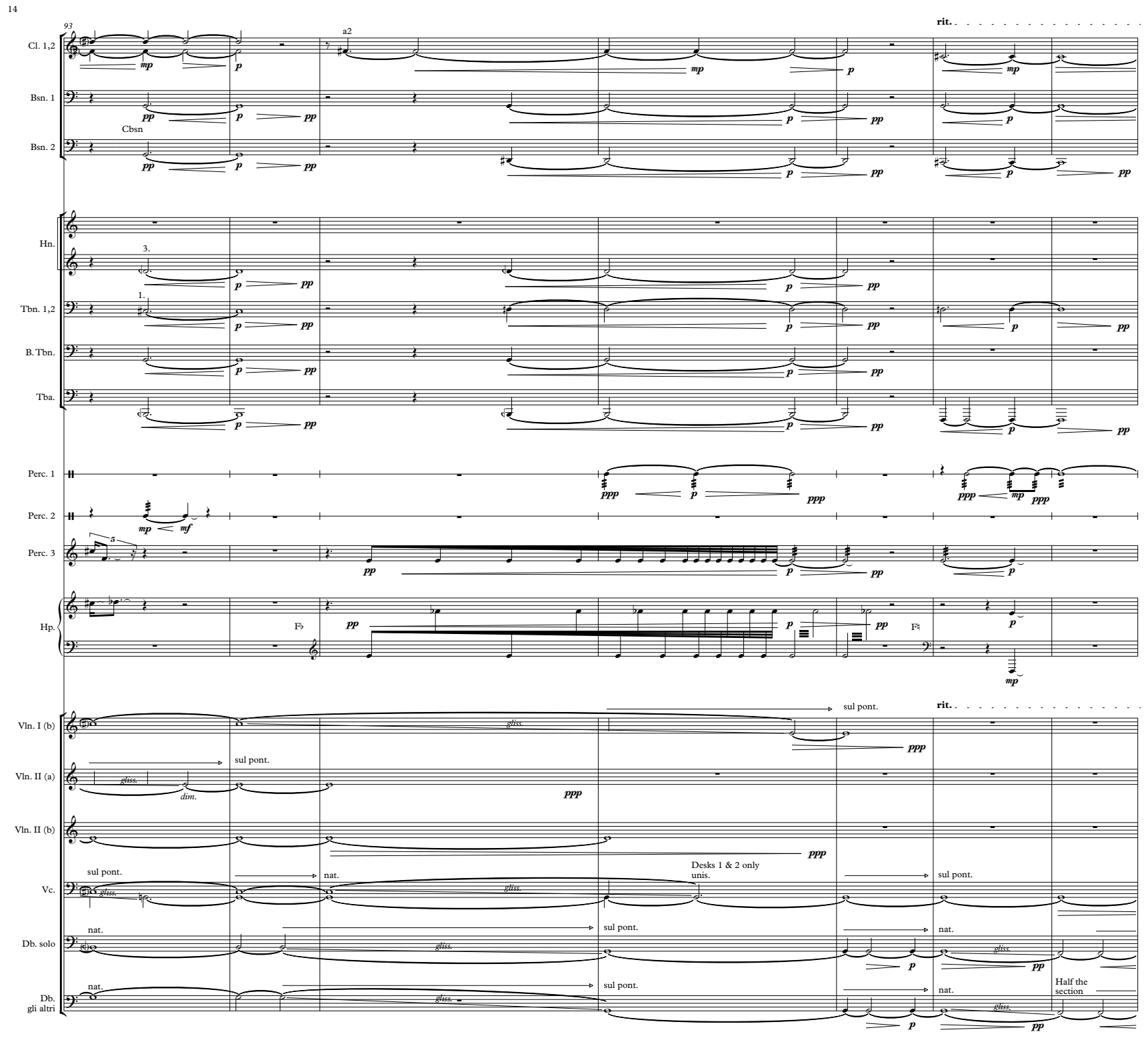

$\mathbf{K}$

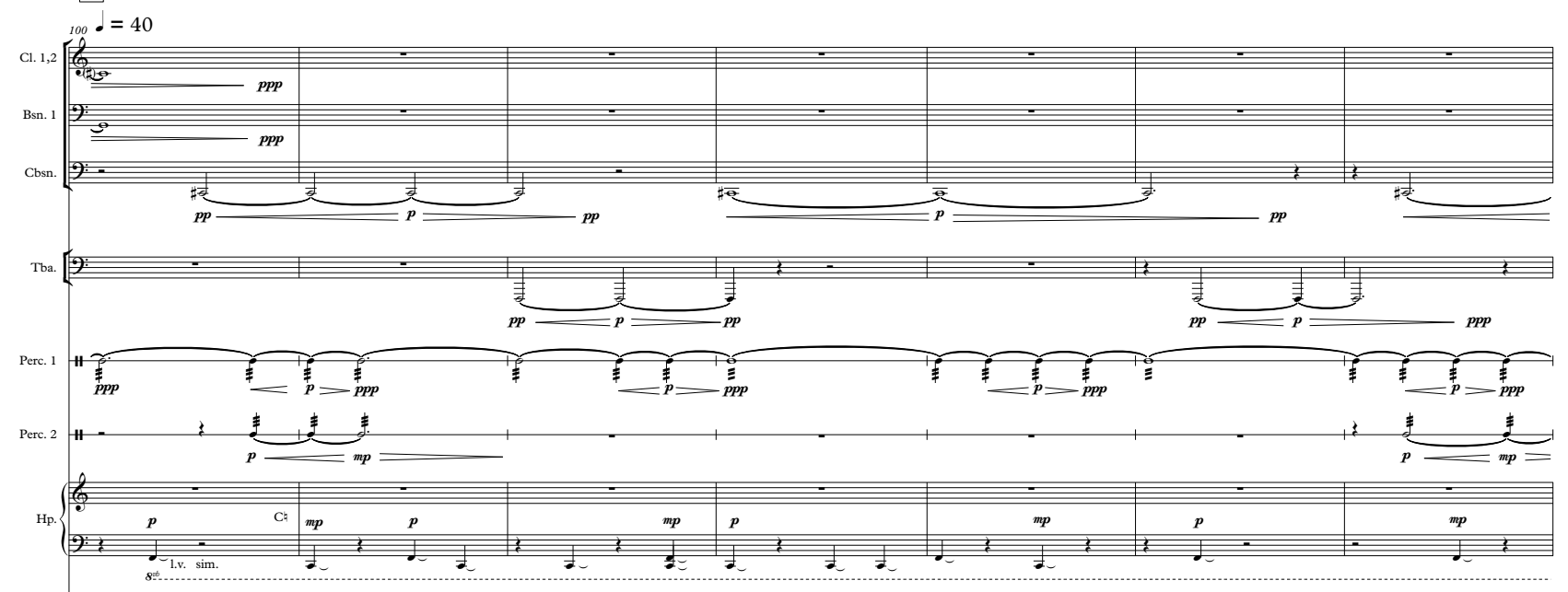

$\mathbf{K}$

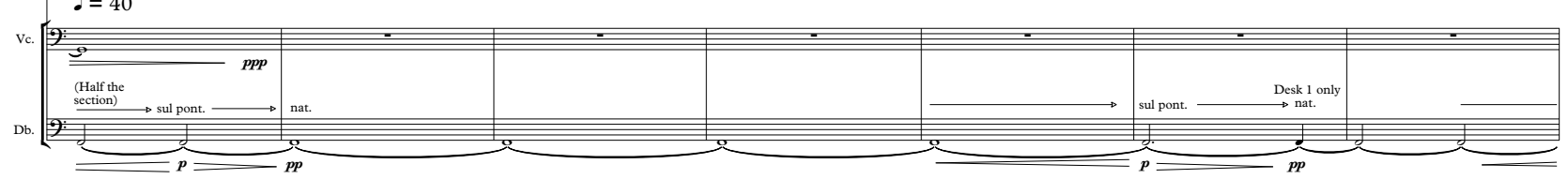




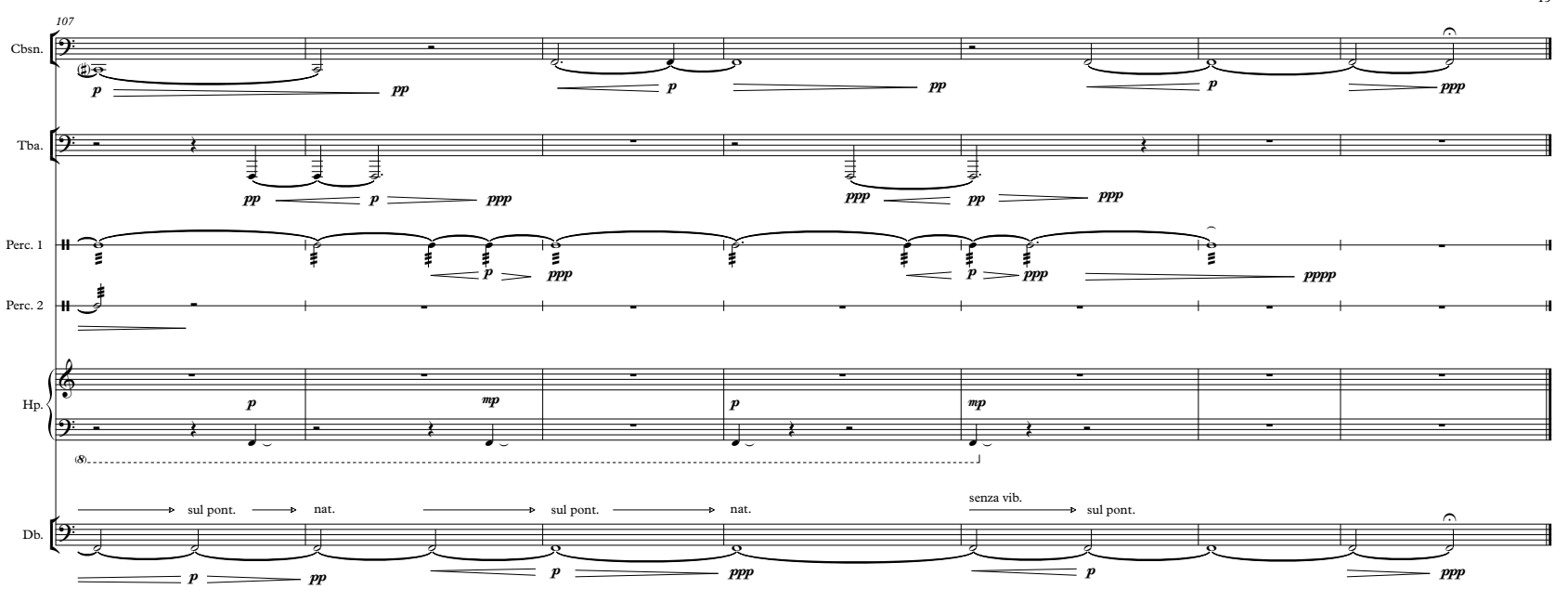




\section{Yōkai}

for guitar

Brad Jenkins 



\section{Yōkai}

Duration 6

\section{Performance notes}

polp. polpastrella - angle the thumb to pluck or strum with the flesh alone, producing a darker sound with considerable body.

rasg. rasgueado - strum with successive fingers.

Chords that are not preceded by an arpeggio line should be plucked with the fingers together (chords marked rasg. are, of course, an exception).

The player should take care to perform portamenti and glissandi as distinctly different types of slide. While glissandi begin immediately on their starting pitch, portamenti should allow their starting pitch to sound for its entire (or almost entire) notated duration before sliding to the next pitch.

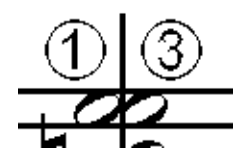

Two identical pitches accompanied by two string numbers indicates that this pitch is to be played on these two strings simultaneously.

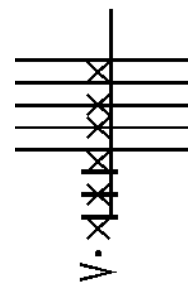

The player is to perform a percussive slap with the fingers onto the strings and momentarily hold the fingers against the strings, completely stopping any sound. 


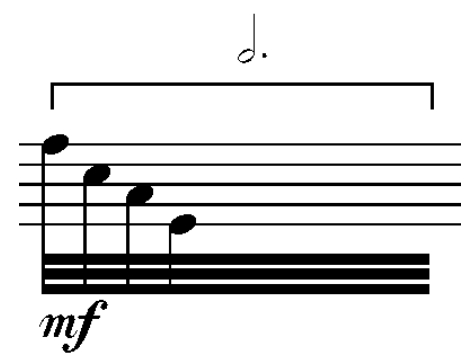

The pitches are to be played as fast as possible as an unmeasured, repeated arpeggio, always in the sequence indicated. The tempo of the piece remains unchanged, with the note value above the bracket indicating the duration of the technique.

There are two instances in which the unmeasured arpeggio occurs during a tempo change: bb.106-108 and bb.112-113. In these instances the arpeggio should become slower, following the molto ritard instruction.

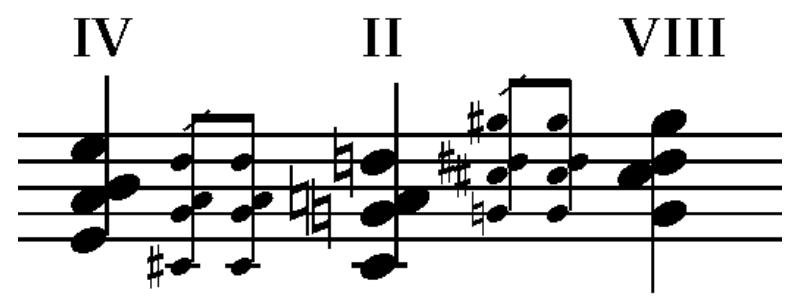

Fret numbers above chords indicate that the same chord fingering is to be maintained, simply moving up or down the fretboard to the indicated fret. 


\section{Yōkai}

for guitar
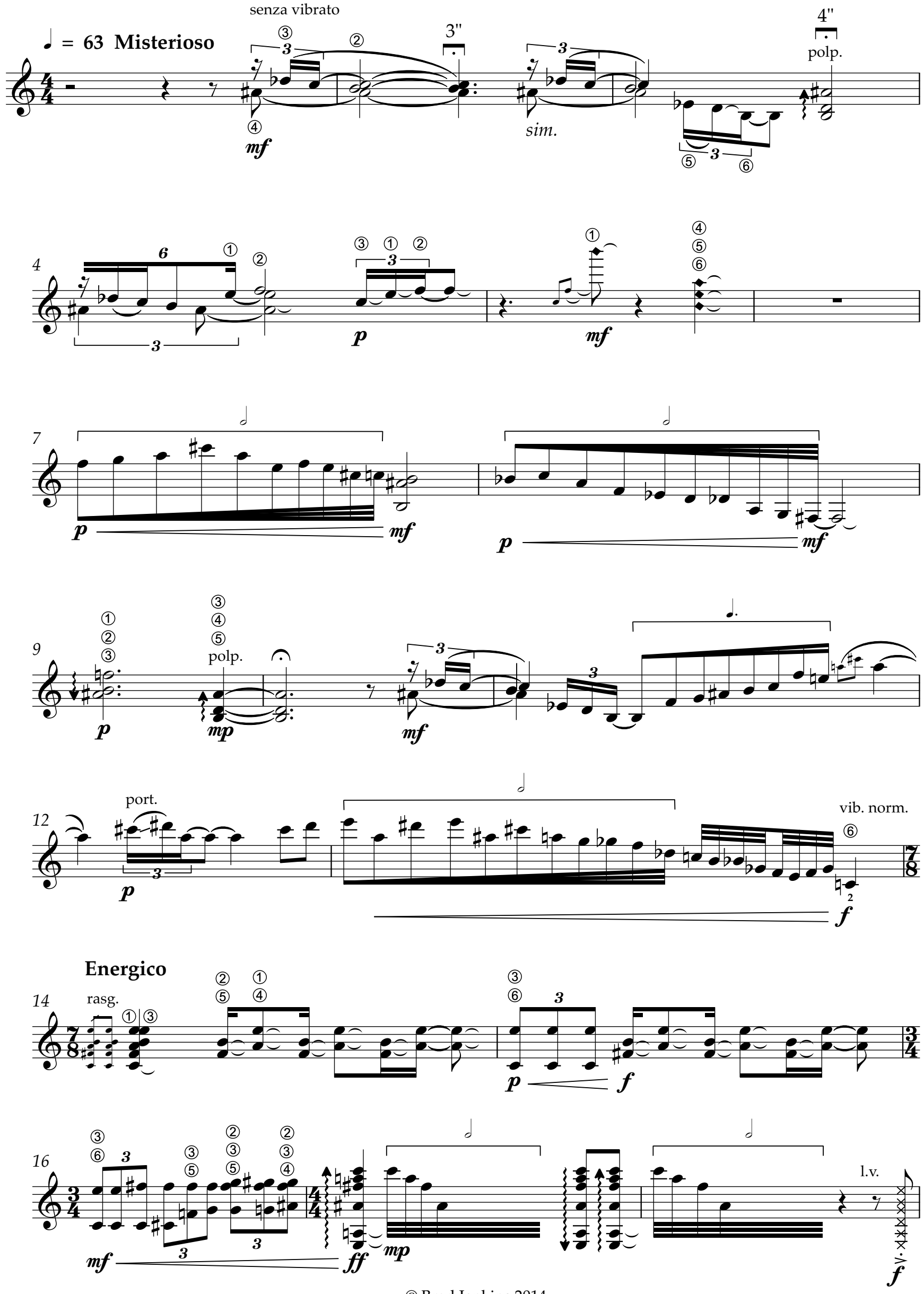

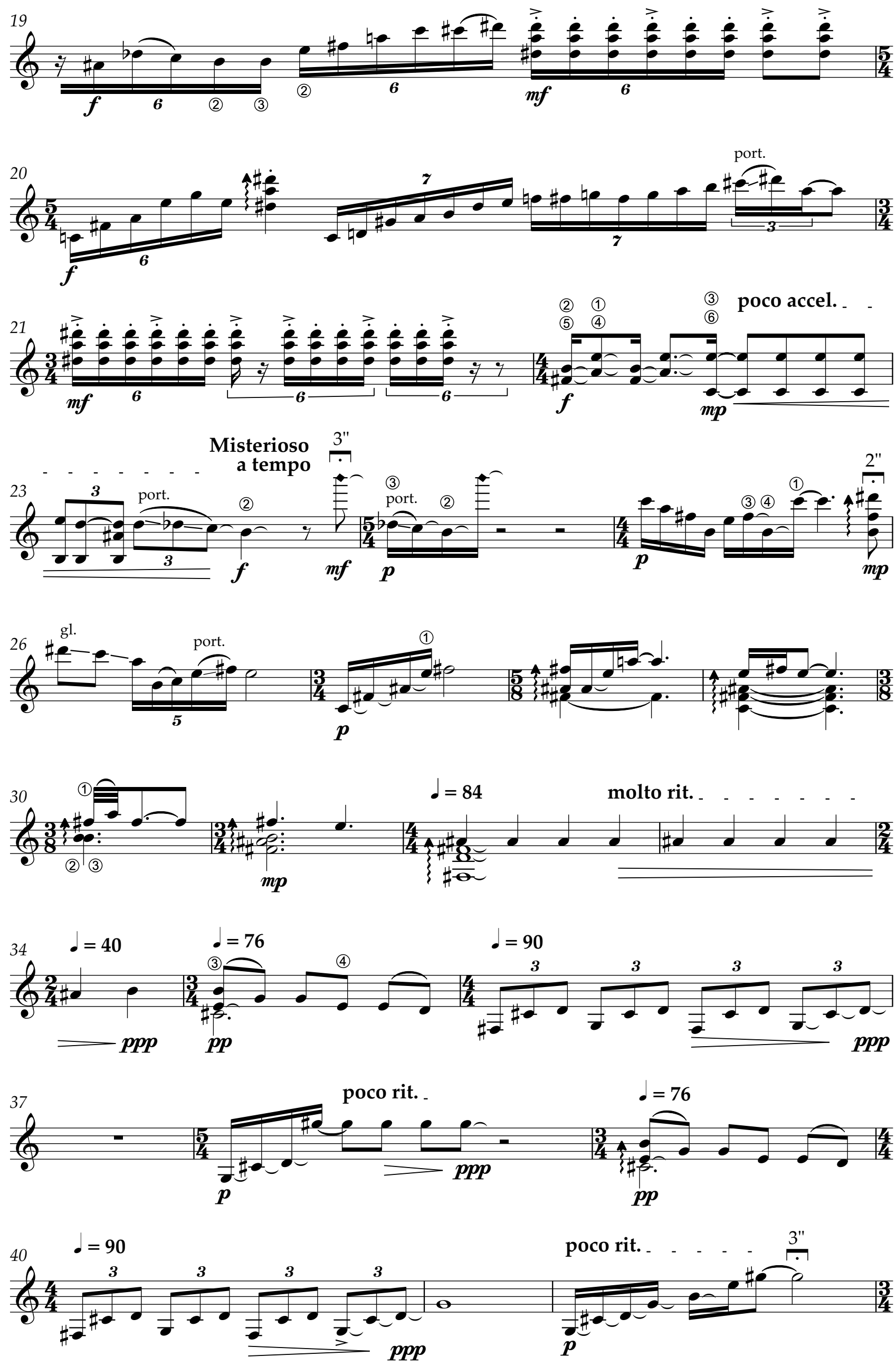
3
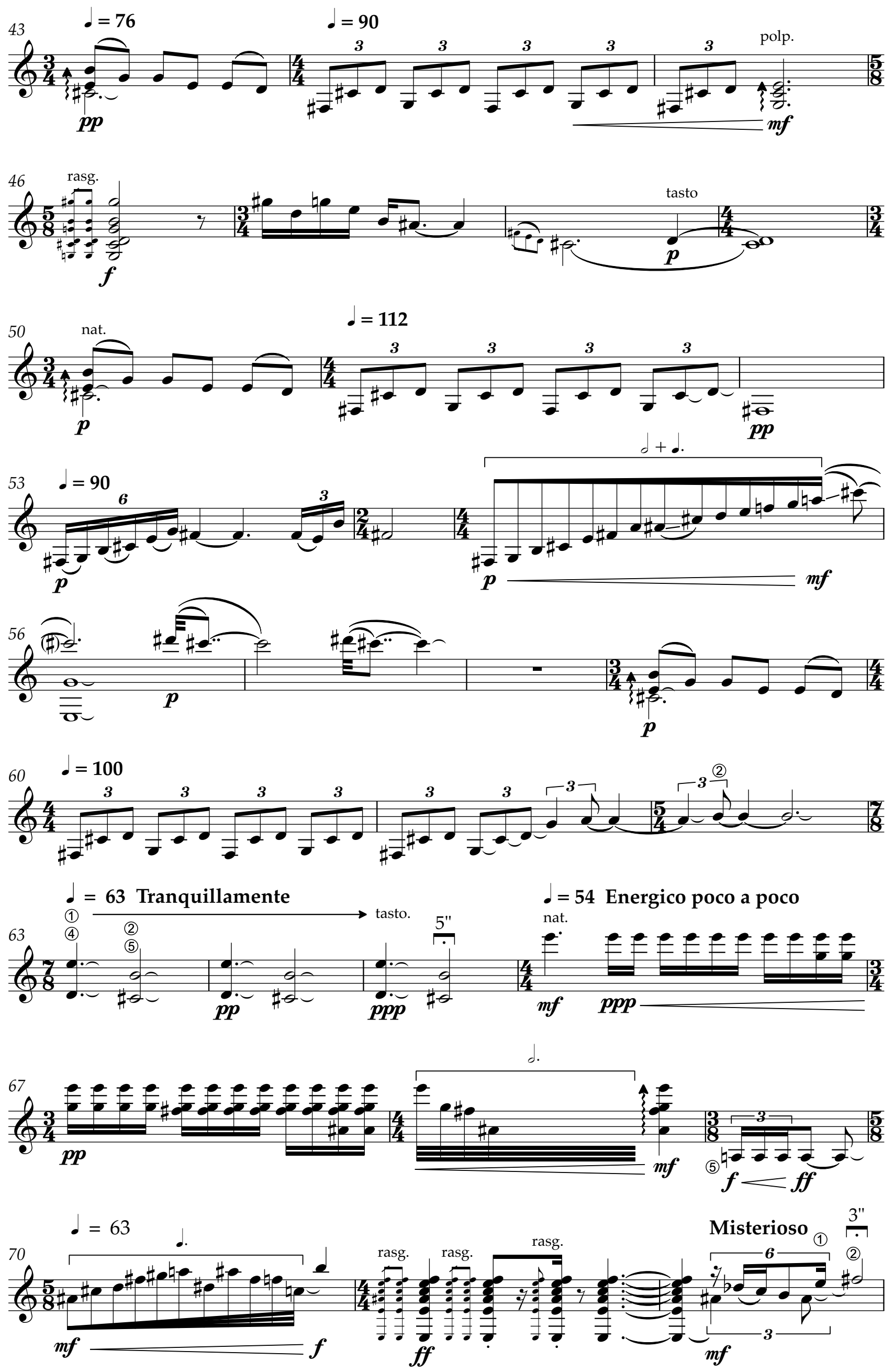

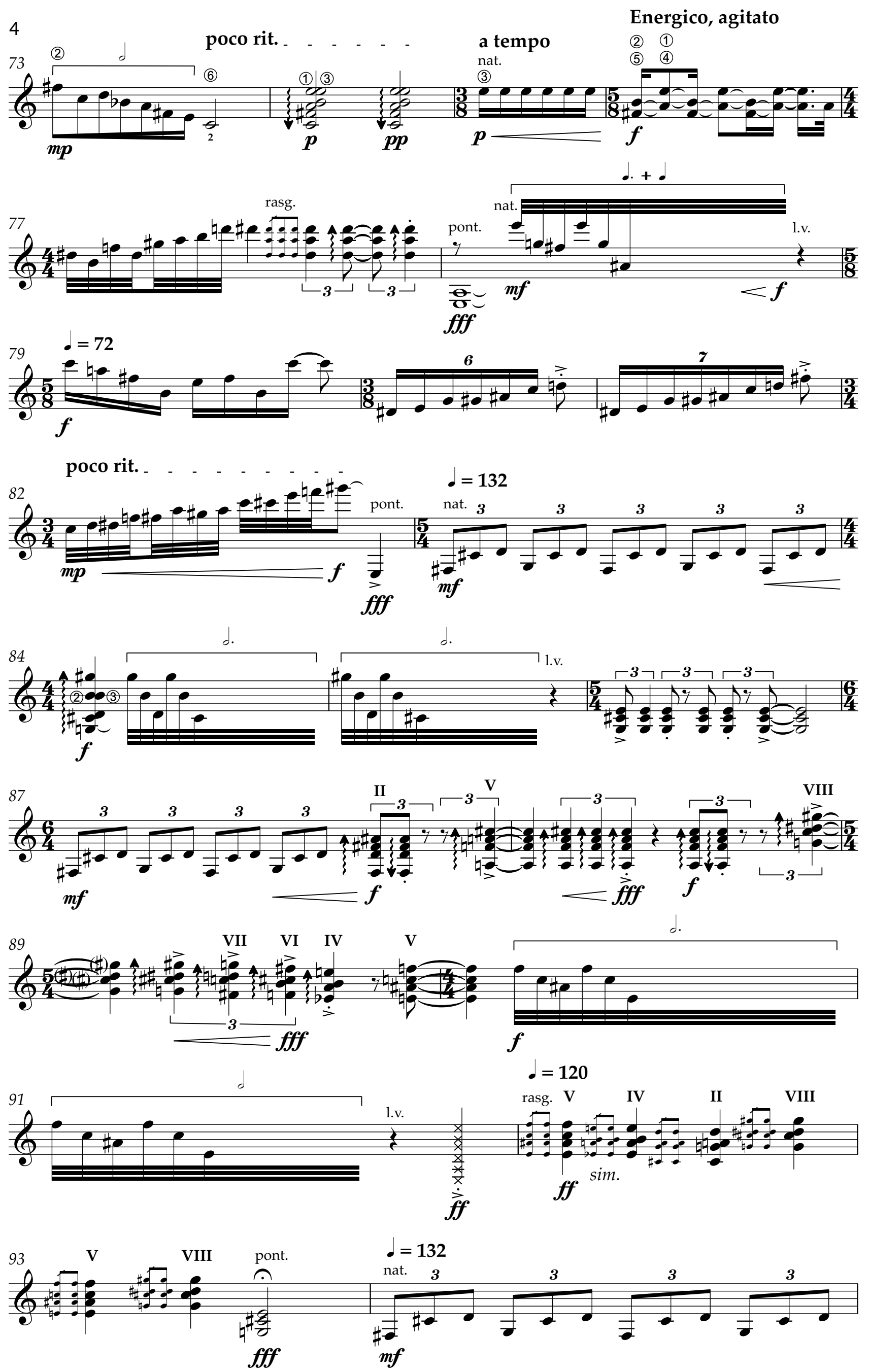
accel. .

$$
\downarrow d=144
$$
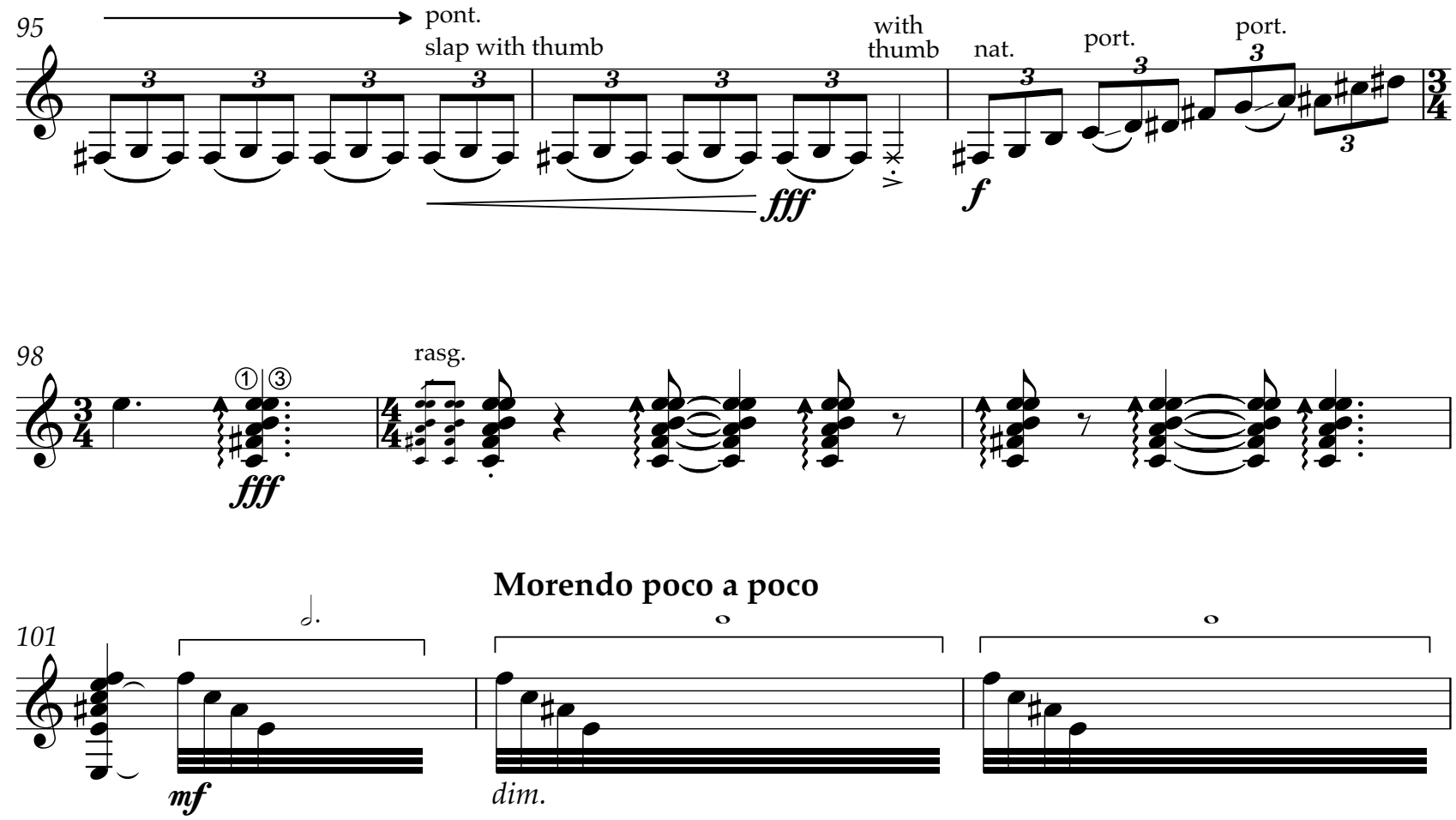

molto rit.

(also applies

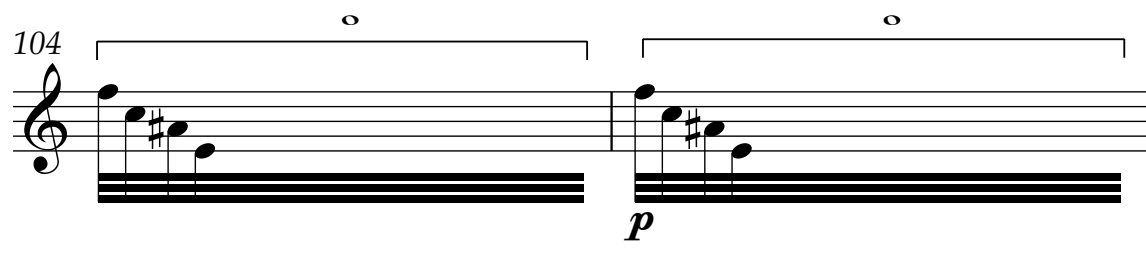

to arpeggio)

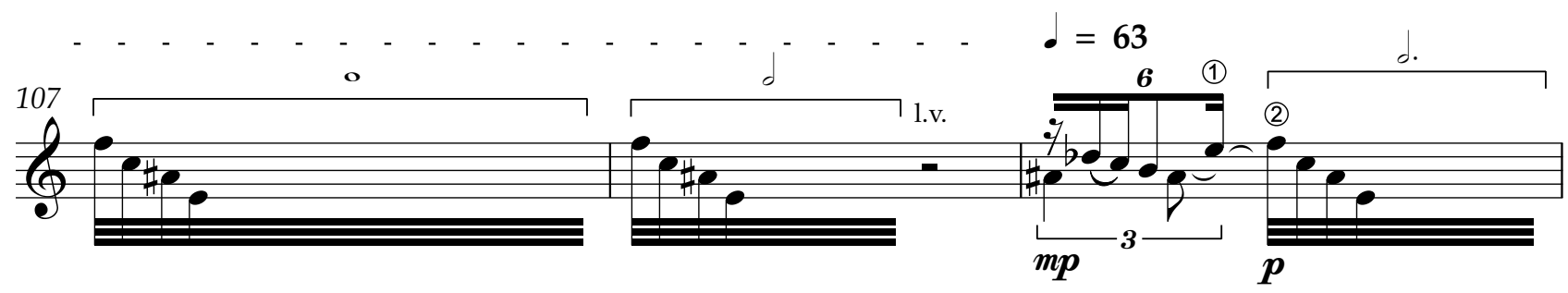

molto rit

(also applies

o to arpeggio)
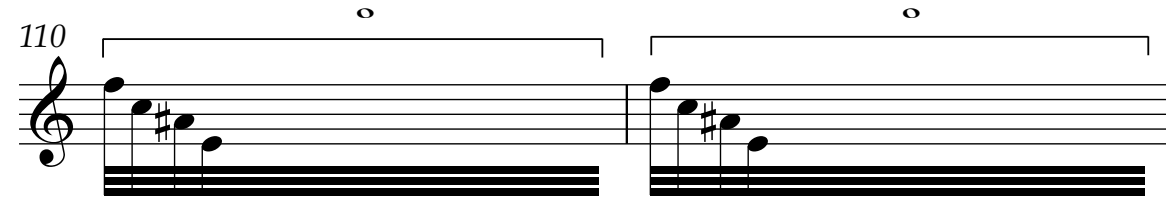

dim.

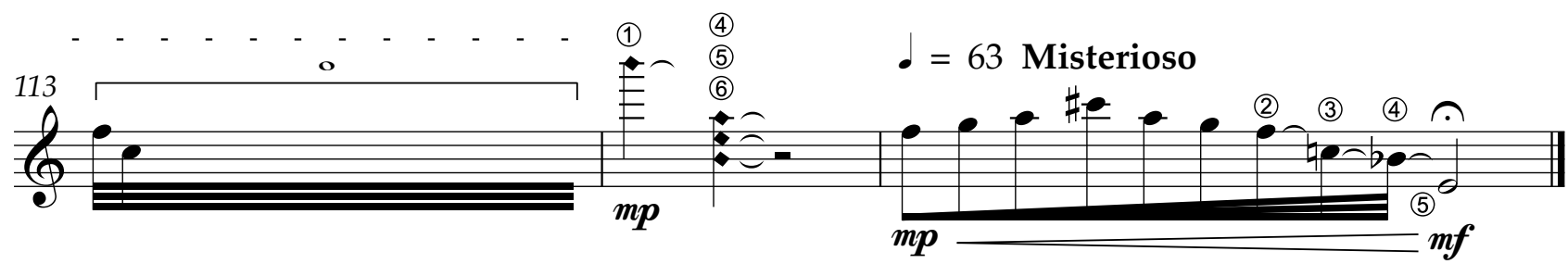




\section{CD tracklisting}

\section{String Quartet No. 3}

Reading by the New Zealand String Quartet (Helene Pohl and Douglas

Beilman, violin; Gillian Ansell, viola; Rolf Gjelsten, cello) at the Adam

Concert Room, Victoria University of Wellington, on 4 October 2013.

\section{The Way Out Is Through}

Reading by the NZSM Orchestra, conducted by Vince Hardaker, at the Adam Concert Room, Victoria University of Wellington, on 22 May 2014. NB: Instruments unavailable for recording: Flute 3, Oboe 3, Clarinet 3, Bassoon 2 \& 3,

Horns in F 1-4, Trumpet 3. Contrabassoon added to recording via MIDI

\section{Yōkai}

Performed by Jamie Garrick at the Adam Concert Room, Victoria University of Wellington, on 27 September 2014. 